S. Abramovich

A. Yücel

Cryogenic Systems for the HEB Accelerator of the Superconducting Super Collider

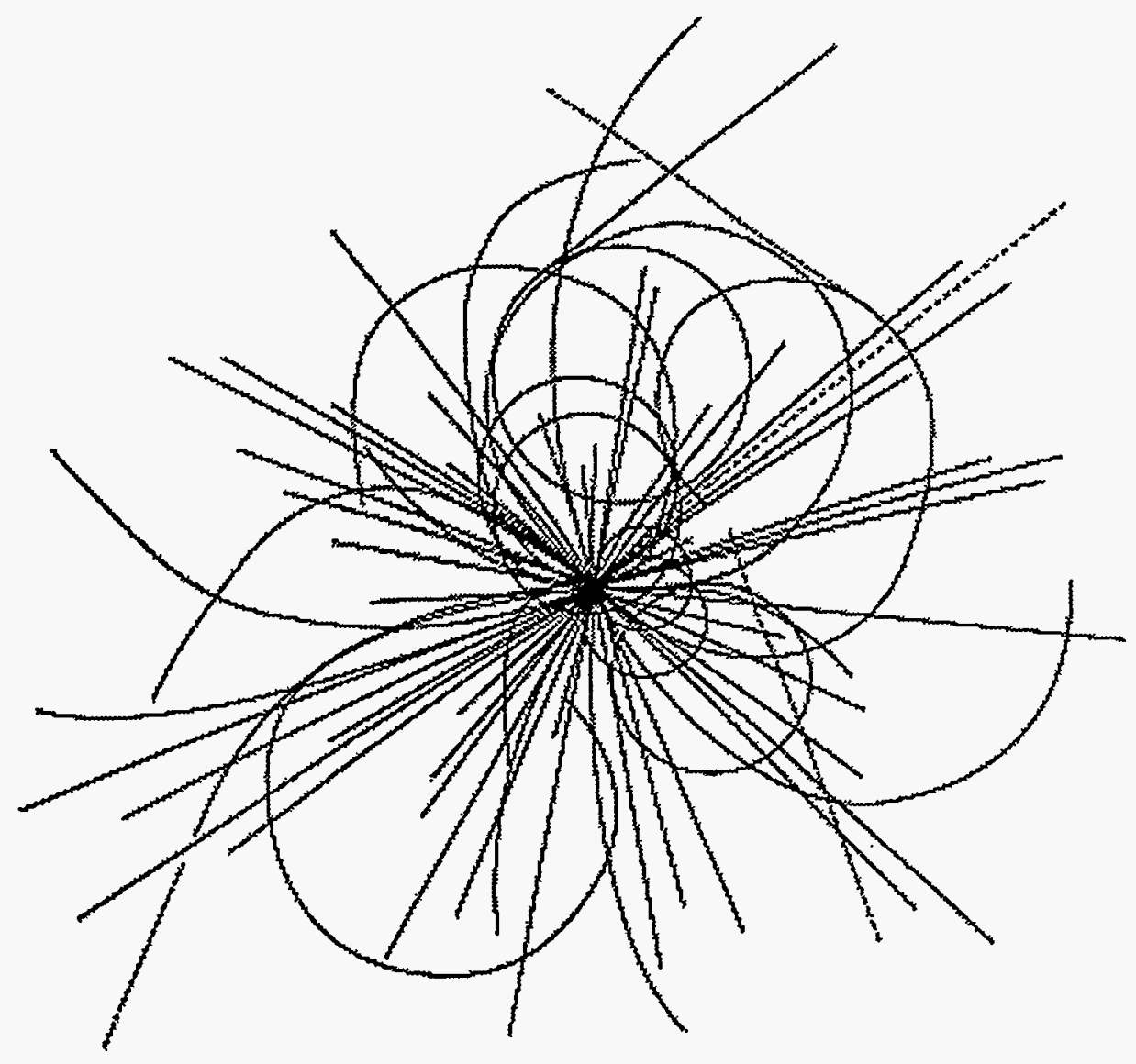

\section{Superconducting Super Collider Laboratory}


Disclaimer Notice

Thls report was prepared as an account of work sponsored by an agency of the United States Govemment. Neither the United States Government or any agency thereof, nor any of their employees, makes any warranty, express or Impliod, or assumes any legal llability or responsibility for the accuracy, completeness, or usefulness of any information, apperatus, product, or process disclosed, or represents that its use would not infringe privately owmed rights. Reference herein to any specific commercial product, process, or service by trade name, trademark, manufacturer, or otherwise, does not necessarily constitute or imply lts endorsement, recommendation, or favoring by the United States Government or any agency thereot. The vews and oplnions of authors expressed herein do not necessarily state or rellect those of the United States Govemment or any agency thereot.

Superconducting Super Collider Laboratory is an equal opportunity employer. 


\section{DISCLAIMER}

Portions of this document may be illegible in electronic image products. Images are produced from the best available original document. 


\title{
Cryogenic Systems for the HEB Accelerator of the Superconducting Super Collider
}

\author{
S. Abramovich and A. Yücel \\ Superconducting Super Collider Laboratory* \\ 2550 Beckleymeade Ave. \\ Dallas, TX 75237 USA
}

July 1994

\footnotetext{
*Operated by the Universities Research Association, Inc., for the U.S. Department of Energy under Contract No. DE-AC35-89ER40486.
} 


\section{CONTENTS}

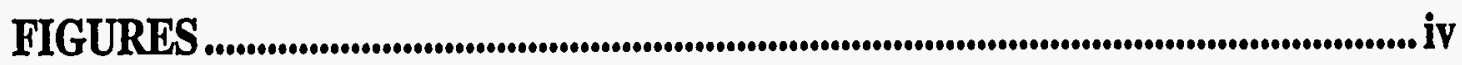

TABLES .......................................................................................................................................... vi

1.0 CRYOGENIC SYSTEM-GENERAL REQUIREMENTS........................................ 1

-1.1 HEB Cryogenic System Geometry..................................................................... 1

1.2 Cryogenic System Configuration ......................................................................... 4

1.2.1 Sector Refrigerator Surface System (SRS) ............................................ 4

1.2.2 Sector Refrigerator Tunnel System (SRT) .............................................. 4

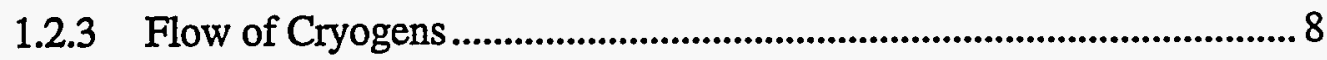

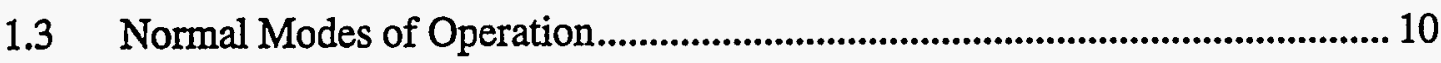

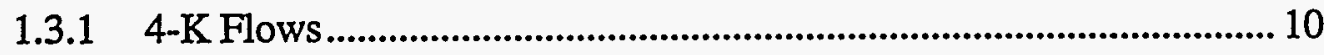

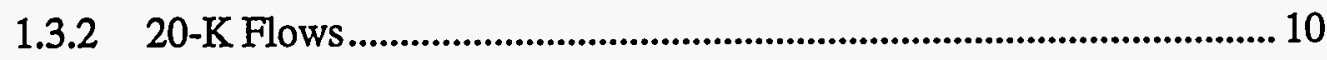

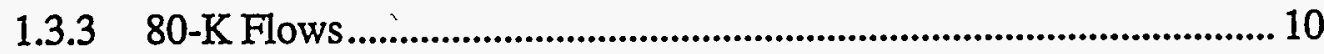

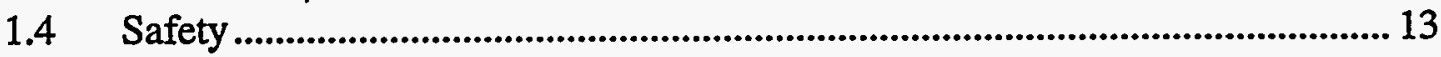

1.5 Maintenance-General Requirements............................................................ 13

$1.6 \quad$ Nitrogen System for the HEB........................................................................... 14

2.0 CRYOGENIC SYSTEM COMPONENTS...........................................................

2.1 Subsystems and Assemblies ................................................................................ 17

2.1.1 Cryogenic System Block Diagram...................................................... 17

2.1.2 HEB Refrigerator and Surface Distribution System Design................ 17

2.1.3 HEB Sector Refrigerator Tunnel System Configuration...................... 28

2.1.4 Nitrogen Distribution and Recooling Systems for the HEB ................28

2.2 Tunnel Cryogenic System Components ...........................................................35

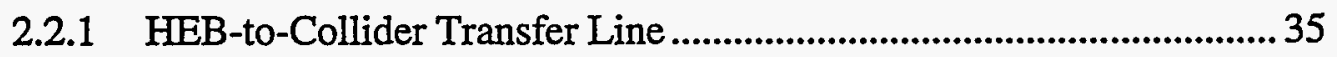

2.2.2 Shaft Transfer Line (Vertical Transfer Line) ...................................... 35

2.2.3 Cold Compressor Box and the Cold Compressor .................................38

2.2.4 Horizontal Transfer Line (HTL) ................................................... 38

2.2.5 Tunnel Distribution Box (TDB)....................................................... 38

2.2.6 Nitrogen Distribution/Pump Box (NPB) and Nitrogen Dump Tanks (NDT) ....................................................................................... 41

2.2.6.1 Nitrogen Distribution/Pump Box......................................... 41

2.2.6.2 Nitrogren Dump Tanks (NDT) ............................................ 41

2.2.7 Nitrogen Compact Subcooler Box (NSB) and Continuous

Recooling ............................................................................................. 41

2.2.8 Auxiliary End Box (AEB) ................................................................... 41

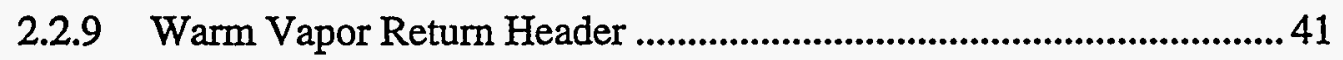

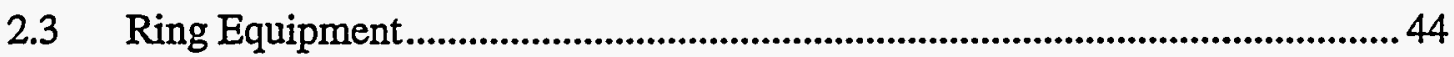

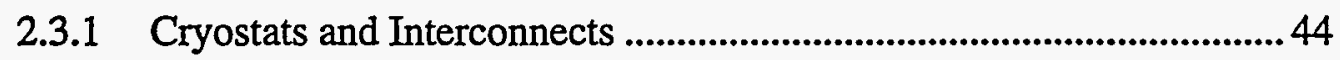

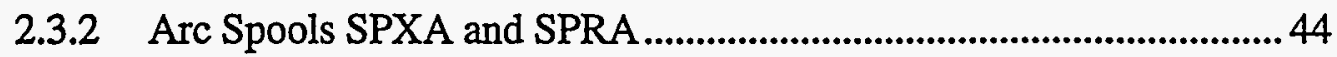




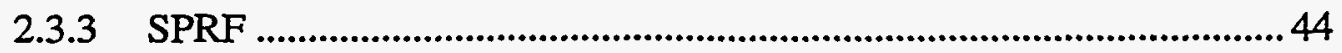

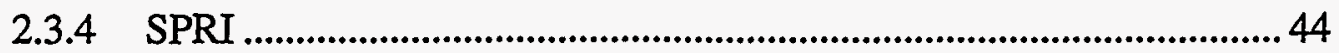

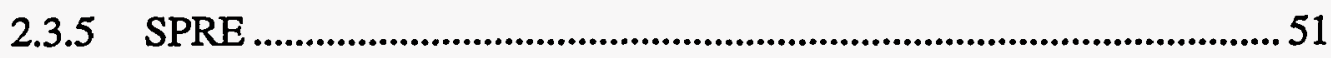

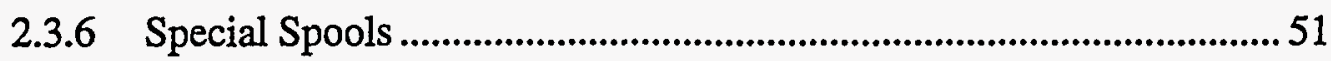

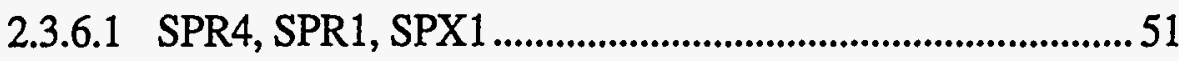

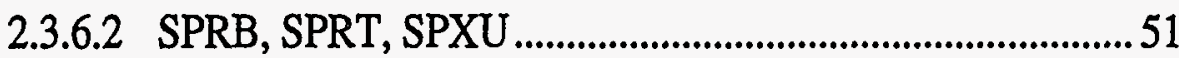

2.3.7 Empty Cryostats (EC) ........................................................................5 5

2.3.8 Cryogenic Bypass Transfer Lines (CBTL) …...................................56

2.3.8.1 Standard and Special Bypass Cryostats (BPCR and BPCR-S) ............................................................................56

2.3.8.2 Connection Boxes BPEB and BPTB, and Tube Sets.......... 56

3.0 HEAT LOAD BUDGETS AND REFRIGERATION PLANT

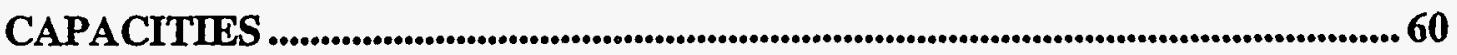

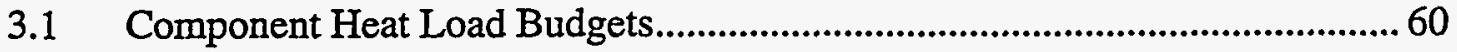

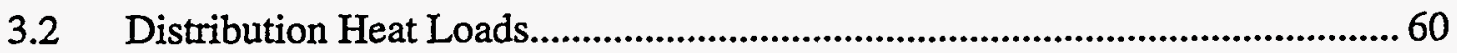

3.3 String and Sector Heat Loads and Plant Capacity Requirements........................ 61

3.4 Nitrogen Heat Budgets .................................................................................. 62

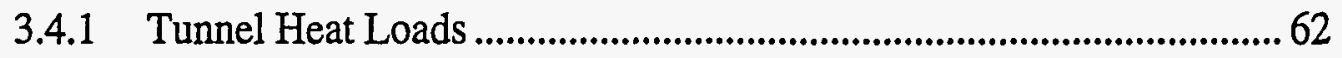

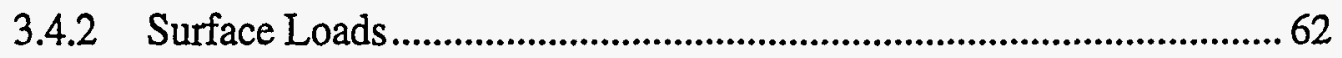

4.0 FLOW AND THERMAL CHARACTERISTICS ..............................................6 64

4.1 Pressure Drop Allocations And Minimum Line Sizes ....................................... 64

4.2 Flow Rates and Configurations for Normal Operation ....................................66

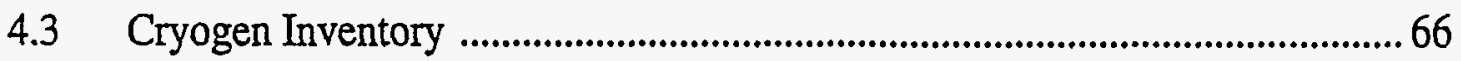

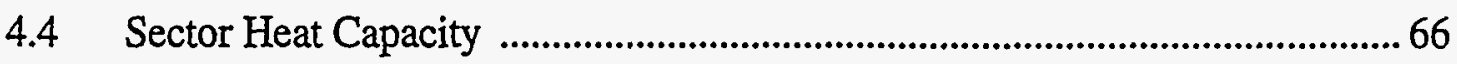

$5.0 \quad$ PROCESS DESCRIPTIONS ............................................................................. 79

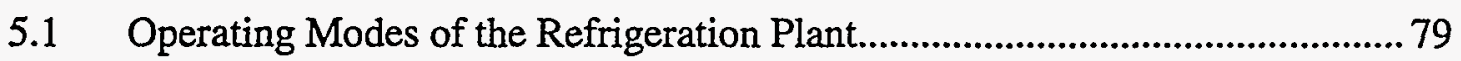

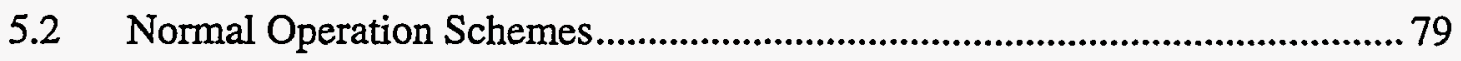

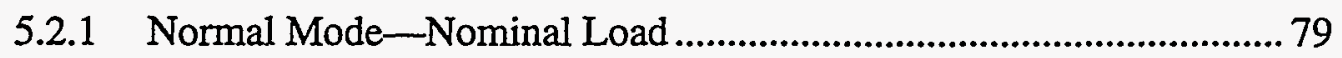

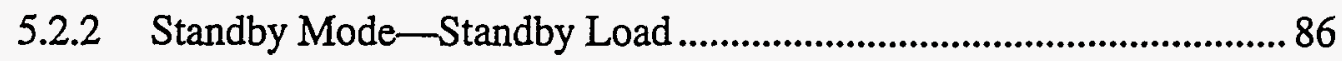

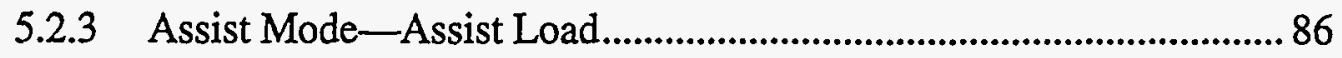

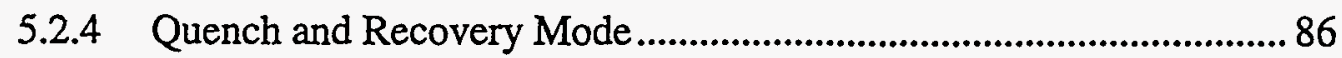

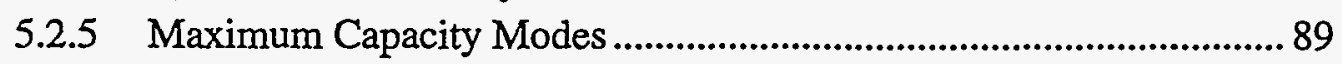

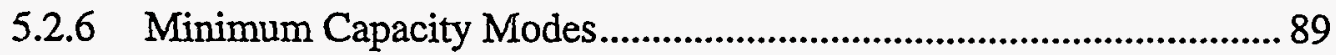

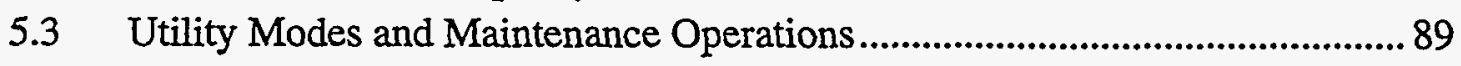

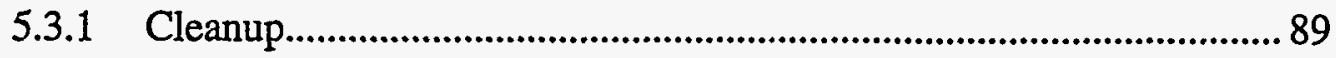

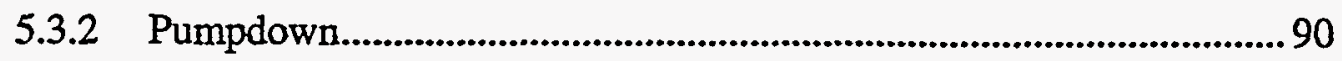

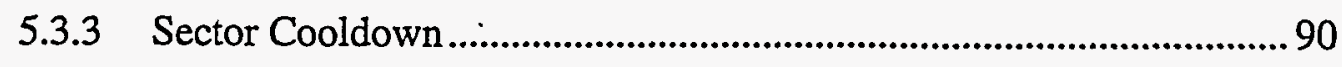

5.3.3.1 Sector 80-K Shield Cooldown from $300 \mathrm{~K}$ to $80 \mathrm{~K}$............. 93

5.3.3.2 Sector 20-K Shield Cooldown from $300 \mathrm{~K}$ to $80 \mathrm{~K}$.............. 95

5.3.3.3 Sector Coldmass Cooldown from $300 \mathrm{~K}$ to $80 \mathrm{~K}$................ 95 
5.3.3.4 Sector Cooldown to $20 \mathrm{~K}$.................................................... 98

5.3.3.5 Sector Cooldown to 4-5 K and Fill-up.................................98

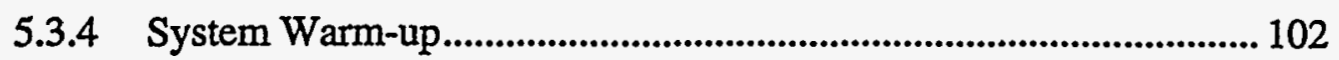

5.3.4.1 System Emptying and Warm-up to $20 \mathrm{~K}$............................. 102

5.3.4.2 System Warm-up to $80 \mathrm{~K}$ and to $300 \mathrm{~K}$............................... 102

5.3.5 Section Repair ............................................................................. 105

5.3.5.1 String Emptying.............................................................. 105

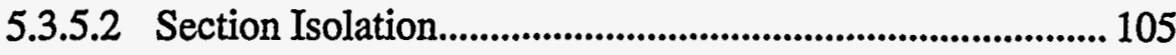

5.3.5.3 Section Warm-up ................................................................ 105

5.3.5.4 Section Cleanup ...................................................................... 110

5.3.5.5 Section Cooldown and Fill-up after Magnet Repair.......... 110

5.4 Emergency Operations-Line Failure or Vacuum Break ................................ 110

6.0 CRYOGENIC CONTROL INSTRUMENTATION................................................... 111

7.0 VALUE ENGINEERING TRADE-OFFS .................................................................. 113

REFERENCES ................................................................................................................................. 115

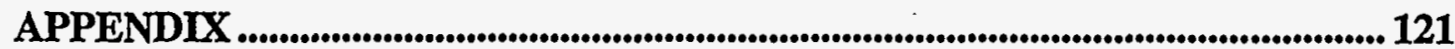




\section{FIGURES}

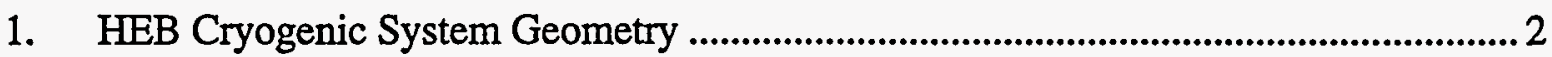

2. HEB Tunnel Cross Section .......................................................................................

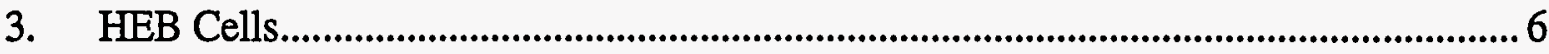

4. Sector Refrigeration System Block Diagram. (See Table 5 for the index to numbers used here.).

5. HEB Dipole Cross Section ........................................................................................ 9

6. Normal Operating Flows........................................................................................... 11

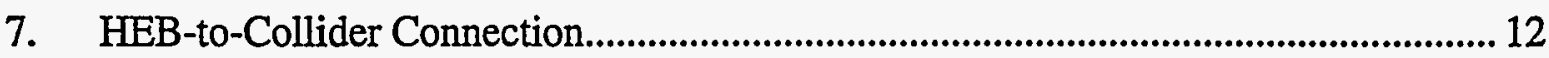

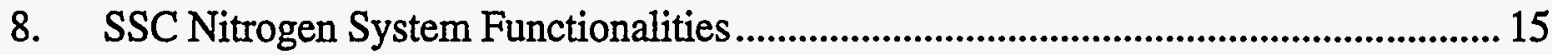

9. Alternative $\mathrm{LN}_{2}$ Supply Systems for the HEB........................................................... 16

10. Hierarchical Organization Block Diagram of the SRS ............................................... 18

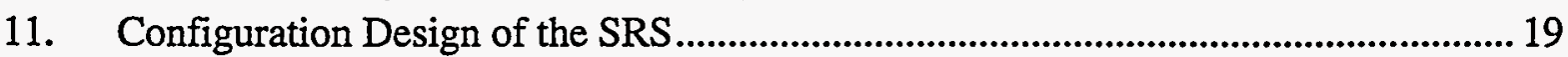

12. Sector Refrigerator Surface System Flow Diagram..................................................... 21

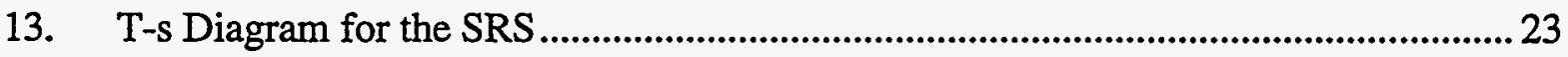

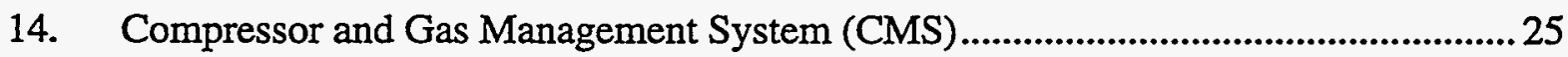

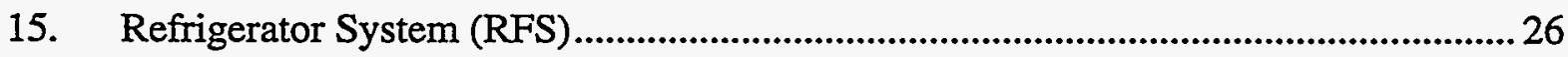

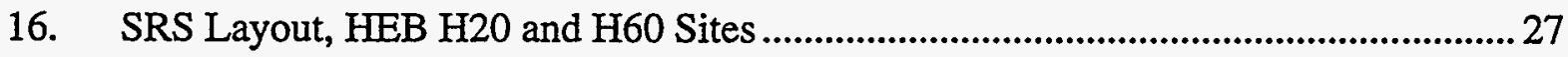

17. Isometric View of the Feed Assembly for the HEB............................................. 29

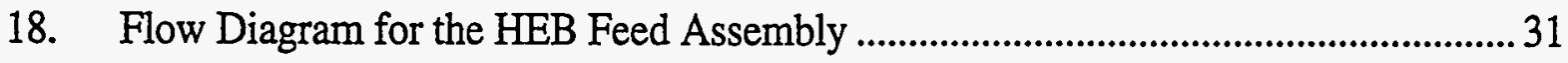

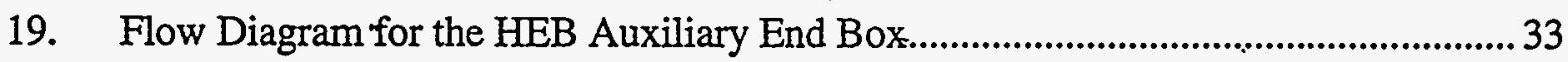

20. Nitrogen Flows and Circulation-Option 1: compact recoolers and one delivery station at $\mathrm{H} 2 \mathrm{O}$

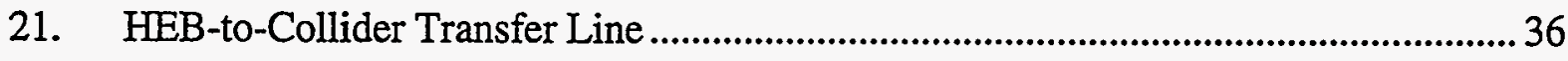

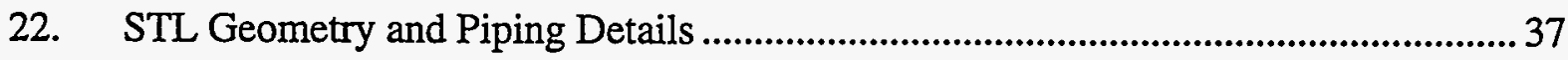

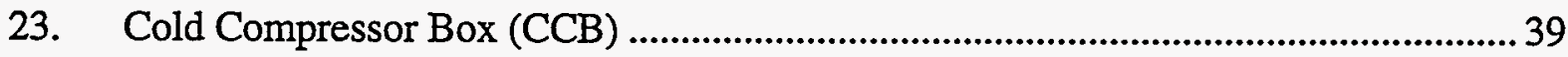

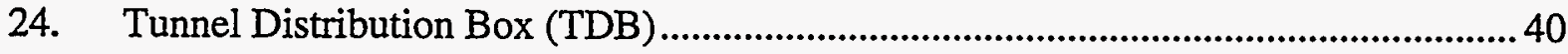

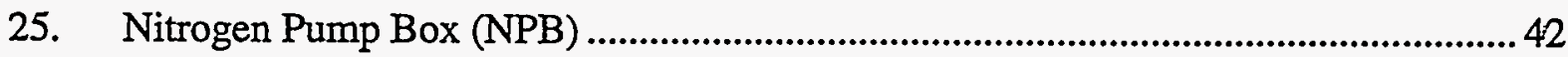

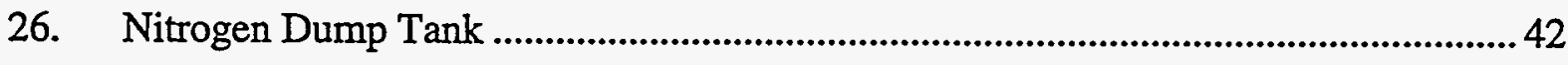

27. Nitrogen Subcooling System: (a) Recoolers Near the Isolation Boxes;

(b) Continuous Recooling by Controlled Injection of Liquid into the Vapor Line..... 43

28. Cryogenic Equipment and Instrumentation for SPXA and SPRA.............................45

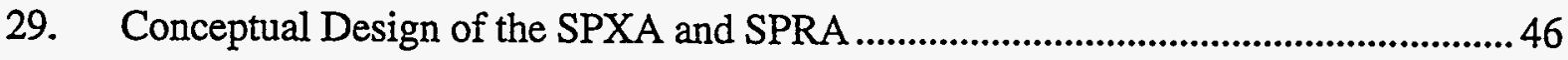

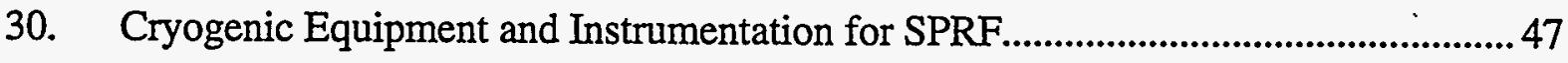

31. Conceptual Design of the SPRF .....................................................................4 48

32. Cryogenic Equipment and Instrumentation for SPRI ...............................................49

33. Conceptual Design of SPRI at $\mathrm{H} 30$ and H70 (3.675 m long) ...................................50

34. Cryogenic Equipment and Instrumentation for SPRE ...........................................55

35. Cryogenic Equipment and Instrumentation for SPRB …........................................5 
36. Cryogenic Equipment and Instrumentation for an Isolated Cryostat,

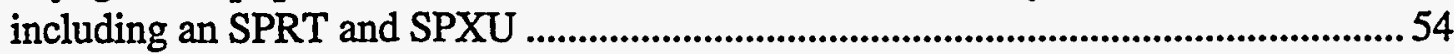

37. Empty Cryostat: (a) Cross Section and (b) Flow Scheme...........................................55

38. Bypass Cryostat Cross Section (Minimum Expected External Diameter $450 \mathrm{~mm}$ ) ...57

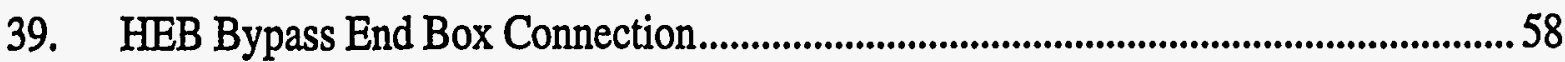

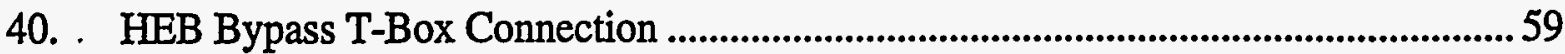

41. Nitrogen System Heat Loads and Mass Flow Rates for the HEB................................63

42. Line Size vs. Pressure Drop Trade-off for Line 3 in the HEB ...................................6 65

43. Flow Configurations in the HEB for Normal Operation................................................6 68

44. Line 1 Helium Temperature Variations over a Cell for Normal Operation.................. 71

45. Flow Configurations in the HEB with H60 Plant Down..............................................72

46. Iron Enthalpy as a Function of Temperature..............................................................76

47. Coldmass Enthalpy for a Long Section and a Full Sector............................................. 77

48. Shield Enthalpy vs. Temperature: (a) 20-K Shield, (b) 80-K Shield. ........................... 78

49. State and Process Diagram for the HEB Cryogenic System......................................... 80

50. HEB Cryogenic System-Normal Operation

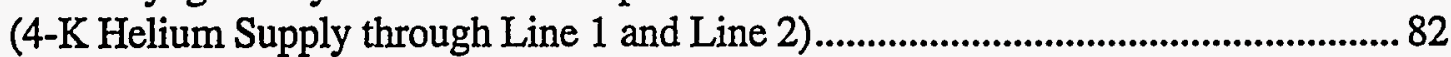

51. HEB Cryogenic System-20-K Refrigeration Loop ................................................. 83

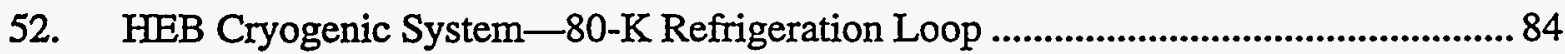

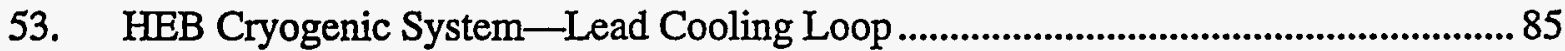

54. HEB Cryogenic System-Standby-Ready

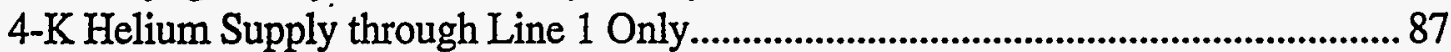

55. Cryogenic System for the HEB-Quench and Recovery ..........................................8

56. Sector Cleanup-Warm Gas Circulation in Line 1, Line 2, and Line 4 ...................... 91

57. Sector Cleanup-Warm Gas Circulation in Line 1, Current Leads, and Warm Return Header ......................................................................................92

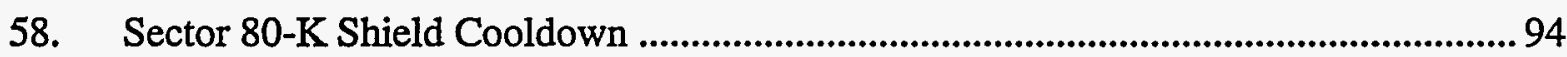

59. Sector Coldmass Cooldown from $300 \mathrm{~K}$ to $80 \mathrm{~K}$-Serial Cooldown......................... 96

60. Sector Coldmass Cooldown from $300 \mathrm{~K}$ to $80 \mathrm{~K}$-Parallel Cooldown........................99

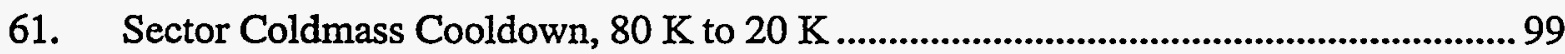

62. Sector Coldmass Cooldown from $20 \mathrm{~K}$ to $5 \mathrm{~K}$ and Fill-up......................................... 100

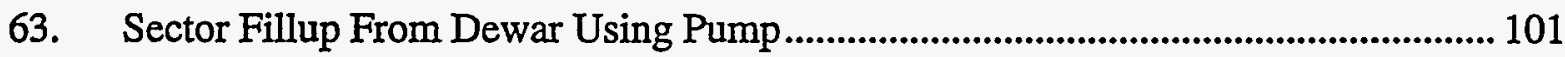

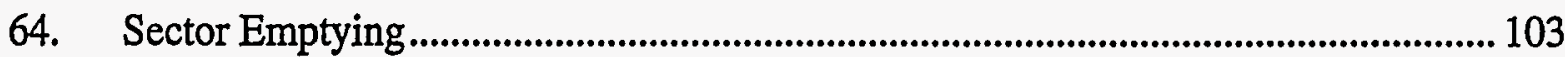

65. Sector Warm-up Using Helium from Pressurized Warm Return Header ................. 104

66. Flow Configuration for Section Repair.................................................................... 106

67. Section Warm-up Using Warm Return Header, Heaters, and Blower........................ 107

68. Section Warm-up Using 20-K Flow and Heaters...................................................... 108

69. Section Warm-up Using Helium from Pressurized Warm Return Header ................ 109 


\section{TABLES}

1. Surface and Beam Altitudes for the HEB (m)............................................................. 1

2. Definition of the Cryogenic Sector and Section Boundaries ......................................... 3

3. Lengths of the Sections in the HEB ......................................................................... 4

4. HEB.Cryostat Count.................................................................................................5

5. Sector Station Cryogenic System State Points...........................................................

6. Shaft Transfer Line System Requirements for the HEB ...............................................35

7. Design Conditions for the Cold Compressor ............................................................... 38

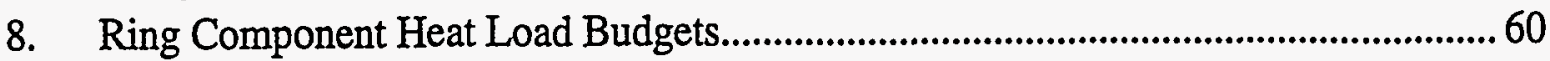

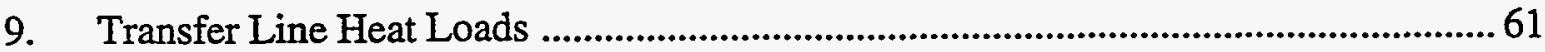

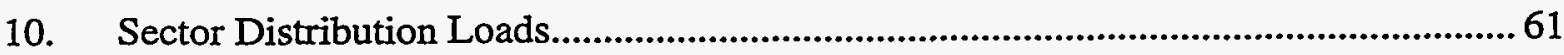

11. H20 Plant Total Heat Loads and Capacity Requirements............................................ 61

12. Minimum Line Sizes, Nominal Conditions, and Pressure Drop Allocations...............64 64

13. Flow Conditions for Normal Operation .......................................................................69 69

14. Helium Flows in Lines 1-3 for Standby and Normal Operation ................................. 70

15. Helium Flows in Lines 1-3 with H60 Plant Down ..................................................... 73

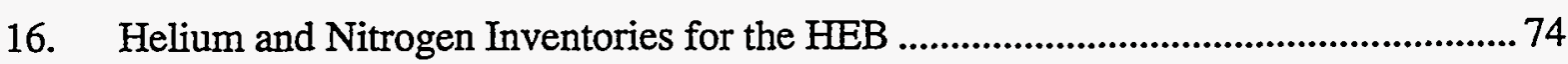

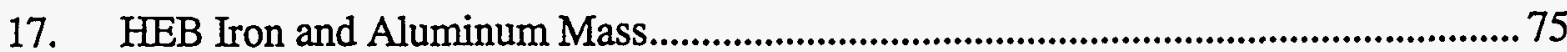

18. Helium and Nitrogen Inventories for Various States of the HEB

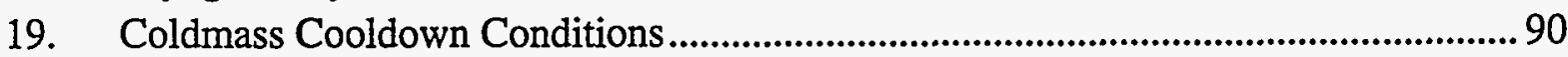

20. Cryogenic Instrumentation for the Ring Components ............................................... 112 


\subsection{CRYOGENIC SYSTEM FOR THE HEB-GENERAL REQUIREMENTS}

\subsection{HEB Cryogenic System Geometry}

The High Energy Booster (HEB) single ring, 10,800 $\mathrm{m}$ in circumference, is designed to be built in a tunnel located in a plane with an inclination of $0.2^{\circ}$ parallel to the collider and is located $14 \mathrm{~m}$ above the plane of the collider. The highest point of the tunnel is close to $\mathrm{H} 20$ and the lowest point near H60. The difference in the elevations between these two points is approximately $16 \mathrm{~m}$. Table 1 shows the depth of the HEB-tunnel and the surface elevation at the H10-H80 locations.

Table 1. Surface and Beam Altitudes for the HEB (m).

\begin{tabular}{|c|c|c|c|c|}
\hline Location & $\begin{array}{c}\text { Surface } \\
\text { Altitude }\end{array}$ & $\begin{array}{c}\text { Depth to } \\
\text { Beamline }\end{array}$ & $\begin{array}{c}\text { Beamline } \\
\text { Altitude }\end{array}$ & $\begin{array}{c}\text { Beamline } \\
\text { Relative Altitude }\end{array}$ \\
\hline H10 & 229.3 & 39.4 & 189.9 & 16.3 \\
\hline H20 & 247.4 & 57.7 & 189.7 & 16.1 \\
\hline H30 & 248.6 & 63.0 & 185.6 & 12.0 \\
\hline$H 40$ & 233.6 & 55.0 & 178.6 & 5.0 \\
\hline H50 & 226.2 & 52.5 & 173.7 & 0.1 \\
\hline$H 60$ & 226.6 & 53.0 & 173.6 & 0.0 \\
\hline$H 70$ & 221.6 & 43.3 & 178.3 & 4.7 \\
\hline$H 80$ & 215.0 & 30.2 & 184.8 & 11.2 \\
\hline
\end{tabular}

The HEB is divided into eight "Beam Sectors," as defined in the HEB Level 3B Specification. ${ }^{1}$ This definition is used for beam physics and has no use for cryogenic design and operation.

For the cryogenic system design and operation, the HEB is divided into cryogenic sectors, strings, and sections, which are delineated by the eight major stations on the HEB lattice named: H1O, H2O, H30, $\mathrm{H} 40, \mathrm{H} 50, \mathrm{H} 60, \mathrm{H70}$, and $\mathrm{H} 80$ (see Figure 1). These locations house the appropriate sector cryogenic feed equipment, cryogenic return equipment, and/or cryogenic isolation equipment. The HEB ring is served by two helium refrigeration plants located at the $\mathrm{H} 20$ and $\mathrm{H} 60$ sites. The supply of cryogens from the Surface Cryogenic Systems (SRS) to the Sector Tunnel Refrigeration Systems (SRT) is provided through vertical utility shafts near the refrigeration plants. Additional service shafts are located near the sector boundaries. The major power supply to the magnet rings and energy extraction systems is designed to use the same shafts and the same connection points to the magnet rings. A schematic of the HEB tunnel cross section is shown in Figure 2.

The HEB ring is divided into two cryogenic sectors, centered at $\mathrm{H} 20$ and $\mathrm{H} 60$. Sector $\mathrm{H} 20$ covers half of the HEB ring between $\mathrm{H} 80-\mathrm{H} 10-\mathrm{H} 20-\mathrm{H} 30-\mathrm{H} 40$. It has a helium refrigeration plant on the surface at $\mathrm{H} 20$. Sector H60 covers the other half of the HEB ring between $\mathrm{H} 40-\mathrm{H} 50-\mathrm{H} 60-\mathrm{H} 70-\mathrm{H} 80$. It has a helium refrigeration plant at $\mathrm{H} 60$. The boundaries of the cryogenic sectors at $\mathrm{H} 40$ and $\mathrm{H} 80$ are designed to enable flows of cryogens from one sector to the other and, if necessary, flows of nitrogen from the tunnel to the surface.

Each cryogenic sector is divided into two cryogenic strings, each with a cryogenic feed box at one end and a return box at the other end. The strings are segmented into sections connected to each other by U-tubes that enable the isolation of parts of the system for maintenance. A section is the smallest part of the ring that can be isolated, warmed up, and cooled down for maintenance. In the HEB a string contains two sections. The actual definition of the HEB sections is given in Table 2 and shown in Figure 1. 


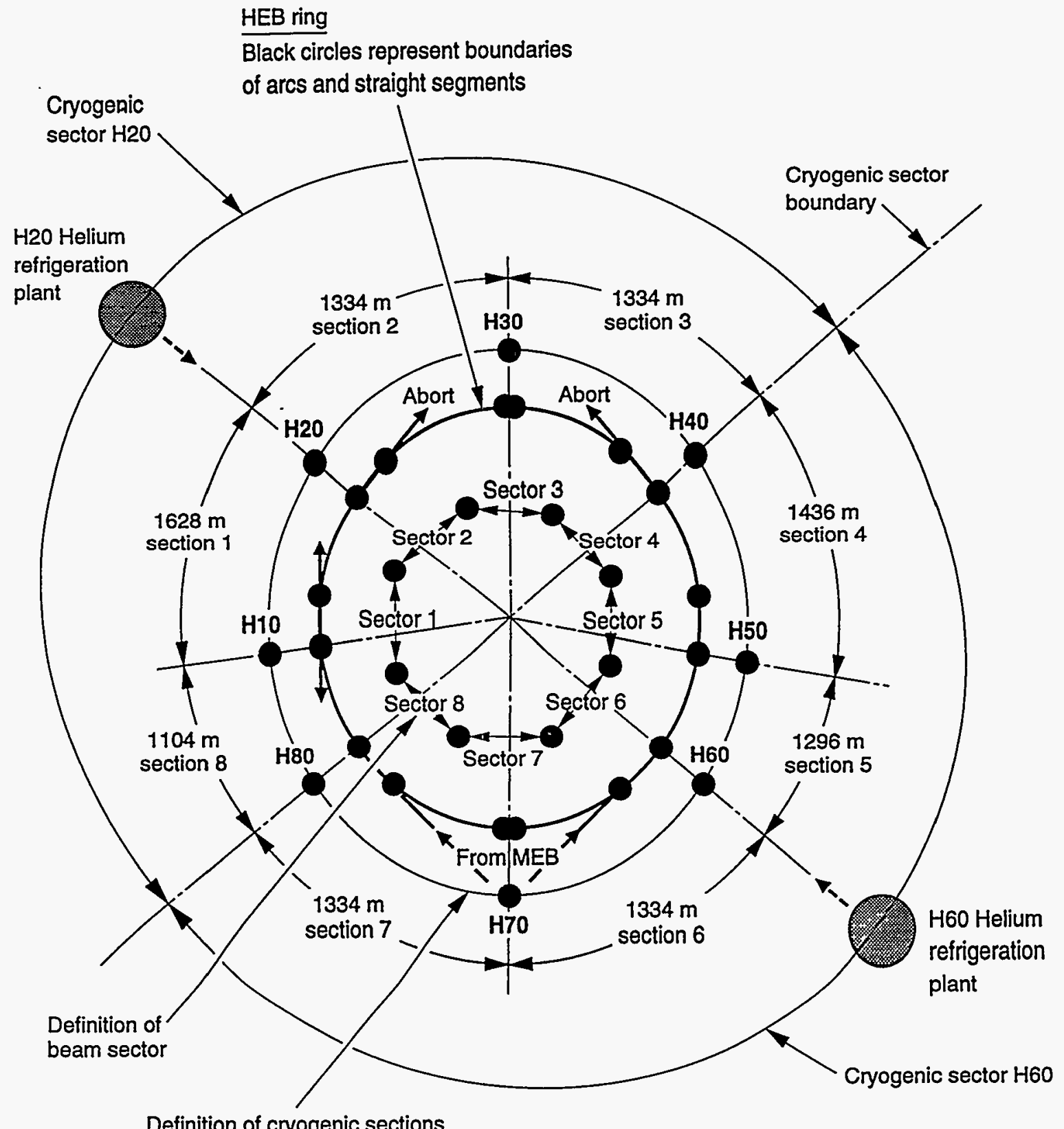

Definition of cryogenic sections

Black circles represent section boundaries and location of isolation spools (SPRI, SPRF, SPRE)

4

Injection to the collider

Warm beam equipment in the straight segments are located at $\mathrm{H} 10, \mathrm{H} 2 \mathrm{O}, \mathrm{H} 40, \mathrm{H} 50, \mathrm{H} 60$, and $\mathrm{H} 80$

Figure 1. HEB Cryogenic System Geometry. 


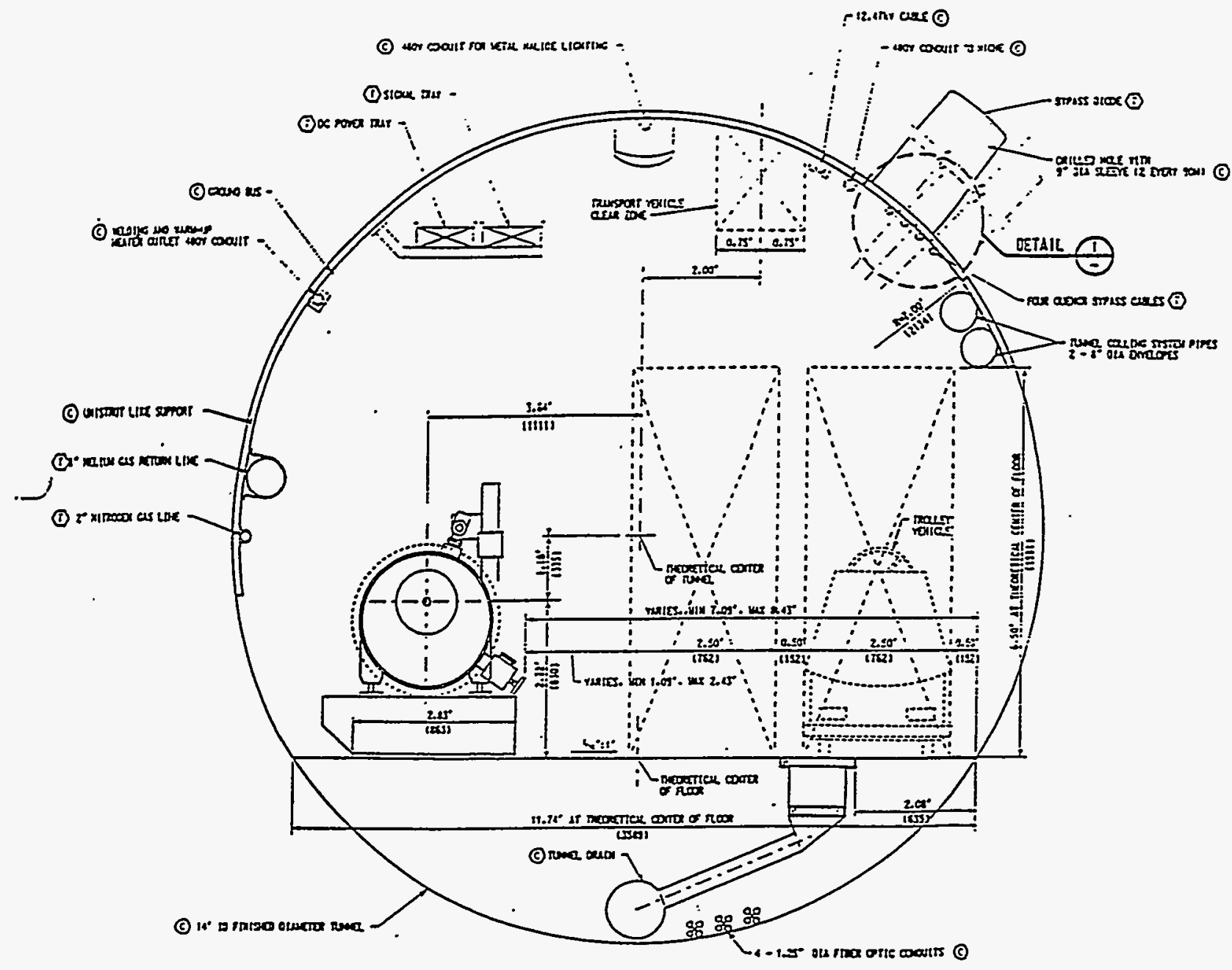

Figure 2. HEB Tunnel Cross Section.

Table 2. Definition of the Cryogenic Sector and Section Boundaries.

\begin{tabular}{|c|c|c|c|}
\hline \multicolumn{2}{|c|}{ Sector H2O (north): H8O-H2O-H40 } & \multicolumn{2}{|c|}{ Sector H6O (south): H40-H6O-H8O } \\
\hline Section $\mathrm{H} 1$ & $\mathrm{H} 80-\mathrm{H} 10$ & Section H5 & $\mathrm{H} 40-\mathrm{H} 50$ \\
\hline Section $\mathrm{H} 2$ & $\mathrm{H} 10-\mathrm{H} 2 \mathrm{O}$ & Section H6 & $\mathrm{H} 50-\mathrm{H} 60$ \\
\hline Section $\mathrm{H3}$ & $\mathrm{H} 2 \mathrm{O}-\mathrm{H} 3 \mathrm{O}$ & Section $\mathrm{H7}$ & $\mathrm{H} 60-\mathrm{H} 70$ \\
\hline Section $\mathrm{H} 4$ & $\mathrm{H} 30-\mathrm{H} 40$ & Section H8 & $\mathrm{H} 70-\mathrm{H} 80$ \\
\hline
\end{tabular}

There are six straight segments in the ring required for beam injection, beam extraction, beam abort, beam test, and other purposes. These segments contain those lengths of the beam tube that are warm. To bridge over the warm segments, the cryogens have to be transferred to Bypass Transfer Lines, which are specially designed cryostats. The straight segments are located in the vicinity of $\mathrm{H} 10, \mathrm{H} 20, \mathrm{H} 40, \mathrm{H} 50$, $\mathrm{H} 60$, and $\mathrm{H} 80$, each with a specific length and design as given by the HEB Level 3B specification. ${ }^{1}$

Table 3 gives the lengths of the sections. The differences in the length of each section and the differences in their contents (i.e., ring components) have to be carefully defined because of their impact on the parameters for normal operation (heat loads, pressure drops, etc.) and on the time duration for maintenance procedures. Table 4 gives the list of ring components in each section. Further details on the HEB specifications and requirements can be found in References $2-4$. 
Table 3. Lengths of the Sections in the HEB.

\begin{tabular}{|c|c|c|}
\hline Section & Updated & Conceptual Design \\
\hline $\mathrm{H} 80-\mathrm{H} 10$ & $1104 \mathrm{~m}$ & $1480 \mathrm{~m}$ \\
\hline $\mathrm{H} 10-\mathrm{H} 20$ & $1628 \mathrm{~m}$ & $1480 \mathrm{~m}$ \\
\hline $\mathrm{H} 20-\mathrm{H} 30$ & $1334 \mathrm{~m}$ & $1220 \mathrm{~m}$ \\
\hline $\mathrm{H} 30-\mathrm{H} 40$ & $1334 \mathrm{~m}$ & $1220 \mathrm{~m}$ \\
\hline $\mathrm{H} 40-\mathrm{H} 50$ & $1436 \mathrm{~m}$ & $1480 \mathrm{~m}$ \\
\hline $\mathrm{H} 50-\mathrm{H} 60$ & $1296 \mathrm{~m}$ & $1480 \mathrm{~m}$ \\
\hline $\mathrm{H} 60-\mathrm{H} 70$ & $1334 \mathrm{~m}$ & $1220 \mathrm{~m}$ \\
\hline $\mathrm{H} 70-\mathrm{H} 80$ & $1334 \mathrm{~m}$ & $1220 \mathrm{~m}$ \\
\hline
\end{tabular}

The sections are further broken down into cells. The cell is the smallest repetitive group of magnets (dipoles and quadrupoles) in an accelerator with a specific function of beam optics. For cryogenic, vacuum, and mechanical purposes, the HEB cell is designed to confine insulating vacuum problems and magnet quenches to a cell, and to prevent the propagation of these problems to the adjacent cells. A regular HEB arc cell is $65 \mathrm{~m}$ long and contains four dipoles, two quadrupoles, and two spool pieces. The cell configurations are different at the end of arc sections and in the straight sections. Figure 3 shows the configurations for a regular arc cell, for a dispersion suppressor cell, and for cells with isolation equipment.

\subsection{Cryogenic System Configuration}

Figure 4 is a block diagram showing the major parts of the sector cryogenic system. The Sector Cryogenic System (SCS) is physically divided into two parts: the Sector Refrigerator Surface System and the Sector Refrigerator Tunnel System.

\subsubsection{Sector Refrigerator Surface System (SRS)}

The Sector Refrigerator Surface System (SRS) for the HEB has the same design, configuration, and capacity as the SRS for the Collider. Since the 4-K liquefaction, the 4-K refrigeration, and the 20-K heat loads of the HEB are different from the collider sector loads, the HEB refrigeration system has to be able to operate at a different working point.

The surface cryogenic system is described in detail in References 24,33 , and 34.

\subsubsection{Sector Refrigerator Tunnel System (SRT)}

The Sector Refrigerator Tunnel System (SRT) for the HEB is designed to serve one magnet ring (compared to the collider, which has two rings). This requires a special design of the tunnel distribution system to support the flow schemes for the normal operation modes and for the maintenance schemes.

The higher dynamic 4-K load of the HEB ring requires the vapor return line in the ring to be larger than in the collider ( $110 \mathrm{~mm}$ in the HEB, $86 \mathrm{~mm}$ in the collider). It also requires the 4-K liquid "return" line to be able to serve as a retum line when the heat load is low (during standby mode) and as a feed line during normal operation (when the beam is on). These issues are discussed in more detail in Section 4.0.

The $20-\mathrm{K}$ helium lines and the $80-\mathrm{K}$ nitrogen lines and distribution boxes are designed such that the flow can be maintained in both directions from one refrigerator to the other, clockwise, or counterclockwise, depending on the specific conditions that may change with time. 
Table 4. HEB Cryostat Count.

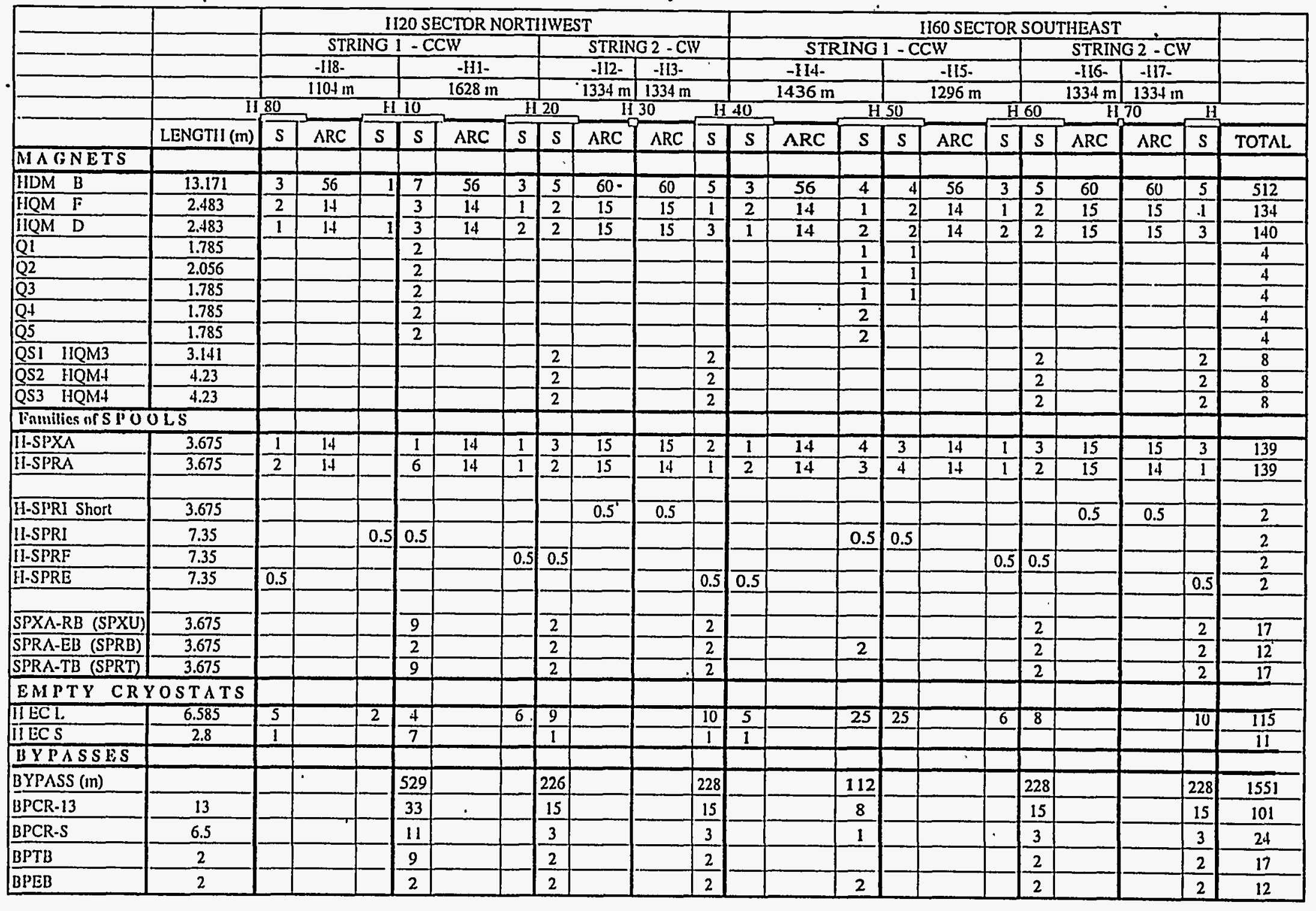


(a)

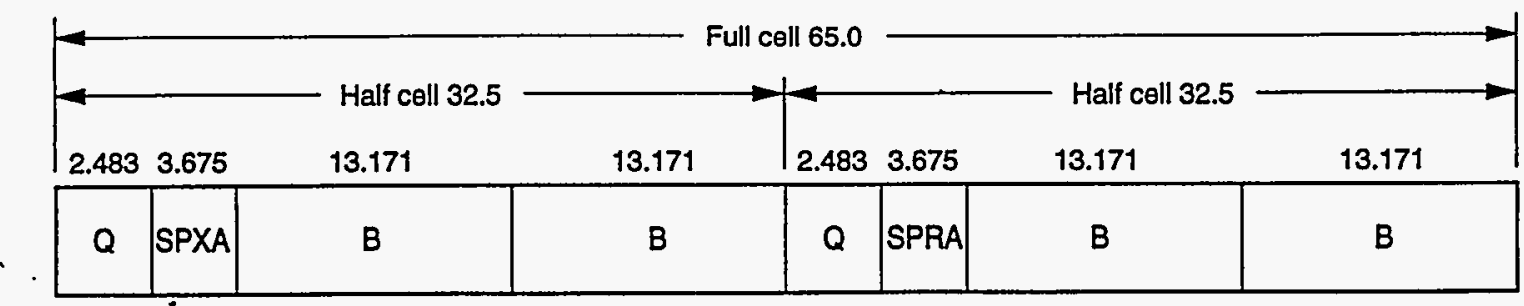

(b)

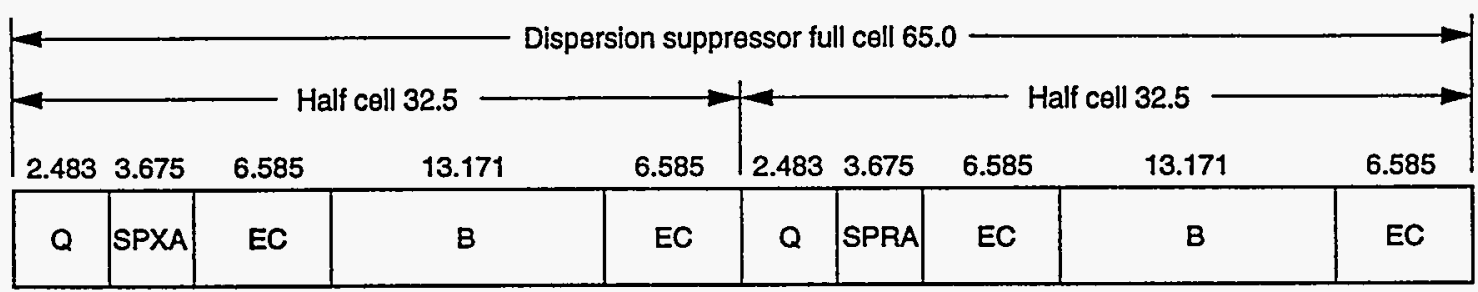

(c)

\begin{tabular}{|c|c|c|c|c|c|c|c|c|c|}
\hline 2.483 & 7.35 & 2.91 & 13.171 & 6.585 & 2.483 & 3.675 & 6.585 & 13.171 & 6.585 \\
\hline $\mathbf{Q}$ & SPRI & EC & B & EC & $\mathbf{Q}$ & SPXA & EC & B & EC \\
\hline
\end{tabular}

All dimensions are in meters

$B=$ Regular Arc Dipole $13.171 \mathrm{~m}$ long

$Q=$ Regular Arc Quadrupole

SPXA = Arc Spool without Recooler with Vacuum Barrier

SPRA = Arc Spool with a Recooler without Vacuum Barrier

$E C=$ Empty Cryostat (standard module length desogned for the HEB $=6.585 \mathrm{~m}$ )

The quadrupole located at the boundary between the D.S. cell and the straight segment may have a different length than a regular arc quadupole. Therefore the adjacent EC may be different.

Figure 3. HEB Cells. 


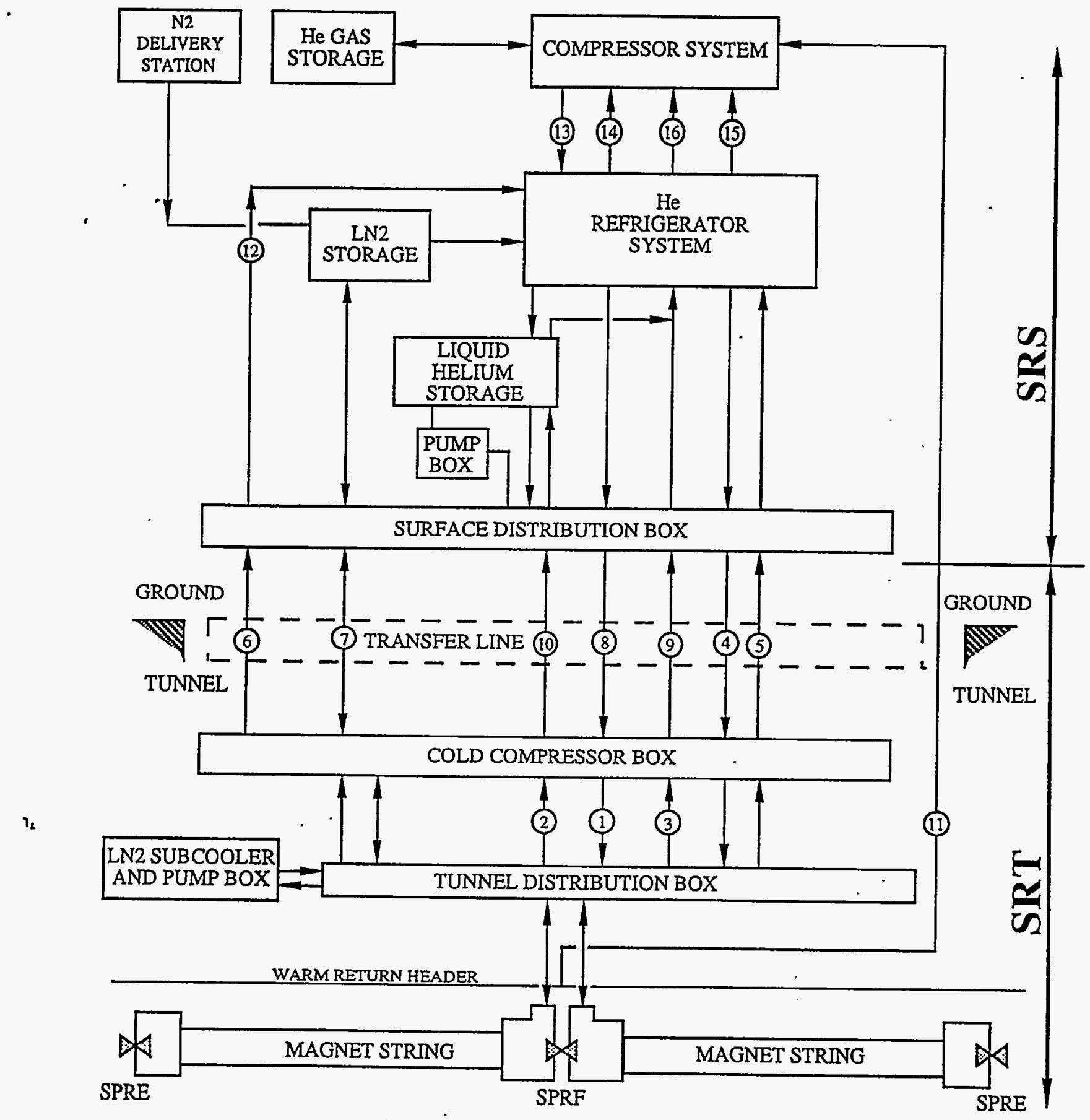

Figure 4. Sector Refrigeration System Block Dlagram. (See Table 5 for the index to numbers used here.) 


\subsubsection{Flow of Cryogens}

The cold components (cryostats with superconductive magnets, spool pieces, empty cryostats, bypass cryostat transfer lines, etc.) in the HEB ring are designed to be refrigerated by single-phase helium flow controlled at a temperature of $4 \mathrm{~K}$ to maintain the magnet windings in the superconductive state. To minimize the heat load on the 4-K loop, the magnet cryostats are designed to provide high-quality thermal insulation achieved by two thermal shields, at nominal temperatures of $20 \mathrm{~K}$ and $84 \mathrm{~K}$, contained in a high vacuum chamber with multilayer insulation (MLI). There are six cryogen lines in a cryostat, plus a warm line external to the cryostat, as follows:

Line 1, single-phase feed. For normal operation, a nominal flow of $100 \mathrm{~g} / \mathrm{s}$ at $4 \mathrm{~K}, 0.4 \mathrm{MPa}$ helium through the magnets maintains the coils in the superconductive state. This flow enters a string at one end and exits at the other end while being recooled periodically along the string. The cross-sectional area for this flow is defined by the sum of the different cooling channel cross sections within the coldmass. A small amount of this feed stream is tapped off at different locations along the string for the refrigeration of the high-current leads, the bypass leads, and the current leads for the corrector magnets.

Line 2, single-phase return. This line, which has an ID of $45.2 \mathrm{~mm}$, is mounted in the vacuum envelope alongside the magnet coldmass. It carries the single phase from the end of the string back to the refrigerator. A sizable portion of this return stream is injected into the recoolers. The heat load of the HEB strings is higher than that of the collider, and the high boil-off rate in the recoolers may require supply of additional single-phase flow from the other end of this line.

Line 3, 4-K helium vapor return. This line, sized at $110 \mathrm{~mm} \mathrm{ID}$ for the $\mathrm{HEB}$ (compared to $86.5 \mathrm{~mm} \mathrm{ID}$ for the collider), returns the boil-off helium from the recoolers to the cold compressor installed in the tunnel. The compressor discharges the vapor to the refrigerator, located more than $60 \mathrm{~m}$ above the tunnel. For normal operation the flow direction may be defined arbitrarily.

Line 4, 20-K helium. An $82.5-\mathrm{mm}$-ID pipe is used for the $20-\mathrm{K}$ shield refrigeration loop. The design flowrate is $100 \mathrm{~g} / \mathrm{s}$ at $0.3 \mathrm{MPa}$. The flow is routed from one refrigerator through the two connecting strings to the other refrigerator.

Line 5, $80-K \mathrm{LN}_{2}$ shield line. This $57.2-\mathrm{mm}$-ID line is used to distribute the liquid nitrogen in the tunnel for the refrigeration of the $80-\mathrm{K}$ shield and to supply liquid nitrogen to the refrigeration plants for precociling.

Line 6, 80-K GN 2 shield line. A second 57.2-mm-ID line is used to return the nitrogen vapor produced in the nitrogen recoolers to the helium refrigerator for precooling purposes. The vapor is vented afterwards to atmosphere at $300 \mathrm{~K}$ or is used in the regeneration skids.

Line 7, warm return header. Sized at $213 \mathrm{~mm} \mathrm{ID}$, this header is installed in the tunnel and is used to return the warm helium flow from the current leads. It is also used to return warm helium during cleaning, cooldown, and maintenance processes. An alternate design calls for two $100-\mathrm{mm}-\mathrm{ID}$ warm headers, one used for cooldown and warmup flows, and the other for current lead return flows.

The insulating spaces around the cryogenic components (magnets, spool pieces, and transfer lines) are evacuated to $1.3 \times 10 \mathrm{E}-2 \mathrm{~Pa}$ by mechanical pumps and to $1.3 \times 10 \mathrm{E}-5 \mathrm{~Pa}$ by cryopumping. This vacuum is required to minimize the heat load on the coldmass. The insulating space is bounded radially by the outer walls of the cryostat and axially by the vacuum barriers located in the spool pieces. The insulating vacuum volume between two vacuum barriers (65 m apart) is approximately $19.5 \mathrm{~m}^{3}$.

Cross section of an HEB dipole cryostat is shown in Figure 5 : 
Table 5. Sector Station Cryogenic System State Points. ${ }^{a}$

\begin{tabular}{|c|l|l|l|}
\hline Loc & \multicolumn{1}{|c|}{ Description } & Temperature (k) & Pressure (bar) \\
\hline & & & \\
\hline 1 & Single-phase helium feed & 4.0 & 4.0 \\
\hline 2 & Single-phase helium return & 4.0 & 3.5 \\
\hline 3 & Gaseous helium retum & 3.95 & 0.77 \\
\hline 4 & $20-K$ shield feed & $14-18$ & 3.0 \\
\hline 5 & $20-K$ shield return & 28 max. & 2.0 \\
\hline 6 & Gaseous nitrogen return & 85 & 1.5 \\
\hline 7 & Liquid nitrogen flow & $80-85$ & $3.0-10.0$ \\
\hline 8 & LHe supply from refrigerator & 4.45 & 4.0 \\
\hline 9 & Cold compressor return to surface & 6.1 & 1.4 \\
\hline 10 & Single-phase helium return to dewar & 4.3 & 3.5 \\
\hline 11 & Warm helium gas return & 305 & 1.1 \\
\hline 12 & Nitrogen gas & 85 & 1.3 \\
\hline 13 & High-pressure helium & 308 & 20 nominal \\
\hline 14 & Medium pressure helium & 303 & 3 nominal \\
\hline 15 & Low-pressure helium & 303 & 1.05 \\
\hline 16 & $20-K$ return pressure helium & 303 & 1.5 nominal \\
\hline
\end{tabular}

aindex to numbers in Figure 4.

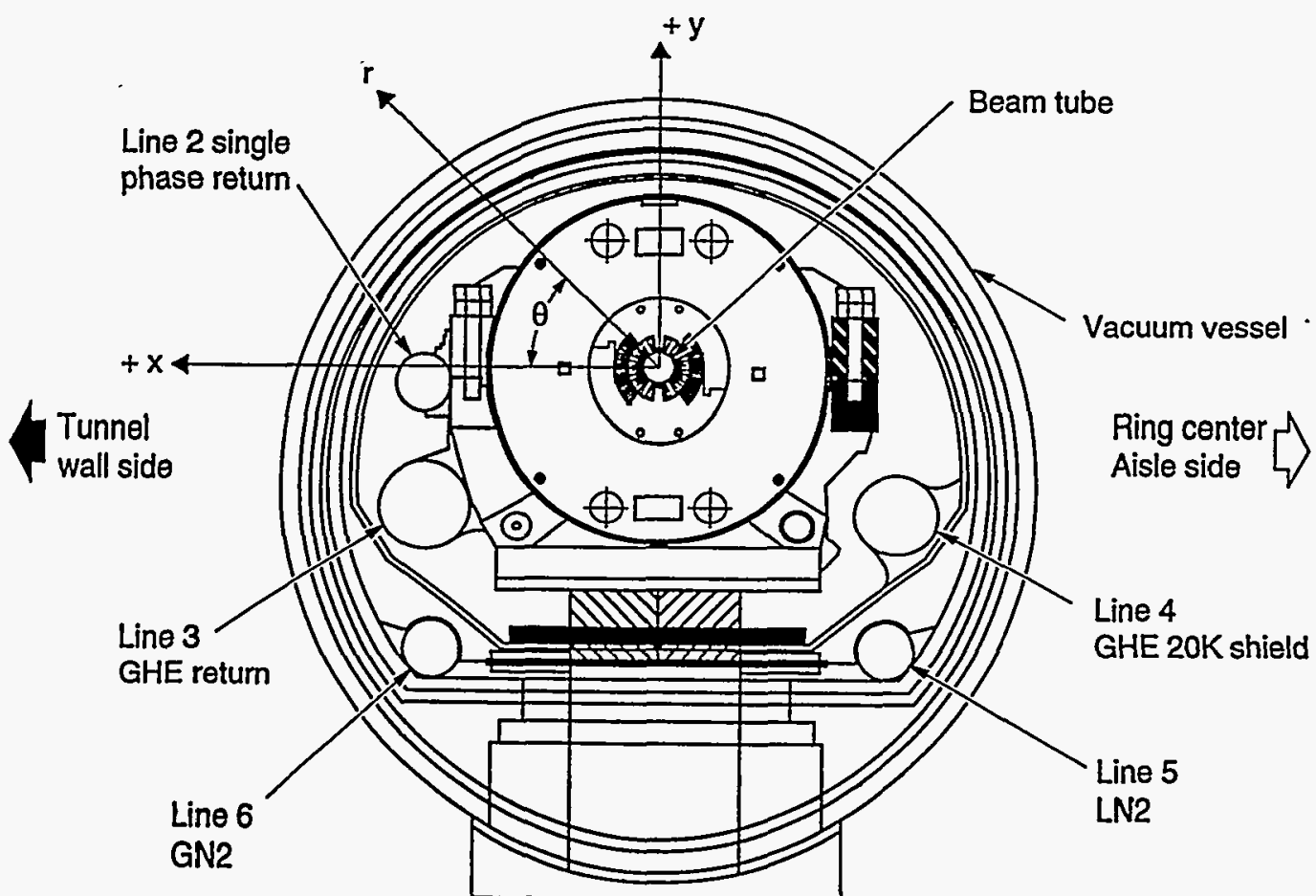

TIP-05078

Figure 5. HEB Dipole Cross Section. 


\subsection{Normal Modes of Operation}

The Normal Modes of Operation of the cryogenic system are required for the following:

1. Standby: when the machine is cold and ready for beam injection. The heat load is static load only.

2. When the machine is cold and the beam is on. The heat load is static plus dynamic.

These two modes are expected to be steady, and the discharge flows from the refrigerator are expected to be equal to the return flows from the tunnel.

The basic requirement of the cryogenic system is to maintain the temperature in the superconductive magnet rings below $4.3 \mathrm{~K}$. The temperature control of the $4-\mathrm{K}$ helium system is based on a repetitive recooling system. This in turn depends on the vapor pressure level in the vapor return line. Given that a recooler can be installed in the system every $65 \mathrm{~m}$ (or one every cell), and given the heat load of the various ring components (see Section 3.0), the following flows are required in order to maintain the required temperature range for normal operation.

\subsubsection{4-K Flows}

Sector H20: 4-K, 100-g/s, helium supplied from the surface to the cryogenic feed box (SPRF) at H2O runs through the two strings to the cryogenic return boxes (SPRE), located at $\mathrm{H} 80$ and at $\mathrm{H} 40$ (string $1=$ $\mathrm{H} 20$ to $\mathrm{H} 80$, string $2=\mathrm{H} 20$ to $\mathrm{H} 40$ ).

Sector H60: 4-K, 100-g/s helium supplied to the cryogenic feed box (SPRF) at H60 runs through the two strings to the cryogenic return boxes (SPRE), located at $\mathrm{H} 40$ and at $\mathrm{H} 80$ (string $1=\mathrm{H} 60$ to $\mathrm{H} 40$, string $2=\mathrm{H} 60$ to $\mathrm{H} 80$ ).

For standby operation (when the beam is off), the 4-K liquid and vapor helium return flows are both brought back to the refrigerator for reprocessing.

During normal operation (when the beam is on), the high heat load of the HEB requires 4-K helium to be supplied to the system' through both the feed line and thè return line at the SPRF. All the 4-K helium supply through the 4-K feed and liquid return lines flows back to the refrigerator as 4-K vapor.

\subsubsection{0-K Flows}

$20-\mathrm{K}, 100-\mathrm{g} / \mathrm{s}$ helium for shield refrigeration is designed to run through the ring from the refrigerator at $\mathrm{H} 20$ to the refrigerator at $\mathrm{H} 60$ through the north arc; a second $100 \mathrm{~g} / \mathrm{s}$ stream runs from the refrigerator at $\mathrm{H} 60$ to $\mathrm{H} 20$ through the south arc. The flow direction is chosen arbitrarily.

\subsubsection{0-K Flows}

80-K liquid nitrogen for shield refrigeration and for surface supply is designed to flow from H2O to H60 through both north and south arcs. The liquid nitrogen has to be periodically recooled using heat exchangers installed near the isolation spools outside the ring. (Other methods of nitrogen recooling are discussed in Section 2.0.) Vapor nitrogen generated in the nitrogen recooling system in the tunnel is brought back to the two surface refrigerators, warmed to $300 \mathrm{~K}$, and vented to the atmosphere. The liquid nitrogen is imported to the SSC from external sources. The system is designed to operate with liquid nitrogen supplied from an external source, delivered at one location $(772 \mathrm{~g} / \mathrm{s}$ at $\mathrm{H} 20)$ or at two locations ( $386 \mathrm{~g} / \mathrm{s}$ at $\mathrm{H} 20$ and $386 \mathrm{~g} / \mathrm{s}$ at $\mathrm{H} 60$ ). An alternative solution for normal operation calls for a large $\mathrm{LN}_{2}$ delivery station in the collider and a $\mathrm{LN}_{2}$ transfer line from the collider to the HEB.

The flow scheme for normal operation is shown in Figure 6. Figure 7 shows the location of the HEB relative to the collider and the connecting transfer line. 


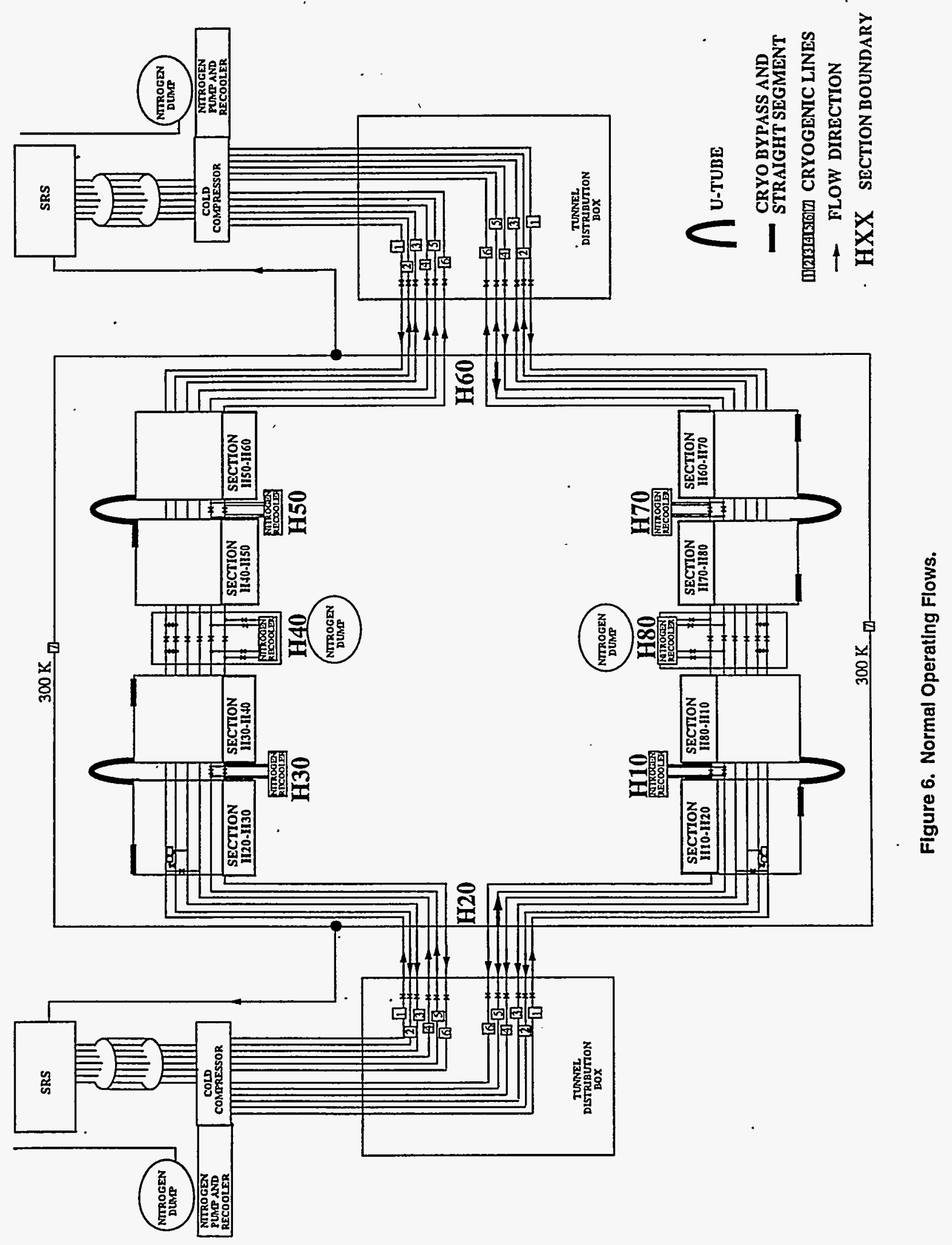




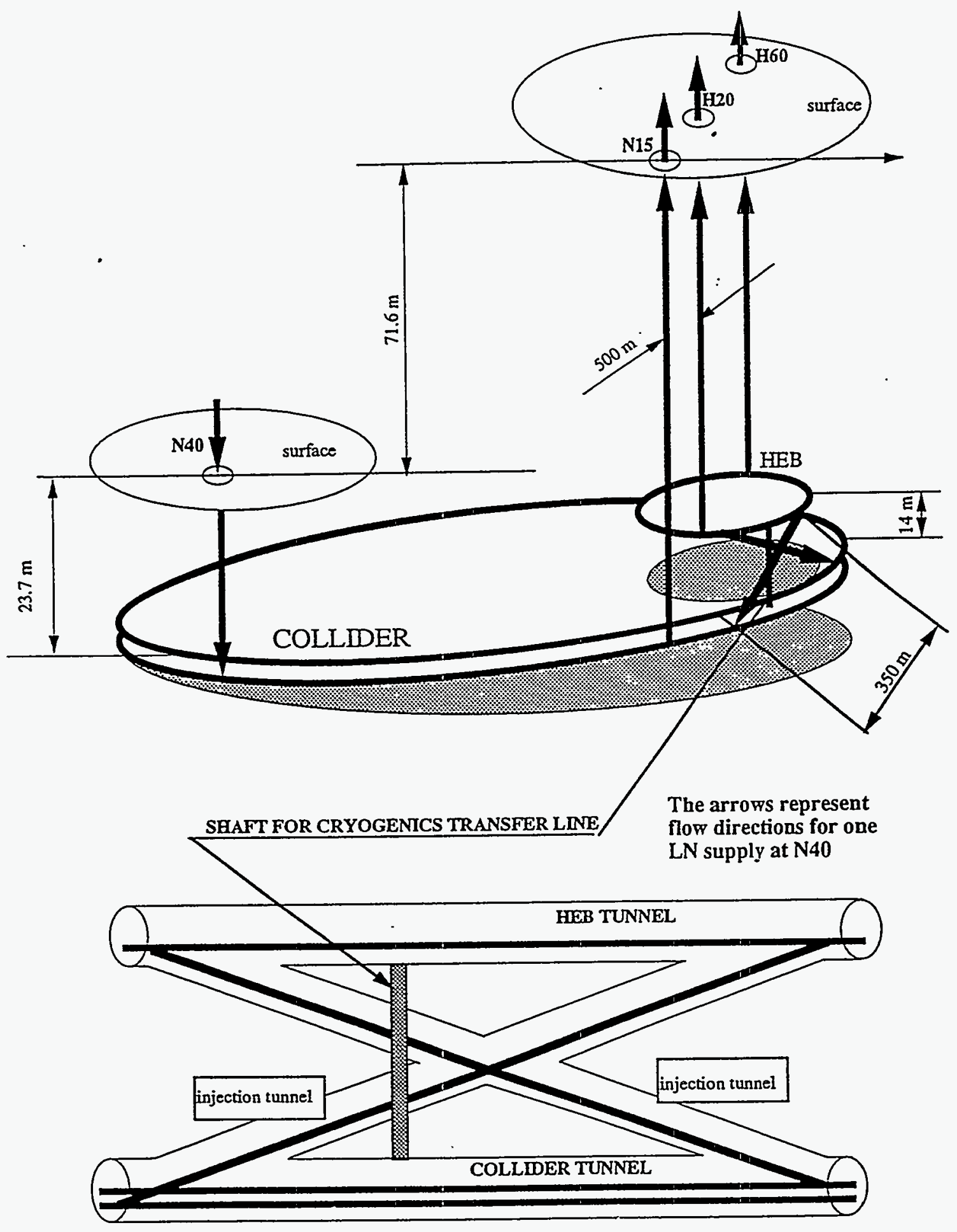

Figure 7. HEB-to-Collider Connection. 


\subsection{Safety}

System safety and safe operation of the machine are major requirements. (See SCDR ${ }^{4}$ and HEB Level 3B Specification. ${ }^{1}$ ) Safety issues relating to cryogenics include the following:

1. System response in case of a quench. The cryogenic system has to remove and recover the warmed helium in a way that the pressure in the system remains below certain limits. Detailed analyses of the quench processes are given in References 10-12.

2. System response in case of a line rupture. The cryogenic system has to minimize the flow of cryogens into the cryostat-nsulating vacuum chamber and eventually into the tunnel, and maximize the return flow to the surface. Analyses of line ruptures are given in References 7-9 and 19.

3. System design. The cryogenic system has to be designed to have the minimum possible inventory of cryogens and to operate at the lowest possible pressure. This is to minimize the amount of cryogens vented into the tunnel in case of emergency or line rupture, and to minimize the time response of the system.

4. Cooldown process from $300 \mathrm{~K}$ to $4 \mathrm{~K}$ and warm-up back to $300 \mathrm{~K}$ are to be performed in the shortest time possible without causing excessive thermal stresses in the system. This time is limited by the allowable gradient of the thermal wave and by the high pressure limit during warm-up or cooldown. Cooldown and warm-up processes are discussed in detail in References 82 and 86.

\subsection{Maintenance-General Requirements}

There are two types of maintenance processes required: When maintenance is performed while the system is cold (for example, when vacuum is degraded and the activation of vacuum pumps may do the correction); and when a ring component has to be replaced. This requires section warm-up and cooldown.

The various cryogenic processes for maintenance purposes are:

- Sector cooldown from $300 \mathrm{~K}$ to $4 \mathrm{~K}$

- Sector warm-up from $4 \mathrm{~K}$ to $300 \mathrm{~K}$

- Section warm-up for repair

- Section cooldown after repair

- Sector warm-up to $20 \mathrm{~K}$ for gas desorption

- System warm-up to $80 \mathrm{~K}$ for long-term storage.

The basic system requirement is to perform all the maintenance processes in the shortest possible time. (The various time budgets related to the processes are given in References 83 and 84.) The time for all these cryogenic processes depends on the following:

- Refrigerator capacity. During the cooldown and warm-up cycles, large quantities of helium and nitrogen vapor are generated in the rings. These have to be brought back to the surface; the helium has to be reliquefied in the refrigerator, and the nitrogen has to be warmed to $300 \mathrm{~K}$ before being vented to the atmosphere. This places additional demand on the refrigerator, on top of the supply of the cryogens for cooldown and warm-up.

- Pressure. A decrease in the process time may be achieved by increasing the flow of . cryogens. This requires raising the supply pressure. However, the pressure level is limited, particularly when temperature changes are involved.

- The allowable longitudinal temperature gradient in the magnet strings limits the cryogen flow rates and the supply pressures.

The detailed scenario for the maintenance cycle for the HEB is discussed in Section 5.0. 


\subsection{Nitrogen System for the HEB}

A block diagram showing all functionalities of the SSC nitrogen system that serves both the collider and the HEB is given in Figure 8. Liquid nitrogen for the SSC is designed to be generated outside the SSC sites, imported by trucks or through pipes, and delivered to the system at one or more supply points. The HEB nitrogen supply should be independent of the collider and is designed to operate with its own supply of nitrogen. This requires special nitrogen delivery stations at one -or both- of the H2O and H60 locations.

The HEB is also designed to have a collider-to-HEB transfer line through which nitrogen may be supplied from the collider to the HEB. This seems to be a more effective way to run the machine during normal operation. In any case, each refrigeration system (at $\mathrm{H} 20$ and at $\mathrm{H} 60$ ) must be equipped with large nitrogen dewars and delivery stations to be used during the cooldown process and when the collider-toHEB transfer cannot be operated.

The total demand of liquid nitrogen for normal operation of the HEB is $772 \mathrm{~g} / \mathrm{s:} 332 \mathrm{~g} / \mathrm{s}$ for the tunnel and $220 \mathrm{~g} / \mathrm{s}$ for each surface refrigeration system. Figure 9 shows a comparison of the three methods of $\mathrm{LN}_{2}$ supply to the HEB. These three methods are discussed in References $44-46$. 


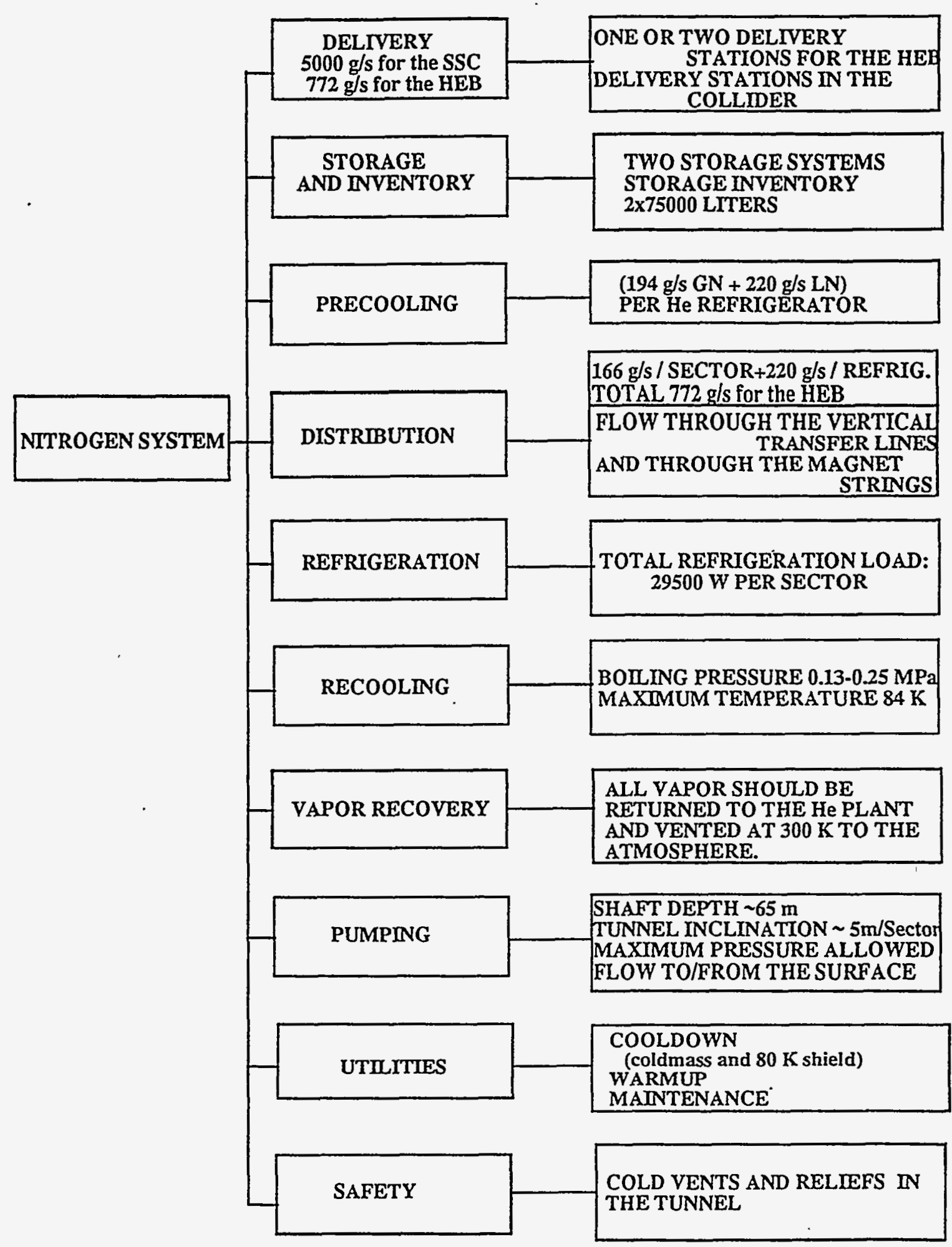

Figure 8. SSC Nitrogen System Functionalities. 
LOAD: TOTAL $84 \mathrm{~K}$ FLOW $=772 \mathrm{~g} / \mathrm{s} \mathrm{LN2}=2779 \mathrm{~kg} / \mathrm{h}=67 \mathrm{ton} / \mathrm{day}$

1) LOCAL GENERATION

Ideal work $768 \mathrm{~kJ} / \mathrm{kg} * 0.772 \mathrm{~kg} / \mathrm{s}$

assuming $30 \%$ Carnot efficiency

$=1.9 \mathrm{MW}=2550 \mathrm{HP}$

2) LOCALSTORAGE

SRS dewar $=\mathbf{7 5 0 0 0}$ liters

$\sim \max 54000 \mathrm{~kg}$ (one day supply /dewar)

3) TRANSPORTATION

22.5 tons/truck $\Rightarrow$ required three trucks/day

If there is no supply for one day and the refill is required in 6 hours,

$-1$ parking for 3 trucks is needed.

向

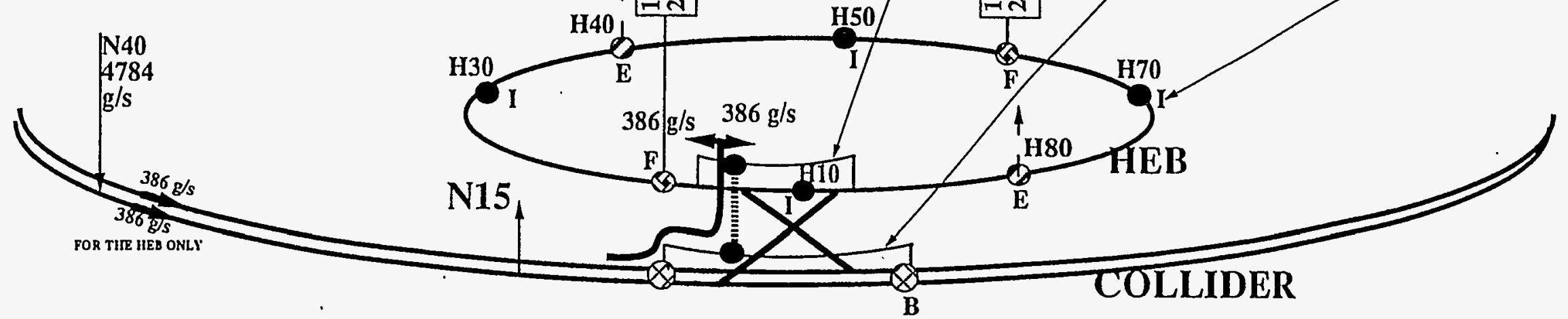

Figure 9. Alternatlve $\mathrm{LN}_{2}$ Supply Systems for the HEB. 


\subsection{CRYOGENIC SYSTEM COMPONENTS}

\subsection{Subsystems and Assemblies}

\subsubsection{Cryogenic System Block Diagram}

A general block diagram of the cryogenic system for the HEB sector is given in Figure 4. The Sector Cryogenic System (SCS) organization block diagram is shown in Figure 10. The status of the cryogenic system and equipment design is given in Reference 27.

\subsubsection{HEB Refrigerator and Surface Distribution System Design}

The Sector Refrigeration Surface System (SRS) is designed to handle a variety of operating conditions. Its primary function is to provide refrigeration to the magnet strings. It also provides services such as cleanup, cooldown, warm-up, and maintenance to the magnet strings. In order to meet the operating requirements for each mode, a minimum set of components is needed to enable the reconfiguration of the system by including or excluding specific subsystems, and to adjust the capacity and the throughput of each subsystem. Thus the design must also provide the appropriate overall control philosophy of the system, in particular that of the liquid management scheme. The liquid management system, which serves as the interface between the surface system and the tunnel cryogenics, should be capable of handling the various operating conditions of the system.

Special effort was invested in the definition of the system configuration, including:

- Independent system for each load

- Integration of the 4- $\mathrm{K}$ and the $20-\mathrm{K}$ loads

- Two identical systems (two parallel plants or two parallel cold boxes)

- One larger system per sector.

The larger serial system containing one cold box was finally chosen. (The other systems were excluded because of much higher cost.)

To define the detailed configuration, a series of process modeling and simulation studies were performed. These included the comparison between various choices, such as

- Warm compression of the return helium gas vs. cold compression

- Cold compressor placement (in the tunnel or on the surface)

- Number of expanders.

The compressor and coldbox sizing were done to optimize the power requirements, the number of skids, and the heat exchanger sizing, which resulted in a system that can be built with existing or available equipment and has capacity adjustment and turndown capabilities.

The resulting basic configuration design is shown in Figure 11. The sector refrigerator surface system flow diagram is shown in Figure 12. The corresponding thermodynamic T-s diagram is presented in Figure 13. (The thermodynamic analysis for the HEB is incomplete. The diagrams in Figure 13 are taken from Reference 43 and are offered as illustrative examples.)

Sector Surface Refrigeration System consists of two major sub-systems: the Compressor and Gas Management System (CMS) and the Refrigeration System (RFS). 


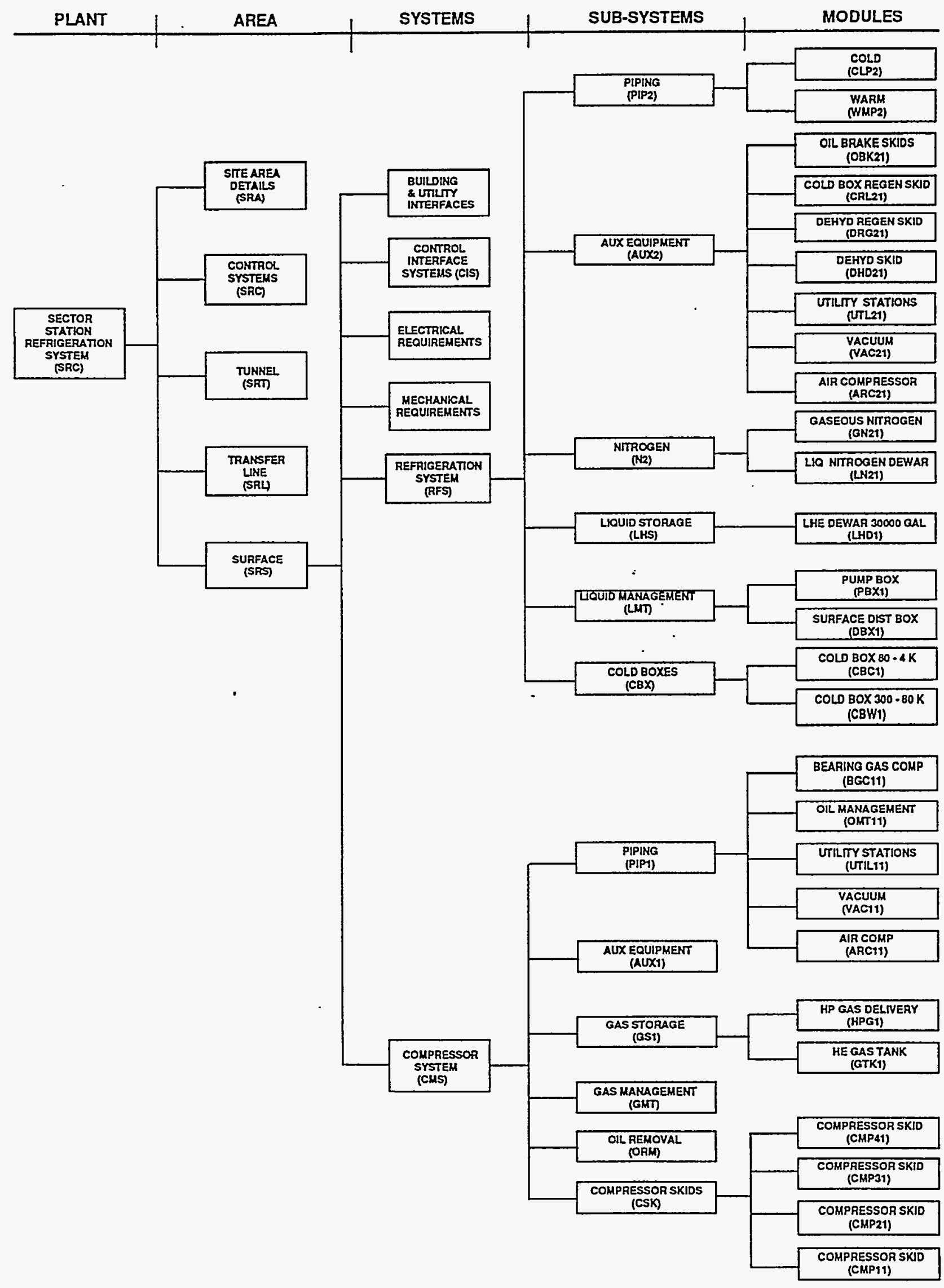

Figure 10. Hierarchical Organization Block Diagram of the SRS. 


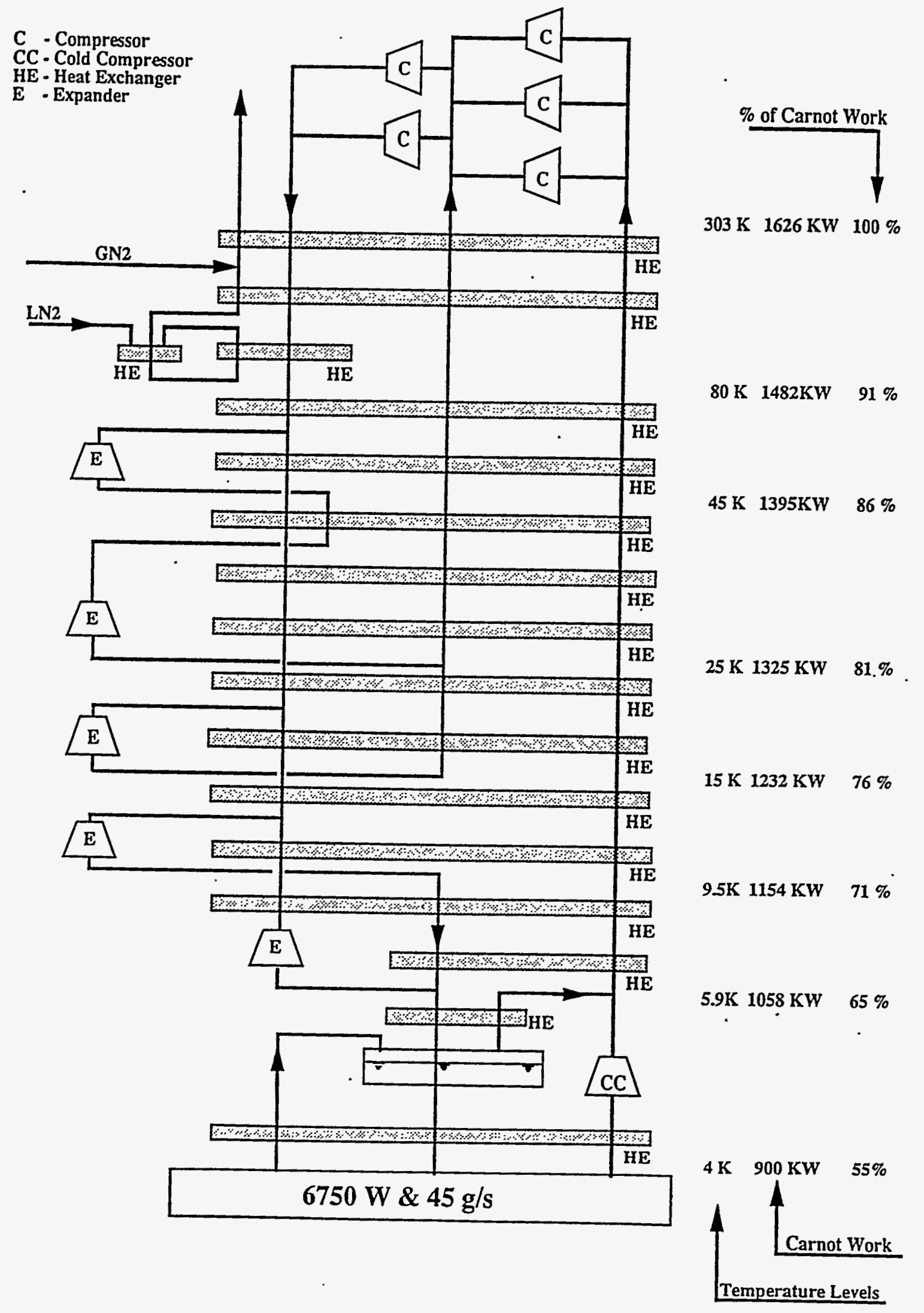

Figure 11. Configuration Design of the SRS. 


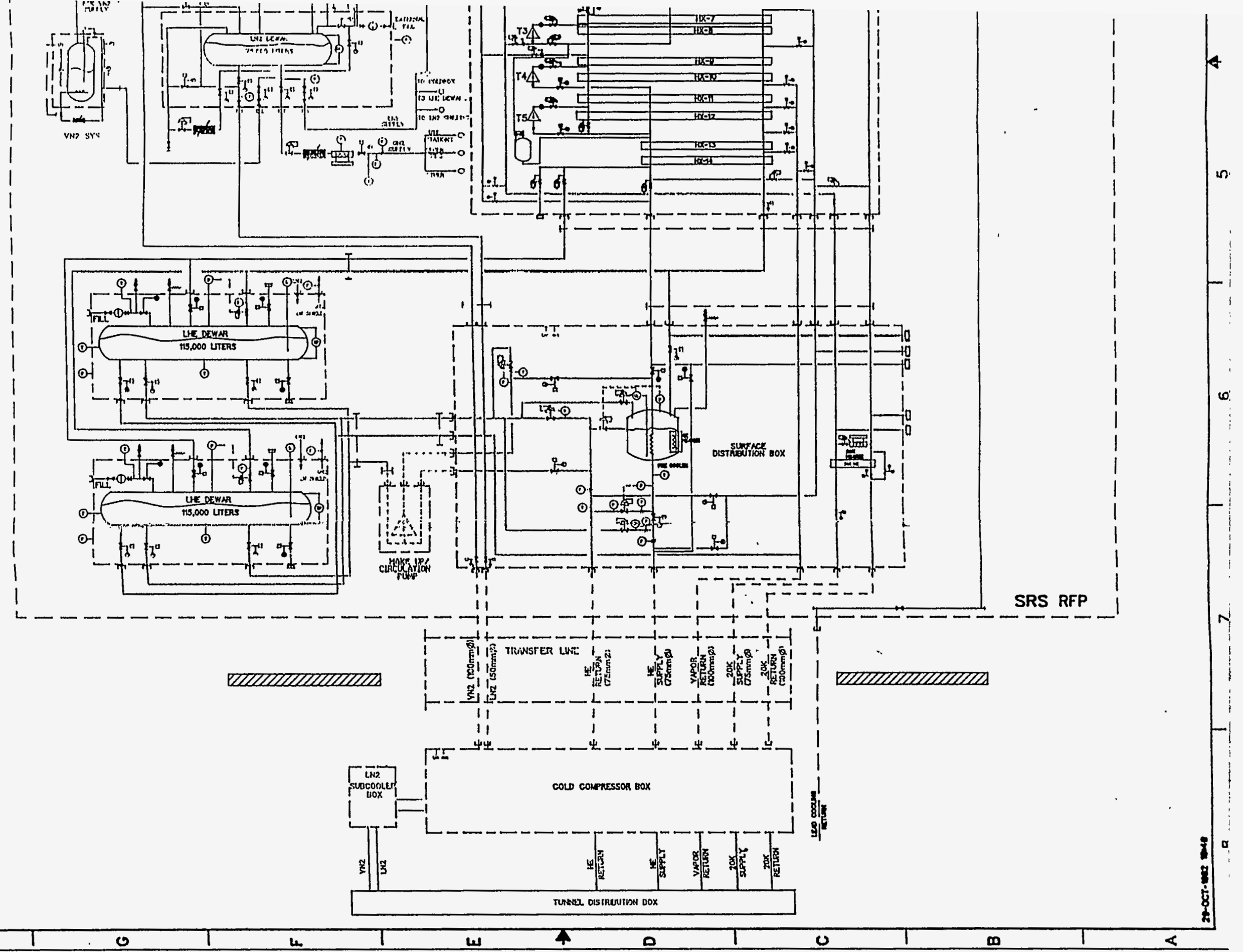

Figure 12. Sector Refrigerator Surface System Flow Dlagram. 


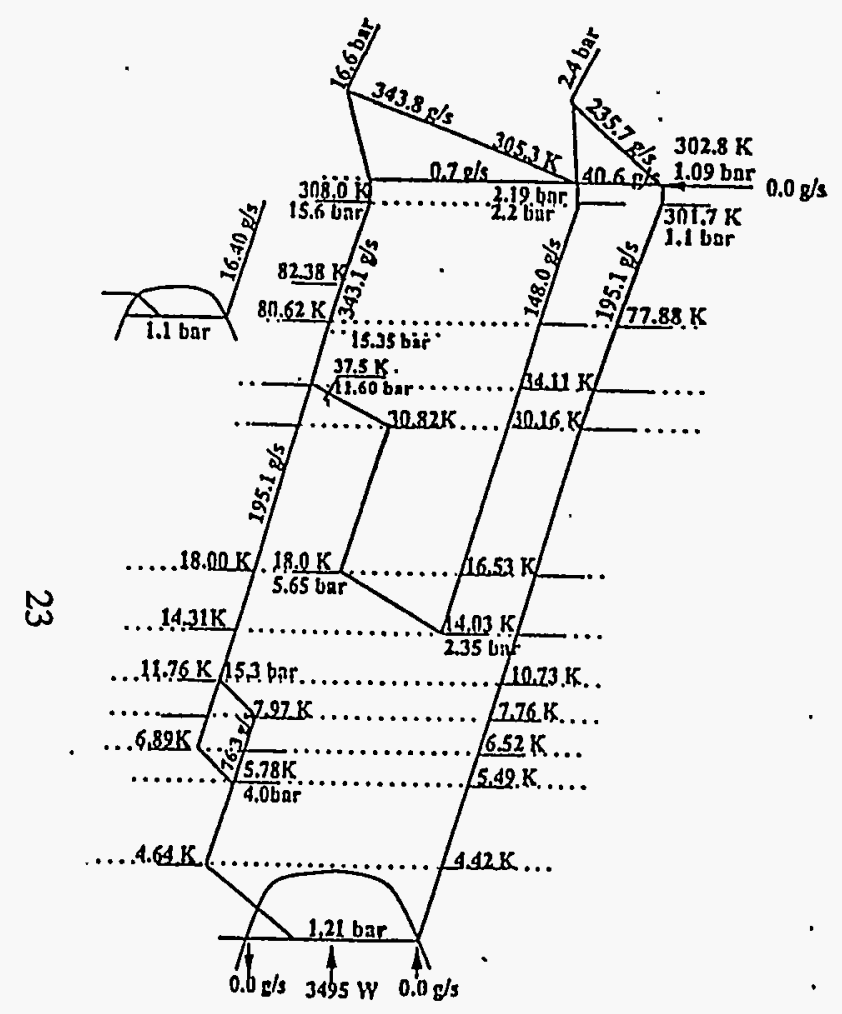

$100 \%$ Refrigeration

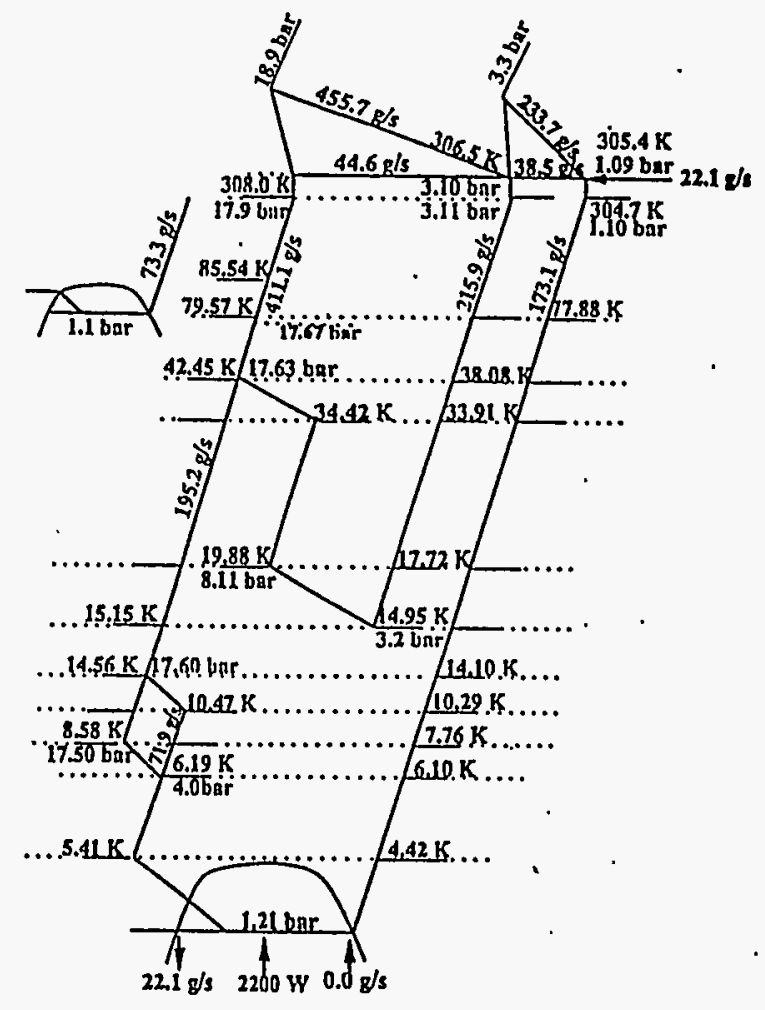

50\% Refrigeration $50 \%$ Liquefaction

Figure 13. T-s Dlagram for the SRS.

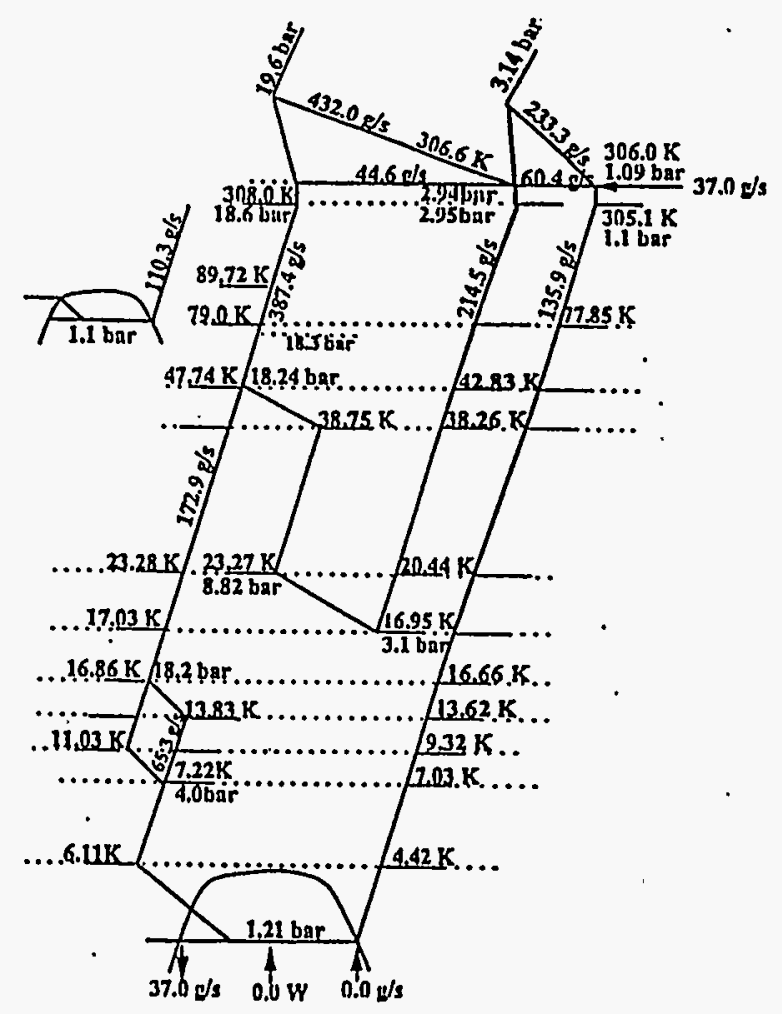

$100 \%$ Liquefaction 
The Compressor System and Gas Management System (Figure 14) consists of:

1. Compressor Group. Two-stage compression of helium gas for the refrigerator. The available power for operation at design load is $5 \mathrm{MW}$.

2. Oil Removal System. Fine oil removal system to remove oil from the compressor discharge helium flow.

3. Gas Management System. A set of control valves that manages the overall inventory in and out of the system at the warm end of the refrigerator and allows the refrigerator to follow load changes.

4. Gas Storage. Warm gas storage capacity of 300000 gal up to 19 bar.

5. Auxiliary Equipment 1. Bearing gas compressor skid, oil management system for compressor system, utility stations, instrument air system.

6. Piping Network 1. Warm piping network between gas storage, compressor system, and coldbox.

The Refrigeration System (Figure 15) contains:

1. Coldbox System. Configured in a series arrangement: The first coldbox (CBW) contains dual, full-size heat exchanger cores, the nitrogen boiler, and 80-K adsorber beds. The second coldbox (CBC) contains the expanders, the low-temperature heat exchangers, $20-\mathrm{K}$ beds, and buffer volume.

2. Liquid Management System. A special surface distribution box serves as the precooler, interface, and distribution manager between the coldboxes, the LHe storage system, and the tunnel cryogenic system. Accommodations have been made for future installation of a LHe circulation pump into the system.

3. Liquid Helium Storage System. Two 30000 -gal dewars provide liquid storage capacity to hold the entire liquid inventory of the magnets in one cryogenic sector.

4. Nitrogen Dewar and Gas Generation System. Provides liquid nitrogen for precooling in the refrigeration system and warm gas generation for adsorber bed regeneration usage. The dewar capacity is sized for 2 days of normal sector usage.

5. Auxiliary Equipment 2. Consists of oil brake skids if oil-bearing expanders are used, regeneration skids to regene-ate adsorber beds in the coldbox, dehydration regeneration skid to regenerate dehydration beds, dehydration unit for moisture removal from the helium loop, additional utility stations, utility vacuum system, and an additional instrument air receiver tank.

6. Piping Network 2. Warm and cold piping system interconnecting the coldbox, the surface distribution box, the dewars, the regeneration skids, and dehydration skid.

The physical layout of the surface equipment for the HEB H20 and H60 sites is shown in Figure 16. Further details can be found in Reference 2 . 


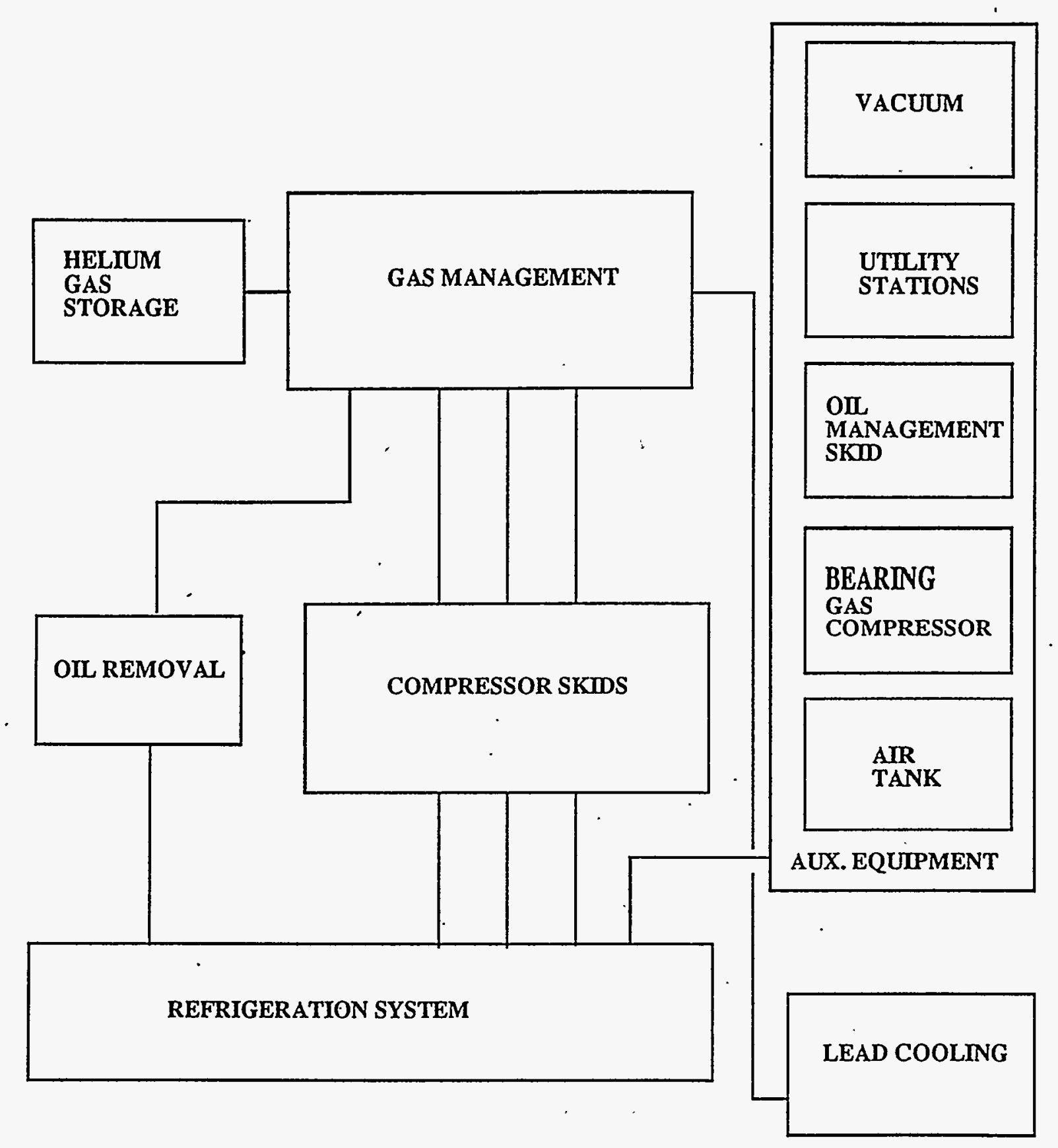

Figure 14. Compressor and Gas Management System (CMS) Interfaces. 


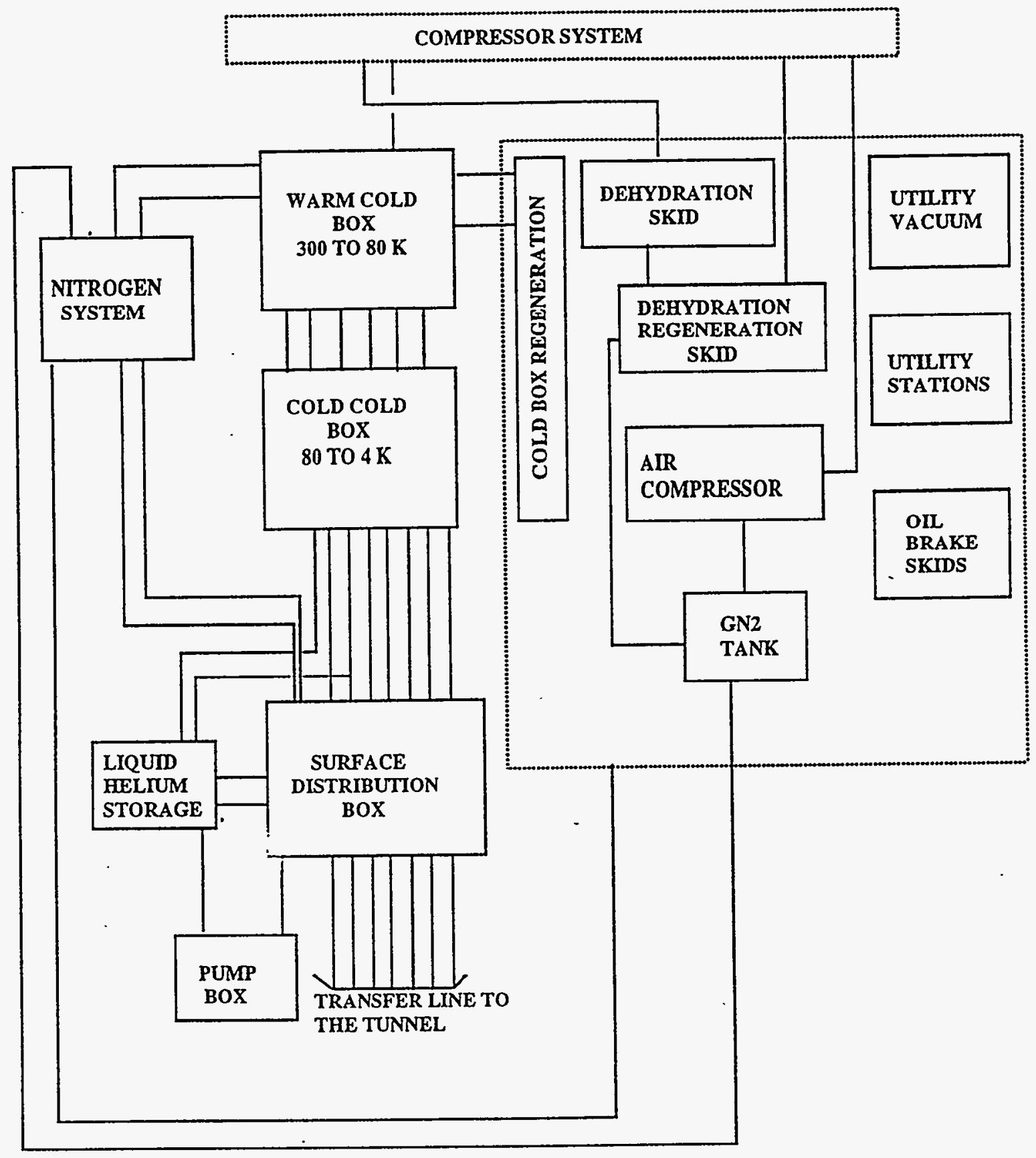

Figure 15. Refrigerator System (RFS). 


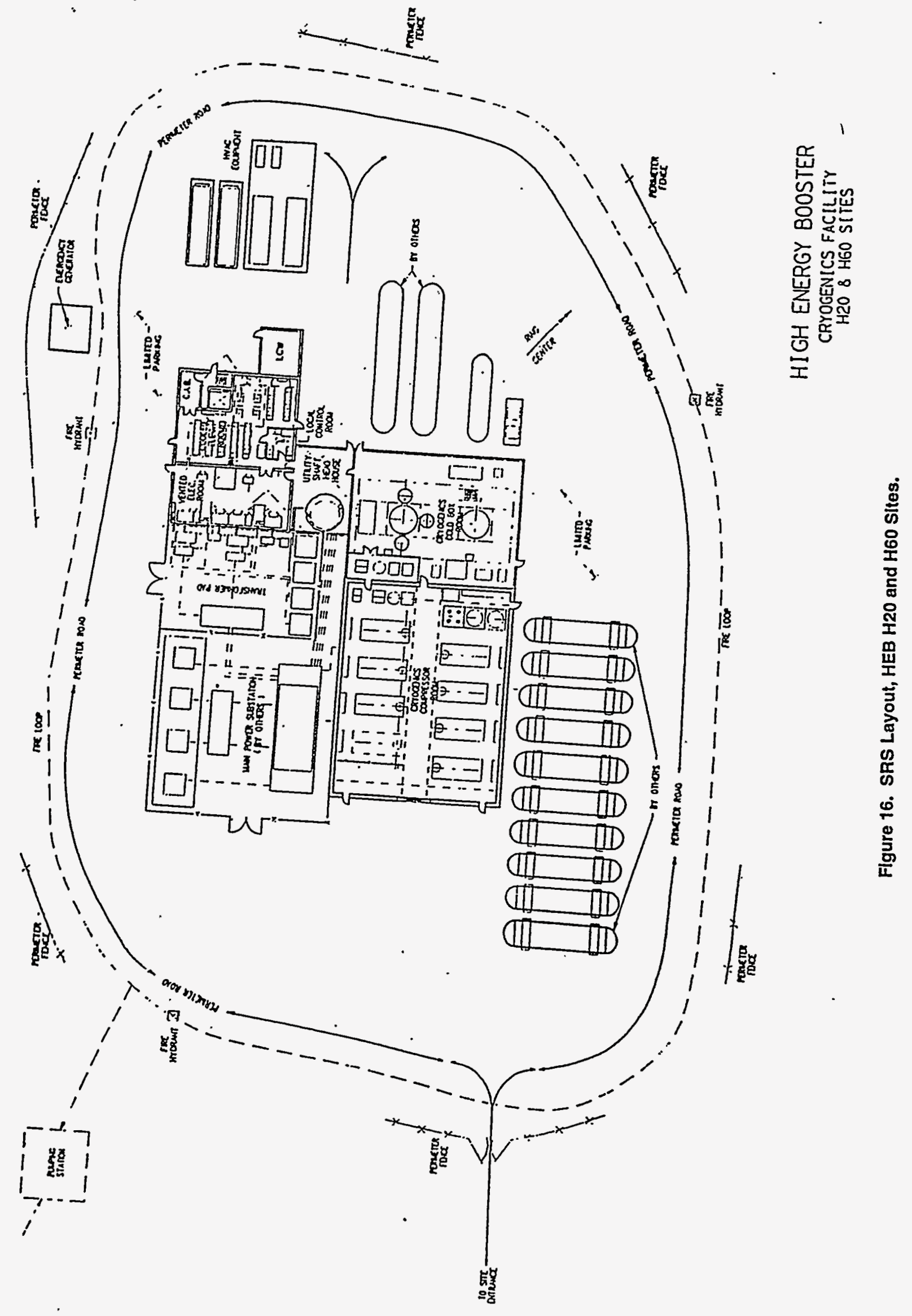




\subsubsection{HEB Sector Refrigerator Tunnel System Configuration}

The boundaries of the SRT are at the outlet of the surface distribution system and include the shaft transfer line, the cold compressor installed in the tunnel, the tunnel horizontal transfer line, the tunnel distribution box, the nitrogen distribution box, the nitrogen recooling system, the magnet ring components, and the auxiliary end box installed at the boundary between two sectors, which is needed to control the flow of cryogens from one sector to the other and the return flows to the refrigerator. Process flow diagrams for the SRT components were developed to cover all the requirements, and certain mechanical conceptual designs were developed to define the space, interfaces, and installation requirements. Figure 17 shows an isometric view of the feed assembly in the SRT. Figure 18 is a flow diagram for the feed assembly. Figure 19 shows the flow diagram for the auxiliary end box.

In several locations along the rings, warm equipment is designed to be in series with the superconducting magnets. Cryogens are designed to flow around these warm sections using cryogenic bypass transfer lines (CBTL). These transfer lines contain cryogenic pipes and superconducting buses that must be maintained at the 4-K level. The CBTL, together with the connecting boxes to the cold magnets, the special boxes with recoolers and vacuum barriers, and the cryogenic and vacuum instrumentation, are all part of the SRT.

Also included in the SRT are nitrogen subcoolers designed to be installed and connected to isolation spools at the end of each cryogenic section. These subcoolers are heat exchangers that periodically recool the shield liquid nitrogen flow.

\subsubsection{Nitrogen Distribution and Recooling Systems for the HEB}

The design temperature of the $80-\mathrm{K}$ shield is based on an average of $84 \mathrm{~K}$. The shield design, the flow rates of the nitrogen in the cryostats, the recooling schemes, and the actual heat loads are the factors that affect the average temperature. The minimum achievable temperature of $\mathrm{LN}$ in the tunnel is $80 \mathrm{~K}$, compared with $78 \mathrm{~K}$ suggested in the CDR. This results from the minimum achievable pressure in the vapor return line which is $0.14 \mathrm{MPa}$.

If the thermal conductance between the LN line and the shield is reasonably good, i.e., the pipe is welded to the shield, then for a nominal load of $3.2 \mathrm{~W} / \mathrm{m}$, the average shield temperature is expected to be around $90 \mathrm{~K}$, which is higher than suggested in the CDR. This will cause an increase in the heat radiated from the $80-K$ shield to the $20-K$ shield.

To limit the temperature rise in the $80-\mathrm{K}$ system, the following solutions were suggested and analyzed:

1. Use of compact recoolers in all the feed, isolation, and end spools, i.e., at every cryogenic section. The LN flow circulation is maintained as high as necessary to keep the temperature in range. The vapor line returns the vapor from the recoolers to the refrigerator.

2. Use the liquid line (line 5) for liquid flow distribution. The vapor line is used for controlled continuous recooling. For this solution, special phase separators/recoolers and circulation pumps are needed at $\mathrm{H} 20$ and $\mathrm{H} 60$. A compact recooler is needed in each of the other isolation spools and end spools.

3. The liquid line is connected to the vapor line in the End Spool (SPRE) so that the vapor line may be flooded. The pressure of the vapor line in the SPRF is maintained as low as possible (0.14 MPa). No additional compact recoolers are required in the system.

Analysis of the different methods is given in References $44-46$ and $49-51$. The LN flow around the HEB ring for normal operation, including one delivery station at $\mathrm{H} 20$ and compact recoolers (see option 1 above), is shown in Figure 20. The GN flow directions are also indicated on the figure. 


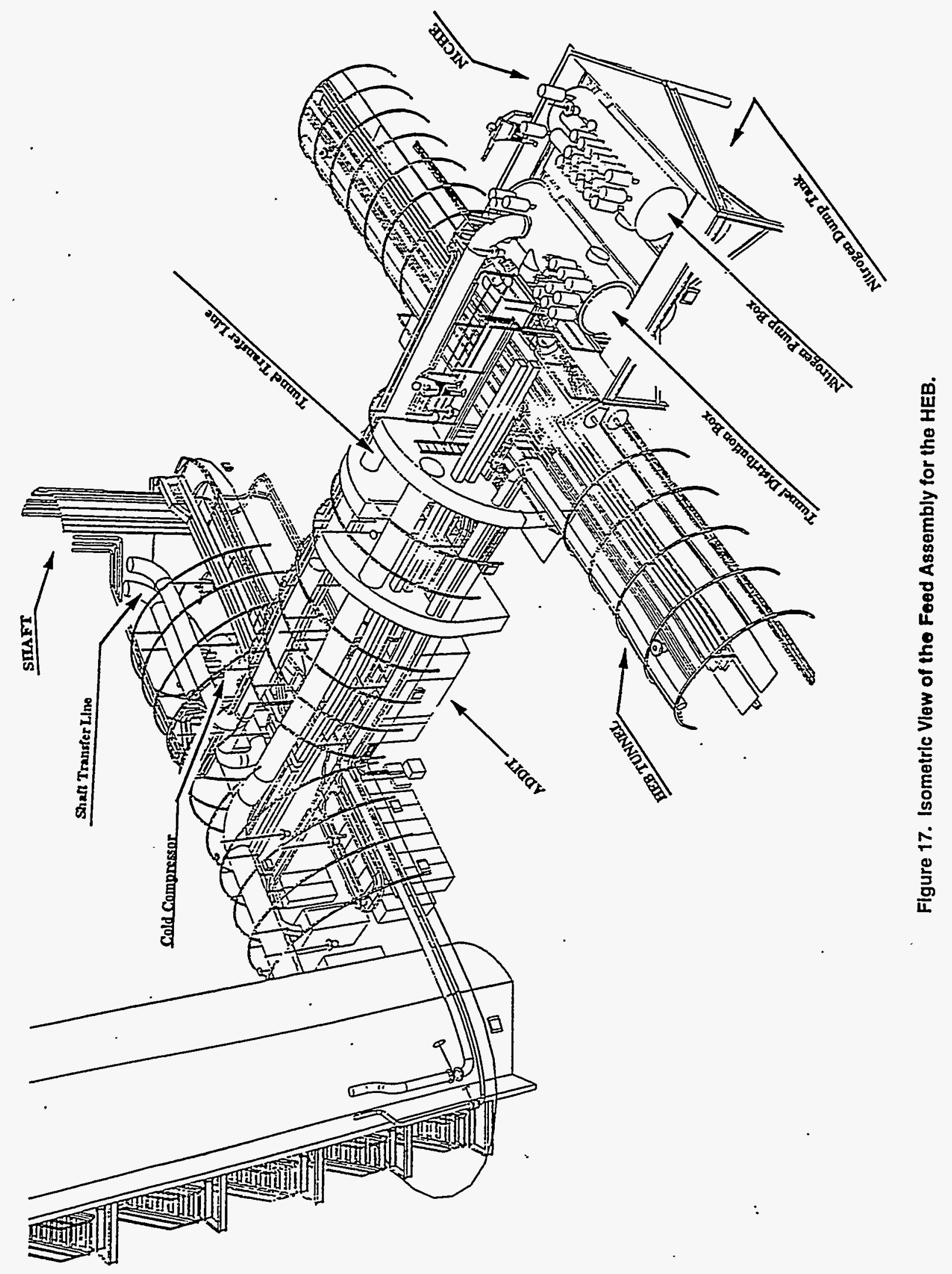




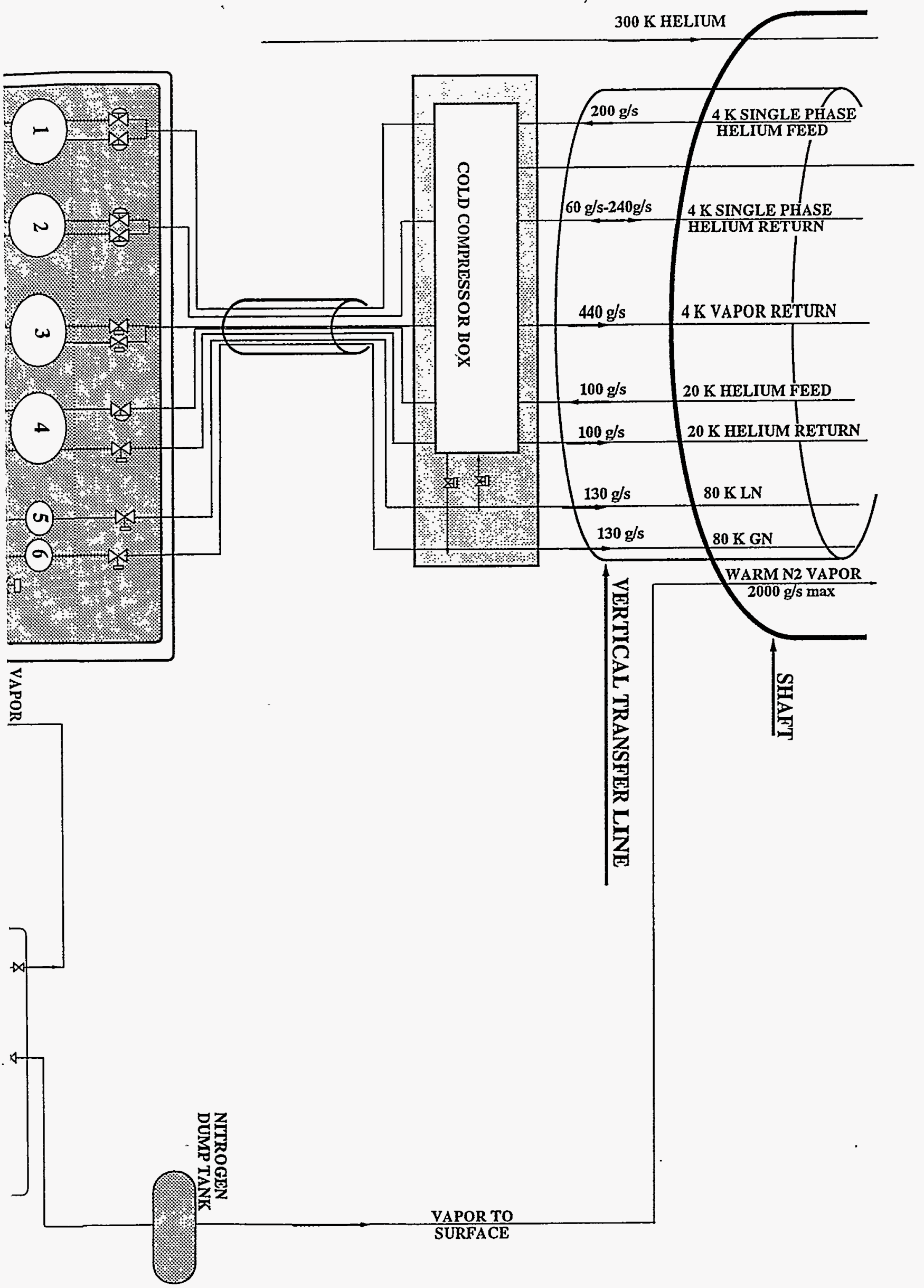




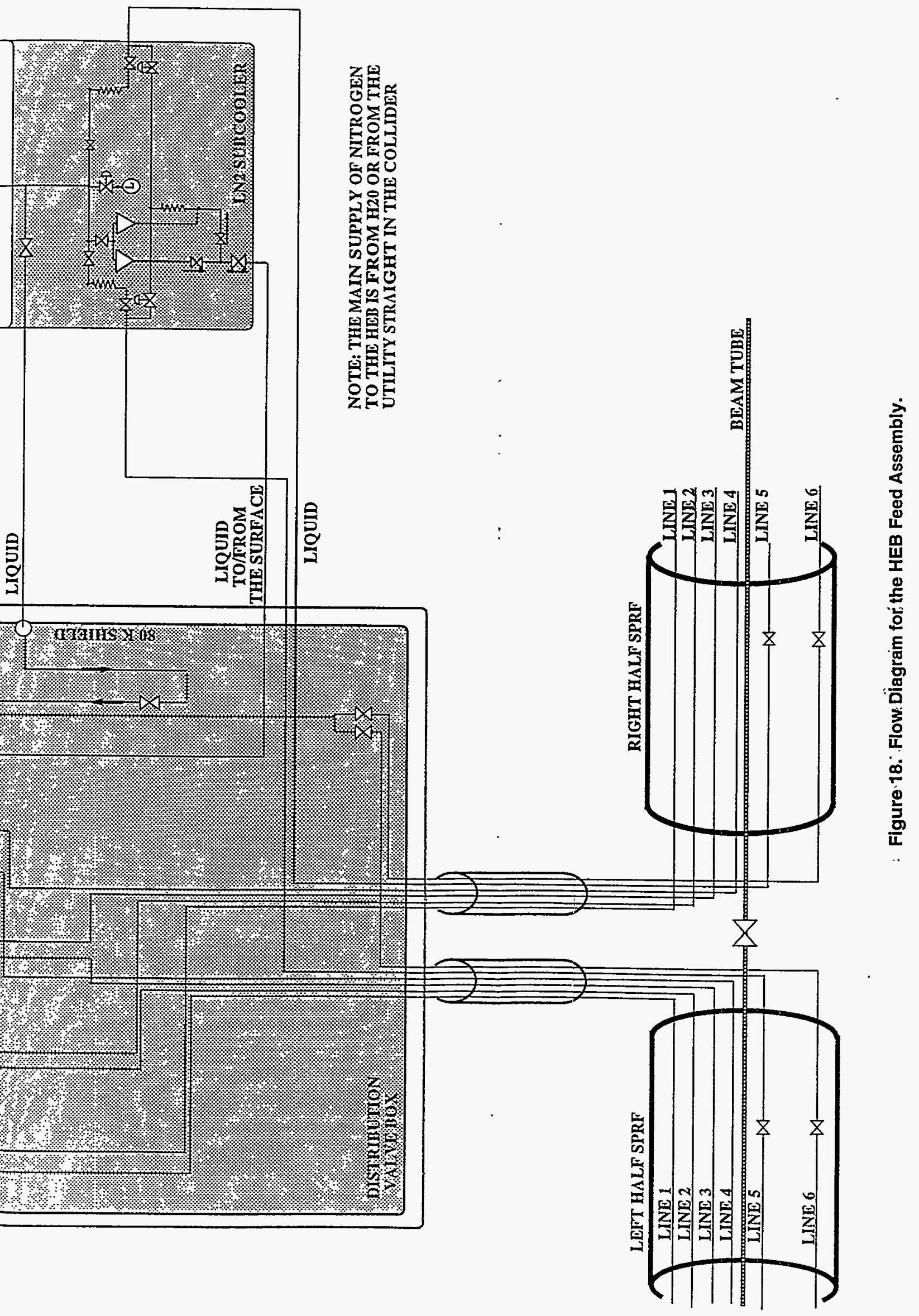




\section{AUXILIARY END BOX}

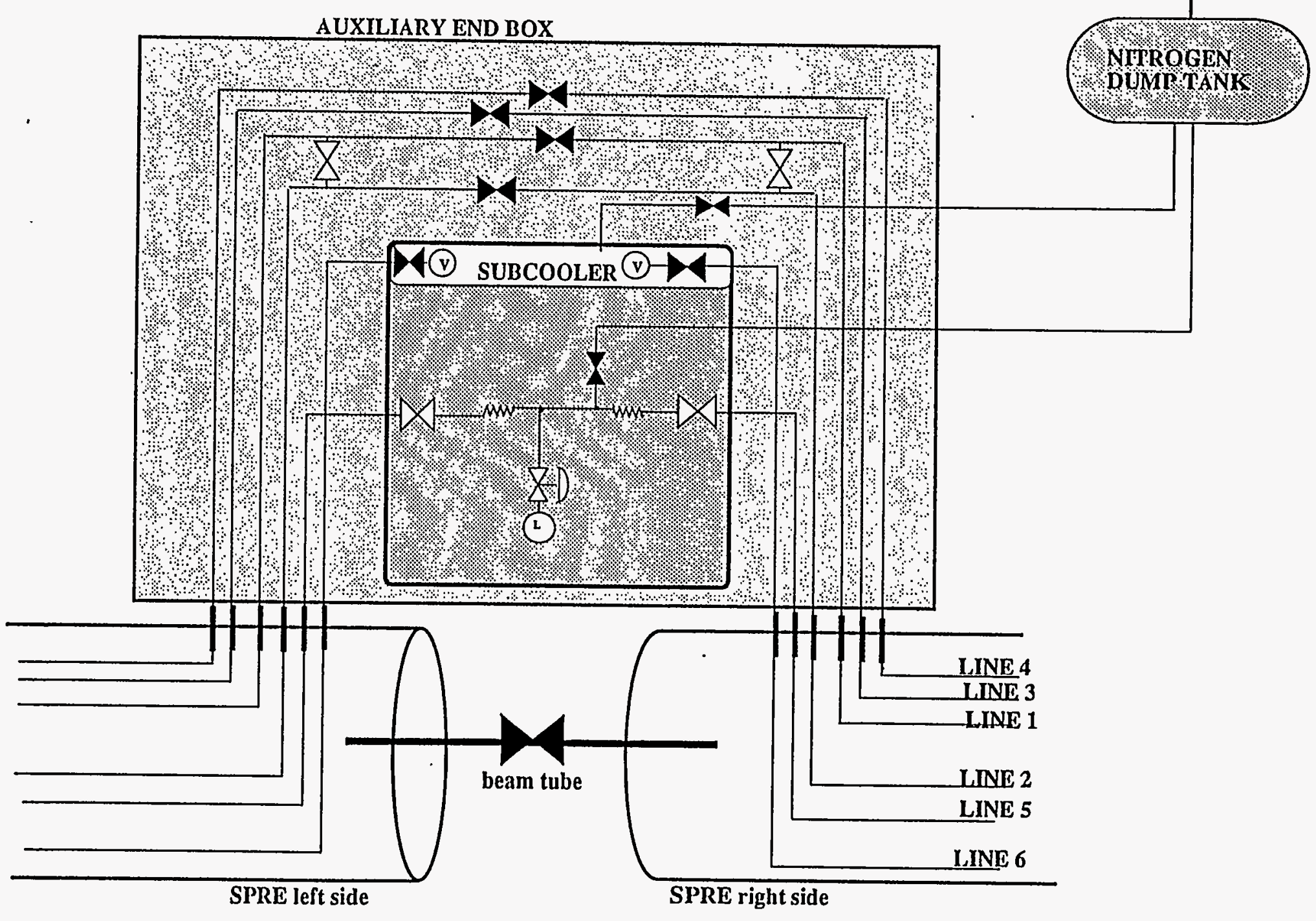

Figure 19. Flow Diagram for the HEB Auxiliary End Box.

VAPOR TOO

SURFACE 


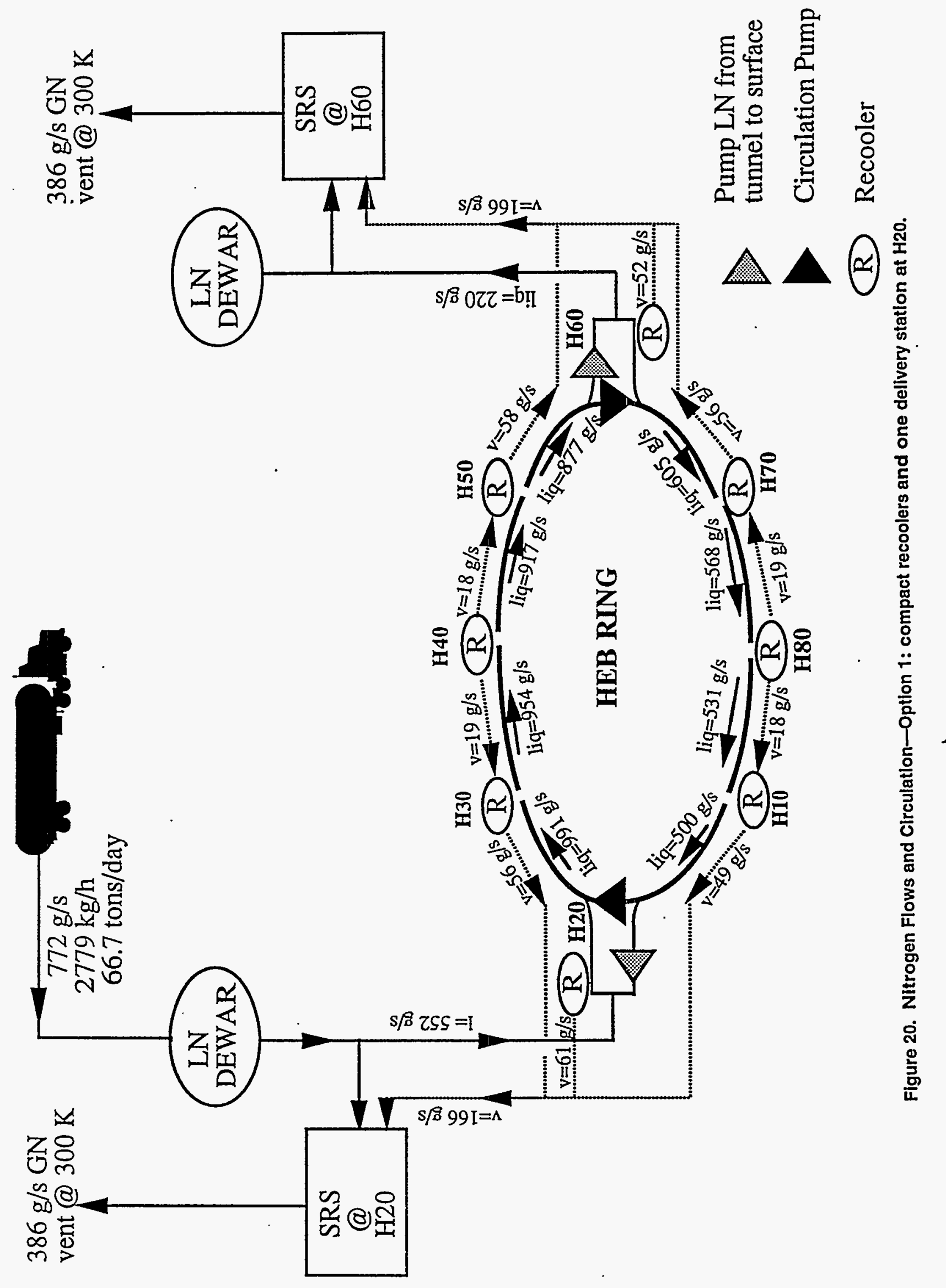




\subsection{Tunnel Cryogenic System Components}

\subsubsection{HEB-to-Collider Transfer Line}

This transfer line is not mentioned in any earlier documents such as the CDR or the SCDR. It results from the requirements to minimize operating costs and to enable flexibility in the LN supply and sharing of helium loads between the collider and the HEB. It was suggested that the functionality and design of this line will be based on the cost comparison between reduction of the operating costs of the HEB with the installation cost of this line, which requires an additional 14-m shaft. The location of this line was defined between the cryogenic bypass transfer line in the collider and the bypass transfer in the HEB in the West Complex.

The minimum design of this line calls for a single vacuum-jacketed tube, $50 \mathrm{~mm}$ in diameter, used only to transfer liquid nitrogen from the collider to the HEB. The maximum design calls for a vacuumjacketed transfer line with 7 lines and valve box, as shown in Figure 21.

The HEB-to-collider transfer line starts with a special box in the HEB bypass near H10, and ends at a special box in the Collider West Straight bypass transfer line. The transfer line is routed through a special shaft designed with radiation shields. The vertical distance between the collider and the HEB is $14 \mathrm{~m}$; hence the minimum length of the line is $25 \mathrm{~m}$. An individual vacuum system is designed for this transfer line.

\subsubsection{Shaft Transfer Line (Vertical Transfer Line)}

The shaft transfer line (STL) is the conduit for cryogen flow between SRS and the tunnel equipment. STL has seven lines: 4-K He supply, 4-K He return, GHe return, 20-K He supply, 20-K He return, 84-K LN, and 84-K GN, all enclosed in a common vacuum jacket. The shaft transfer line system requirements are given in Table 6.

Table 6. Shaft Transfer Line System Requirements for the HEB.

\begin{tabular}{|c|c|c|c|c|c|}
\hline \multirow[b]{2}{*}{ Cryogen Flows } & \multicolumn{2}{|c|}{$\mathbf{P}$} & \multirow{2}{*}{$\frac{T}{(K)}$} & \multicolumn{2}{|c|}{ Flow Rate } \\
\hline & Design (bar) & Nom (bar) & & Design $(\mathrm{g} / \mathrm{s})$ & Nom $(g / s)$ \\
\hline 4-K He Supply & 20 & 4 & 4.5 & 400 & 200 \\
\hline 4-K He Return & 20 & 3.5 & 4.3 & 300 & 250 \\
\hline 4-K GHe Return & 10 & 1.1 & 4 & 450 & 450 \\
\hline 20-K He Feed & 20 & 3 & 16.5 & 200 & 100 \\
\hline 20-K He Retum & 20 & 2 & 24 & 200 & 100 \\
\hline $80-K \mathrm{LN}_{2}$ & 20 & 10 & 84 & 750 & 750 \\
\hline $80-\mathrm{KGN}_{2}$ & 20 & 1.5 & 84 & 400 & 250 \\
\hline
\end{tabular}

The HEB has two shaft transfer lines, to be installed in the utility shafts at the midpoint of the sectors. The total length of each STL depends on the depth of the individual utility shaft as well as on the respective locations of the surface distribution box and the cold compressor box in the tunnel. The STL is designed to hang vertically on the wall of the utility shaft and has a vacuum pumpout port on each end. The shaft depths can be found in Table 1.

The vacuum jacket can be made of $600-\mathrm{mm}$ carbon steel pipe, designed to maintain a vacuum of 1.5E-5 $\mathrm{Pa}$ with a maximum leak rate $10 \mathrm{E}-6 \mathrm{std}-\mathrm{cc} / \mathrm{s}$. An $80-\mathrm{K}$ thermal shield (gage 19 copper sheet soldered to the $80-\mathrm{K}$ lines) and multilayer insulation should be used to reduce heat leaks into the line (two 32-layer MLI blankets over the thermal shield and a 16-layer blanket over each cryogenic line). The estimated heat load for the STL is $0.4 \mathrm{~W} / \mathrm{m}$ for the $4-\mathrm{K}$ lines, $0.4 \mathrm{~W} / \mathrm{m}$ for the $20-\mathrm{K}$ lines, and $3.0 \mathrm{~W} / \mathrm{m}$ for the 84-K lines. The STL will be built in standard, 12-m-long, straight modules, with standard and special elbow pieces and special makeup pieces, and will be assembled on site. The estimated weight of a module is $150 \mathrm{~kg} / \mathrm{m}$.

Figure 22 shows design details of the shaft transfer line. 


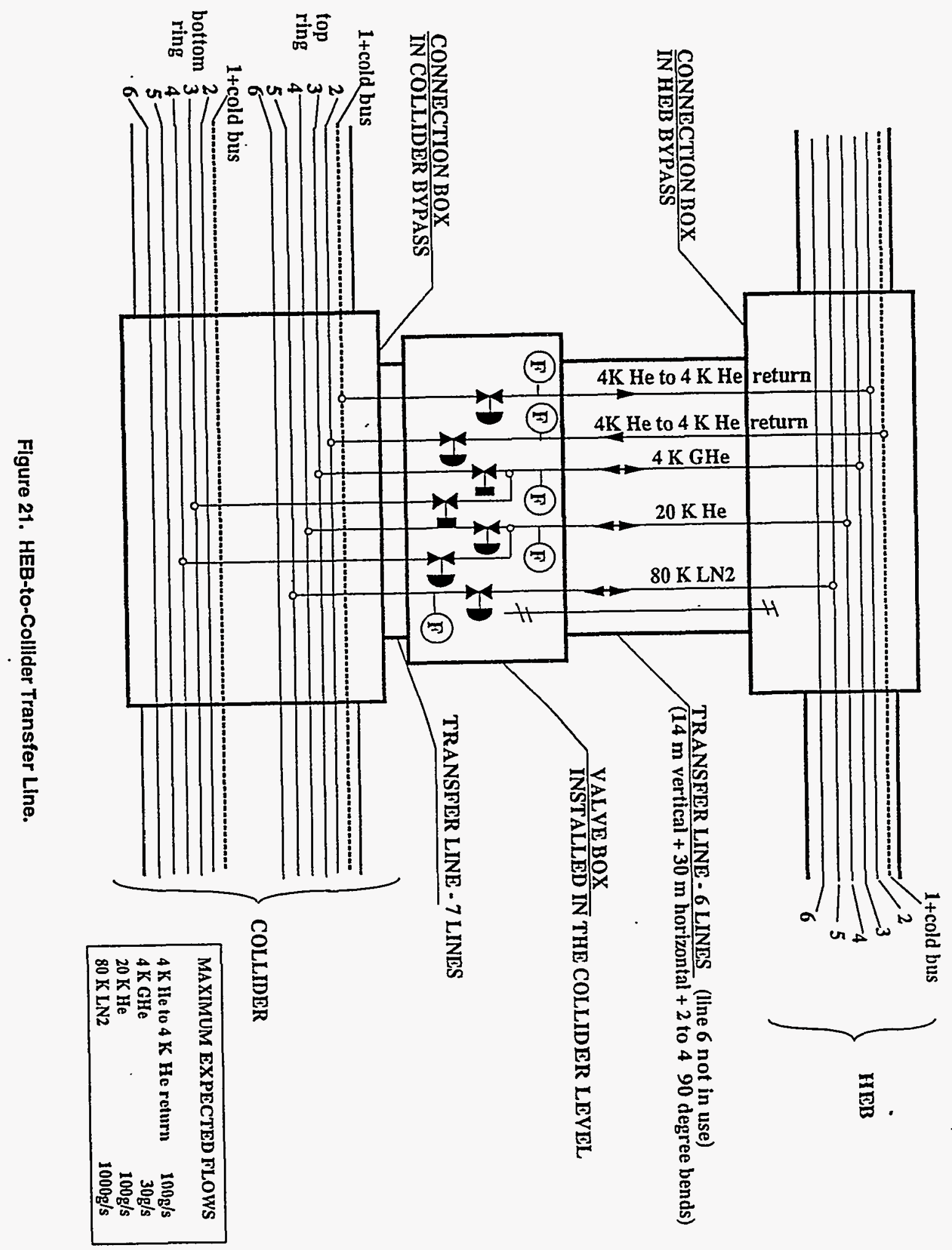



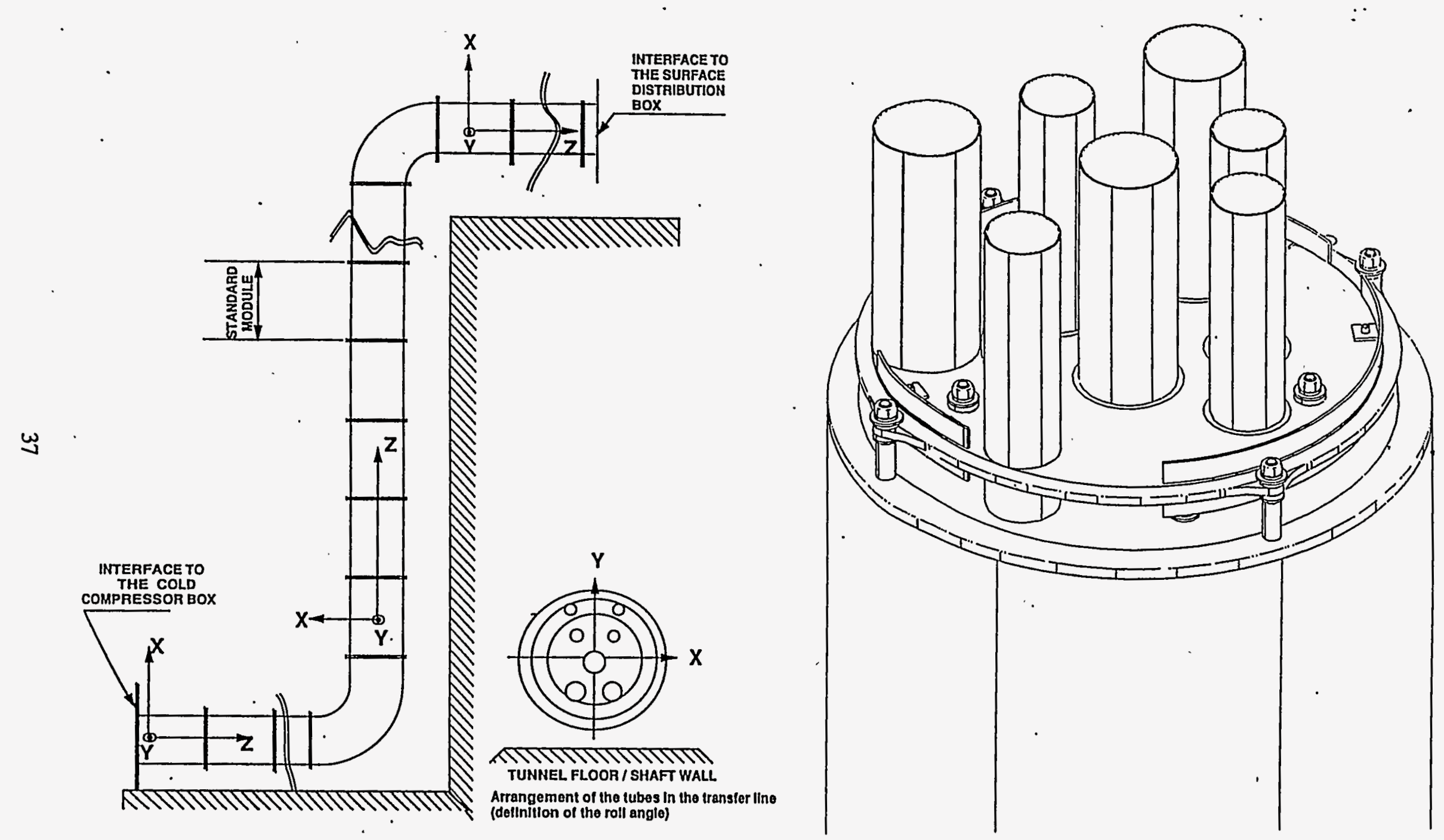

Figure 22. STL Geometry and PIping Detalls. 


\subsubsection{Cold Compressor Box and Cold Compressor}

Each sector requires a cold compressor module to be installed in the tunnel near the utility shaft. A cold compressor module (Figure 23), consisting of a cold compressor and a separate cold compressor box, provides the low pressure level in the vapor return line, which is the main temperature controlling factor. Two modules are needed for the HEB: one each at $\mathrm{H} 20$ and at $\mathrm{H} 60$.

The cold compressor must follow the various operating modes-design, nominal, and standby-as determined by magnet system demand, and by refrigerator capacity and availability. Table 7 shows the design conditions for each mode, with the minimum required isentropic efficiencies for the cold compressor. The compressor shall be capable of safe start and shall continue to operate through a wide range of inlet and outlet temperatures, pressures, and flow rates. It is also necessary to be able to bring the compressor on line from room temperature with the rest of the system at operating conditions. The system shall be designed with either a water- or air-cooling system, and high-pressure helium gas will not be available for static gas bearing.

Modeling and simulation results for the cold compressor are detailed in References 80 and 81.

Table 7. Design Conditions for the Cold Compressor.

\begin{tabular}{|c|c|c|c|c|c|}
\hline $\begin{array}{l}\text { Mode of } \\
\text { Operation }\end{array}$ & $\begin{array}{l}\text { Inlet } \\
\text { P (bar) }\end{array}$ & $T(K)$ & $\begin{array}{l}\text { Outlet } \\
\text { P (bar) }\end{array}$ & $\begin{array}{c}\text { Minimum } \\
\text { Efficiency } \\
\%\end{array}$ & $\begin{array}{l}\text { Flow } \\
\text { g/s }\end{array}$ \\
\hline Design & 0.75 & 4.3 & 1.45 & 65 & 330 \\
\hline Nominal & 0.75 & 4.3 & 1.40 & 60 & 264 \\
\hline Standby & 0.75 & 4.3 & 1.35 & 55 & 138 \\
\hline
\end{tabular}

Two separate boxes are designed to contain the cold compressor module: one for the cold compressor (two stages), and one for the cold compressor box, which includes control valves, a heat exchanger, a phase separator, strainers, and tubing. Both boxes are designed to have an $80-\mathrm{K}$ shield and MLI blankets, and both are vacuum-insulated.

\subsubsection{Horizontal Transfer Line (HTL)}

The horizontal transfer line (HTL), connecting the cold compressor box and the tunnel distribution box, differs from the shaft transfer line (STL) only in its supports and installation. Whereas the STL is designed to be supported vertically in the shaft, the HTL will be supported horizontally from the tunnel ceiling. The HTL for each sector is approximately $23 \mathrm{~m}$ long, with a vacuum barrier and a vacuum pumpout port at each end. The HTL is designed to have three standard length modules $(6.0 \mathrm{~m}$ each): one module with a special length, and two end units with elbows, pumpout ports for the insulating vacuum, and relief valves. Each module has internal and external supports and uniform interconnect with bellows connections. Two units are required for the HEB.

\subsubsection{Tunnel Distribution Box (TDB)}

The tunnel distribution box is a nitrogen-shielded coldbox to be installed in a niche behind the feed spool, in the outer part of the ring (see Figures 17 and 24$)$. It is vacuum-jacketed (10E-5 Pa) and connected to the cold compressor box through the horizontal transfer line. The TDB for the HEB has two short, vacuum-jacketed transfer lines, each containing six pipes, that feed cryogens to the two magnet strings through the feed spool piece. (The collider-TDB feeds four strings.) The required valving and the flow diagram for the TDB-HEB are given in Figure 18. 


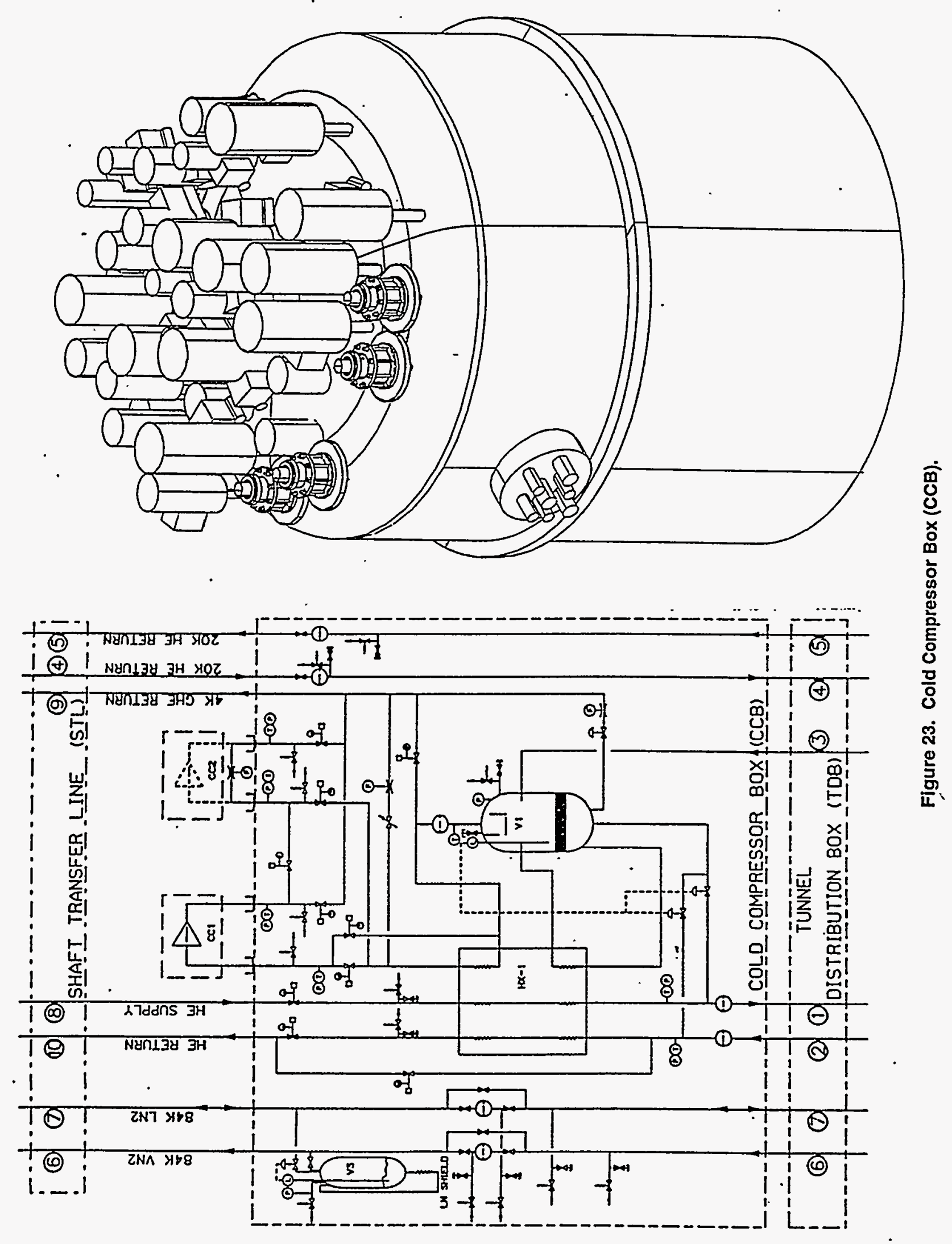



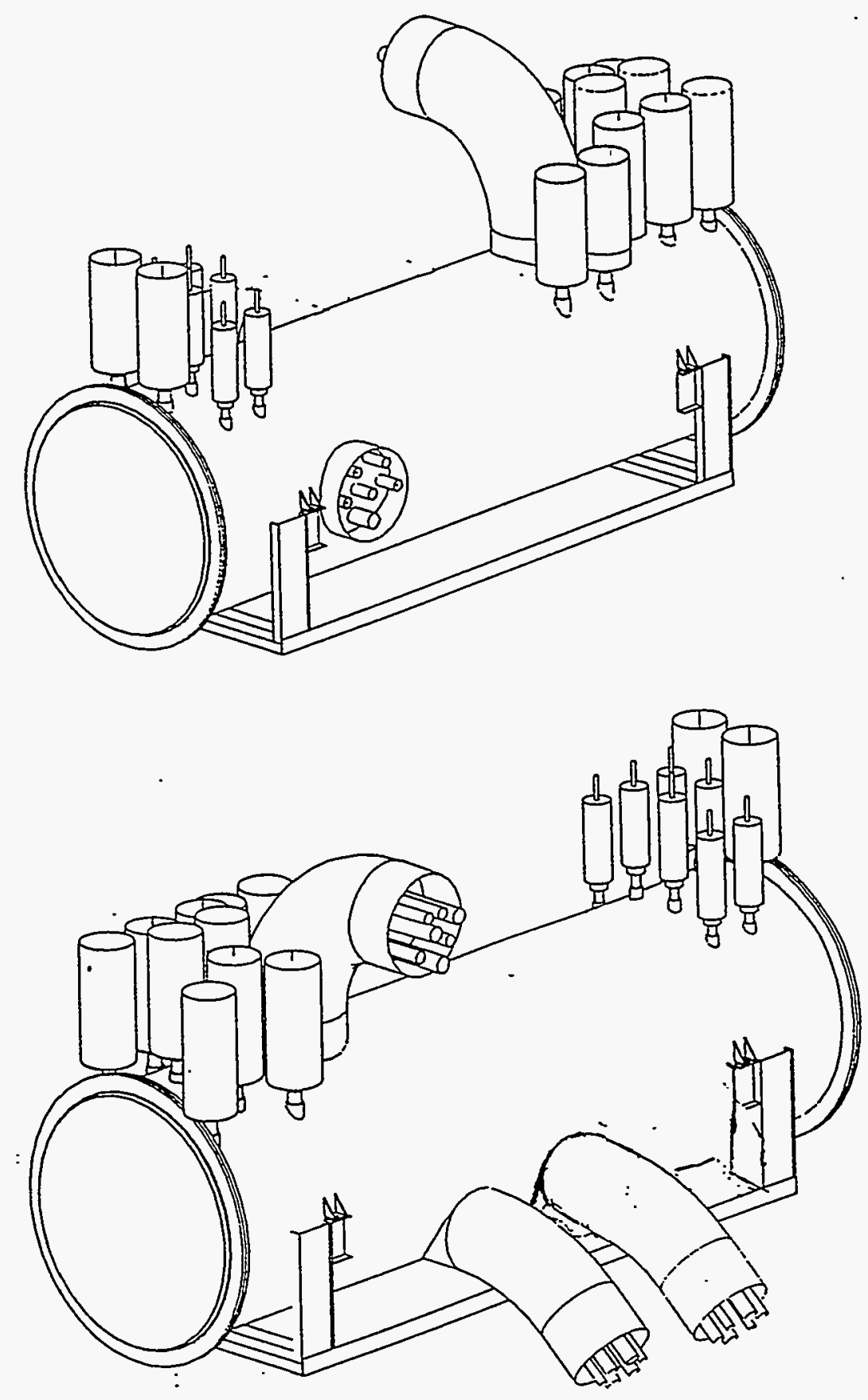

Figure 24. Tunnel Distribution Box (TDB). 


\subsubsection{Nitrogen Distribution/Pump Box (NPB) and Nitrogen Dump Tanks (NDT)}

\subsubsection{Nitrogen Distribution/Pump Box}

Approximately $5 \mathrm{~kg} / \mathrm{s}$ of liquid nitrogen is required for normal operation of the collider and the HEB. The liquid nitrogen will be imported by the SSCL and delivered to one or more locations. From the delivery points it will be distributed around the rings for ring refrigeration and to the 12 helium refrigeration plants for helium precooling. The distribution of the nitrogen in the tunnel is done through the nitrogen pipes in the magnet strings. The flow is controlled by the nitrogen pump boxes (NPB), which are installed in the tunnel near the tunnel distribution boxes.

The NPB will contain a nitrogen subcooler, two or more pumps, and associated valves. One pump is used for circulation of the main flows and for distribution of the nitrogen in the tunnel. A second pump is required for pumping liquid nitrogen to the surface dewar. The pumps will be configured for parallel operation and for interchangeable application (see Figure 20).

The subcooler in the nitrogen pump box will be designed to support flow rates up to $2 \mathrm{~kg} / \mathrm{s}$ in each of two streams, with heat loads up to $6 \mathrm{~kW}$ per stream. The box will be an independent vacuum unit $(10 \mathrm{E}-5 \mathrm{~Pa})$ and will have ports for pumping and monitoring instrumentation. Figure 25 shows the conceptual design and the flow diagram for the nitrogen pump box.

\subsubsection{Nitrogen Dump Tanks (NDT)}

For the HEB, an uninsulated nitrogen dump tank (Figure 26) is to be installed in the tunnel niches near each of the feed and end spools. These tanks will be used for emergency venting and may be used during cooldown and warm-up. Each tank has a minimum capacity of 100001 . The liquid nitrogen dumped into these tanks will vaporize, and the vapor will be vented to the atmosphere through a pipe routed to the surface, as shown in Figures 18 and 19.

\subsubsection{Nitrogen Compact Subcooler Box (NSB) and Continuous Recooling}

To limit temperature changes in the $84-\mathrm{K}$ shield, the liquid nitrogen must be recooled periodically. The expected heat load of the $84-\mathrm{K}$ system is around $3.2 \mathrm{~W} / \mathrm{m}$ per string, and the maximum temperature of the liquid nitrogen should not exceed $89 \mathrm{~K}$. In order to cover the whole range of $\mathrm{LN}_{2}$ flows, including the lowest expected flow rates, the subcoolers will be located: $(1)$ in the nitrogen distribution box in the feed assembly, (2) in the auxiliary end box, and (3) near the isolation spools. The isolation spools (SPRI) are located approximately $1300 \mathrm{~m}$ apart in the HEB; each SPRI has two cryostats connected to one another by six U-tubes. Thus it is reasonable to connect the $\mathrm{LN}_{2}$ subcoolers through these U-tubes at the isolation spool locations at $\mathrm{H} 10, \mathrm{H} 30, \mathrm{H} 50$, and $\mathrm{H} 70$.

Figure 27(a) is a flow diagram for the nitrogen subcoolers. Figure 27(b) shows the flow diagram for continuous recooling. The continuous recooling scheme is detailed in Reference 46.

\subsubsection{Auxiliary End Box (AEB)}

The auxiliary end box contains a set of valves that connect the six cryogenic lines of the two cryogenic sectors in the HEB. The valves are required to transfer nitrogen flows across the sector boundaries during normal operation and to transfer helium flows during the "assist" mode. The auxiliary end box may be designed as a separate box or may be incorporated in the nitrogen subcoolers. It will be connected to the middle of the end spool, as shown in Figure 19.

\subsubsection{Warm Vapor Return Header}

A warm return header, sized at $213 \mathrm{~mm} \mathrm{ID}$, is installed in the tunnel. The warm header is used to return the warm helium flow from the current leads and to return warm helium during cleaning, cooldown, and maintenance processes. The warm header can also be used as a dump to relieve pressure in the ring (Line 1) under emergency conditions. An alternate design calls for two $100-\mathrm{mm}-\mathrm{WD}$ warm headers, one used for cooldown and warm-up flows, and the other for current lead return flows. 


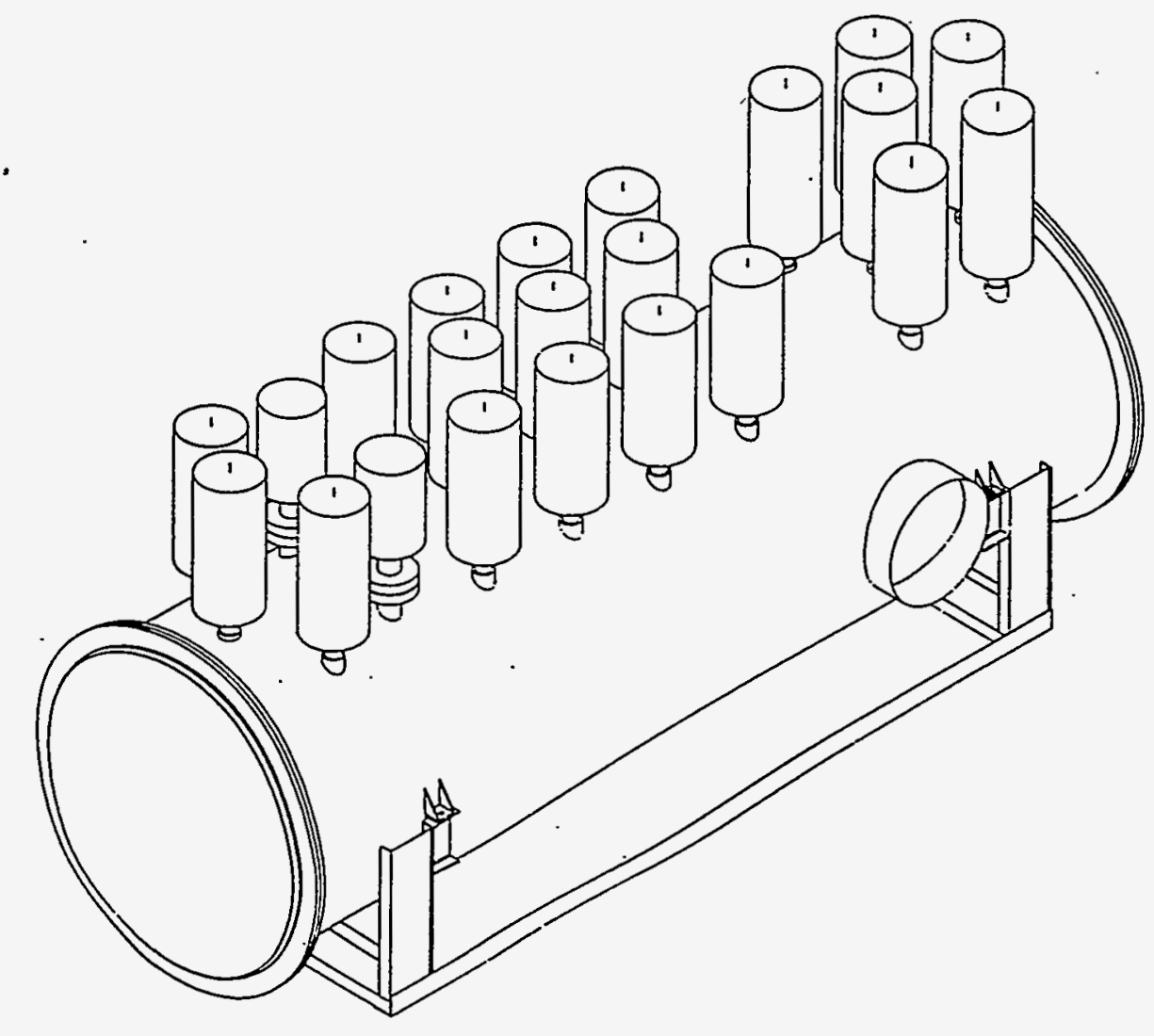

Figure 25. Nitrogen Pump Box (NPB).

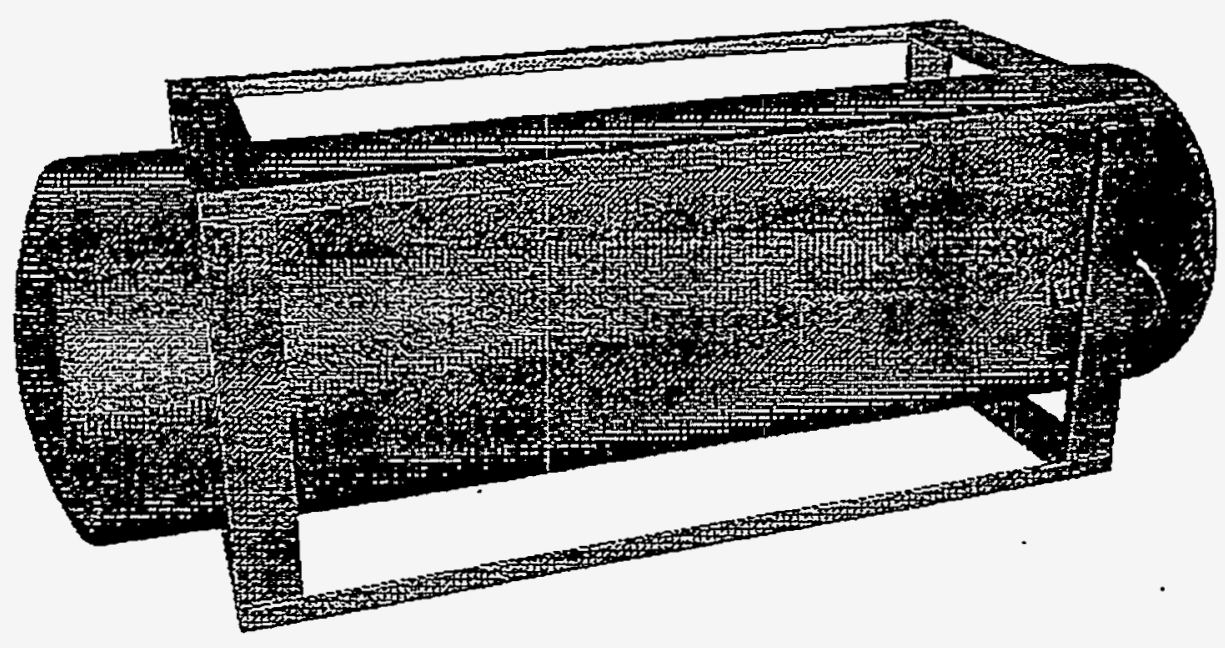

Figure 26. Nitrogen Dump Tank. 

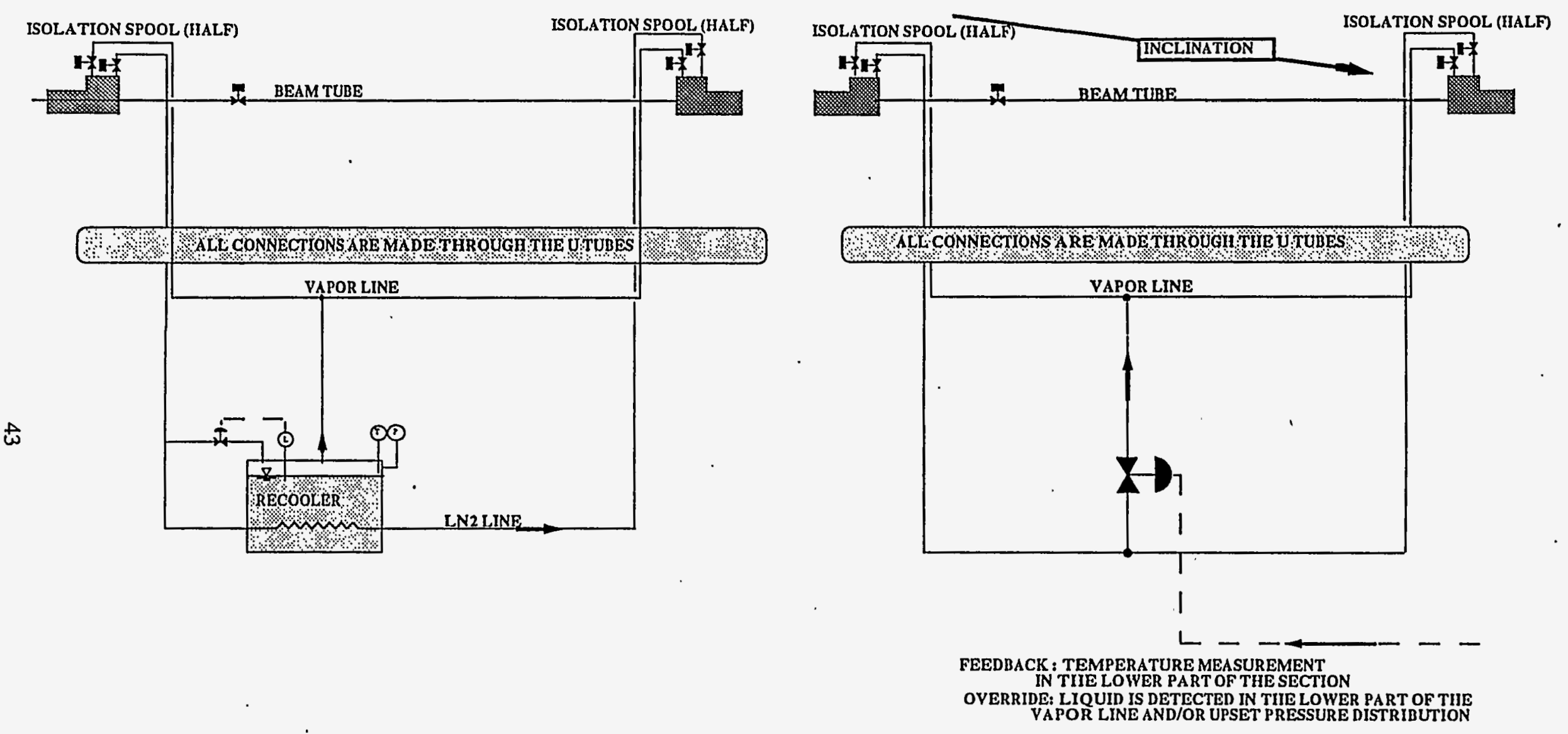

a) Recoolers Near the Isolation Boxes

b) Continuous Recooling by Controlled Injection of Liquid Into the Vapor Line

Figure 27. Nitrogen Subcooling System: (a) Recoolers Near the Isolatlon Boxes; (b) Continuous Recooling by Controlled Injection of Liquid Into the Vapor LIne. 


\subsection{Ring Equipment}

\subsubsection{Cryostat and Interconnect}

The cold components in the HEB ring are housed in leak-tight cryostats designed to maintain an insulating vacuum and to provide high-quality thermal insulation through thermal shields and multilayer insulation (MLI).

The ring components interface with each other through interconnects. Two families of interconnects are required to enable the installation of the ring components:

1. the standard in-line axial interconnects for magnet-magnet, magnet-spool, or magnet-empty cryostat connections, and

2. off-line connections, including connections to the SPRF, connections between the SPRE and the auxiliary end box, U-tube connections between the two halves of the SPRIs, and connections to the bypass transfer lines.

The interconnect requirements are documented in Reference 6.

\subsubsection{Arc Spools SPXA and SPRA}

Spools are cryogenic boxes that contain correction elements, cryogenic piping and valves, instrumentation, and electrical and vacuum system components. The cryogenic piping requirements for standard spools are the same as those for the superconducting magnets, as discussed in Section 1.2.

SPXA is a standard spool piece with a vacuum barrier to provide insulating vacuum on a cell basis (see Figure 3). SPRA is a standard spool piece with a recooler, but it does not have a vacuum barrier-as does its counterpart in the collider-due to the shorter length of a cell in the HEB. SPXA and SPRA both have a quench valve connecting Lines 1 and 4; they provide cooling for the bypass leads and corrector element power leads (CEPL). SPXA contains a single-phase relief valve venting to the tunnel, and SPRA has a cooldown valve connecting Line 1 to the warm header. Figure 28 is a schematic for the cryogenic equipment and instrumentation in SPXA and SPRA. SPXA and SPRA for the HEB have a slot length of $3.675 \mathrm{~m}$ compared to $5.85 \mathrm{~m}$ in the collider. Figure 29 shows a conceptual design of the SPXA/SPRA.

\subsubsection{SPRF}

SPRF are spool pieces located at $\mathrm{H} 20$ and $\mathrm{H} 60$ that connect the corresponding tunnel distribution box to the HEB ring. SPRF has a recooler, a quench relief valve, cooldown and relief valves for each of the six lines, pressure and temperature instrumentation on each of the six lines, power leads, CEPL, and a beam tube transition joint for each of the two strings connected to it on either side. Figure 30 shows a schematic for the cryogenic equipment and instrumentation in SPRF. SPRF for the HEB has a slot length of $7.35 \mathrm{~m}$ and is very similar in design to the SPRF for the collider. Figure 31 shows a conceptual design for the SPRF.

\subsubsection{SPRI}

SPRI are spool pieces located at $\mathrm{H} 10, \mathrm{H} 30, \mathrm{H} 50$, and $\mathrm{H} 70$ that allow isolation of cryogenic sections for maintenance (warm-up and cooldown). The cryogenic connections between the two halves of the SPRI are made through U-tubes, together with a nitrogen subcooler box for the nitrogen system. The SPRI at $\mathrm{H} 10$ and $\mathrm{H} 50$ have slot lengths of $7.35 \mathrm{~m}$ and are similar in design to the SPRF. The SPRI at H30 and $\mathrm{H} 70$ have slot lengths of only $3.675 \mathrm{~m}$ and require a special design. Figure 32 shows a schematic for the cryogenic equipment and instrumentation in SPRI. Figure 33 shows a conceptual design for the 3.675-m-long SPRI. 


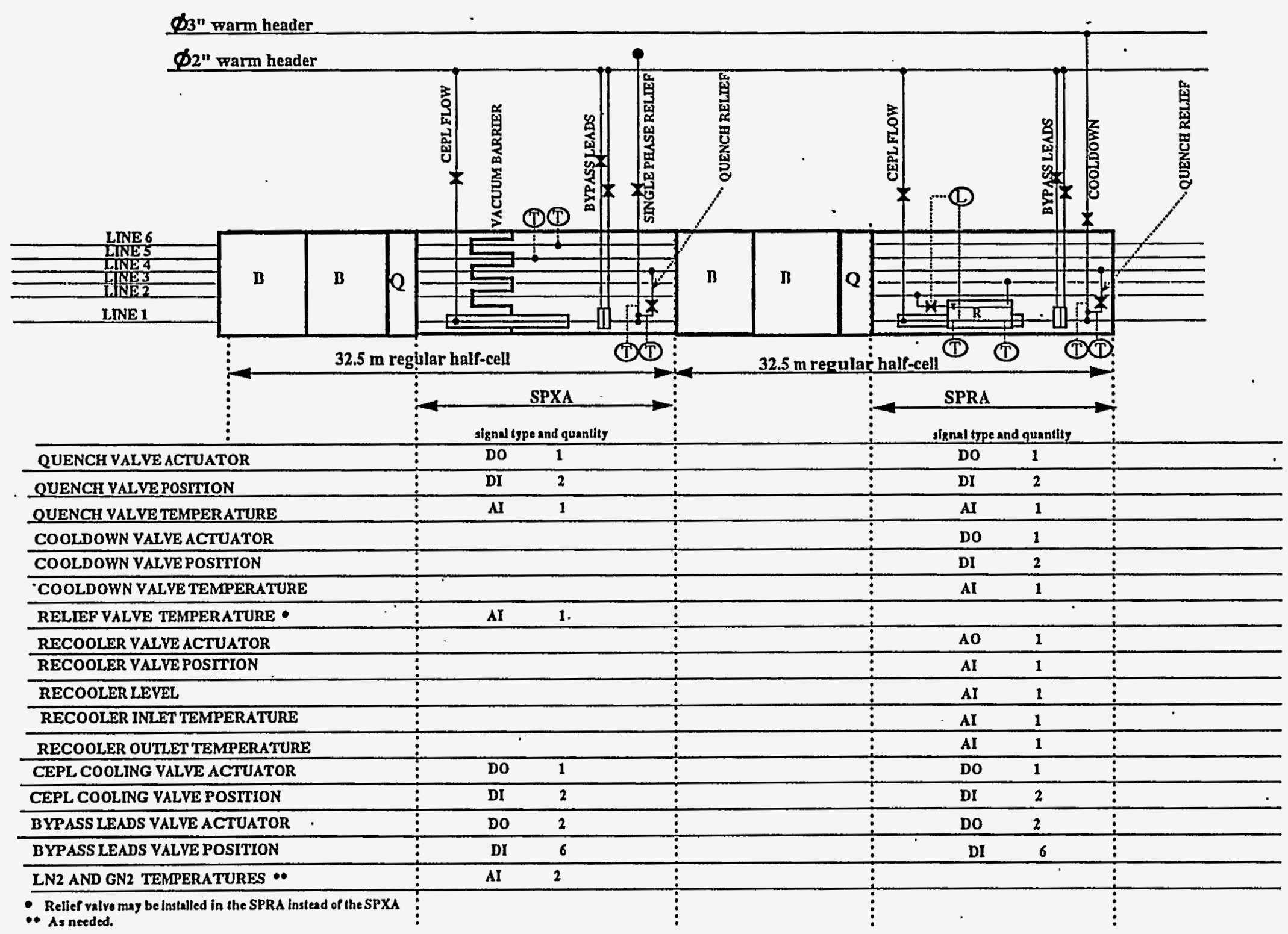

Figure 28. Cryogenlc Equipment and Instrumentation for SPXA and SPRA. 

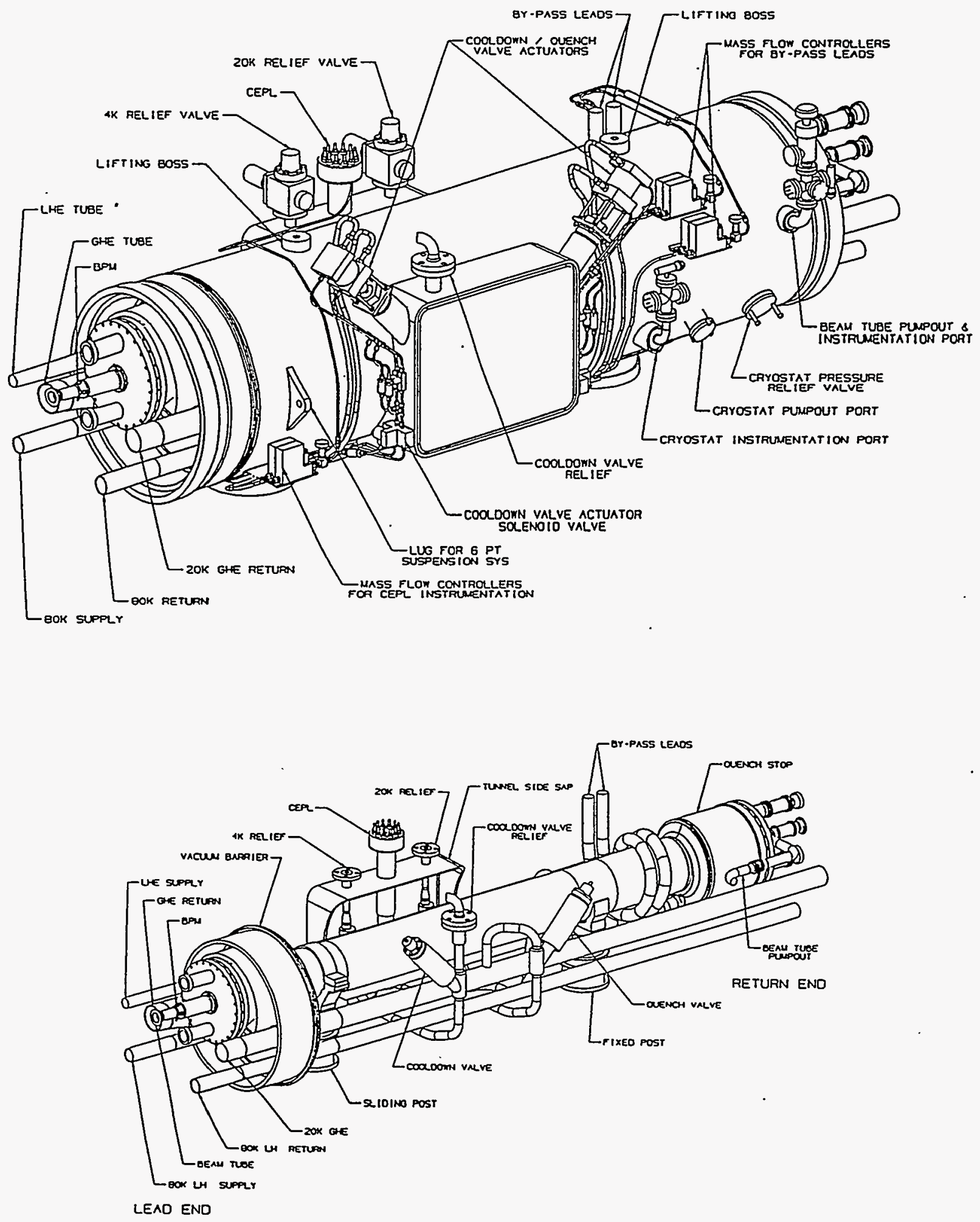

Figure 29. Conceptual Design of the SPXA and SPRA. 


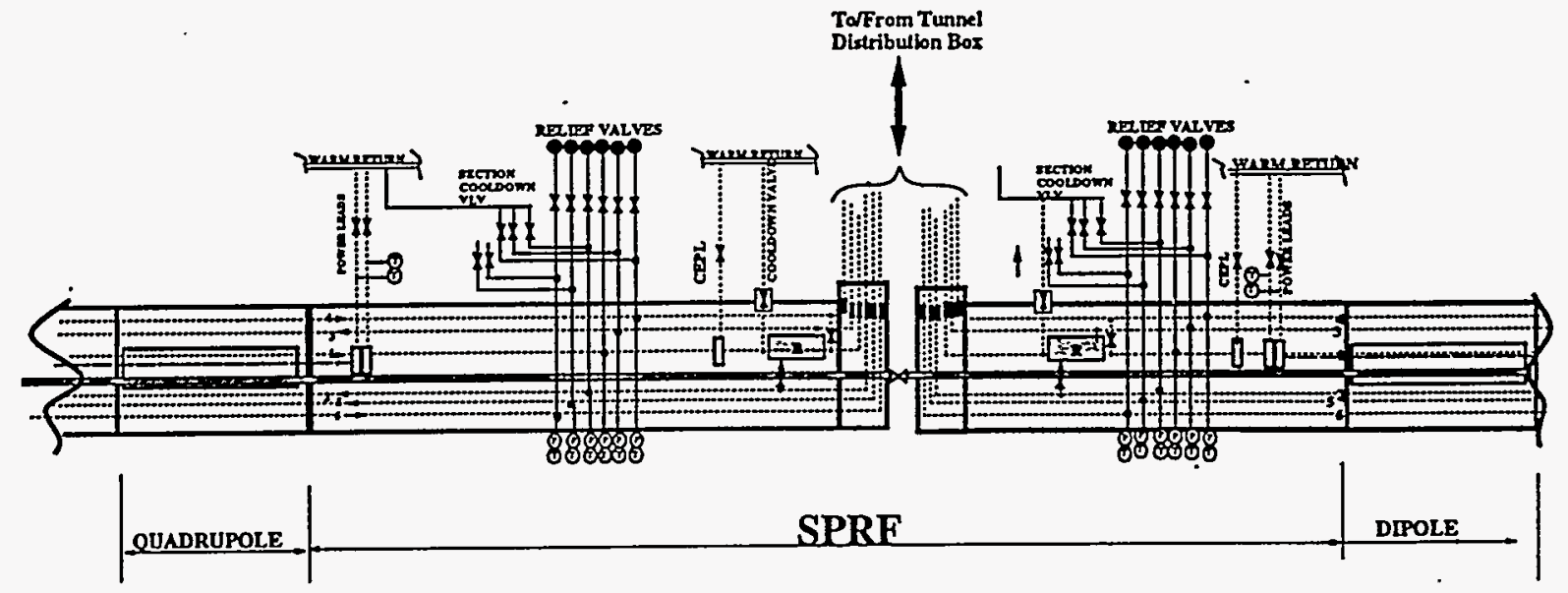

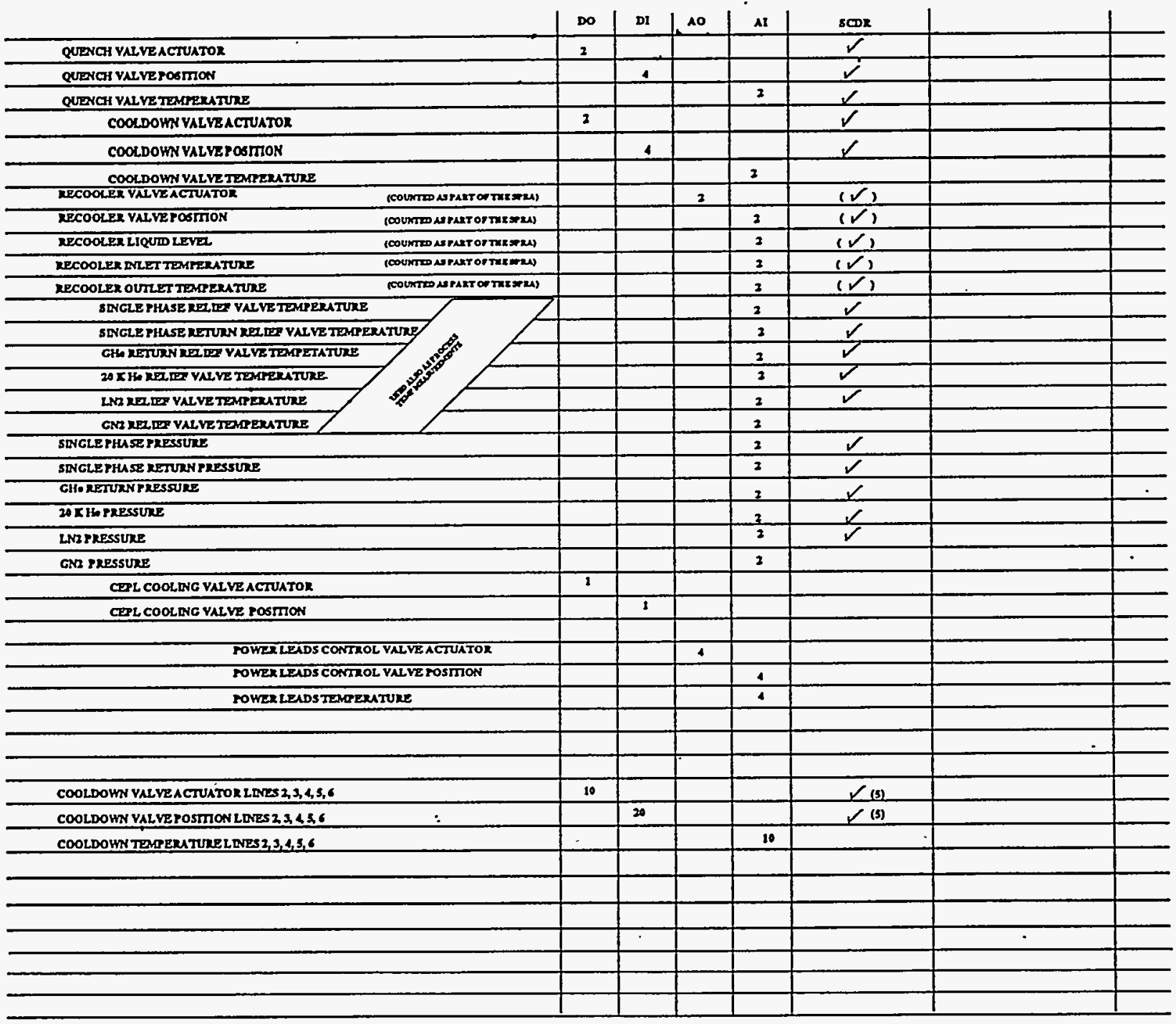

Figure 30. Cryogenic Equipment and Instrumentation for SPRF. 


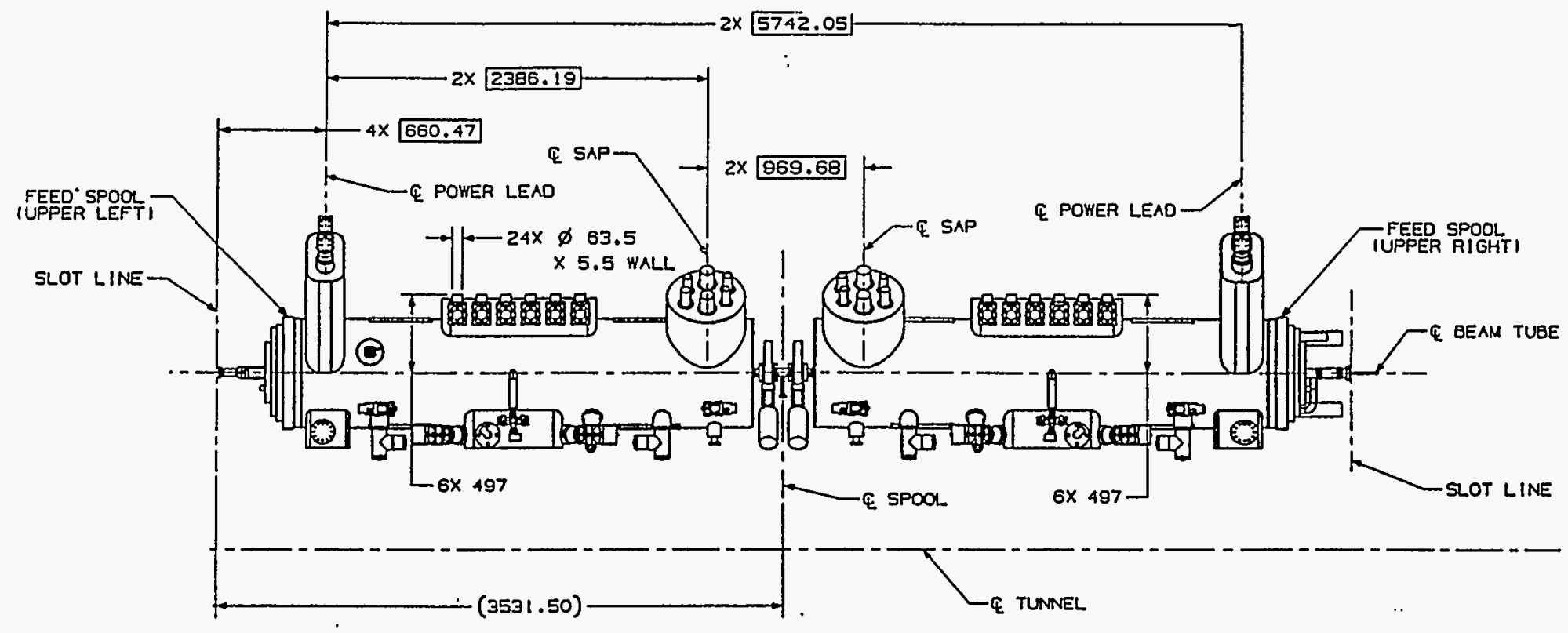

Figure 31. Conceptual Design of the SPRF. 


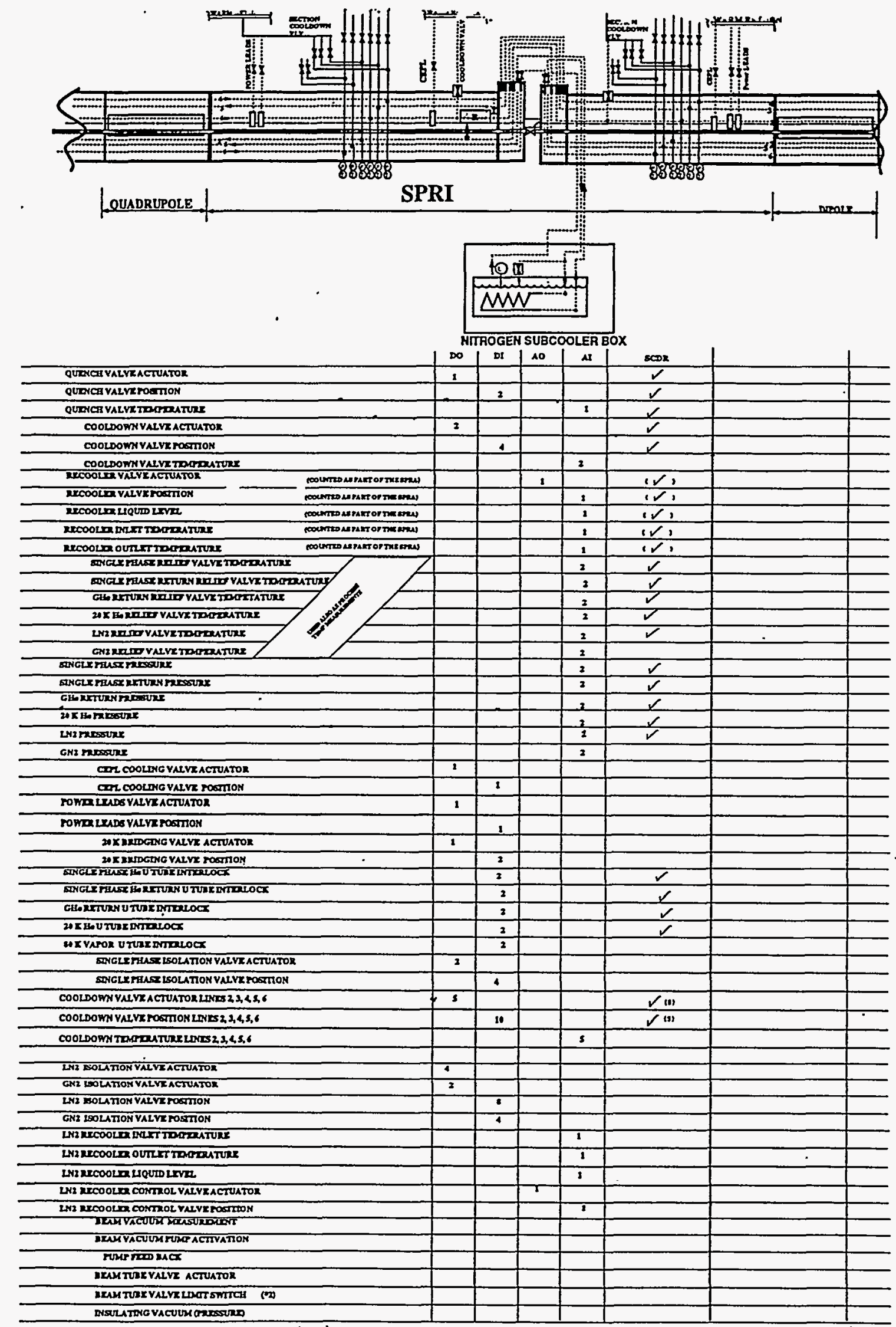

Figure 32. Cryogenic Equipment and Instrumentation for SPRI. 


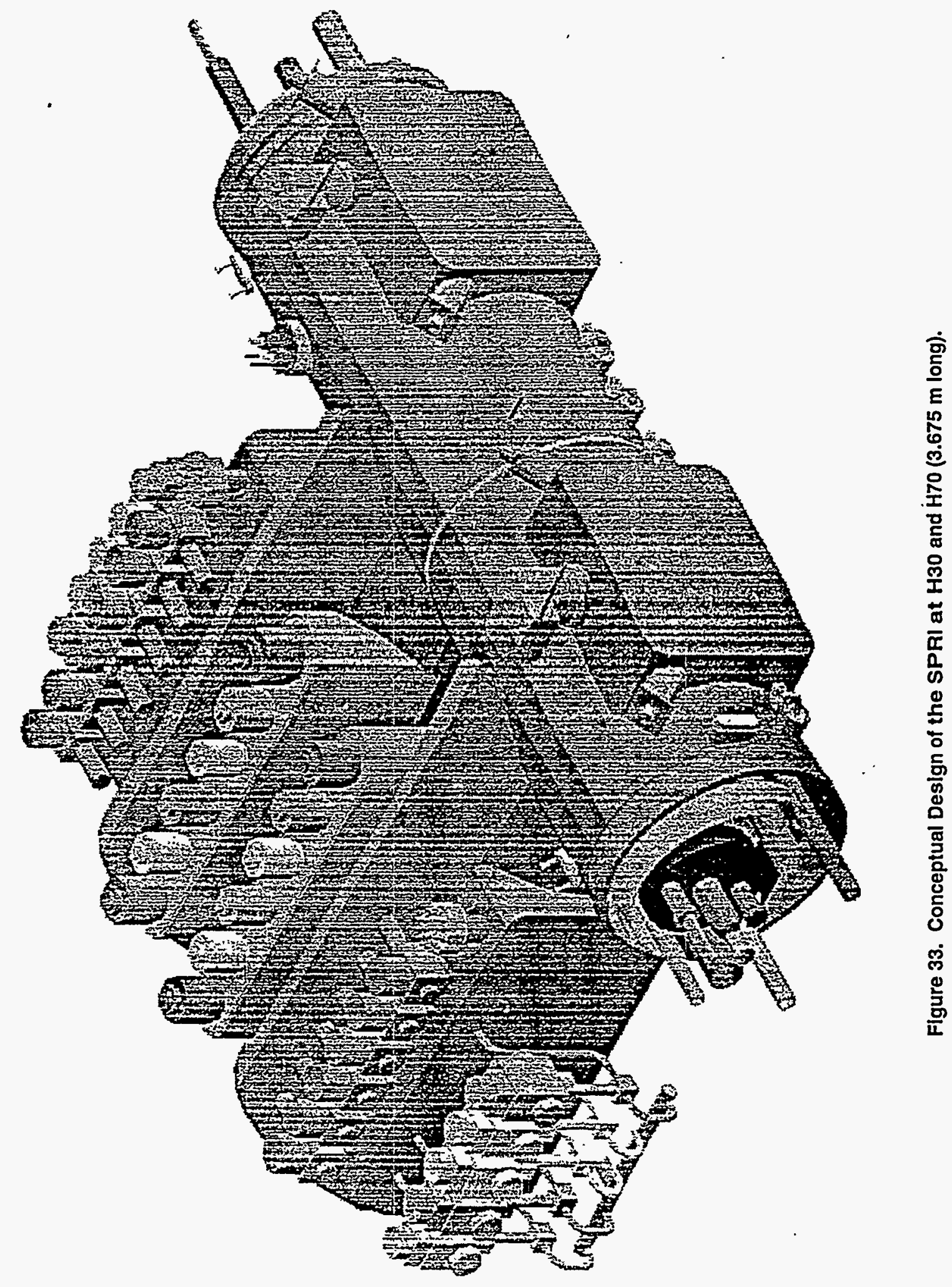




\subsubsection{SPRE}

SPRE are spool pieces located at $\mathrm{H} 40$ and $\mathrm{H} 80$ that allow for sector-to-sector connections through the auxiliary end box. SPRF has a quench relief valve, cooldown and relief valves for each of the six lines, pressure and temperature instrumentation on each of the six lines, power leads, CEPL, and a beam tube transition joint for each of the two strings conneeted to it on either side, but it has only one recooler. Figure 34 shows a schematic for the cryogenic equipment and instrumentation in SPRE. SPRE for the HEB. has a slot length of $7.35 \mathrm{~m}$ and is very similar in design to the SPRF.

\subsubsection{Special Spools}

\subsubsection{SPR4, SPR1, SPX1}

SPR4, SPR1, and SPX1 are special spools in the HEB straight segments. These spools are similar in design to the SPRA and SPXA, but have different slot lengths.

\subsubsection{SPRB, SPRT, SPXU}

SPRB and SPRT are special spools that connect the HEB ring components to the cryogenic bypass transfer lines used in the straight segments. SPRB and SPRT are basically an SPRA with a short extension for the connections to the bypass. SPRB connects a long string of magnets to one end of a cryogenic bypass. The connections contain the six full-size cryogenic lines and the superconducting bus. A schematic of SPRB is shown in Figure 35. SPRT connects isolated cryostats to the cryogenic bypass. The connections contain the full set of six cryogenic lines and the superconducting bus, but the 4-K vapor return line and the 20-K line may be less than full-size.

SPXU are special spools attached to an isolated cryostat used to turn around cryogens. SPRB, SPRT, and SPXU have warm-to-cold transitions and a warm beam tube valve. A schematic of an isolated cryostat including an SPRT and SPXU is given in Figure 36.

\subsubsection{Empty Cryostats (EC)}

There are cold drift segments in the dispersion suppressors, as defined in the half-cell diagram (Figure 3). There are also cold drifts in the straight sections. These drifts will be empty cryostats that contain the cold tubes for the 4-K, 20-K, and 80-K lines as well as the cold beam tube. The longer drifts are broken into a minimum number of viable lengths of empty cryostats. A standard empty cryostat module has a slot length of $6.585 \mathrm{~m}$. There are also several other empty cryostats with shorter slot lengths. The empty cryostats are designed to have the same interconnect as the magnet-to-magnet and magnet-to-spool interconnects. Special design is needed to shield the magnetic field generated around the cold bus and to prevent interaction with the beam. To enable this, the cold bus is located at a distance from the cold beam tube. The standard empty cryostat module has also an expansion vessel in which the cold bus expansion loop can be accommodated. A cross section of the proposed empty cryostat design is given in Figure 37(a) (see Reference 57), and a flow scheme is shown in Figure 37(b). 


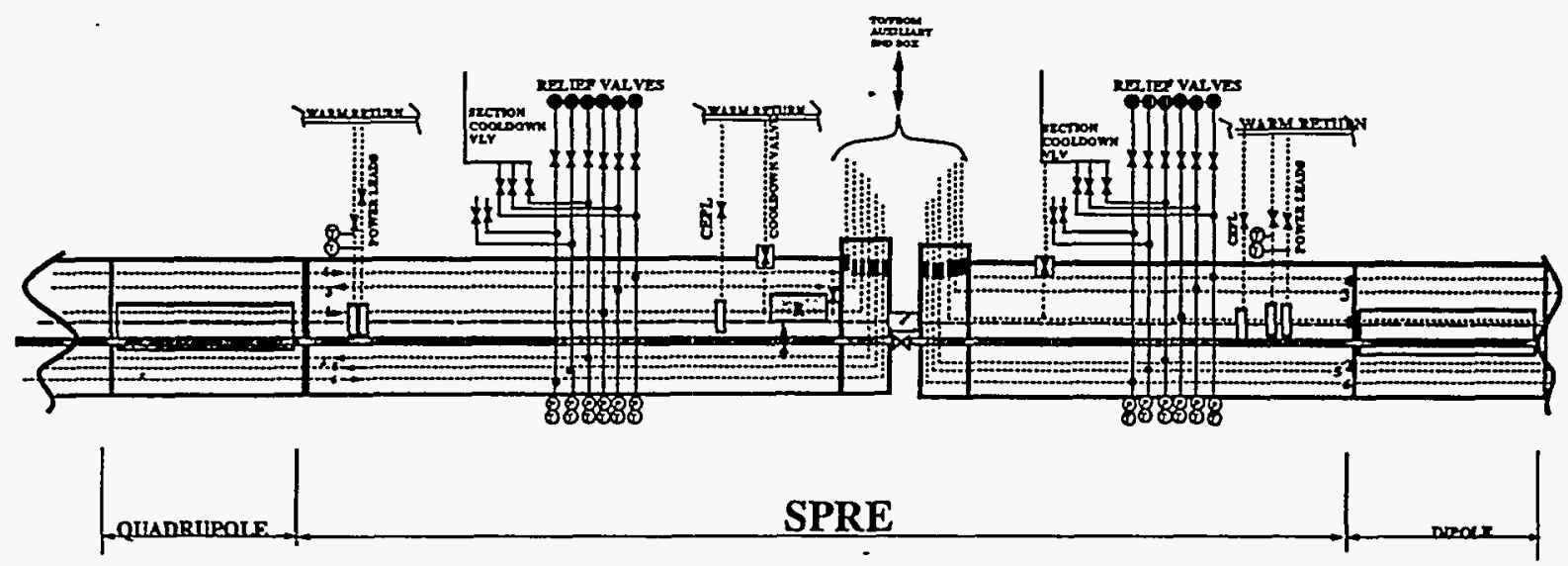

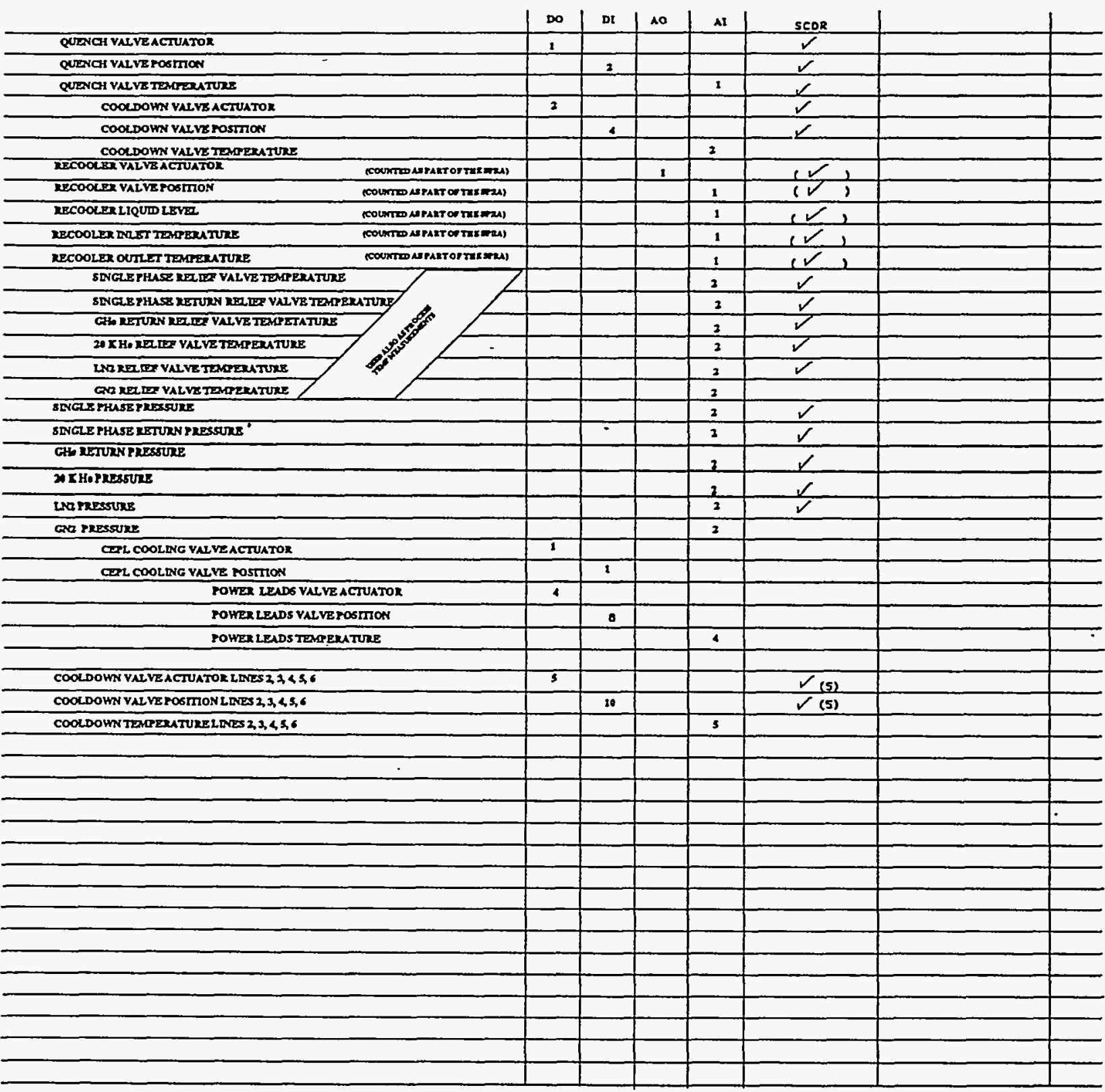

Figure 34. Cryogenic Equipment and Instrumentation for SPRE. 


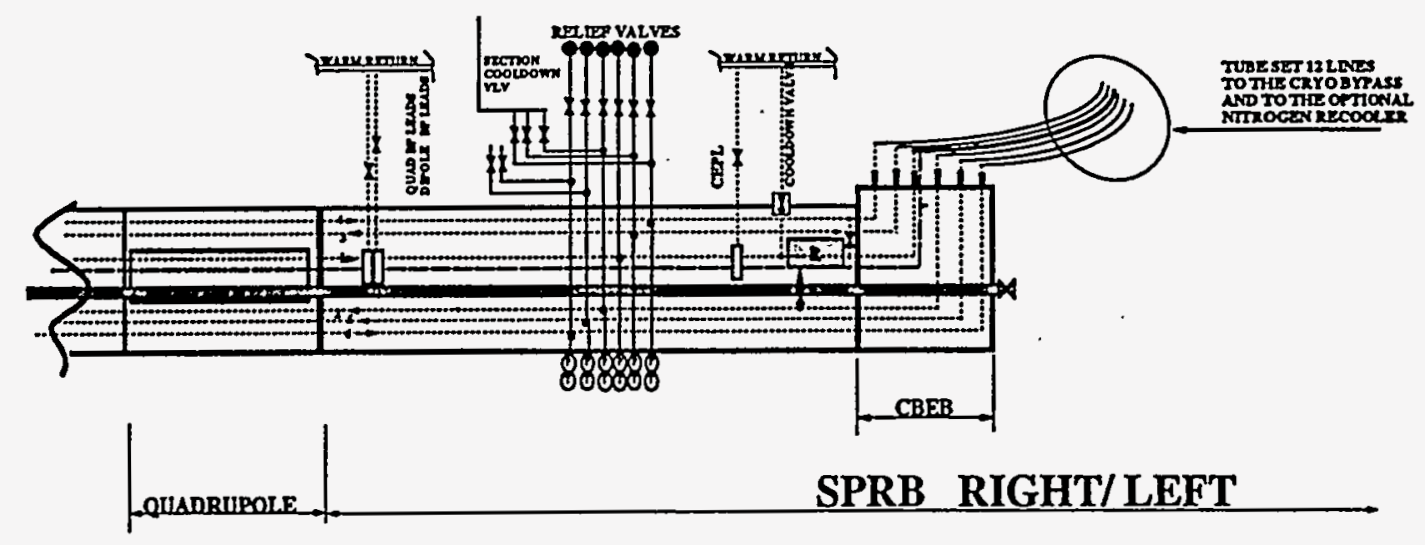

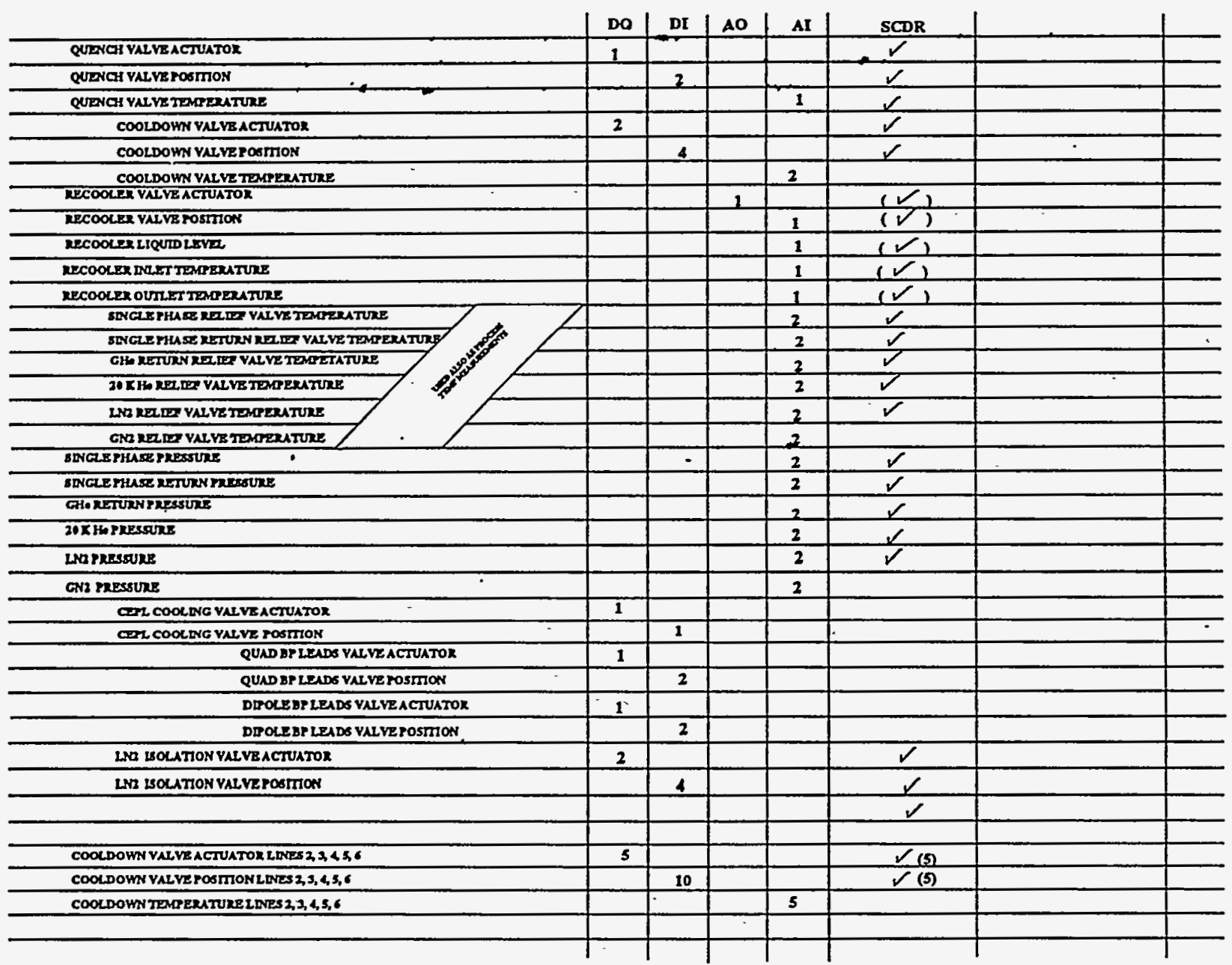

Flgure 35. Cryogenic Equipment and Instrumentation for SPRB. 


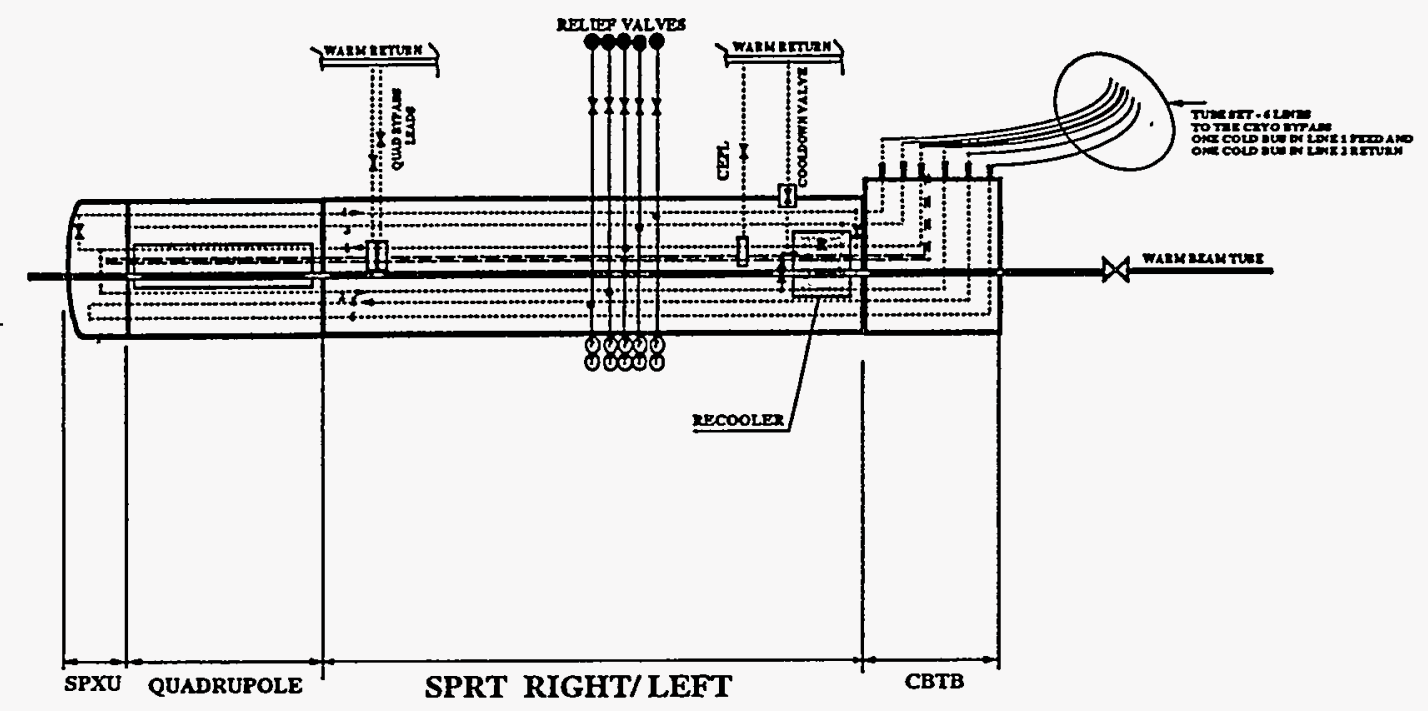

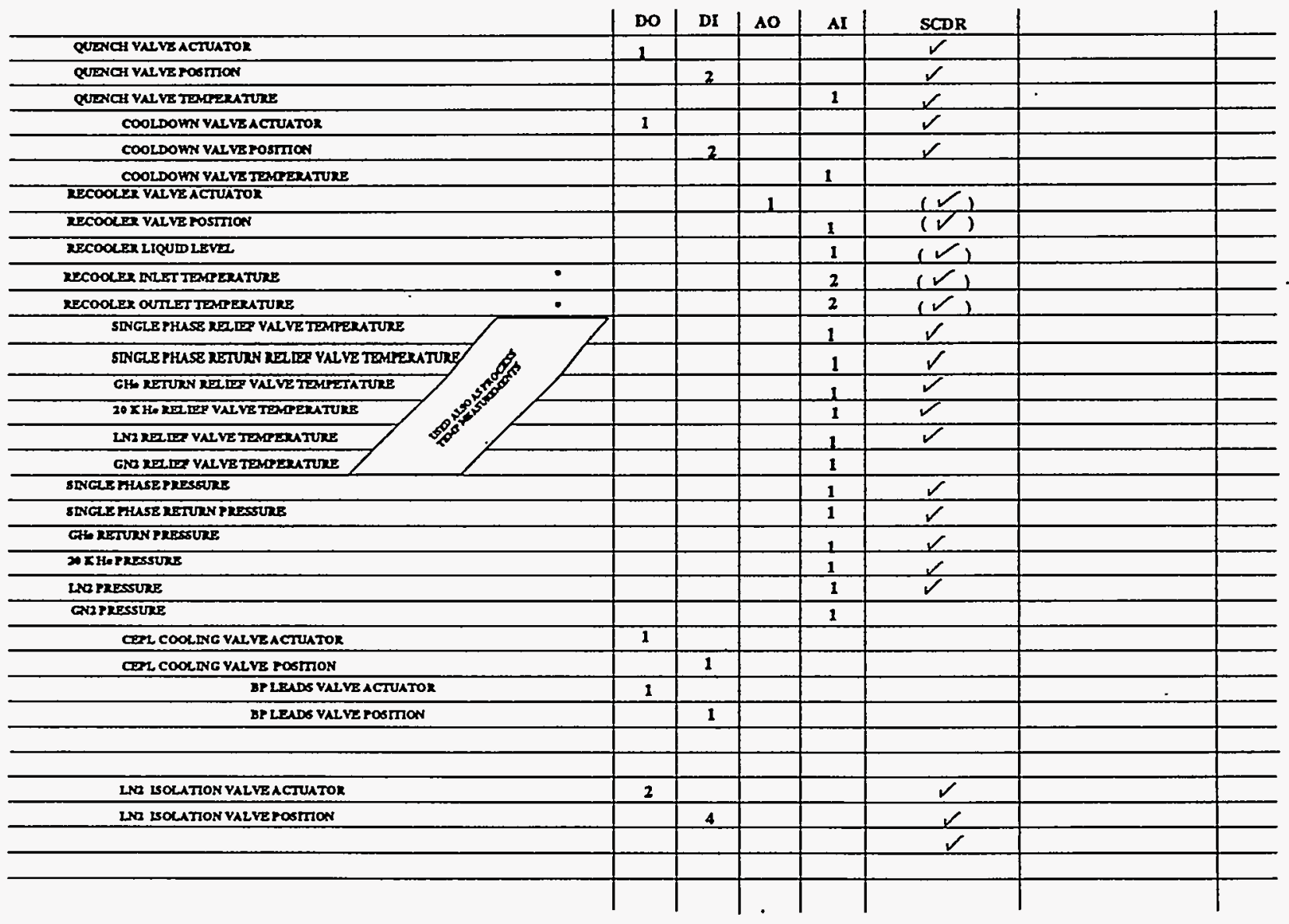

Figure 36. Cryogenic Equipment and Instrumentation for an Isolated Cryostat, including an SPRT and SPXU. 

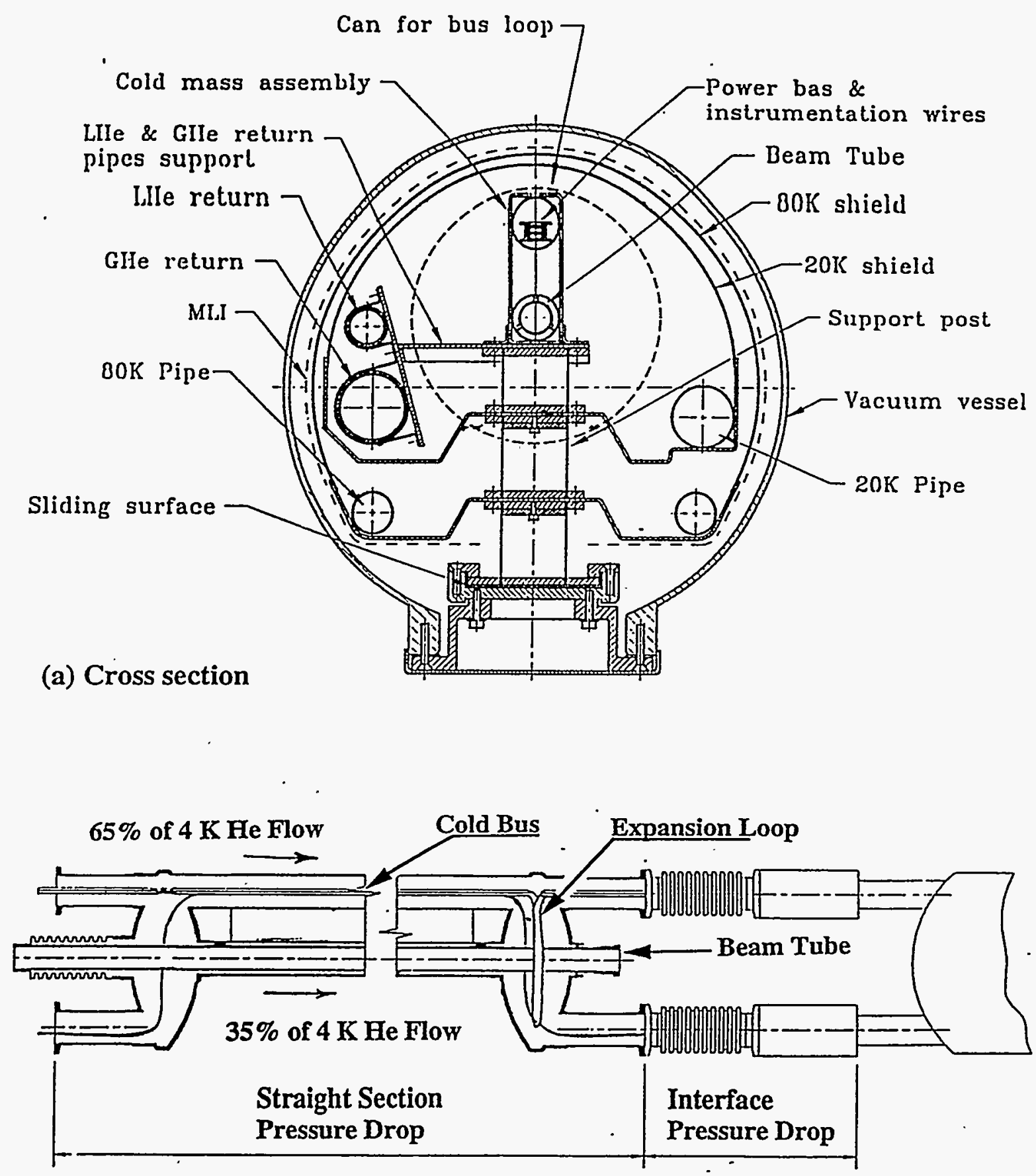

(b) Flow Scheme

Figure 37. Empty Cryostat: (a) Cross Section and (b) Flow Scheme. 


\subsubsection{Cryogenic Bypass Transfer Lines (CBTL)}

Cryogenic bypass transfer lines (CBTLs) route the cryogens and superconducting buses around various warm equipment in the HEB tunnel, such as warm magnets, scrapers, injection transfer lines, and if cavities. The bypasses also serve various isolated superconducting magnets between warm equipment in the HEB ring. A total of $1300 \mathrm{~m}$ of bypass lines, containing the six cryogen lines, will be installed in the HEB. The CBTLs include standard 13.2-m modules (BPCR), end boxes (BPEB), where the connections to the magnet strings are made, and T-boxes (BPTB), where " $T$ " connections are needed to feed the isolated cryostats.

CBTLs are required along the $\mathrm{H} 10, \mathrm{H} 20, \mathrm{H} 40, \mathrm{H} 50, \mathrm{H} 60$, and $\mathrm{H} 80$ straight segments. At $\mathrm{H} 20, \mathrm{H} 40$, $\mathrm{H} 60$, and $\mathrm{H} 80$, the bypass transfer lines are designed to cover the straight segment length between the dispersion suppressor cells, a distance of approximately $200 \mathrm{~m}$. At H50 the bypass transfer line is designed to cover an 111-m-long portion of the straight segment between the dispersion suppressor cells. At $\mathrm{H} 10$ the bypass transfer line is designed to cover the whole length of the straight segment, plus a portion of the dispersion suppressor cells, for a total length of $482 \mathrm{~m}$. The detailed design of the lattice and the bypass transfer line configuration is given in the HEB Level 3B Specification. ${ }^{1}$

\subsubsection{Standard and Special Bypass Cryostats (BPCR and BPCR-S)}

The standard bypass cryostat (BPCR) module is the basic building block of the bypass transfer line. It provides an insulating vacuum and contains the six cryogen lines. The superconducting bus is routed through the single-phase helium supply line. Provision must be made for bus expansion and contraction during cooldown and warm-up. The standard BPCR module has a slot length of $13.171 \mathrm{~m}$, including the interconnect, and an outer diameter of approximately $450 \mathrm{~mm}$. A cross section view of the HEB bypass cryostat is shown in Figure 38.

In addition to the standard bypass cryostats, a number of shorter bypass cryostats are needed to match the total bypass or section lengths dictated by the lattice requirements. These special units (BPCR-S) are identical to the standard bypass cryostats in cross section and simply differ in slot length. Those BPCR-S that are shorter than $3 \mathrm{~m}$ are designed without the bus expansion loop.

\subsubsection{Connection Boxes BPEB and BPTB, and Tube Sets}

Two types of connection boxes are needed in the bypasses: Bypass End Boxes (BPEB), and Bypass T-Boxes (BPTB).

Bypass End Boxes (BPEB), located at the ends of a bypass, allow the cryogenic and bus connections between the bypass and the magnet strings (Figure 39). End Boxes are classified as Left and Right based on the particular end of the bypass. The BPEB insulating vacuum is isolated from the ring vacuum by a specific vacuum barrier. The end boxes contain cryogenic measurement devices, relief and cooldown valves, and vacuum instrumentation.

Tube sets are needed to make the connections between the bypass connection boxes and the corresponding spools in the magnet strings. For the BPEB the tube set is composed of six cryogenic lines, with the following size requirements:

Line 1: 4-K LHe feed with the superconducting bus; $\Phi 50 \mathrm{~mm}$ nominal.

Line 2: 4-K LHe return; $\Phi 50 \mathrm{~mm}$ nominal.

Line 3: 4-K GHe return; $\Phi 110 \mathrm{~mm}$ nominal.

Line 4: $20-\mathrm{K}$ He retum; $\Phi 90 \mathrm{~mm}$ nominal.

Line 5: 80-K LN $;$; $\$ 57 \mathrm{~mm}$ nominal.

Line 6: $80-\mathrm{K} \mathrm{GN}_{2}$ return; $\Phi 57 \mathrm{~mm}$ nominal. 
Bypass T-Boxes (BPTB) accommodate cryogenic and bus connections between the bypass and various isolated superconducting magnets (Figure 40). The BPTB insulating vacuum is also isolated from the ring vacuum by a vacuum barrier. Bypass T-Boxes may also contain in-line vacuum barriers.

For the BPTB the tube set is also composed of six cryogenic lines, with the following size requirements:

Line 1: 4-K LHe Feed with the superconducting bus; $\Phi 50 \mathrm{~mm}$ nominal.

Line 2: 4-K LHe Return, with one superconducting bus; $\Phi 50 \mathrm{~mm}$ nominal.

Line 3: $4-\mathrm{K}$ GHe return; $\Phi 25 \mathrm{~mm}$ nominal.

Line 4: $20-\mathrm{K}$ He return; $\Phi 25 \mathrm{~mm}$ nominal.

Line 5: $80-\mathrm{K} \mathrm{LN}_{2} ; \Phi 57 \mathrm{~mm}$ nominal.

Line 6: $80-\mathrm{K} \mathrm{GN}_{2}$ return; $\Phi 57 \mathrm{~mm}$ nominal.

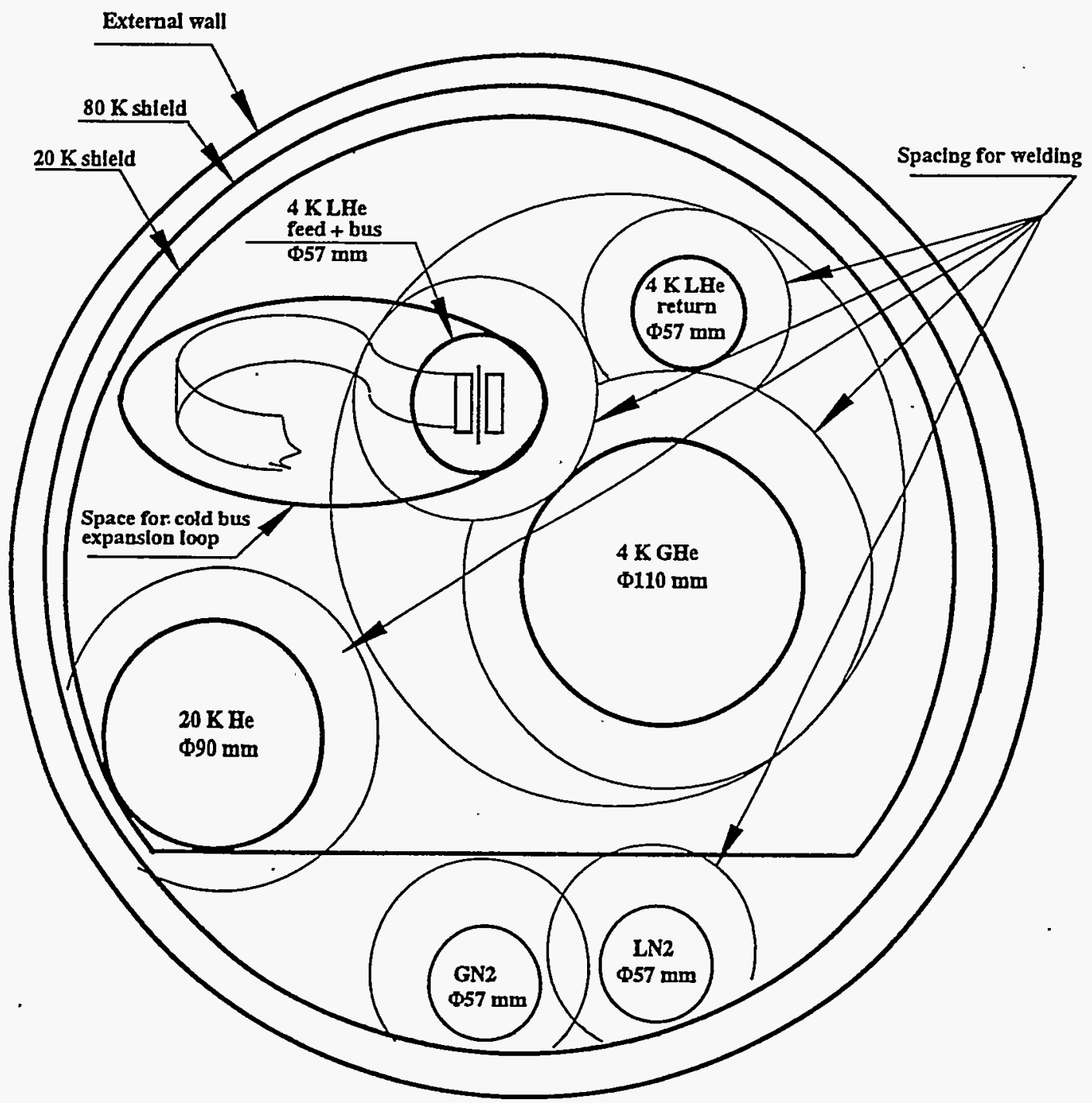

Figure 38. Bypass Cryostat Cross Section (Minimum Expected External Diameter $450 \mathrm{~mm}$ ). 


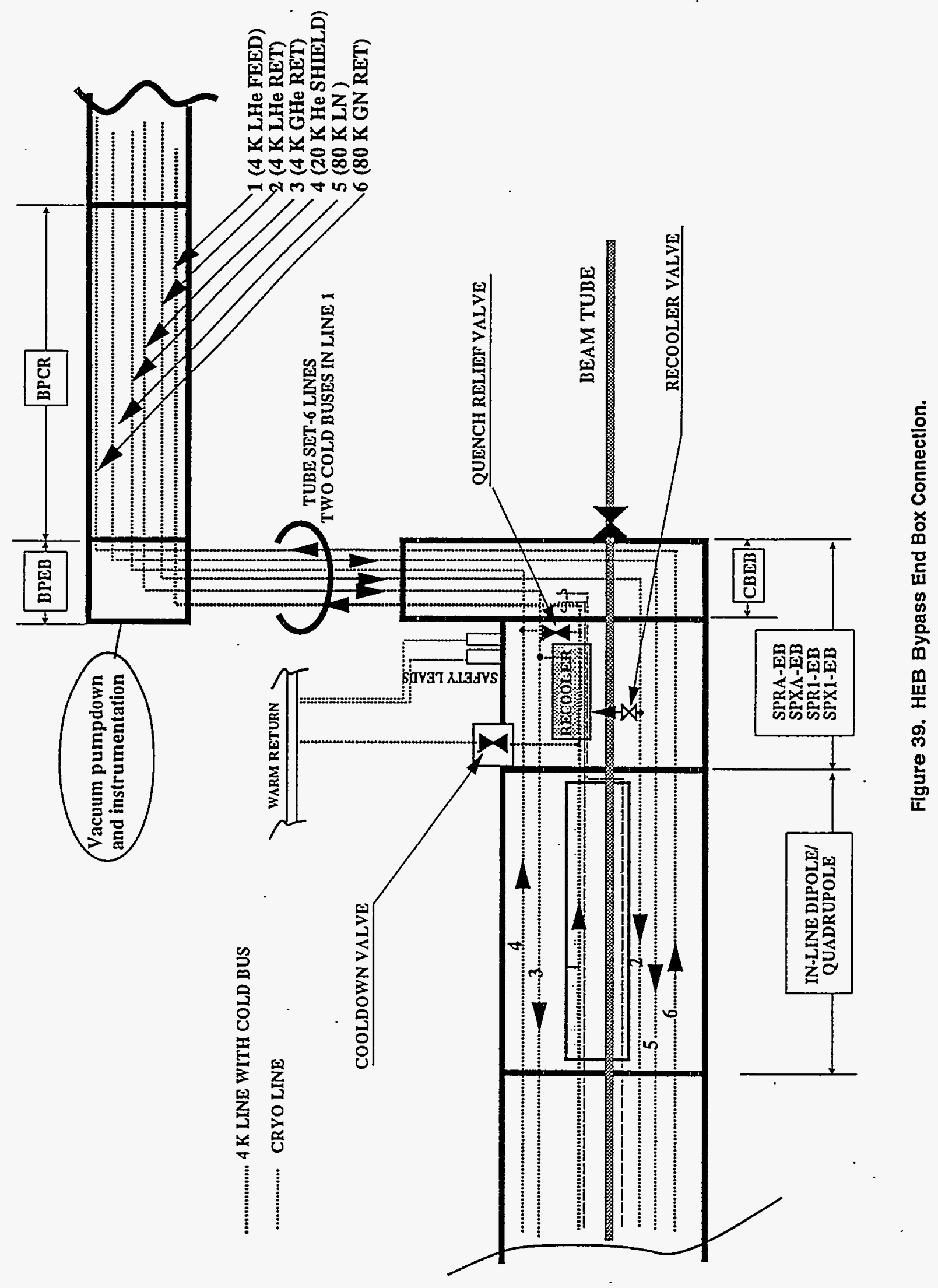




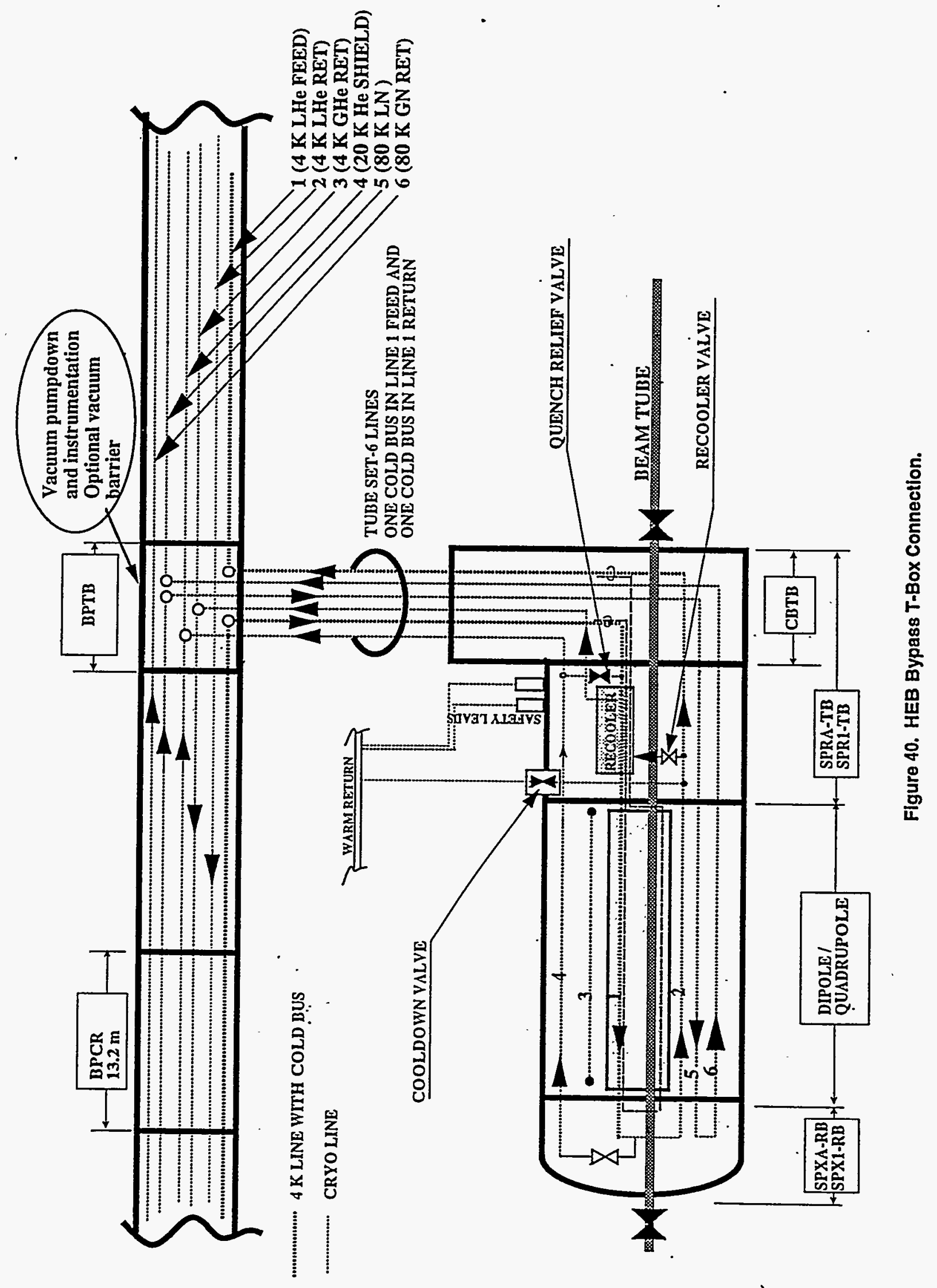




\subsection{HEAT LOAD BUDGETS AND REFRIGERATION PLANT CAPACITIES}

\subsection{Component Heat Load Budgets}

Heat transfer into the components at liquid helium temperature is minimized by two thermal shields maintained at $84 \mathrm{~K}$ and $20 \mathrm{~K}$, and by an insulating space maintained at high vacuum. Heat input to the 4- $\mathrm{K}$ components can be defined as the sum of two loads, dynamic and static. The major portion of dynamic load is caused by ramping heat loads together with eddy current losses (approximately $1 \mathrm{~W} / \mathrm{m}$ ). Static load results from the heat conduction and thermal radiation loads from the warmer parts in the cryostat. The total heat load is removed from the $4-\mathrm{K}$ components by circulating single-phase $4-\mathrm{K}$ helium through these components and by recooling this single-phase stream in recoolers along the string.

The heat load from the 4- $\mathrm{K}$ components is reflected as a 4- $\mathrm{K}$ refrigeration load on the helium plant. Some components that protrude from the outside into the 4-K parts of the cryostat, such as electrical leads, are cooled by small streams of 4-K helium; this helium is returned warm to the plant and translates into a liquefaction load on the helium plant.

The temperature of the $20-\mathrm{K}$ shield is maintained by circulating 3-bar helium gas through the shield at a supply temperature of $14 \mathrm{~K}$. Heat into the $80-\mathrm{K}$ shield is removed by an independent nitrogen cooling system. The heat loads of the various equipment are budgeted to one of three loads on the helium refrigeration system - that is, the 4-K refrigeration load, the liquefaction load, and the $20-\mathrm{K}$ shield load. The 80-K loads are budgeted to the nitrogen cooling system.

The heat budgets for the various ring components-including various magnets, spools, empty cryostats, and bypass equipment-are summarized in Table 8 . Also listed in Table 8 is the heat load for a full cell (see Figure 3), which is important in sizing the helium recoolers. Details of the static and dynamic loads for these components are presented in the Appendix.

\subsection{Distribution Heat Loads}

Distribution heat loads are static loads associated with the equipment supplying the cryogens from the refrigerator to the ring. These include the vertical and horizontal transfer lines, the surface and tunnel distribution boxes, cold compressor, auxiliary box, and pump boxes. Table 9 gives the heat load allocations (per unit length) for the vertical and horizontal transfer lines. Table 10 gives the overall distribution loads associated with each helium plant.

Table 8. Ring Component Heat Load Budgets.

\begin{tabular}{|l|c|c|c|c|c|c|}
\hline & $\begin{array}{c}\text { Llquif. } \\
(\mathrm{g} / \mathrm{s})\end{array}$ & $\begin{array}{c}4 \mathrm{~K} \text { Static } \\
(\mathbf{W})\end{array}$ & $\begin{array}{c}4 \mathrm{~K} \text { Dynamic } \\
(\boldsymbol{W})\end{array}$ & $\begin{array}{c}4 \mathrm{~K} \text { Total } \\
(\mathbf{W})\end{array}$ & $\begin{array}{c}20 \mathrm{~K} \text { Total } \\
(\mathbf{W})\end{array}$ & $\begin{array}{c}80 \mathrm{~K} \text { Total } \\
(\boldsymbol{W})\end{array}$ \\
\hline HDM & & 0.46 & 12.73 & 13.19 & 5.61 & 41.18 \\
\hline HQM & & 0.30 & 2.01 & 2.30 & 1.90 & 13.53 \\
\hline HQM1 & & 0.29 & 1.30 & 1.59 & 1.77 & 12.47 \\
\hline HQM2 & & 0.30 & 1.57 & 1.87 & 1.82 & 12.88 \\
\hline HQM3 & & 0.30 & 2.67 & 2.97 & 2.02 & 14.53 \\
\hline HQM4 & & 0.30 & 3.77 & 4.08 & 2.22 & 16.19 \\
\hline EC 6.5 m & & 0.32 & 0.32 & 0.64 & 2.80 & 20.98 \\
\hline SPXA & 0.072 & 2.63 & 0.29 & 2.92 & 14.85 & 53.67 \\
\hline SPRA & 0.072 & 2.73 & 0.29 & 3.01 & 15.71 & 57.87 \\
\hline SPRF/SPRI/SPRE & 1.728 & 39.63 & 0.66 & 40.28 & 39.63 & 242.34 \\
\hline SPXU & 0.012 & 0.67 & 0.26 & 0.93 & 7.97 & 23.14 \\
\hline BPCR 13.2 m & & 0.13 & 0.08 & 0.21 & 3.48 & 26.86 \\
\hline BPEB+CBEB & & 4.13 & 0.08 & 4.21 & 15.47 & 166.80 \\
\hline BPTB+CBTB & & 3.79 & 0.08 & 3.87 & 12.78 & 143.80 \\
\hline Full-Cell & 0.144 & 7.81 & 55.50 & 63.31 & 56.8 & 303.32 \\
\hline
\end{tabular}


Table 9. Transfer Line Heat Loads.

\begin{tabular}{|l|c|c|c|}
\hline & $4-\mathrm{K}$ Load & $20-\mathrm{K}$ Load & $80-\mathrm{K}$ Load \\
\hline Shaft Transfer Line & $0.4 \mathrm{~W} / \mathrm{m}$ & $0.4 \mathrm{~W} / \mathrm{m}$ & $3.0 \mathrm{~W} / \mathrm{m}$ \\
\hline Horizontal Transfer Line & $0.3 \mathrm{~W} / \mathrm{m}$ & $0.3 \mathrm{~W} / \mathrm{m}$ & $2.0 \mathrm{~W} / \mathrm{m}$ \\
\hline
\end{tabular}

Table 10. Sector Distribution Loads.

\begin{tabular}{|l|c|c|c|c|}
\hline & $\begin{array}{c}\text { Liquif. } \\
(g / s)\end{array}$ & $\begin{array}{c}4 \mathrm{~K} \text { Total } \\
(\mathbf{W})\end{array}$ & $\begin{array}{c}20 \mathrm{~K} \text { Total } \\
(\mathbf{W})\end{array}$ & $\begin{array}{c}80 \mathrm{~K} \text { Total } \\
(\mathbf{W})\end{array}$ \\
\hline Helium Refrigerator $-\mathrm{LN}_{2}$ precooling & & & & 30000 \\
\hline Helium Storage & 0.8 & & & 800 \\
\hline Surface Distribution Box \& Interfaces & & 60 & 50 & 400 \\
\hline Helium Pump Box \& Interfaces & & 60 & & 400 \\
\hline Transfer Lines, Bends \& Interfaces & & 120 & 100 & 600 \\
\hline Cold Compressor System & & 150 & 50 & 600 \\
\hline Tunnel Distribution Box \& Interfaces & & 100 & 50 & 600 \\
\hline Auxiliany End Box \& Interfaces & & 100 & 50 & 400 \\
\hline LN2 Pump Box & & & & 2400 \\
\hline Utilities & & & & 3800 \\
\hline Quench and Cooldown Recovery & 3.5 & & & \\
\hline Performance and Control & 1.5 & 500 & 800 & 2000 \\
\hline Total Sector Distribution Loads & 5.8 & 1090 & 1100 & 42000 \\
\hline
\end{tabular}

\subsection{String and Sector Heat Loads and Plant Capacity Requirements}

The string heat loads are calculated by summation of the static and dynamic loads of all the ring components connected to the same feed. The sector heat load is composed of the heat loads for the two strings in an HEB cryogenic sector, plus the distribution loads of the sector. Table 11 lists the static and dynamic heat loads for the two strings of the H2O sector and the total heat load for the H2O plant.

Table 11. H2O Plant Total Heat Loads and Capacity Requirements.

\begin{tabular}{|l|c|c|c|c|}
\hline & $\begin{array}{c}\text { Liquif. } \\
(\mathrm{g} / \mathrm{s})\end{array}$ & $\begin{array}{c}4 \mathrm{~K} \text { Total } \\
(\mathrm{W})\end{array}$ & $\begin{array}{c}20 \mathrm{~K} \text { Total } \\
(\mathrm{W})\end{array}$ & $\begin{array}{c}80 \mathrm{~K} \text { Total } \\
(\mathrm{W})\end{array}$ \\
\hline Static Heat Load-Strings & 18 & 850 & 5000 & 29500 \\
\hline Dynamic Heat Load-Strings & & 3660 & & \\
\hline Distribution Loads & 6 & 1090 & 1100 & 42000 \\
\hline Unallocated & 12 & 0 & 3900 & 8500 \\
\hline H20 Plant Total Load & 36 & 5600 & 10000 & 80000 \\
\hline $\begin{array}{l}\text { H20 Plant Design Load } \\
\text { (Capacity Requirement) }\end{array}$ & 45 & 6750 & 15000 & 80000 \\
\hline
\end{tabular}

The refrigeration system is designed with a specific capacity to meet the various normal loads, all the loads during specific upset conditions, and the redundancy requirements. The system is able to reach its maximum design capacity, given in Table 11, when all of its components are functioning properly.

In the event of failure of any single expander, the system must continue to operate with at least the steady-state capacity given in Table 11. Also, when the other sector needs assistance in the form of liquefaction load or other loads, the refrigerator must turn up to provide this assistance. Due to the flowrate limitations of the cold piping in the magnet strings, it is difficult to transfer $4-\mathrm{K}$ refrigeration between 
sectors. However, liquefaction and $20-\mathrm{K}$ loads can be transferred relatively easily by shifting the warm gas flow from one sector to the other. The extra capacity also allows for quick recovery after a quench in a sector. During and after a quench the inventory and recovery process must quickly be handled. The plant has to be turned up to handle this transient.

The plant is operated in the minimum capacity mode when the sector heat loads are low for long-term cold storage of the ring. The plant is capable of operating between maximum capacity and the minimum capacity obtainable without bringing a compressor or expander off-line. In this capacity range the gas management and coldbox control schemes are capable of allowing the plant to turn up and to turn down according to the demands of the load. At lower load demands, one or more compressors and/or expanders may be shut down for efficient operation of the plant.

\subsection{Nitrogen Heat Budgets}

The heat loads for the nitrogen system are composed of the tunnel loads and the surface loads.

\subsubsection{Tunnel Heat Loads}

The $84-\mathrm{K}$ shield and the $\mathrm{LN}$ tunnel system are designed to prevent direct infrared radiation from the $300-\mathrm{K}$ shield to the $20-\mathrm{K}$ shield and to intercept the heat conducted through the supports and other connections between the warm and cold components. Heat intercepted at a level of $84 \mathrm{~K}$ compared to the same amount of heat intercepted at a level of $20 \mathrm{~K}$ requires less than one-fifth of the ideal work. The 84-K shield heat load and the $20-\mathrm{K}$ shield heat load used for the budget calculations are based on two MLI blankets, each with 32 layers on the $84-\mathrm{K}$ shield. The detailed budgets for the 84-K shield heat loads of various ring components are given in Table 8.

\subsubsection{Surface Loads}

The $\mathrm{GN}_{2}$ generated in the tunnel is used in the surface refrigeration system for helium precooling. The SRS is designed to use additional liquid nitrogen for the $3006 \mathrm{~K}$ to $80-\mathrm{K}$ cold box. The total flow of $\mathrm{LN}_{2}$ results from trading off the operating cost of the nitrogen system and the installation and operation of the helium system.

Figure 41 is a diagram of the nitrogen system heat loads and the associated mass flow rates. 


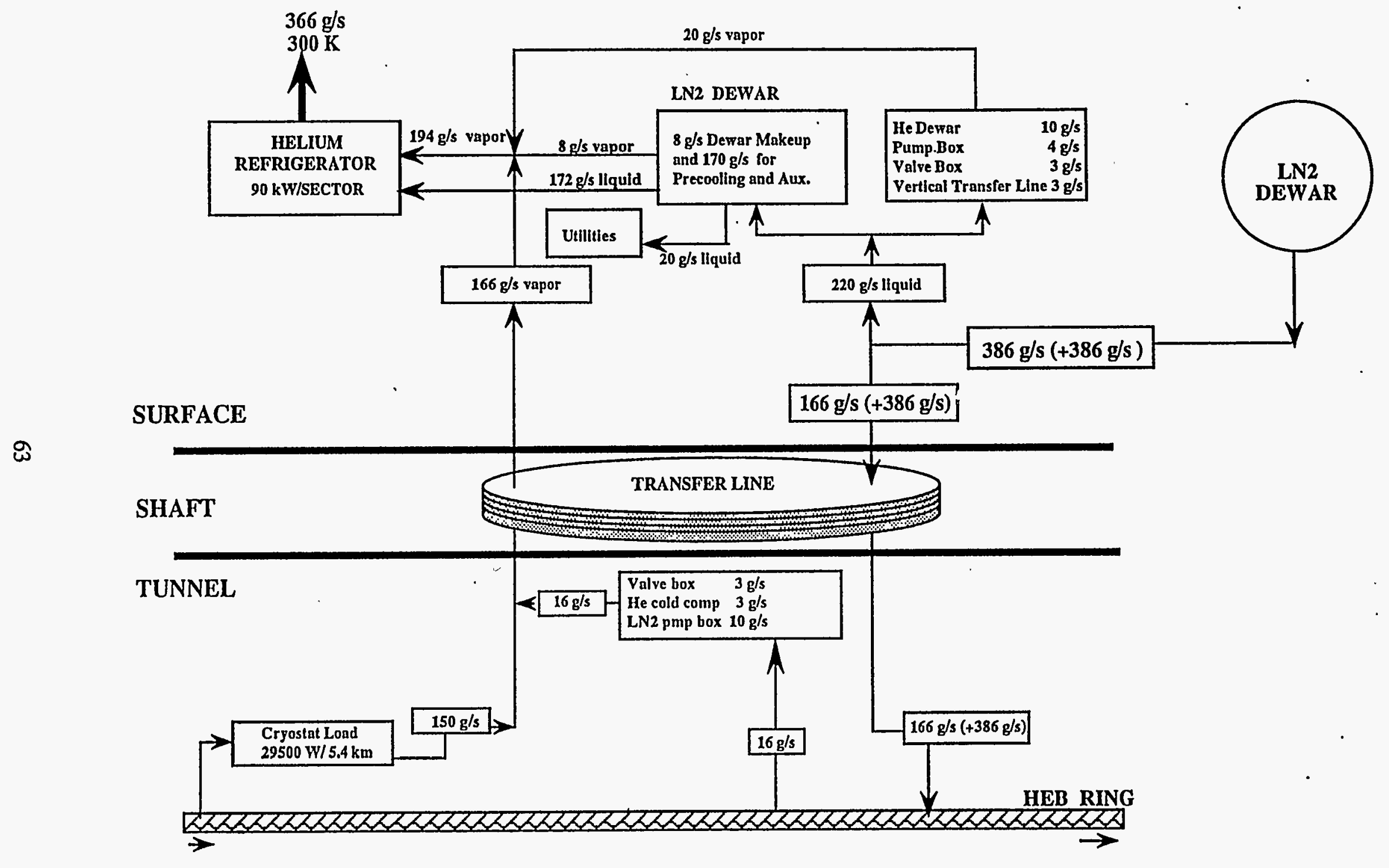

Figure 41. Nitrogen System Heat Loads and Mass Flow Rates for the HEB. 


\subsection{FLOW AND THERMAL CHARACTERISTICS}

\subsection{Pressure Drop Allocations and Minimum Line Sizes}

The normal operating pressure level for the single-phase helium supply and return was chosen as $0.4 \mathrm{MPa}$ in order to maintain supercritical flow everywhere in the system. This includes the flows in the transfer lines from or back to the surface. The pressure level in line 4 has to be lower than the lowest pressure in lines 1 and 2 to prevent leakage or flow from line 4 to line 1 through the quench valves under normal operation. The pressure in line 4 is not allowed to fall below $0.25 \mathrm{MPa}$ in the tunnel to support the pressure drops in the surface refrigeration plant. These constraints on the pressure, together with the nominal helium flow rate of $100 \mathrm{~g} / \mathrm{s}$ in lines 1 and 4, determined the nominal pressure drop allocations for the tunnel components. The minimum line sizes to support these pressure drop allocations are presented in Table 12, together with the nominal pressures, temperatures, and flow rates in each of the cryogenic lines.

Table 12. Minimum Line Sizes, Nominal Conditions, and Pressure Drop Allocations.

\begin{tabular}{|l|c|c|c|c|c|}
\hline & $\begin{array}{c}\text { Line 1 } \\
4 \mathrm{~K} \mathrm{He} \\
\text { Supply }\end{array}$ & $\begin{array}{c}\text { Line 2 } \\
4 \mathrm{~K} \mathrm{LHe} \\
\text { Return }\end{array}$ & $\begin{array}{c}\text { Line 3 } \\
4 \mathrm{~K} \mathrm{GHe} \\
\text { Return }\end{array}$ & $\begin{array}{c}\text { Line 4 } \\
20 \mathrm{~K} \mathrm{He}\end{array}$ & $\begin{array}{c}\text { Line 5,6 } \\
80 \mathrm{~K} \mathrm{LN2}\end{array}$ \\
\hline Minimum Line ID (m) & & 0.0452 & 0.110 & 0.0824 & 0.0572 \\
\hline Nominal P (MPa) & 0.4 & 0.3 & 0.085 & 0.25 & 0.5 \\
\hline Nominal T (K) & 4.05 & 4.3 & 4.3 & 20 & 84 \\
\hline Nominal Density (kg/) & 0.140 & 0.133 & 0.0012 & 0.060 & 0.780 \\
\hline Nominal Flow (g/s) & 100 & 60.5 & 68.5 & 100 & 750 \\
\hline & Pressure Drop Allowance (Pa) & & \\
\hline HDM & 106.4 & 26.6 & 3.42 & 70.0 & 222 \\
\hline HQM & 31.9 & 5.0 & 0.65 & 13.0 & 42 \\
\hline HQM1 & 28.4 & 3.6 & 0.46 & 9.0 & 30 \\
\hline HQM2 & 30.1 & 4.1 & 0.53 & 11.0 & 35 \\
\hline HQM3 & 36.3 & 6.3 & 0.82 & 17.0 & 53 \\
\hline HQM4 & 41.7 & 8.5 & 1.10 & 23.0 & 71 \\
\hline SPXA & 106.0 & 7.0 & 1.00 & 19.0 & 62 \\
\hline SPRA & 406.0 & 7.0 & 1.00 & 19.0 & 62 \\
\hline EC-6.585 m & 67.0 & 15.0 & 2.00 & 40.0 & 122 \\
\hline Bypass Cryostat-13.2 m & 134.0 & 30.0 & 4.00 & 80.0 & 243 \\
\hline Interconnect & 4.0 & 2.0 & 0.30 & 5.0 & 20 \\
\hline
\end{tabular}

-Lines 5 and 6 are identical in diameter. The nominal pressure, temperature, and flow rates presented are for line 5 , but they can also be applied to line 6 for line size and pressure drop calculations.

With the exception of line 4 , the minimum line sizes are the same as in the collider. The recooler bath temperatures in the HEB are limited to $3.85 \mathrm{~K}$ to $4.05 \mathrm{~K}$. This defines the range of pressures in line 3 (0.085 MPa minimum at the suction to the cold compressor). Due to the higher heat load in the HEB, the boil-off per cell and the total vapor flow are higher than those in the collider. This requires a larger diameter for the $4-\mathrm{K}$ vapor return line. The minimum ID for line 4 in the HEB is set at $110 \mathrm{~mm}$ (compared to $86 \mathrm{~mm}$ in the collider). Figure 42 shows the results of a trade-off study between pressure drop and line size. Lines 5 and 6 are identical in diameter. The nominal pressure, temperature, and flow rates in Table 12 are for line 5, but can also be applied to line 6 for line size and pressure drop calculations. 


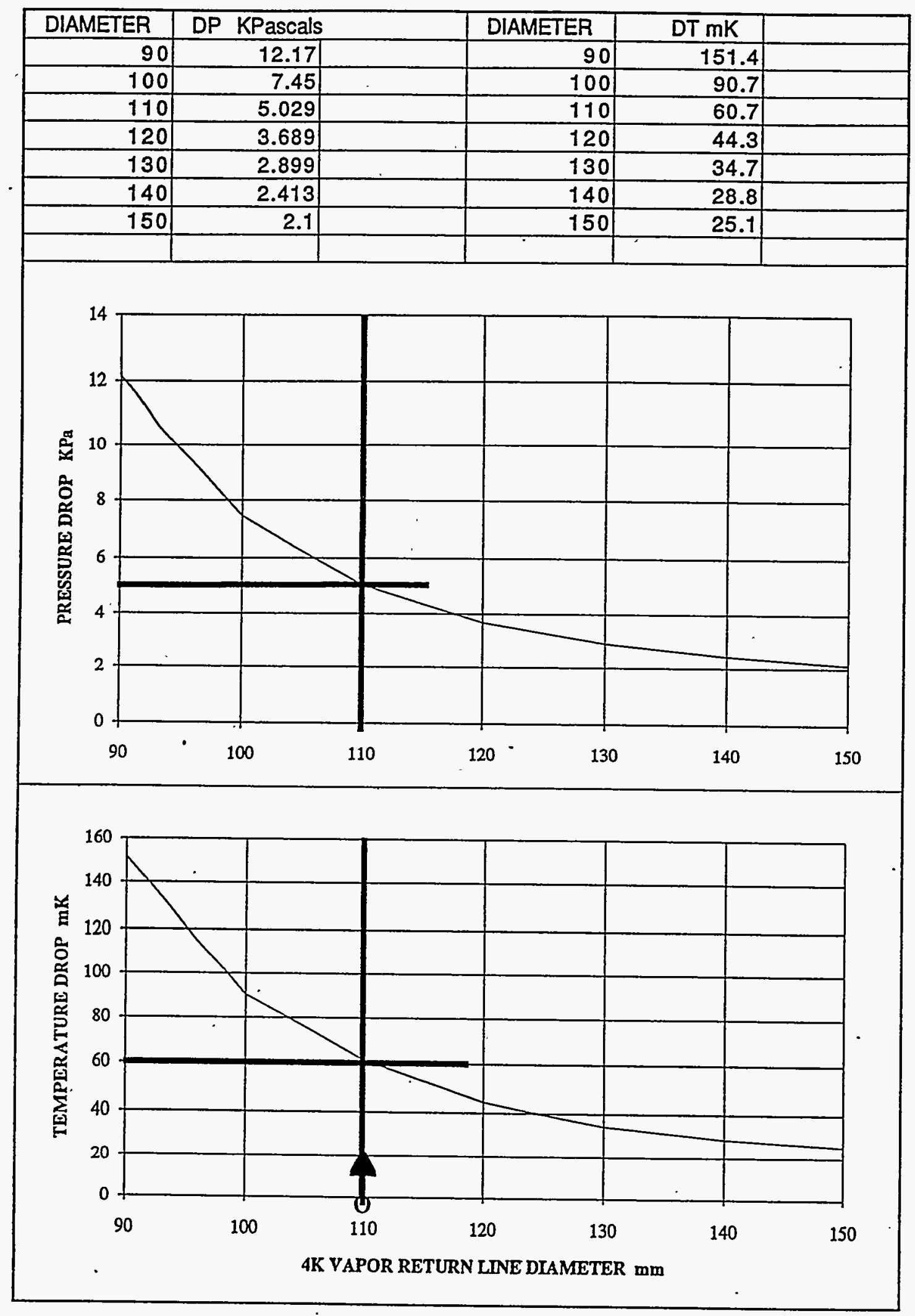

Figure 42. Line Size vs. Pressure Drop Trade-off for Line 3 in the HEB. 


\subsection{Flow Rates and Configurations for Normal Operation}

The flow configurations and the corresponding flow rates in the cryogen lines vary, depending on the mode of operation. Figure 43 shows the flow configurations in the cryogen lines for normal operation. The corresponding pressures, temperatures, and flow rates for normal operation under the full design heat load (with the beam on) are given in Table 13. The flow rates in lines 1-3 for normal operation under the standby heat load and the full design heat load are shown in Table 14. The line-1 helium temperature variations in the different coldmass passages of the magnets over a full-cell are shown in Figure 44. The calculations are based on $100 \mathrm{~g} / \mathrm{s}$ of flow, full design heat load, and crossflow scheme to cool the dipole magnets.

Figure 45 shows the flow configurations in the cryogen lines when one of the two plants (H60 in this example) is down. The flow rates required in lines $1-3$ for operation with the $\mathrm{H} 60$ plant down under the standby heat load and the full design heat load are shown in Table 15. The total heat load of the HEB $(2 \times 5600 . \mathrm{W})$ cannot be handled by a single refrigeration plant. Therefore, the HEB cannot be operated under full dynamic load when one plant is down.

The flow configurations for other modes of operation are discussed in Section 5.0.

\subsection{Cryogen Inventory}

Fluid inventory data is crucial information for system analysis, especially in response to fast disturbances or when large quantities of cryogens have to be shifted from the surface to the ring or vice versa.

Fast disturbances such as quenches (e.g., the quench of a half- or full-cell) require a quick response, but usually do not involve large amounts of cryogens. Following a full-cell quench, about $100 \mathrm{~kg}$ of helium may have to be shifted from line 1 to line 4 within $50-60 \mathrm{~s}$, and then to the surface. A larger-scale quench such as a full-section quench, may involve up to $1200 \mathrm{~kg}$ of helium within $50-60 \mathrm{~s}$ of the quench. A line rupture may not requires as fast a response as a quench, but it may affect the whole helium inventory of full string (about $4700 \mathrm{~kg}$ ). Changes in the state of the system, such as warm-up or cooldown, also require large quantities of cryogens to be shifted from the surface to the ring or vice versa.

As a general rule the fluid inventory is a design parameter for each ring component that has to be minimized. The optimization should consider the pressure drop and heat budget allocations as well as structural constraints. Table 16 shows the HEB cryogen inventory for each component family and the summaries for the section, string, and sector inventories. Because some of the components are still in the design stage, the inventory is defined here as a "budget" value and not as an optimized value.

\subsection{Sector Heat Capacity}

The heat capacities of the ring components and of the sector as a whole are important in determining the time constant of the HEB for processes that involve cooldown and warm-up of the coldmasses and the shields. The material mass and thermal properties determine the heat capacity. Table 17 lists the iron mass (coldmass) for the various components and for the short and long sections. The stainless steel and aluminum masses for the $20-\mathrm{K}$ and $80-\mathrm{K}$ shields are also listed in Table 17.

Figure 46 presents the enthalpy of iron as a function of temperature, which is used to determine the heat capacities for the coldmasses. Figure 47 shows the coldmass enthalpy as a function of temperature for the long section and for a full sector. The combined thermal masses of the aluminum shields and the stainless steel pipes attached to the shields make up the heat capacity of the shields. Figure 48 shows the heat capacities of the $20-\mathrm{K}$ and $80-\mathrm{K}$ shields for a long section and for a full sector. 
The data presented in Figures 47 and 48 can be used to determine the process time, flow, and refrigeration requirements. Consider cooldown of a sector coldmass, from $300 \mathrm{~K}$ to $80 \mathrm{~K}$, for example. The heat capacity of a sector coldmass between $80 \mathrm{~K}$ and $300 \mathrm{~K}$ is $1.9 \mathrm{E} 11 \mathrm{~J}$. If $200 \mathrm{~g} / \mathrm{s}$ of helium flow is used (100 g/s for each string), the time required for cooldown is approximately 10 days:

Cooldown Time $\quad=$ Q80 K to $300 \mathrm{~K} /\left(\mathrm{m} \mathrm{c}_{\mathrm{p}} \mathrm{DT}\right) \mathrm{He}$

$=(1.9 \mathrm{E} 11 \mathrm{~J}) /(0.2 \mathrm{~kg} / \mathrm{s} * 5200 \mathrm{~J} / \mathrm{kg}-\mathrm{K} *(300-80) \mathrm{K})$

$=8.3 \mathrm{E} 5 \mathrm{~s}$

$=231 \mathrm{~h}$

$=9.5$ days.

The amount of liquid nitrogen to be supplied to the refrigerator to perform this cooldown is about 480 tons, or 5 truckloads per day (assuming 10-ton trucks). For simplicity, this example did not include the shields, which will impose additional time and energy requirements. 


\section{HEB}

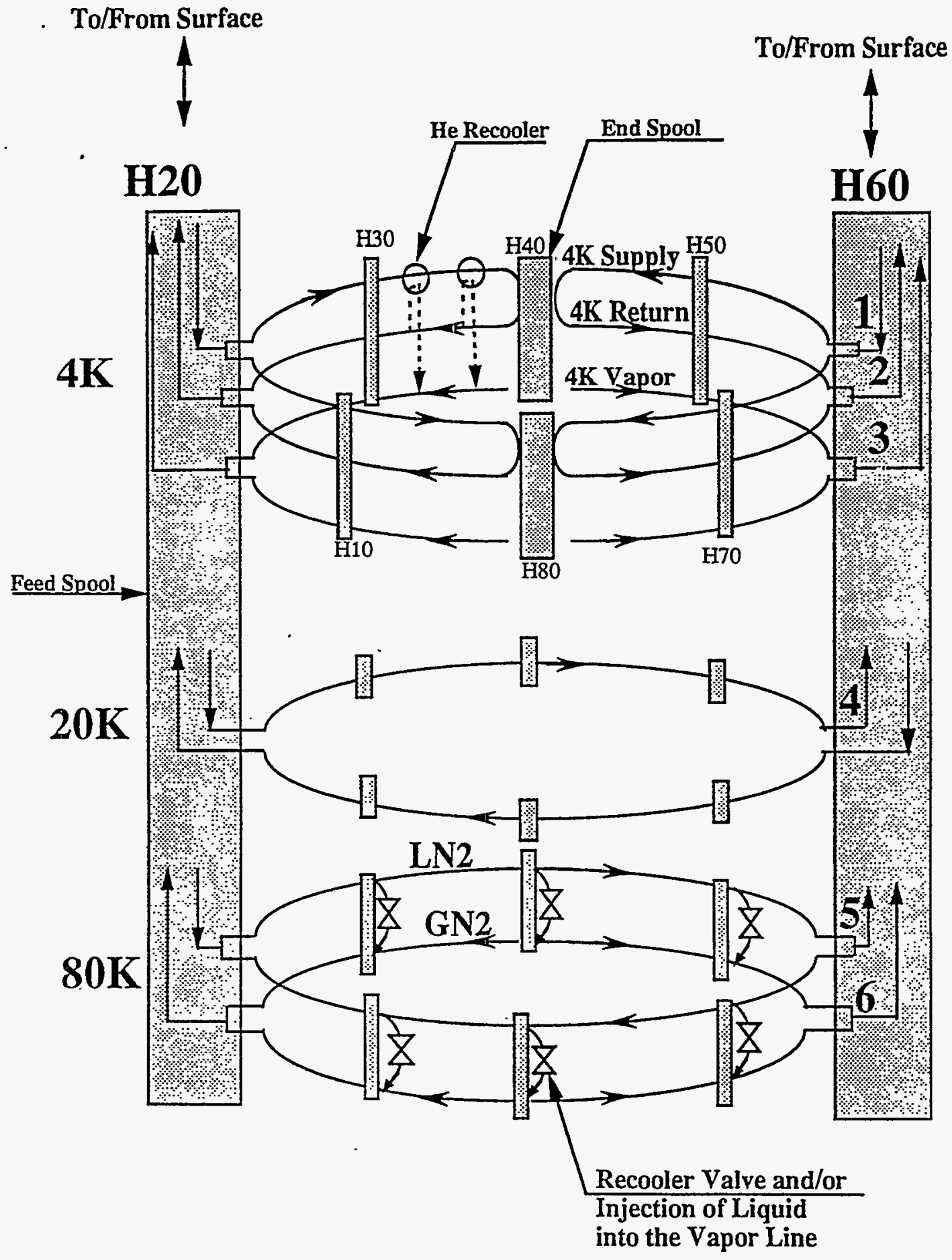

Figure 43. Flow Configurations in the HEB for Normal Operation. 
Table 13. Flow Conditions for Normal Operation.

\begin{tabular}{|c|c|c|c|c|c|c|c|c|c|}
\hline & & & \multicolumn{4}{|c|}{ TOTAL LENGTH $10800 . \mathrm{m}$. } & & & \\
\hline & & \multicolumn{4}{|c|}{ NORTH - WEST HEB $/ 25400 \mathrm{~m}$} & \multicolumn{3}{|c|}{ SOUTH -EAST HER $/ 25400 \mathrm{~m}$} & \\
\hline & & \multicolumn{2}{|c|}{ STRING1 CCW } & \multicolumn{2}{|c|}{ STRING2 CW } & \multicolumn{2}{|c|}{ STRINGI CCW } & \multicolumn{2}{|c|}{ STRING2 CW } \\
\hline & & $\mathrm{H} 8$ & $\mathrm{H} 1$ & $\mathrm{H} 2$ & $\mathrm{H3}$ & $\mathrm{H} 4$ & $\mathrm{H} 5$ & $\mathrm{H} 6$ & $\mathrm{H} 7$ \\
\hline & & $1104 \mathrm{~m}$ & $1628 \mathrm{~m}$ & $1334 \mathrm{~m}$ & $1334 \mathrm{~m}$ & $1436 \mathrm{~m}$ & $1296 \mathrm{~m}$ & $1334 \mathrm{~m}$ & $1334 \mathrm{~m}$ \\
\hline & $\mathrm{H}$ & $80 \quad \mathrm{H}$ & $10 \quad \mathrm{H}$ & $20 \quad \mathrm{H}$ & $30 \quad \mathrm{H}$ & $40 \quad \mathrm{H}$ & \begin{tabular}{|ll}
50 & $\mathrm{H}$ \\
\end{tabular} & $60 \quad \mathrm{H}$ & $70 \quad \mathrm{H} 80$ \\
\hline \multirow[t]{9}{*}{$4 \mathrm{~K}$} & SLOAD W & 175 & 260 & 205 & 205 & 230 & 205 & 205 & 205 \\
\hline & $\overline{D L O A D} \mathbf{W}$ & 725 & 1075 & 930 & 930 & 950 & 850 & 930 & 930 \\
\hline & LIQ $\mathrm{g} / \mathrm{s}$ & 4.6 & 4.6 & 4.6 & 4.6 & 4.6 & 4.6 & 4.6 & 4.6 \\
\hline & $\mathrm{P} \quad \mathrm{MPa}$ & 0.356 & 0.4 & 0.4 & 0.36 & 0.358 & 0.4 & 0.4 & 0.36 \\
\hline & $\mathrm{DP} \quad \mathrm{KPa}$ & 18 & 26 & 20 & 20 & 23 & 19 & 20 & 20 \\
\hline & $\operatorname{Tin} \mathrm{K}$ & & 4.05 & 4.05 & & & 4.05 & 4.05 & \\
\hline & $T \max \mathrm{K}$ & \multicolumn{2}{|c|}{ (Tmaxmax $=4.05+d t(c e$} & ()) $=4.22)$ & 4.05 & 4.05 & & & \multirow{2}{*}{$\frac{4.05}{100}$} \\
\hline & $M \quad g / s$ & 100 & 100 & 100 & 100 & 100 & 100 & 100 & \\
\hline & & - & $\Longrightarrow$ & & $\rightarrow$ & $E$ & $\rightarrow$ & & $\Rightarrow$ \\
\hline 4KRET & $\mathrm{P} \quad \mathrm{MPa}$ & 0.35 & & & 0.35 & 0.35 & & & 0.35 \\
\hline $45.2 \mathrm{~mm}$ & $\mathrm{Pm}$ in $\mathrm{MPa}$ & & & & & & & & \\
\hline I.D. & Tin $\mathrm{K}$ & 4.3 & & & 4.3 & 4.3 & & & 4.3 \\
\hline & $\mathrm{g} / \mathrm{s}$ & 100 & & 9 & 100 & 100 & & 9 & 100 \\
\hline & & 5 & $\exists$ & $\rightarrow-1$ & $\Rightarrow$ & b- & $\rightarrow$ & $t \rightarrow-\infty$ & $\Leftrightarrow$ \\
\hline $4 \mathrm{KV}$ & $\mathrm{Pmin} \mathrm{MPa}$ & & 83 & 83 & & & 84.5 & 84.5 & \\
\hline $110 \mathrm{~mm}$ & $\mathrm{P} \max \mathrm{MPa}$ & 85 & & & 85 & 85 & & & 85 \\
\hline & TSAT $\mathrm{K}$ & 4.005 & 4.023 & 4.023 & 4.005 & 4.005 & 4.023 & 4.023 & 4.005 \\
\hline $\mathrm{T}=4.3 \mathrm{~K}$ & \begin{tabular}{|ll}
$\mathrm{DT}$ & $\mathrm{K}$ \\
\end{tabular} & $18 \mathrm{~m}$ & & $18 \mathrm{ml}$ & & $18 \mathrm{~m}$ & & $18 \mathrm{ml}$ & \\
\hline & $\mathrm{g} / \mathrm{s}$ & 43 & 107 & 109 & 54 & 57 & 107 & 109 & 54 \\
\hline & & 5 & $\Rightarrow$ & $=$ & $\Rightarrow$ & & $\Rightarrow$ & 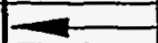 & 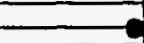 \\
\hline & to account $f$ & r bellows. be & nds and $\mathrm{U}$ & tubes: & rease press & re drop per & ector by 0. & $\mathrm{kPa}$ & \\
\hline $20 \mathrm{~K}$ & LOAD W & 1045 & 1540 & 1220 & 1220 & 1285 & 1155 & 1220 & 1220 \\
\hline $82.6 \mathrm{~mm}$ & $\begin{array}{|ll|}\mathrm{P} & \mathrm{MPa} \\
\end{array}$ & 0.225 & 0.214 & $0.25 \quad .243$ & 0.235 & 0.225 & 0.214 & $0.25 \quad .243$ & 0.235 \\
\hline I.D. & $\mathrm{K}$ & 21.9 & 24.1 & $15 \quad 172$ & 19.4 & 21.9 & 24.1 & $\begin{array}{|ll|}15 & 17.2 \\
\end{array}$ & 19.4 \\
\hline & $\mathrm{g} / \mathrm{s}$ & 100 & 100 & 100 & 100 & 100 & 100 & 100 & 100 \\
\hline & & & $\Rightarrow$ & & & & $\rightarrow$ & & $\Rightarrow$ \\
\hline $80 \mathrm{~K} \mathrm{~L}$ & LOAD W & 5950 & 8700 & 6935 & 6935 & 7680 & 6970 & 6935 & 6935 \\
\hline $57.2 \mathrm{~mm}$ & $P_{\min } \mathrm{MPa}$ & & 2.2 & & & & 2.2 & & \\
\hline I.D. & $\mathrm{T} \quad \mathrm{K}$ & & 81 & & & & 81 & & \\
\hline & $\mathrm{g} / \mathrm{s}$ & 531 & 500 & 991 & 954 & 917 & 877 & 605 & 568 \\
\hline & $\mathrm{DM} \quad \mathrm{g} / \mathrm{s}$ & 31 & 45 & 37 & 37 & 40 & 36 & 37 & 37 \\
\hline (to surface) & DMS $\mathrm{g} / \mathrm{s}$ & & 16 & & & & $220+16$ & & \\
\hline & & & $\rightarrow-1$ & & & & & & $=$ \\
\hline $80 \mathrm{~K} \mathrm{~V}$ & $\mathrm{MPa}$ & 0.17 & 0.14 & $0.14^{-}$ & 0.17 & 0.17 & 0.14 & $\sqrt{0.14}$ & 0.17 \\
\hline $57.2 \mathrm{~mm}$ & $\mathrm{~K}$ & 82.1 & 80.3 & 80.3 & 82.1 & 82.1 & 80.3 & 80.3 & 82.1 \\
\hline I.D. & $\mathrm{g} / \mathrm{s}$ & 18 & 49 & 56 & 19 & 18 & 58 & 56 & 19 \\
\hline & & & & & & & & & \\
\hline & & & $\longrightarrow$ & $\rightarrow$ & $=$ & & $\rightarrow$ & $\square$ & \\
\hline & & & & & & & & & \\
\hline & & He boiloff: & $3.0 \mathrm{~g} / \mathrm{s}$ per $\mathrm{c}$ & cell & & & & & \\
\hline & & & & & & & & & \\
\hline
\end{tabular}


Table 14. Helium Flows in Lines 1-3 for Standby and Normal Operation.

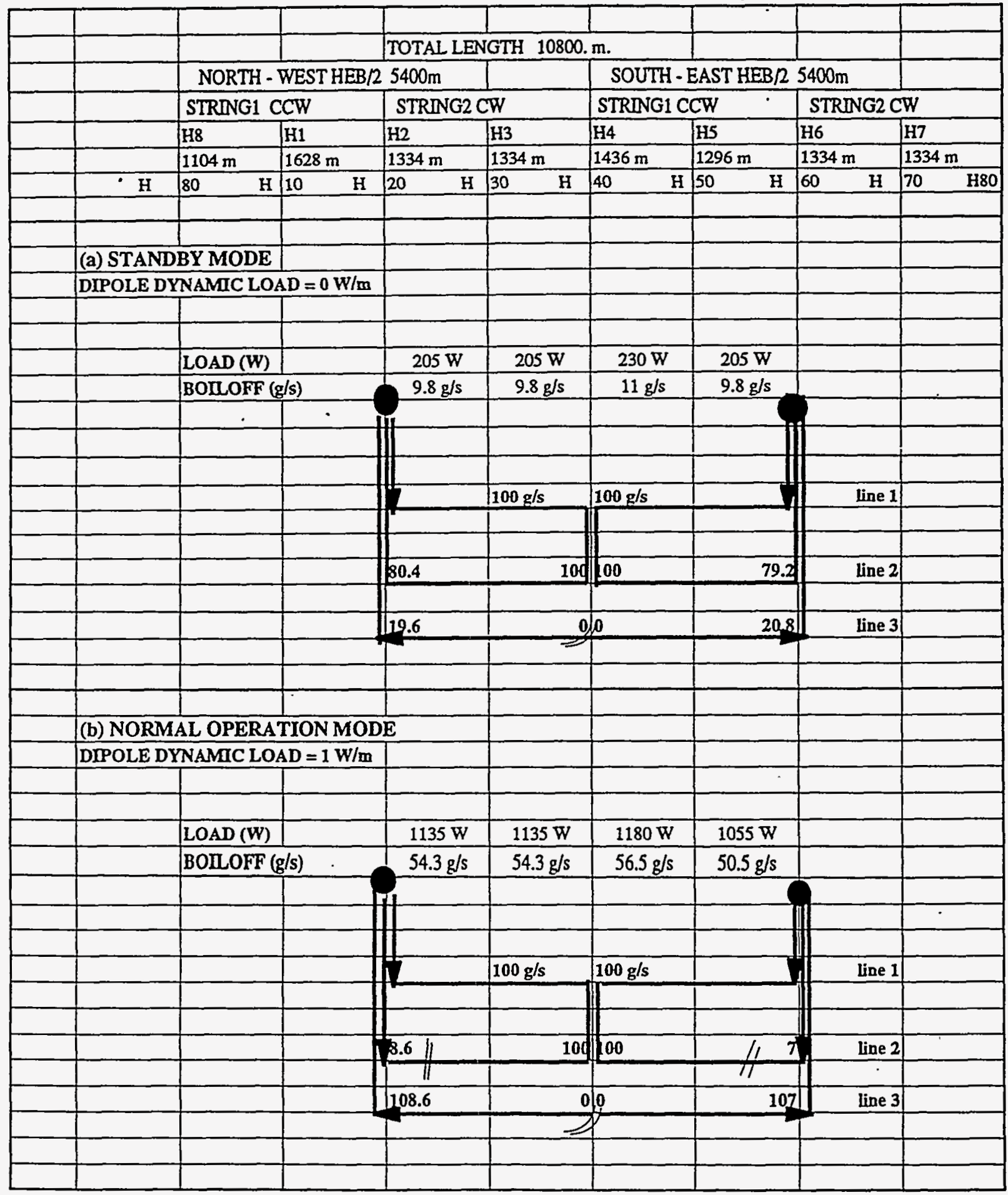




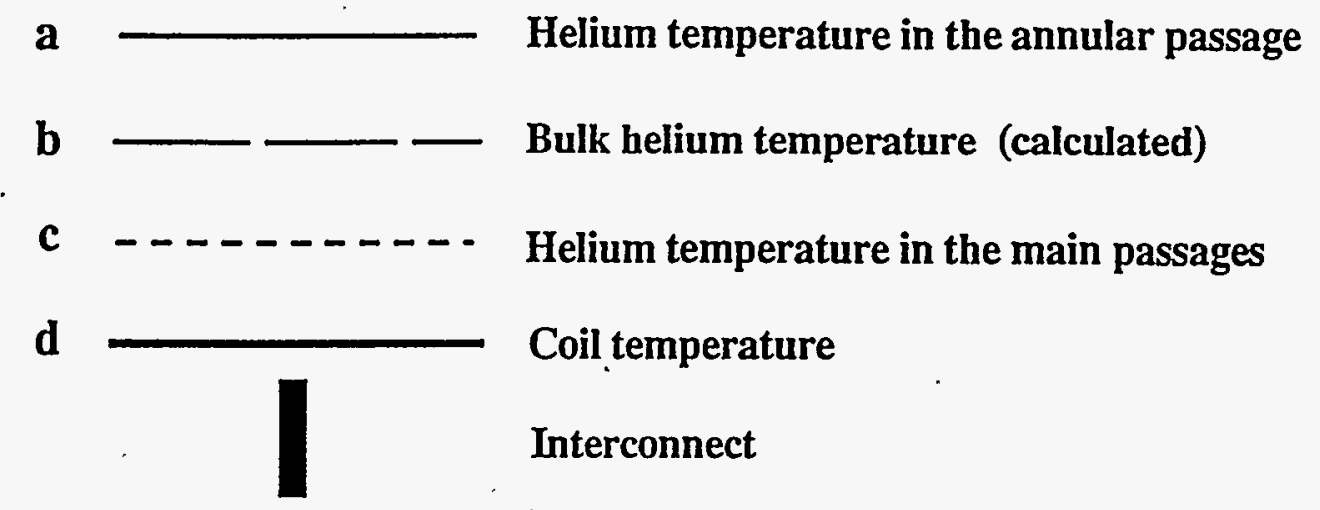

TEMPERATURES in $\mathrm{K}$ (based on cross-flow)

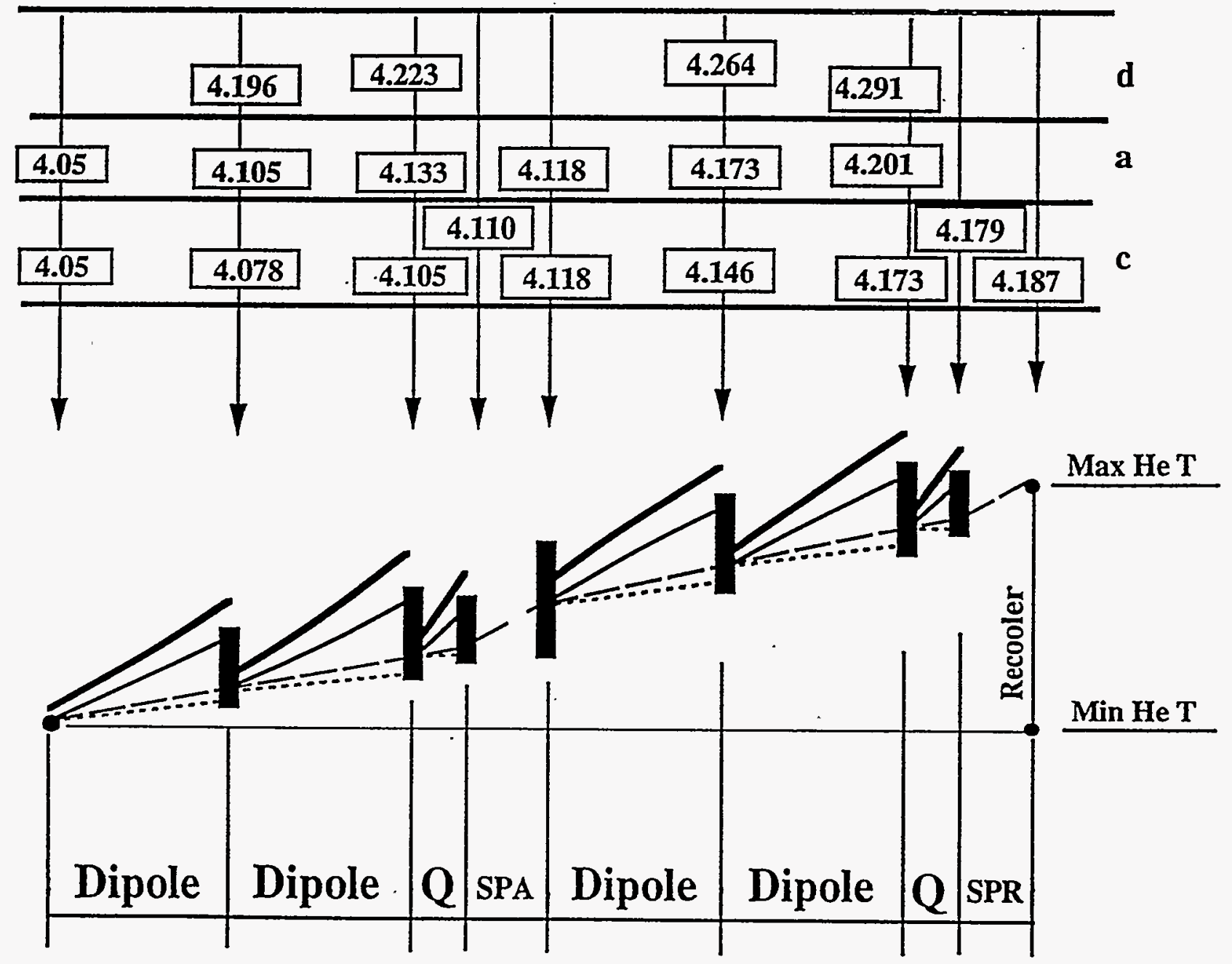

Flgure 44. Line-1 Hellum Temperature Variations over a Cell for Normal Operation. 


\section{HEB}

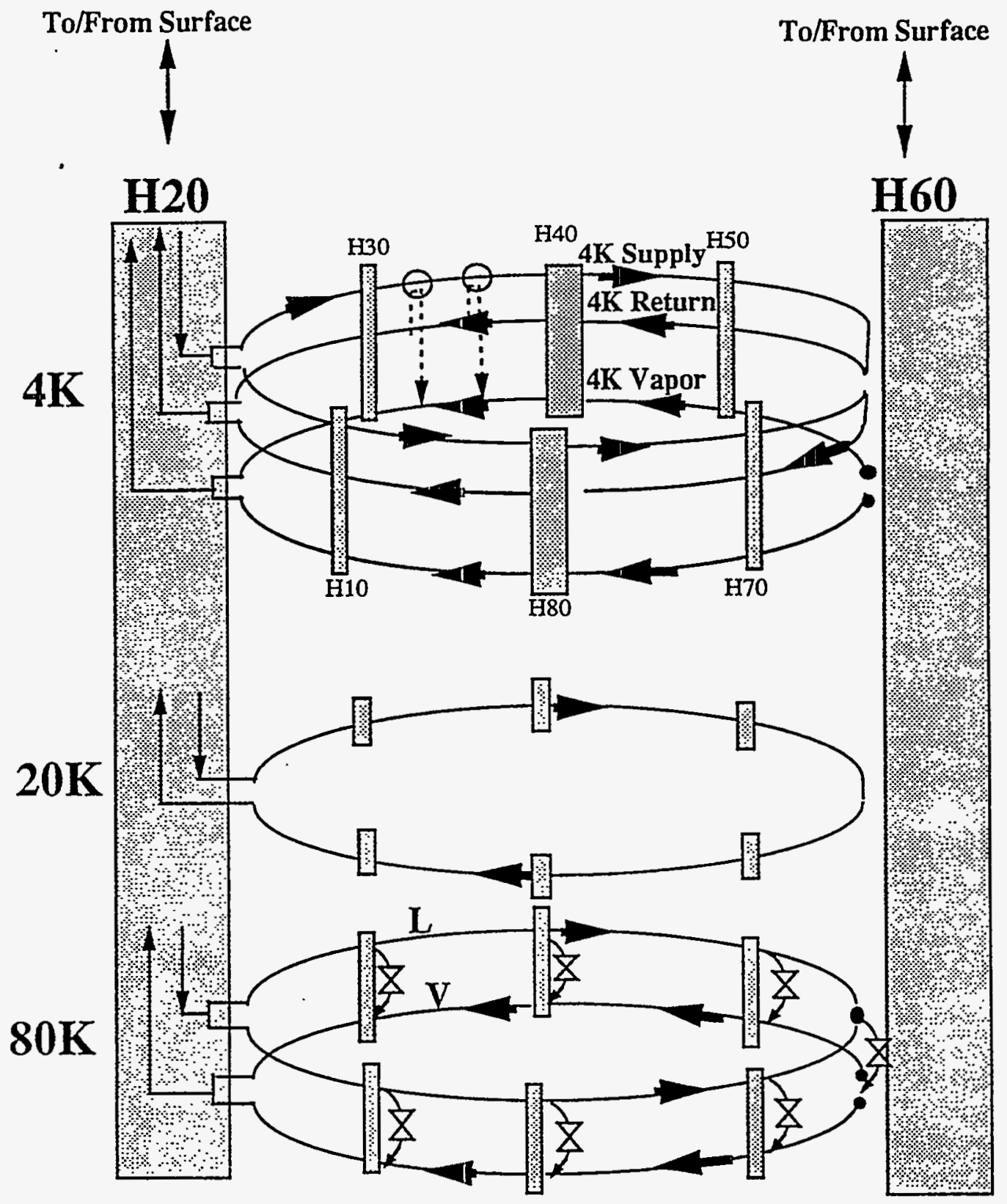

Figure 45. Flow Configurations in the HEB with H60 Plant Down. 
Table 15. Helium Flows in Lines 1-3 with H60 Plant Down.

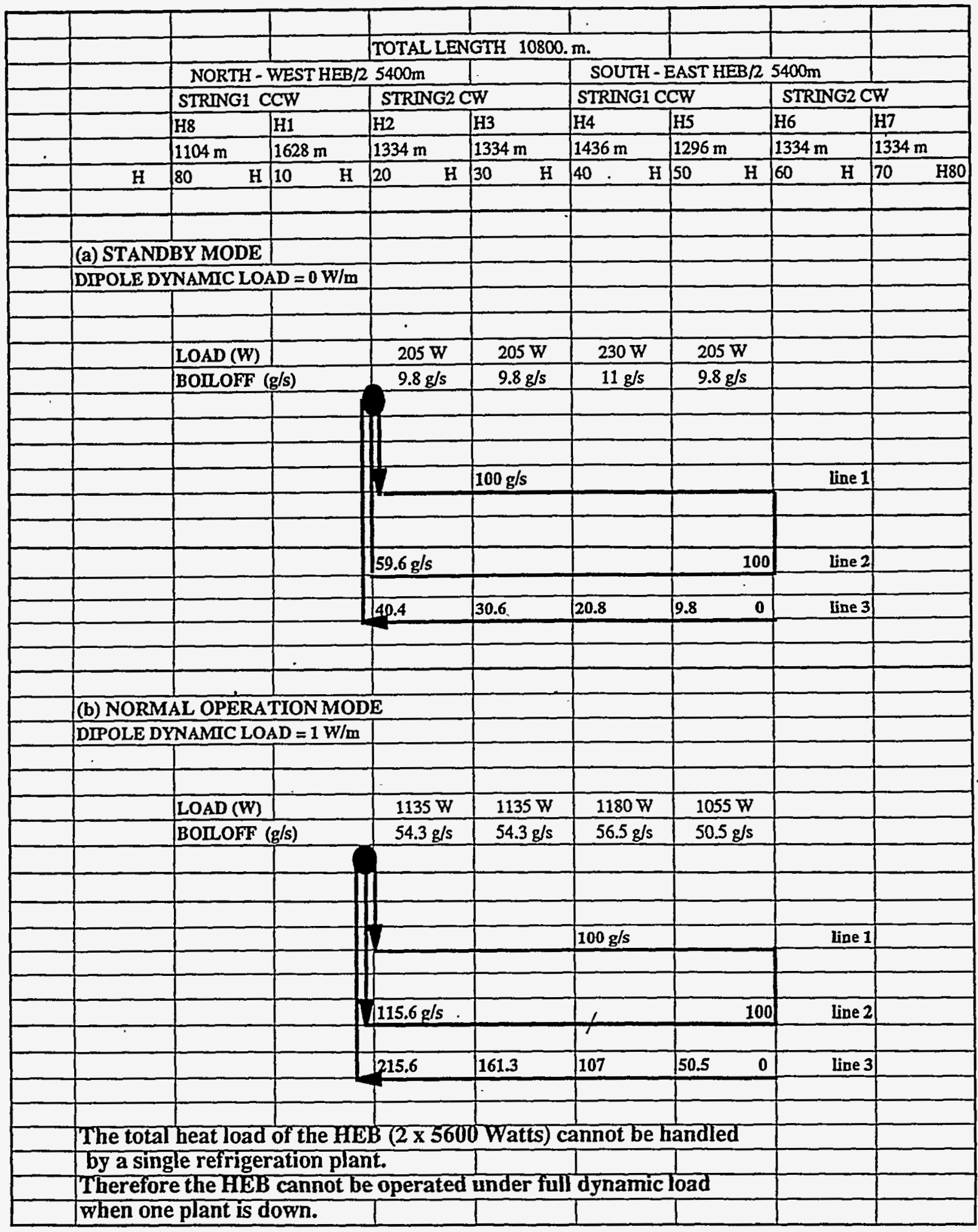




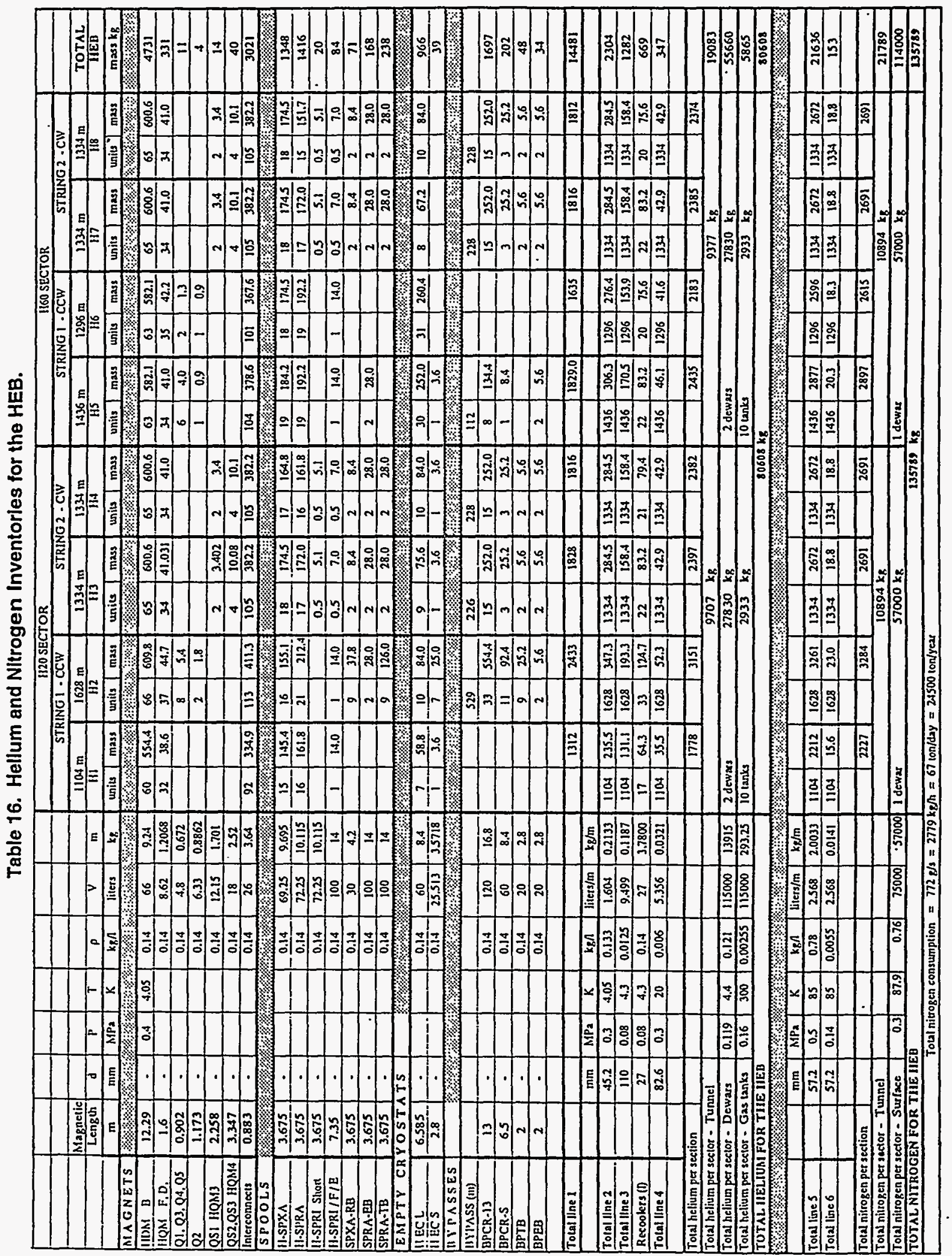


Table 17. HEB Iron and Aluminum Mass.

\begin{tabular}{|c|c|c|c|c|c|c|c|c|c|}
\hline & & & & \multicolumn{3}{|c|}{ Long section } & \multicolumn{3}{|c|}{ Short section } \\
\hline & & & & \multicolumn{2}{|c|}{1628} & $\mathrm{~m}$ & \multicolumn{2}{|c|}{1104} & \multirow{3}{*}{ 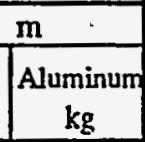 } \\
\hline & diameter & length & unit mass & \multirow{2}{*}{$\begin{array}{c}\text { Number } \\
\text { of units }\end{array}$} & \multirow{2}{*}{$\begin{array}{c}\text { Iron/SS } \\
\mathrm{kg}\end{array}$} & \multirow{2}{*}{$\begin{array}{c}\text { Aluminum } \\
\mathrm{kg}\end{array}$} & \multirow{2}{*}{$\begin{array}{l}\text { Number } \\
\text { of units }\end{array}$} & \multirow{2}{*}{$\begin{array}{c}\text { Iron/SS } \\
\mathrm{kg}\end{array}$} & \\
\hline & $\mathrm{mm}$ & $\mathbf{m}$ & $\mathrm{kg} / \mathrm{m}$ & & & & & & \\
\hline MAGNETS & \%:\% & 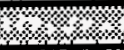 & ২ ২ & 28. & 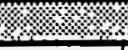 & 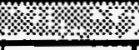 & 2.8 & $4.2 . \%$ & $\$$ \\
\hline HDM B & & 12.29 & 650 & 66 & 527241 & & 60 & 479310 & \\
\hline $\mathrm{HQM}$ F,D & & 1.6 & $650^{\circ}$ & 37 & 38480 & & 32 & 33280 & \\
\hline $\mathrm{Q} 1, \mathrm{Q3}, \mathrm{Q} 4, \mathrm{Q5}$ & & 0.902 & 650 & 8 & 4690 & & & & \\
\hline Q2 & & 1.173 & 650 & 2 & 1525 & & & & \\
\hline QS1 $\mathrm{HQM3}$ & & 2.258 & 650 & & & & & & \\
\hline QS2, QS3 HQM4 & & 3.347 & 650 & & & & & & \\
\hline Interconnect & & 0.883 & 50 & 113 & 4989 & & 92 & 4600 & \\
\hline SPOOLS & \%, & ২ে. & ঋ & ো. & \% & 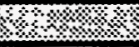 & \% & (4) & 10 \\
\hline H-SPXA & & 3.675 & 300 & 16 & 17640 & & 15 & 16538 & \\
\hline H-SPRA & & 3.675 & 300 & 21 & 23153 & & 16 & 17640 & \\
\hline H-SPRI Short & & 3.675 & 300 & & & & & & \\
\hline H-SPRI/F/E & & 7.35 & 300 & 1 & 2205 & & 1 & 2205 & \\
\hline SPXA-RB & & 3.675 & 300 & 9 & 9923 & & & & \\
\hline SPRA-EB & & 3.675 & 300 & 2 & 2205 & & & & \\
\hline SPRA-TB & & 3.675 & 300 & 9 & 9923 & & & & \\
\hline EMPTY CRYOSTATS & ২\% & 1. & \% & 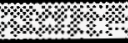 & 筙 & \% ४ : & 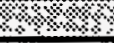 & \% & 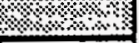 \\
\hline $\mathrm{HECL}$ & & 6.585 & 33 & 10 & 2173 & & 7 & 1521 & \\
\hline HEC S & & 2.8 & 33 & 7 & 647 & & 1 & 92 & \\
\hline BY PASSES & \% & & 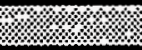 & স্যো & (minem & & & & \\
\hline BYPASS (m) & & & & $529 \mathrm{~m}$ & & & & & \\
\hline BPCR-13 & & 13 & 33 & 33 & 14157 & & & & \\
\hline BPCR-S & & 6.5 & 33 & 11 & 2360 & & & & \\
\hline BPTB & & 2 & 100 & 9 & 1800 & & & & \\
\hline BPEB & & 2 & 100 & 2 & 400 & & & & \\
\hline Tatol lino 2 (coccombly-2*) & & & & $1600 \mathrm{~m}$ & 5170 & & 1104 & 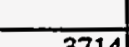 & \\
\hline & 43.21 & & 3.36 & $1628 \mathrm{~m}$ & 13327 & & $1104 m$ & $\frac{3114}{0.37}$ & \\
\hline Total line 3 (+assembly=2*) & 110 & & 8.19 & $1028 \mathrm{~m}$ & 13321 & & & 9020 & \\
\hline COLD MASS / S & ICTION & (tons) & & & 682 & & & 568 & \\
\hline Total line 4 (+assembly $\left.=2^{*}\right)$ & 82.6 & & 6.15 & $1628 \mathrm{~m}$ & 10007 & & $1104 \mathrm{~m}$ & 6786 & - \\
\hline $20 \mathrm{~K}$ shield & 600 & & 10.17 & $1628 \mathrm{~m}$ & & 16563 & $1104 \mathrm{~m}$ & & 11232 \\
\hline Total $20 \mathrm{~K}$ SHIELD / S & CTION & (tons) & & & 10.0 & 16.6 & & 6.8 & 11.2 \\
\hline Total line 5 (+assembly $\left.=2^{*}\right)$ & 57.2 & & 4.26 & $1628 \mathrm{~m}$ & 6930 & & $1104 \mathrm{~m}$ & 4699 & \\
\hline Total line $6\left(+\right.$ assembly $\left.=2^{*}\right)$ & 57.2 & & 4.26 & $1628 \mathrm{~m}$ & 6930 & & $1104 \mathrm{~m}$ & .4699 & \\
\hline $80 \mathrm{~K}$ shield & 650 & & 11.02 & $1628 \mathrm{~m}$ & & 17943 & $1104 \mathrm{~m}$ & & 12168 \\
\hline Total 80 K SHAELD / S & CTION & (tons) & & & 13.9 & 17.9 & & 9.4 & 12.2 \\
\hline
\end{tabular}




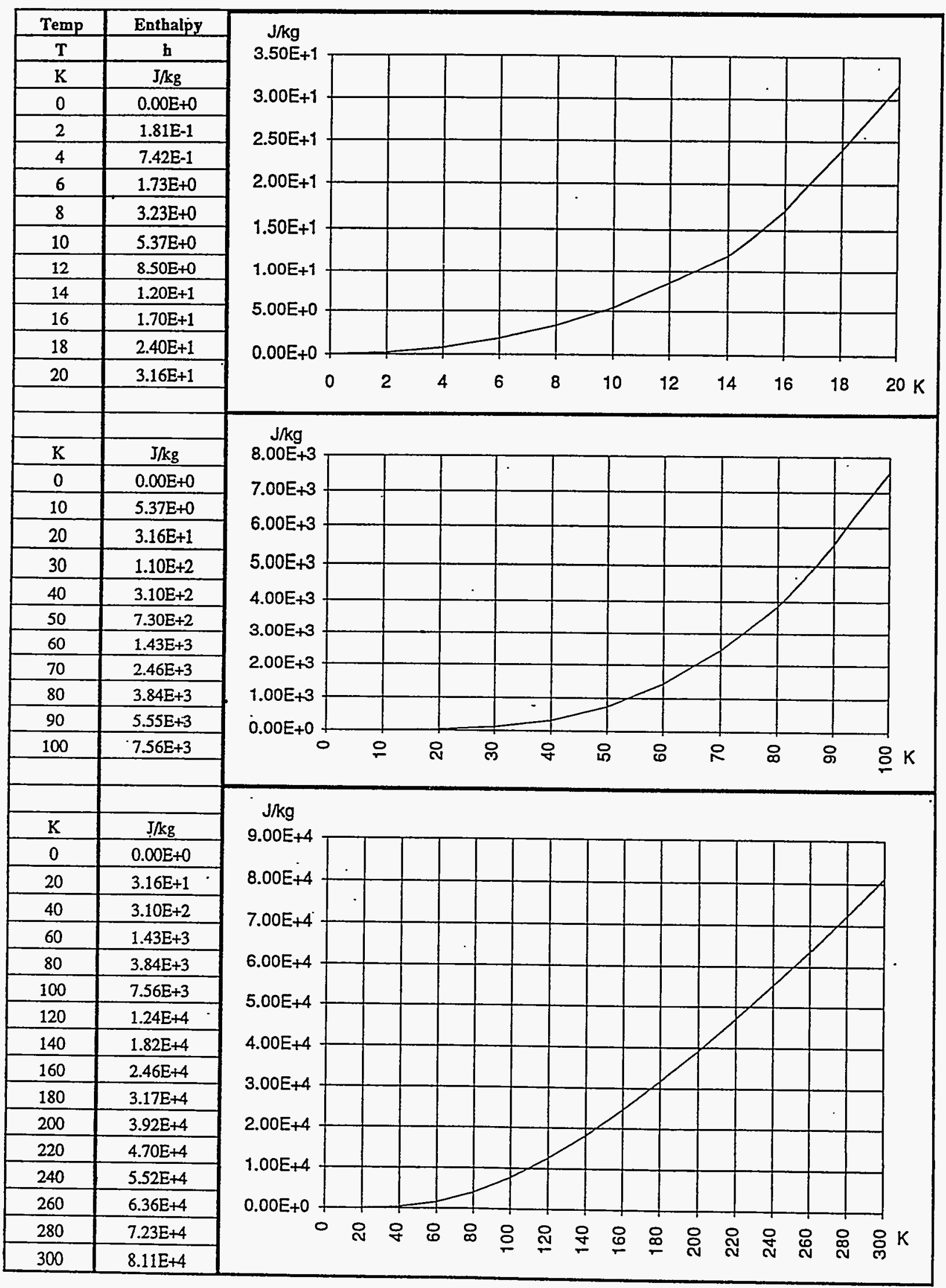

Figure 46. Iron Enthalpy as a Function of Temperature. 


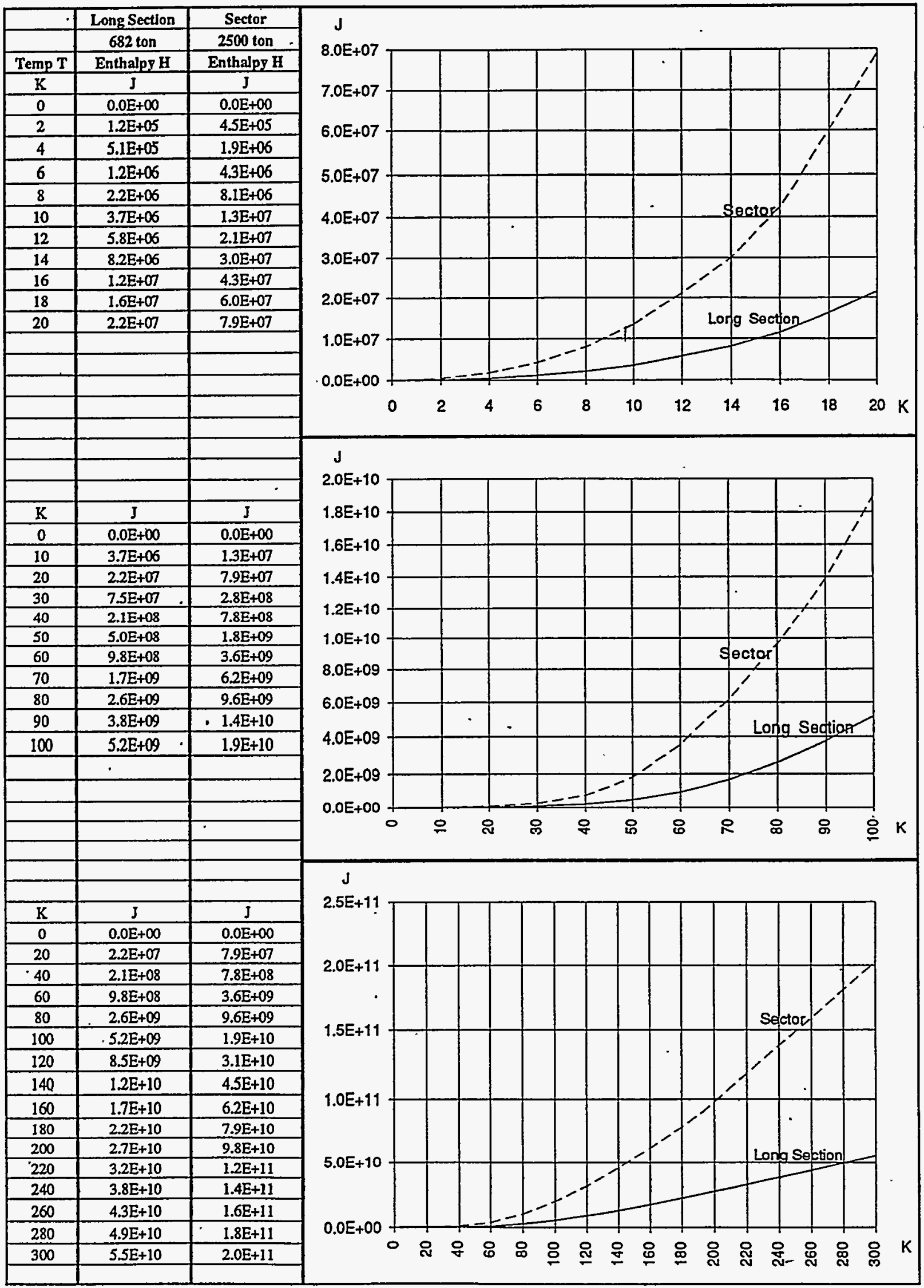

Figure 47. Coldmass Enthalpy for a Long Section and a Fuli Sector. 


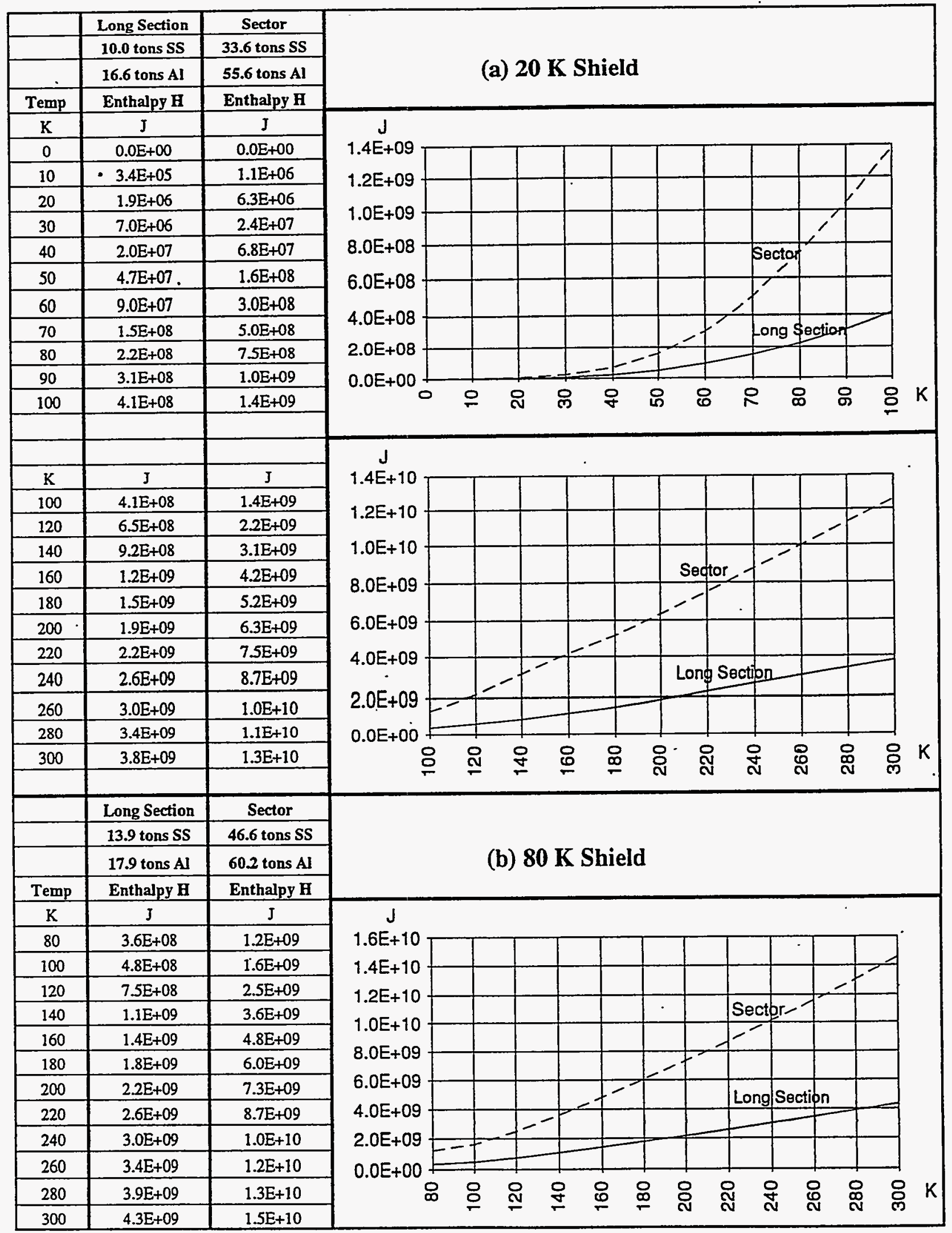

Figure 48. Shield Enthalpy vs. Temperature: (a) 20-K Shield, (b) 80-K Shield. 


\subsection{PROCESS DESCRIPTIONS}

\subsection{Operating Modes of the Refrigeration Plant}

The modes of operation for the HEB cryogenic system are defined by different states. Such states are determined by steady state temperatures, pressures, flows, or other measured parameters, and by processes, which are the required transients to change the conditions of the system to a new status. Figure 49 shows the logic diagram for the states and processes corresponding to the different operational modes of the refrigeration plants. Table 18 presents the helium and nitrogen inventories for the various states of the system, together with brief descriptions of the processes.

The two refrigeration plants for the HEB are identical in design and capacity to those for the collider. However, there are differences in the loads for each plant because of variations in sector design. The plants are designed to handle a range of capacities, including standby load, when the beam is not active; nominal load, when the beam is active; assist load, when a neighboring plant needs assistance; upset loads, in particular for quench recovery; and loads during cooldown, warm-up, and maintenance. The plants are also designed to operate in a minimum capacity mode. For the different situations mentioned above the refrigeration plant operates in different modes, defined below:

- The plant is operated in the Normal Mode when the system is at full normal operation. This means the system is cold and the beam is on. In this mode the load on the refrigeration plant may vary according to the beam intensity.

- The plant is operated in the Standby Mode when the system is cold with no beam operating, and there is no current in the magnets. In this mode, the load on the refrigeration plant depends on the static heat load.

- The plant is operated in the Assist Mode when part of its capacity needs to be transferred to a neighboring plant. In this mode, capacity is transferred by shifting cryogens through sector boundaries.

- The plant is operated in the Quench Recovery Mode after a quench is detected in a string.

- The plant is operated in one of the Utility Modes during cleanup, cooldown, warm-up, and maintenance.

- The plant is operated in the Minimum Capacity Mode when the sector heat loads are low for long-term cold storage of the ring.

\section{$5.2 \quad$ Normal Operation Schemes}

\subsubsection{Normal Mode-Nominal Load}

This is the nominal heat load expected when the beam is on and at full power. This load will vary slightly from one sector to another because of the difference in the design of the sectors. The normal operation of the HEB will be 2-3 h per day. During the remaining time the HEB will be idle, in the "standby cold" status. The HEB has a very high dynamic load compared to the collider load. Because there is only one ring in the HEB, the $20-\mathrm{K}$ shield line has to be routed in a different way compared to the collider. The $20-\mathrm{K}$ shield route starts at one plant and ends in the other. If inventory accumulates in one plant, the 20-K supply flows can be temporarily adjusted to return the excess inventory; otherwise, inventory can be exchanged through the warm return header. Helium from the dewar will be used during the normal operation, if necessary, and the dewar will be refilled when the system is in standby status.

If a quench occurs in one sector, the proton beam is dumped and the refrigeration system in this specific sector goes into quench recovery mode. The currents in the magnets of the other sector are ramped down to zero; its refrigerator is turned down from normal mode to standby mode during recovery in the quenched sector.

The flow conditions for normal mode of operation are given in Tables 13 and 14. The corresponding 4- $\mathrm{K}$ flow configuration is given in Figure 50. The $20-\mathrm{K}$ flow, the $80-\mathrm{K}$ flow, and the lead-cooling flow configurations are shown in Figures 51-53, respectively. 


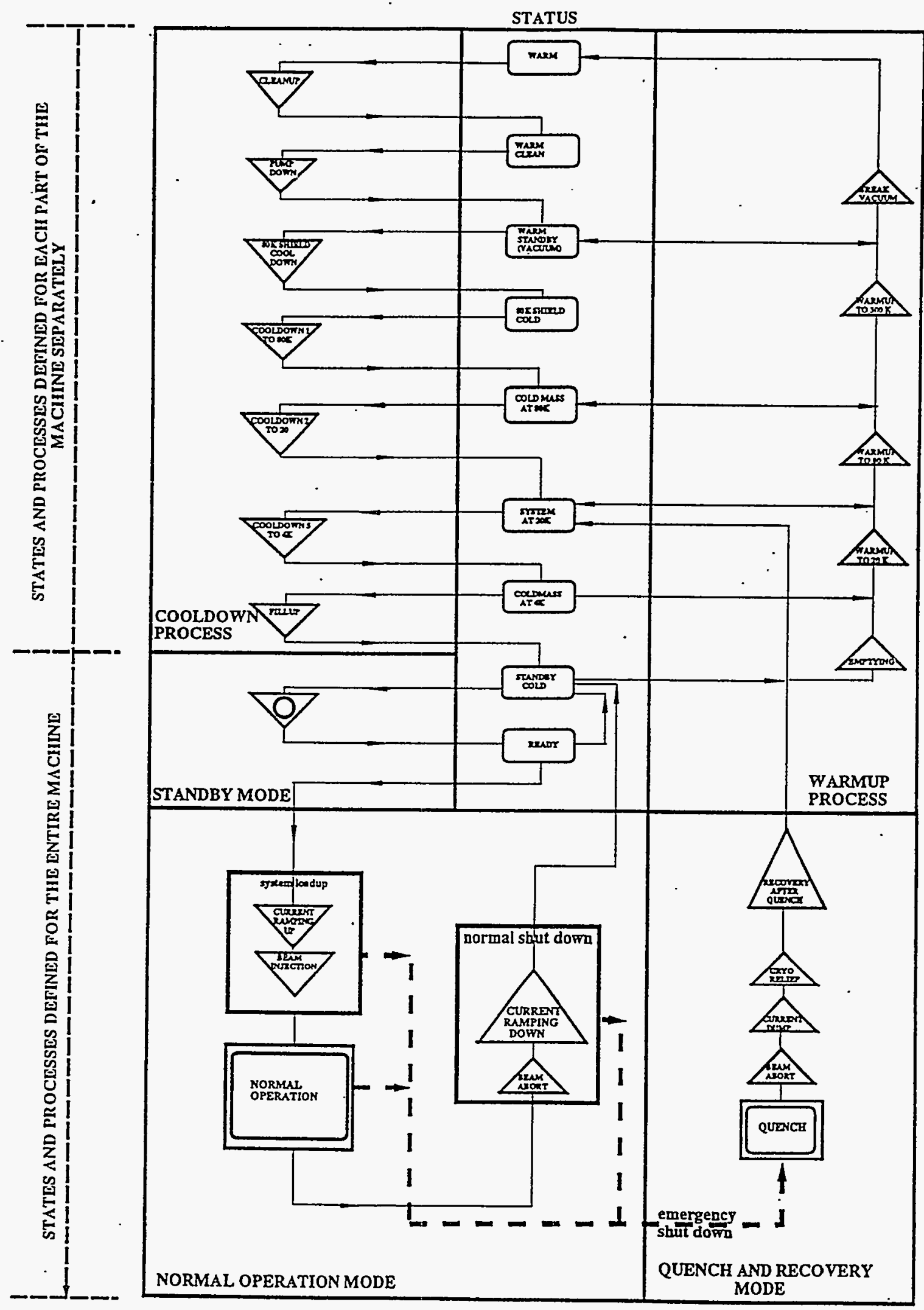

Figure 49. State and Process Diagram for the HEB Cryogenic System. 
Table 18. Helium and Nitrogen Inventories for Various States of the HEB Cryogenic System.

\begin{tabular}{|c|c|c|c|c|c|c|c|c|c|c|c|c|c|}
\hline \multirow{9}{*}{1} & & & & & & & \multicolumn{3}{|c|}{ SECTOR TREATMENT } & \multirow[b]{2}{*}{ COLDMUSS } & & & \\
\hline & & & & CLEANUP & WARM & 10 K SHED & $20 \mathrm{KSH}$ SHe & COLDMUSS & COLDMASS & & \multicolumn{3}{|c|}{ NORMAL OPERATION } \\
\hline & & & & $300 \mathrm{~K}$ & STANDBY & COLD & AT BOK & AT $80 K$ & AT $20 \mathrm{~K}$ & ATSK & & $4 x$ & \\
\hline & & & & $0.3 \mathrm{MPa}$ & $0.2 \mathrm{MPa}$ & & $03 \mathrm{MPa}$ & $0.3 \mathrm{MP}$ & $0.3 \mathrm{MP}$ & $0.3 \mathrm{MPa}$ & & $0.4 \mathrm{MO}_{\mathrm{z}}$ & \\
\hline & & & & Hedeativy, ken & HE dxperity, ken & LNdkariy,kgn & HE dasily, kgn & He deariy, xML & HE \&asity, kel & He deaciry, Kal & \multicolumn{3}{|c|}{ Hedeaciry,kyn } \\
\hline & LONO & & & 0.0004808 & 0.00032 & \begin{tabular}{|l|}
0.78 \\
\end{tabular} & 0.001714 & 0.001714 & 0.006 & 0.1175 & & 0.14 & \\
\hline & SECTION & STRMNO & SECTOR & TOTAL & SECTOR & SECTROR & SECTOR & SECTOR & SECTOR & SECTOR & LONG & STRING & SECTOR \\
\hline & \multirow{2}{*}{\multicolumn{3}{|c|}{$\begin{array}{l}\text { VOLUME } \\
\text { LTIESS }\end{array}$}} & Muss Fow & Muss & MASS & Muss & MASS & Muss & Mass & SECTION & MNSS & Muss \\
\hline & & & & $1 x$ & $k_{k}$ & $k_{x}$ & 38 & se & 8 & $k$ & $3 x$ & $k_{8}$ & $\mathrm{~kg}$ \\
\hline LANE I \& KHE FEPD & 17379 & 20750 & $\sin 9$ & 76 & 17 & 17 & 17 & 90 & 317 & 6201 & 2433 & 3745 & 7319 \\
\hline LNRE 24 KLKE RETURN & 2011 & 4362 & 2562 & 12 & 3 & 3 & 3 & 13 & 52 & 1018 & 347 & 383 & 1132 \\
\hline LINE3 4 X GHe RETURN & 15454 & 25951 & 51295 & 74 & 16 & 16 & 16 & 8 & 300 & 615 & 193 & 324 & 611 \\
\hline RECOOLLERS & 91 & 1350 & 2538 & 4 & 1 & 1 & 1 & 4 & 15 & 30 & 125 & 189 & 33s \\
\hline LnNE $420 \mathrm{~K}$ & 8720 & 14633 & 28922 & 42 & 9 & 9 & so & so & 174 & 174 & 52 & 88 & 174 \\
\hline UNRS LN2 & 4111 & 7016 & 13267 & 150 & 33 & 10816 & 10816 & 10816 & 10816 & 10816 & 3261 & 5472 & $10+16$ \\
\hline LINE6 ON2 & 4181 & 7016 & 13867 & 150 & 33 & 76 & 76 & 76 & 76 & 76 & .23 & 39 & 76 \\
\hline & & & & & & & & & & & & & \\
\hline & & & & & & & & & & & & & \\
\hline CLEANUP & & & & $->$ & & & & & & & & & \\
\hline Required: Circulation of & Ary clean 8 & as at 3001 & L through & he whole systef & II. Total $=5 \mathrm{i}$ & es the volume 0 & of the system. $N$ & Maximum allow & & a. Expected 4 & ime 2 hour & & \\
\hline Fanal conditions: $300 \mathrm{~K}$, & $0.1 M_{2,5}$ & ystem is $f$ & ull with pu & re dy gas (helit & um in the heliun & n system and nit & trogen in the nit & (rogen system). & & & & & \\
\hline Total amoun of helium 1 & bepurifie & $\mathrm{d}: 500 \mathrm{~kg}$ & & & & & & & & & & & \\
\hline PUMPDOWN & & & & & $\Leftrightarrow$ & & & & & & & & \\
\hline Puinpdown of $5 \mathrm{Akm}-10 \mathrm{n}$ & $8 \operatorname{sector}(6$ & 4 cells. 65 & meach + & bypasses and is & olated cyostats & $19.5 \mathrm{~m}^{3} \mathrm{pera}$ & & & & & & & \\
\hline Final pressure: 1.3E-2Pa & - Expected & 1 time: $8 \mathrm{bc}$ & ours per ce & 11, including $\mathrm{ka}$ & checking. & & & & & & & & \\
\hline & & & & & & & & & & & & & \\
\hline COOLDOWN $80 \mathrm{~K}$ SIII & IELD FRO & $5 \mathrm{M} 300 \mathrm{~K}$ & TO $80 \mathrm{~K}$ & & 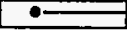 & $\Rightarrow$ & & & & & & & \\
\hline Cooldand of 46.6 lons of & steel and & $50.21000^{\circ}$ & f aluminus & 1. Toual of 1.38 & Eloj loberem & oved from the ss & hicld. LN2 con & nsumption for co & oldown: 35 ton & 15. Iritial now t: & Iteper st & ing: $20 \mathrm{~g} / \mathrm{s}$ & $\max$. \\
\hline Expected time: 7 days (at & 2n average & now or 6 & $08 / s) .80$ & KLN2 which is & warmed up to & $300 \mathrm{~K}$ during co & oldown is vente & & here. & & & & \\
\hline Inventory of LN2 in the b & ines increas & ses from & $33+33) \mathrm{kg}$ & $10(108,16+76) 1$ & & & & & & & & & \\
\hline COOLDOWN $20 \mathrm{~K} \mathrm{SH}$ & IELD FRO & $\mathrm{M300K}$ & TO $80 \mathrm{~K}$ & & & & $\Rightarrow$ & & & & & & \\
\hline Cooldown of 33.6 lons of & stoel and S & 55.6 tons 0 & faluminer & n. Total of $t .25$ & Elos loberem & ved from the s: & hield. Helium & consumplion for & 8 cooldown $(80$ & K helium wan & dup to 3i & $(0, \mathrm{~K}): 35$ & ions. \\
\hline Inidal now rale per string & $20 \mathrm{~g} / \mathrm{s} \mathrm{ma}$ & aximun. & Expectedt & ime: 2 days (at: & an average now & of $60 \mathrm{~g} / \mathrm{s})$ & & & & & & & \\
\hline & & & & & & & & & & - & & & \\
\hline COLDMUSS COOLDO & WNFRO & $\mathrm{M} 300 \mathrm{~K}$ & TO80K & & & & 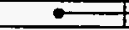 & $\Rightarrow$ & & & & & \\
\hline Cooldoonn of 2700 lons of & firon: Tou & Iof 1.9E1 & IJ tober & moved from its & ecold mass. $\mathrm{H}$ & econsumplion $\mathrm{f}$ & for cooldown (8) & $30 \mathrm{Khelium} \mathrm{w}$ & med up 10300 & K): 166 tons. & & & \\
\hline Avera ge now rale per stif & $\mathrm{ng}: 100 \mathrm{~g} / \mathrm{s}$ & Expecte & d time: 10 & days. Increase ? & he He invenias & $y$ in the system ! & from $86 \mathrm{~kg} 102$ & $47 \mathrm{~kg}$. & & & & & \\
\hline Nitrogen consumpeion in & the SRS fo & the coldr & nass coold & own: 475 lons. & & & & & & & & & \\
\hline COLDMASS COOLDO & WN FRO & $\mathrm{M} 80 \mathrm{KT}$ & $020 \mathrm{~K}$ & & & & & 10 & $\Rightarrow$ & & & & \\
\hline Cooldown of 2700 tons of & firon: Tola & 1069.669 & Jto be rer & noved from the & cold mass. He & consumption for & cooldown 30. & 5 tons of $20 \mathrm{KH}$ & de. $20 \mathrm{Kh}$ helium & ineturns to the t: & Efrigeralo & $180 \mathrm{~K}$. & \\
\hline at an average flow rate pe & 8 string: 70 & g/s. Exp & ected time & 60 bours. Ingere & ease the He inve & nlory in the sys & $\operatorname{lem}$ from $247 \mathrm{x}$ & $\mathrm{kg} 10865 \mathrm{~kg}$ & & & & & \\
\hline & & & & & & & & & & & & & \\
\hline COLDMASS COOLDO & WNFROI & $\mathrm{M} 20 \mathrm{KT}$ & $045 \mathrm{~K}$ & & & & & & 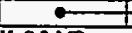 & & & & \\
\hline Cooldown of 2700 tons of & Iron: Toa & $1017.7 \mathrm{E}$ & Jloberes & noved from the & cold mass. He & consumption fo & 1 cooldown: 75 & $55 \mathrm{~kg}$ or $\mathrm{keal} 4 \mathrm{l}$ & K.0.3 MPP w/2 & ned up $1020 \mathrm{~K}$ & & & \\
\hline It an average now rate per & string: 10 & $0 \mathrm{~g} / \mathrm{s} . \mathrm{Ex}$ & ected tim & $10-12$ hours. & ncrease the He & inventory in the & cold mass from & $\mathrm{m} 865 \mathrm{~kg} 108038$ & $8 \times \mathrm{K}(\mathrm{al} 5 \mathrm{~K})$ & & & & \\
\hline & & & & & & & & & & & & & \\
\hline FILLUP & & & & & & & & & & $\because-$ & & & $\rightarrow$ \\
\hline Activalion of recooker km & perature a & ontsol loog & $295 \mathrm{Kg}$ & LHe transferrec & d to fill the reco & okers: increase U & he He inventory & $y$ in the system & from $8038 \mathrm{~kg} 10$ & $09711 \mathrm{~kg}$. & & & \\
\hline Final Conditions: System & in "Standb & $y / R \in 2 d y^{-}$ & Status. & & & & & & & & & & \\
\hline & & & & & & & & & & & & & \\
\hline STANDBY COLD & & & & & & & & & & & & & \\
\hline The system is cold and rea & dy for bea & $m$ injectio & - The he: & It load is static & only. $4 \mathrm{~K}$ heliur & is supplied 2 & gh line I al 2 & $2(x)$ g/s per secto & x. Line 2 serves & for 4 KLHe rel & & & \\
\hline Expecled vapor felum pet & sector 41 & & & & & & & & & & & & \\
\hline & & & & & & & & & & & & & \\
\hline NORMAL OPERATION & & & & & & & & & & & & & \\
\hline The system is cold and the & beam is o & D. The be: & loas is st & atic plus dynam & ic. $4 \mathrm{~K}$ helium & is supplied thre & ch lixe 1 at 20 & $0 \mathrm{~g} / \mathrm{s}$ per sector. & Additional I & d/s is supplied & hrough if & & \\
\hline Expecled vapor relum per & $\sec 10216$ & g/s. & & & & & & & & & & & \\
\hline & & & & & & & & & & & & & \\
\hline QUENCH & & & & & & & & & & & & & \\
\hline The expected amount of er & nergy relea & sed when & cell is & nelied is $5 \mathrm{MJ}$ & During the firs & $\frac{30 \text { seconds } 1 / 3}{\text { nlory will be red }}$ & 3 of this energ & is transferred & the helium & 1. The he & $\operatorname{lin} 0$ & ench & \\
\hline $\begin{array}{l}\text { wamed } 1020 \mathrm{~K} \text { and press } \\
\text { the He inventory the quen }\end{array}$ & $\frac{\text { unized lo } 2}{\text { ch valve cl }}$ & $\frac{\text { maximum }}{\text { oses, andt }}$ & $\frac{0.12 \mathrm{~N}}{\mathrm{he} 4 \mathrm{~K} \text { an }}$ & & $\begin{array}{l}\text { id that the inver } \\
\text { reestablished. }\end{array}$ & nlory will be red & Uuced liom $90 \mathrm{~K}$ & $\frac{\text { Kg per cell to } 20}{\text { in the system bac }}$ & $\frac{K_{8} \text { in the first }}{\operatorname{ck} 104 \hat{K} \text { and }}$ & Oseconds. Final & $\frac{\text { al condt }}{3 \text { loper }}$ & s: afte & oops. \\
\hline EMPTYING & & & & & & & & & & & & & \\
\hline Indial conditions: Standby & Id. The & pying & process is & performed for & whole string. 2 & $20 \mathrm{~K}$ helium is $\mathrm{p}$ & oumped inlo line & $x+1$ through 2 qu & ueneh valve an & the $4 \mathrm{~K}$ helium & is forced & back & \\
\hline 10 the dewar on the surface & & & & & & & & & & & & & \\
\hline & & & & & & & & & & & & & \\
\hline \begin{tabular}{|l|} 
WARMUP \\
\end{tabular} & & & & & $\frac{1}{10300 \mathrm{Kareps}}$ & frormed in $\frac{1}{1}$ & & & & & & & \\
\hline Warmup processes from 4 & $\mathrm{~K} 1020 \mathrm{~K}$ & from 20 & $\mathrm{~K} 1080 \mathrm{~K}$ & and from $80 \mathrm{~K}$ & to $300 \mathrm{~K}$ are $\mathrm{pe}$ & erformed individ & dually for eachs & section. & & & & & \\
\hline & & & & & & & & & & & & & \\
\hline & & & & & & & & & & & & & \\
\hline \begin{tabular}{|l|} 
GAS DESORPTION \\
Gas desorpdion involves en \\
\end{tabular} & mplying an & dwamup & of the stri & nes from $4 \mathrm{~K} 10$ & $20 \mathrm{~K}$. Wamup & p to above $20 \mathrm{~K}$ & may also be ne & ecessary. & & & & & \\
\hline & & & & & & & & & & & & & \\
\hline & & & & & & & & & & & & & \\
\hline
\end{tabular}




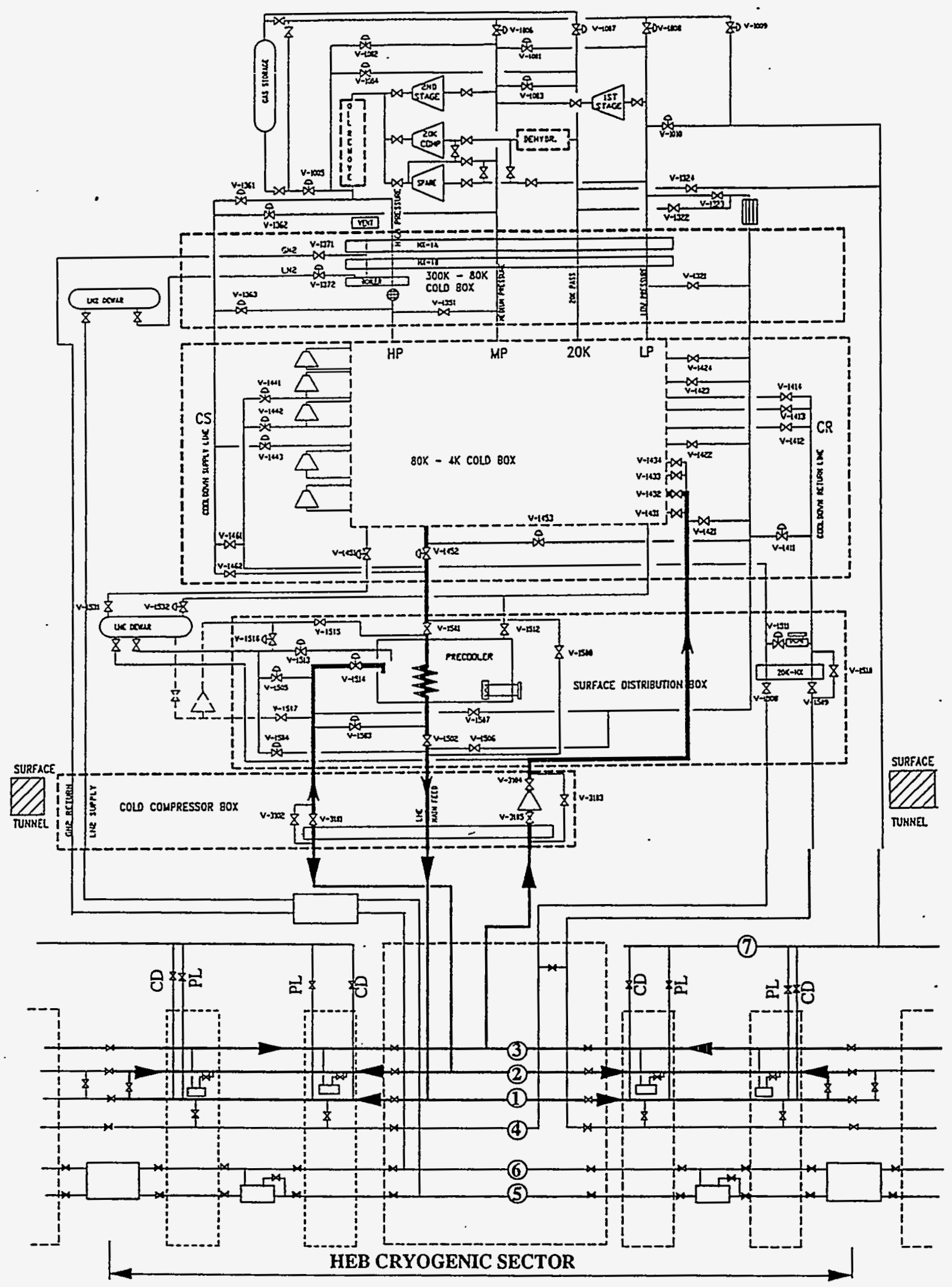

Figure 50. HEB Cryogenic System-Normal Operation 4-K Helium Supply through Line 1 and Line 2. 


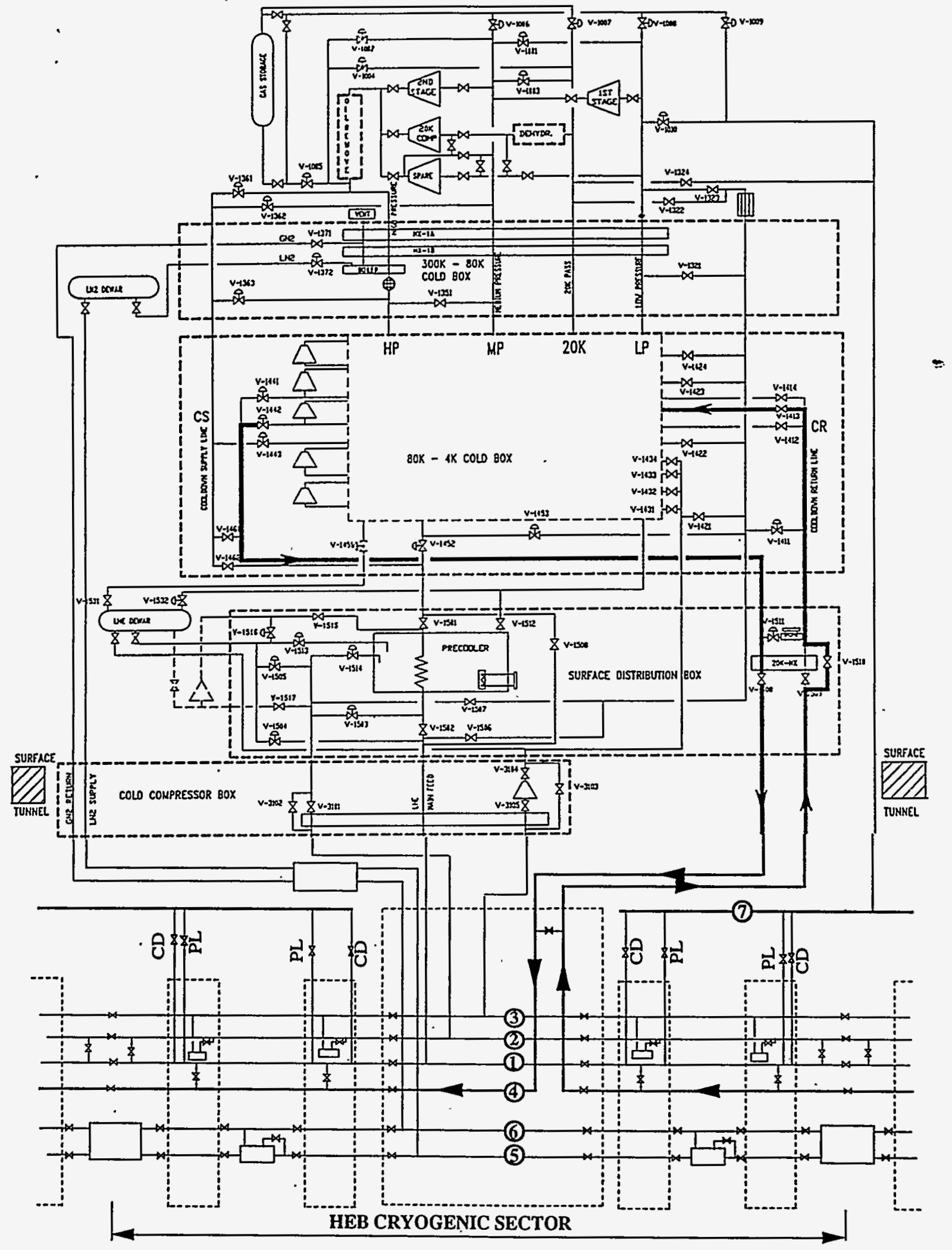

Figure 51. HEB Cryogenic System-20-K Refrigeration Loop. 


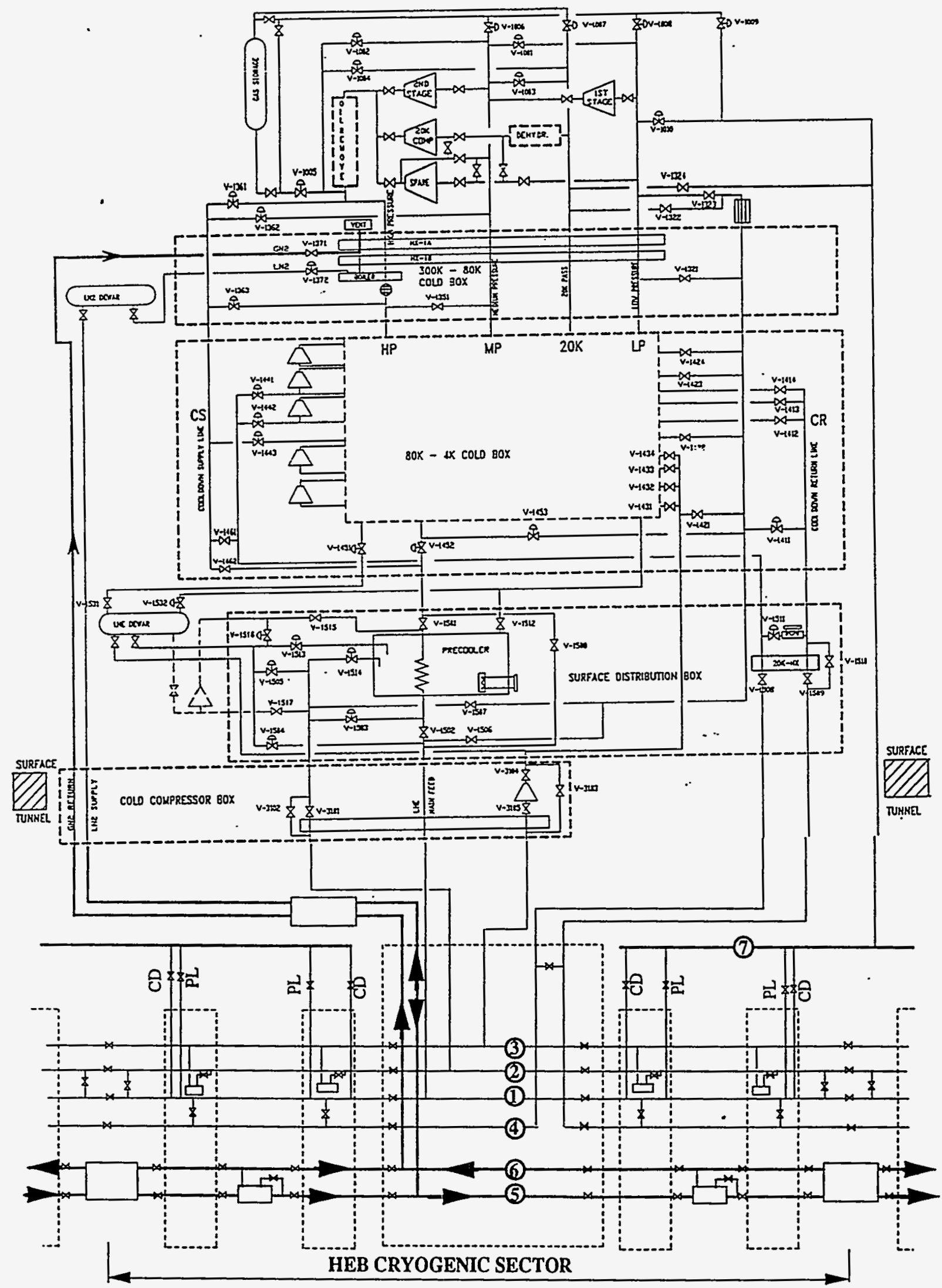

Figure 52. HEB Cryogenic System-84-K Refrigeration Loop. 


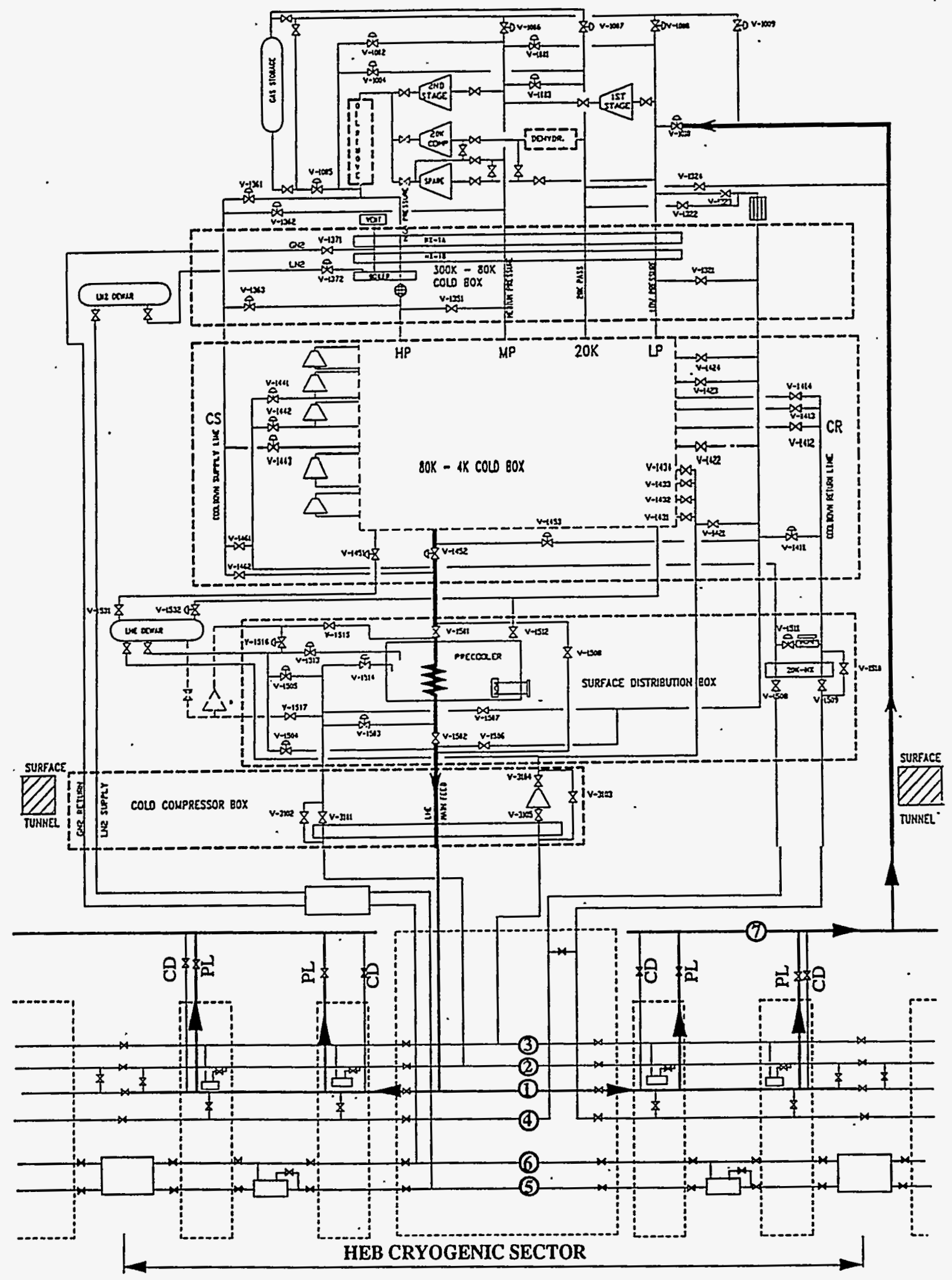

Figure 53. HEB Cryogenic System-Lead Cooling Loop. 


\subsubsection{Standby Mode-Standby Load}

When the HEB ring is cold with no beam and no current, the only refrigeration heat loads are reduced to the static conduction and thermal radiation loads only. Flow through the leads is also decreased, reducing the liquefaction loads from $36 \mathrm{~g} / \mathrm{s}$ to about $25 \mathrm{~g} / \mathrm{s}$. The refrigeration system is operated in its standby mode.

The flow conditions for standby mode of operation are given in Table 14. The 4-K flow configuration for this case is given in Figure 54. The $20-\mathrm{K}$ flow, the $80-\mathrm{K}$ flow, and the lead-cooling flow configurations are the same as in the normal mode of operation.

\subsubsection{Assist Mode-Assist Load}

In the event of a more serious failure in one of the sectors (e.g., more than one expander failure), such that its refrigerator could not handle the nominal operating loads, the other plant could be turned up to its maximum capacity to take the liquefaction loads and $20-\mathrm{K}$ loads from the sector requiring assistance. Part of these loads may also be taken up by the collider N15 plant through the collider-to-HEB transfer line.

The assist mode for the HEB plants is of lesser importance than for the collider, since the normal operation of the HEB is only 2-3 h per day, which allows sufficient time for the system to recover-i.e., to liquefy warm gas and refill the dewars, etc.

\subsubsection{Quench and Recovery Mode}

The quench protection system is designed to dump the stored energy into specific energy dumps in the event of a quench. However, some of the half-cell stored energy is dissipated in the magnet windings, causing them to warm up. When a quench is detected in any magnet, a quench is induced in the entire full cell $(65 \mathrm{~m})$ for protection. The cell-stored energy of roughly $5 \mathrm{MJ}$ is divided between the helium and coldmass, with about one-third of this energy going to the helium during the first $30 \mathrm{~s}$. As the temperature and pressure of the helium increase, the inventory of the cell, equivalent to roughly 6501 , must be absorbed by the SRS in a few minutes to relief the system. The quench detection system opens the quench relief valves to vent the warm helium to the $20-\mathrm{K}$ shield line; otherwise, the warm helium flow may induce a quench in the rest of the string. If many cells quench at a given time, the temperature in the $20-\mathrm{K}$ line drops and the pressure rises. This low-temperature helium returns through the $20-\mathrm{K}$ return line to the plant, exchanging heat with the $20-\mathrm{K}$ feed flow. The rising suction pressure on the $20-\mathrm{K}$ compressor increases its mass flow throughput, thus aiding the quench recovery and inventory management associated with the quench process. The $20-\mathrm{K}$ compressor and its gas management operate with varying suction pressure, nominally between 2 bar and 4 bar. The 4-K helium loop provides the additional inventory for cooling and filling of the magnets back to the normal operating condition. As the quenched section is cooled back down, helium vents from the coldmass through the quench valve into the $20-\mathrm{K}$ line until it reaches normal operating temperatures. The remainder of the 5-MJ energy per cell is removed from the coldmass during this recovery period. Excess inventory that cannot be reliquefied goes to the warm storage. When the single-phase return flow is not sufficient because of depletion during the recovery period, liquid from the dewar is used to aid subcooling in the surface precooler. The plant is able to absorb the $5 \mathrm{MJ}$ released by one cell in approximately $2 \mathrm{~h}$.

The flow configuration for the quench recovery mode is given in Figure 55. The quench recovery process involves both HEB refrigerators ir: isorbing and shifting the helium inventory from the quenched string. The balance of the flows in ine refrigerators during quench transients requires further analysis. Simulations of local helium venting in the magnet strings for various stages of a quench are given in References 10-12 and 39. 


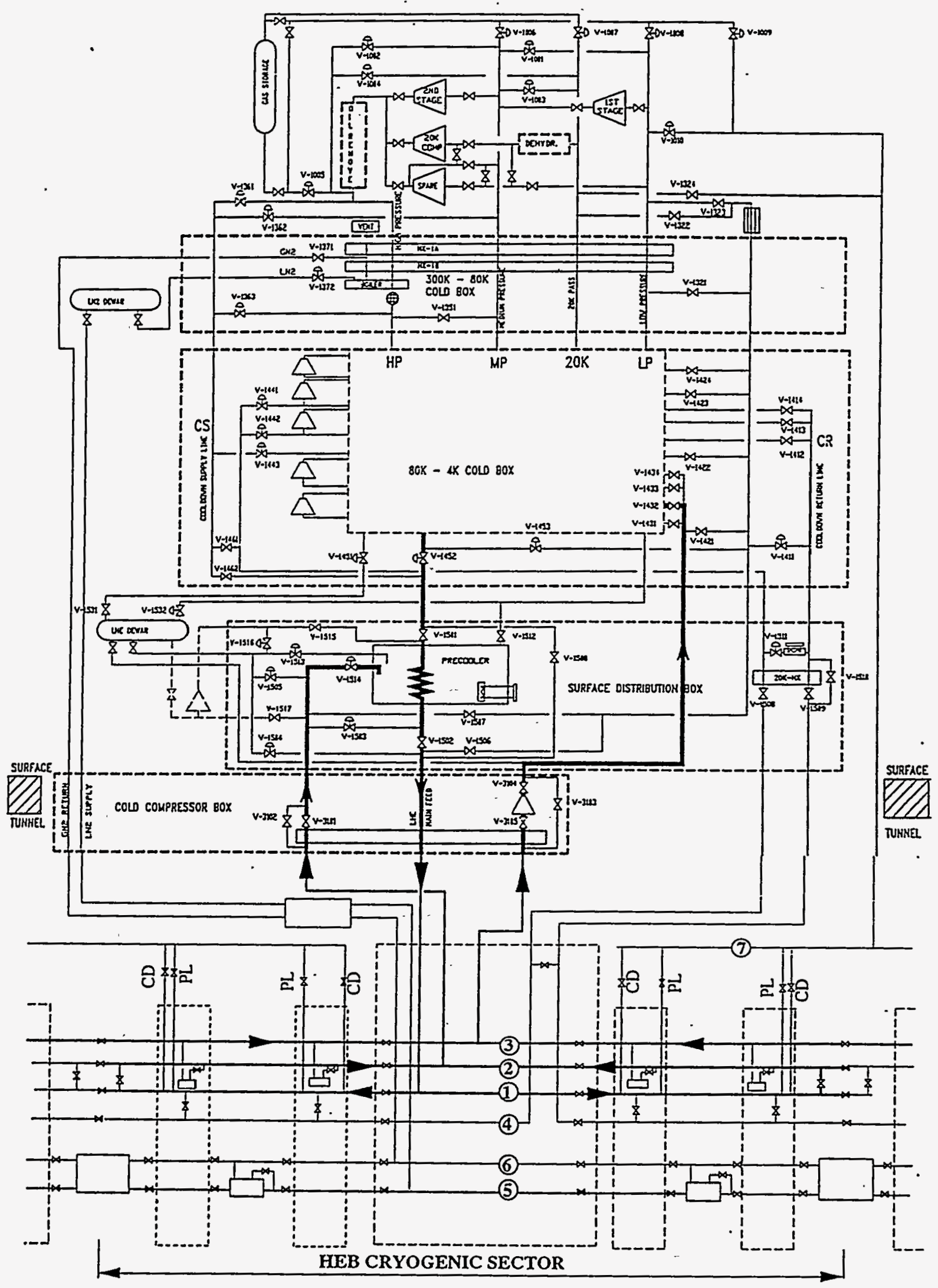

Figure 54. HEB Cryogenic System-Standby-Ready 4-K Helium Supply through Line 1 Only. 


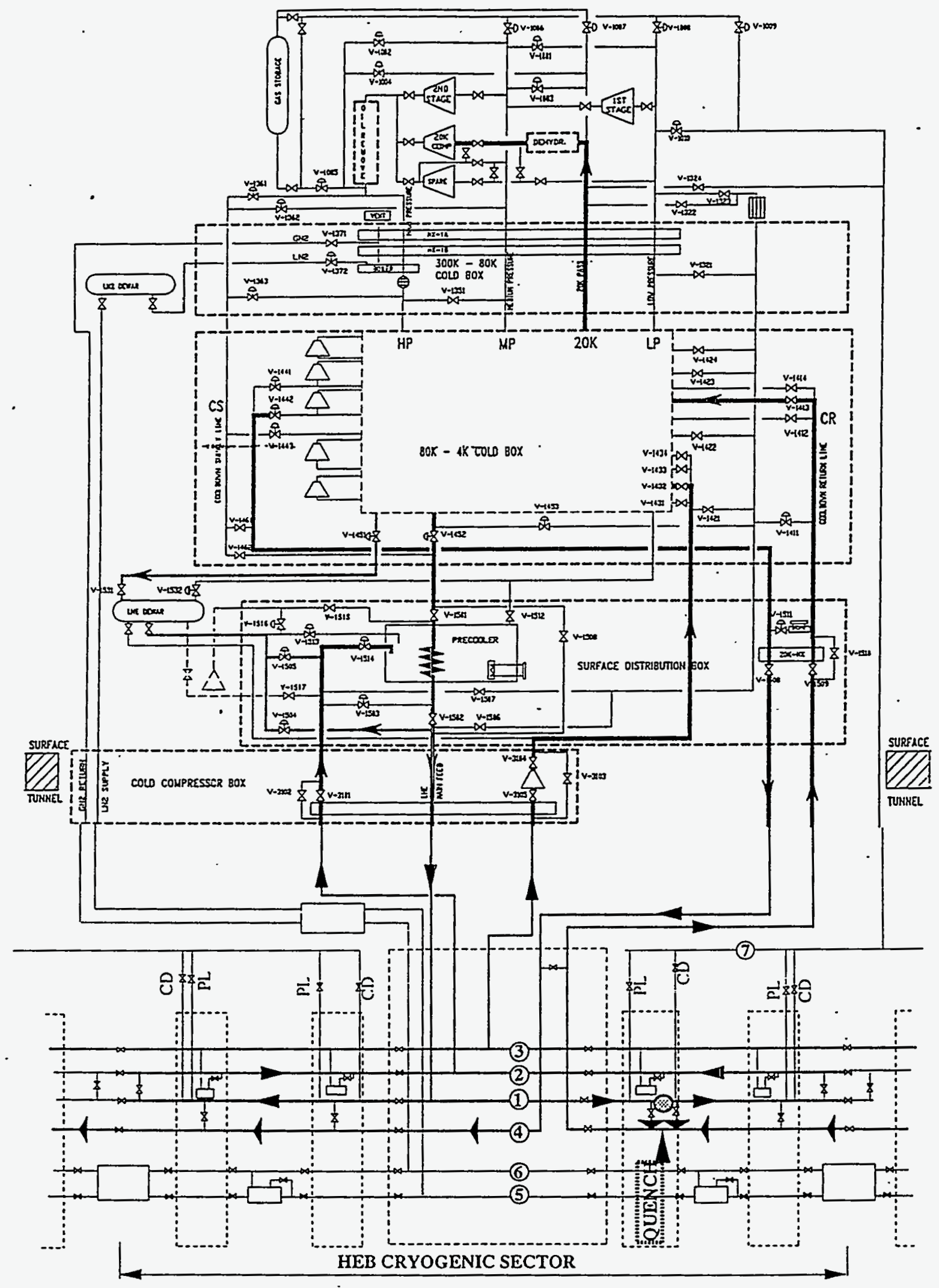

Figure 55. Cryogenic System for the HEB-Quench and Recovery. 


\subsubsection{Maximum Capacity Modes}

In maximum capacity mode the full set of compressors is running. When warm gas has to be liquefied from external delivery, the refrigerator operates in maximum liquefaction mode. When cold gas has to be processed during external liquid delivery, the refrigerator operates in maximum refrigeration mode. When the system is at $20 \mathrm{~K}$, the refrigerator operates in maximum $20-\mathrm{K}$ refrigeration mode. Any combination of these modes may be needed:

- Maximum liquefaction mode for full (100\%) liquefaction capacity

- Maximum refrigeration mode for full refrigeration capacity

- Maximum $20-\mathrm{K}$ refrigeration mode for full (100\%) 20-K refrigeration capacity.

\subsubsection{Minimum Capacity Modes}

When 4-K cooling of the magnet strings is not required for a prolonged period of time-during repair, maintenance, and cold storage of the collider rings at $80 \mathrm{~K}$ or $20 \mathrm{~K}$-the plant runs at a minimum capacity. That is, it runs with a minimum set of compressors, one first and one second stage, to process boil-off from the dewar and to keep the $20-\mathrm{K}$ shield cold. One or more expanders may be shut down to run in this mode. In this minimum capacity arrangement, the plant must be able to operate in full liquefaction mode, full refrigeration mode, and any liquefaction/refrigeration (mixed) ratio mode.

\subsection{Utility Modes and Maintenance Operations}

The following utility modes and maintenance operations are described in this section. The corresponding process diagrams are included at the end of the chapter.

- Cleanup

- Pumpdown

- Sector cooldown

- System warm-up .

- Section repair.

\subsubsection{Cleanup}

Initial commissioning of the HEB requires the circulation of clean, warm helium gas through the magnet strings and associated equipment to remove contaminants, particularly moisture and residual gases in the windings and piping. The $20-\mathrm{K}$ compressor is used for this purpose. The warm, clean gas is supplied to the magnet string and the various helium flow loops through the cooldown supply line. The return flow is routed directly to $20-\mathrm{K}$ compressor suction. Molecular sieve adsorber beds in the compressor suction line remove moisture and contaminants. The dryer bed design shall be verified for operation at these flow and pressure conditions.

The cleanup process is performed prior to cooldown of the HEB from $300 \mathrm{~K}$ down. The whole system is warm, and the lines are full of dry air. Before the warm circulation process is initiated, the system is purged, evacuated, and charged with helium.

The 20-K compressor is used for this purpose with appropriate suction pressure (2-4 bar nominal) and outlet at the system design pressure to provide up to $200 \mathrm{~g} / \mathrm{s}$ of $300-\mathrm{K}$ helium flow. The helium flows through the high-pressure side of coldbox heat exchangers $\mathrm{HX}-1 \mathrm{~A}$ and $\mathrm{HX}-1 \mathrm{~B}$, and the $80-\mathrm{K}$ adsorber bed requiring availability of $\mathrm{LN}_{2}$. The helium is then bypassed to the medium-pressure circuit of $\mathrm{HX}-1 \mathrm{~A}$ (via V-1351) at the operating pressure for warmup to room temperature. The high-pressure, 300-K helium is routed through valves V-1362, V-1462, and V-1506 to Line 1 in the feed spool (SPRF), while part of it may be diverted to line 2 through valve $V-1503$. The low-temperature coldbox is not operating. The boiloff from the dewar goes to suction of the first stage compressor. If necessary the compressors may be operated to process this gas. 
There are several loops to be cleaned: the magnet string, the single-phase return, the gas helium return, the $20-\mathrm{K}$ lines, the helium recoolers, the power leads, etc. The return flow has several routes:

1. The return flow is directed through the $20-\mathrm{K}$ line, then through the quench relief valves located in the spool pieces, and it returns to the dehydration skid via valves V-1411 and V-1323. Figure 56 shows the cleanup process of the magnet string and the single-phase return line.

2. The return flow is directed through the warm return header, then through cooldown and lead cooling valves, and it returns to the dehydration skid through valve V-1324. Figure 57 shows the circulation process of the magnet strings and current leads.

3. The return flow is directed through the GHe return, then through recooler valves, and it returns to the dehydration skid via valves V-1421 and V-1323.

4. The return flow may be returned through the single-phase return line and via $V-1507$ to the compressor.

A maximum flow rate of $100 \mathrm{~g} / \mathrm{s}$ per string is available for cleanup. Flow resistance limits the flow rate through the magnet string to a maximum of $50 \mathrm{~g} / \mathrm{s}$. The flow rate through the system varies depending on the cleanup routes.

The status of the system after warm circulation is "WARM CLEAN": The cold lines and passages are at $300 \mathrm{~K}$, and the quench valves, cooldown valves, and recooler control valves are closed. The system is clean and ready for insulating vacuum pumpdown and cooldown.

The entire volume in the sector has to be circulated at least five times. The volumes of the piping and magnet flow channels are listed in Table 16. Estimated cleanup time is approximately $2 \mathrm{~h}$.

\subsubsection{Pumpdown}

Before any cooldown processes can be initiated, the insulating vacuum chambers of the cryostats and the beam tube must be pumped down to the appropriate level of $1.3 \mathrm{E}-2 \mathrm{~Pa}$. Total insulating volume to be pumped down per sector includes the insulating space for 64 cells, plus bypasses and isolated cryostats, with a volume of approximately $19.5 \mathrm{~m}^{3}$ per cell. Expected time, including leak-checking, is about $8 \mathrm{~h}$ per cell.

\subsubsection{Sector Cooldown}

Cooldown of the magnet strings is carried out in various phases. The supply pressures and temperatures for the various phases are given in Table 19. Although the helium refrigeration system is designed for a nominal supply of $400 \mathrm{~g} / \mathrm{s}$ of helium flow for cooldown from $300 \mathrm{~K}$ to $80 \mathrm{~K}$, the system pressure drop does not allow flow rates higher than $100 \mathrm{~g} / \mathrm{s}$ per string. The system is designed to enable the control of the cooldown feed flow temperature by mixing the warm and cold helium supply (V-1362 and V-1363). Some or all of the expanders may be used in various cooldown phases. The return flow is valved into the refrigerator return side at various temperatures during successive cooldown phases. The goal is to reduce the temperatures of the different parts of the cryostat to their nominal operating values in a controlled way to achieve minimum cooldown time and minimum cooldown cost, and to prevent excessive thermal stresses.

Table 19. Coldmass Cooldown Conditions.

\begin{tabular}{|c|c|c|c|c|c|c|c|c|}
\hline $\begin{array}{c}\text { Starting } \\
\text { Temp } \\
(\mathbf{K})\end{array}$ & $\begin{array}{c}\text { Ending } \\
\text { Temp } \\
(\mathbf{K})\end{array}$ & $\begin{array}{c}\text { Supply } \\
\text { Pressure } \\
(\text { bar) }\end{array}$ & $\begin{array}{c}\text { Return } \\
\text { Pressure } \\
(\text { bar) }\end{array}$ & $\begin{array}{c}\text { Supply } \\
\text { Flow rate } \\
(\mathbf{g} / \mathbf{s})\end{array}$ & $\begin{array}{c}\text { Cooling } \\
\text { Capacity } \\
(\mathbf{k W})\end{array}$ & $\begin{array}{c}\text { Wave } \\
\text { Speed } \\
(\mathbf{m} / \mathbf{h})\end{array}$ & $\begin{array}{c}\text { Cooldown } \\
\text { Time } \\
\text { (days) }\end{array}$ & $\begin{array}{c}\text { Sector He } \\
\text { Inventory } \\
(\mathbf{k g})\end{array}$ \\
\hline 300 & 80 & 16 & 4 & 200 & 450 & 12 & 10 & 247 \\
\hline 80 & 20 & 16 & 2.5 & 140 & 50 & 45 & 2.5 & 865 \\
\hline 20 & 5 & 4 & 2.5 & 200 & $>12^{*}$ & 225 & 0.5 & 8038 \\
\hline
\end{tabular}

With liquid consumption from dewar. 


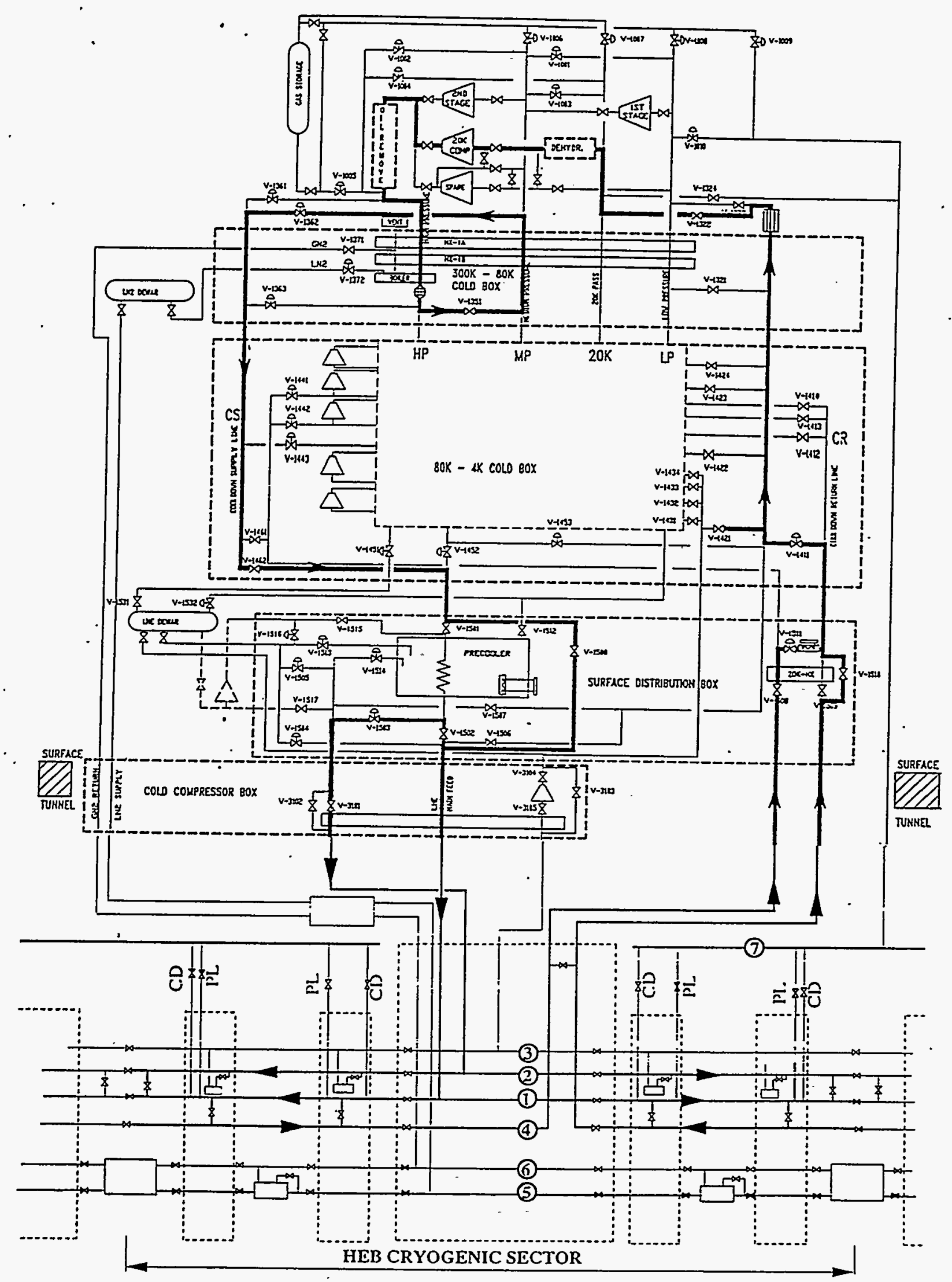

Figure 56. Sector Cleanup-Warm Gas Circulation in Line 1, Line 2, and Line 4. 


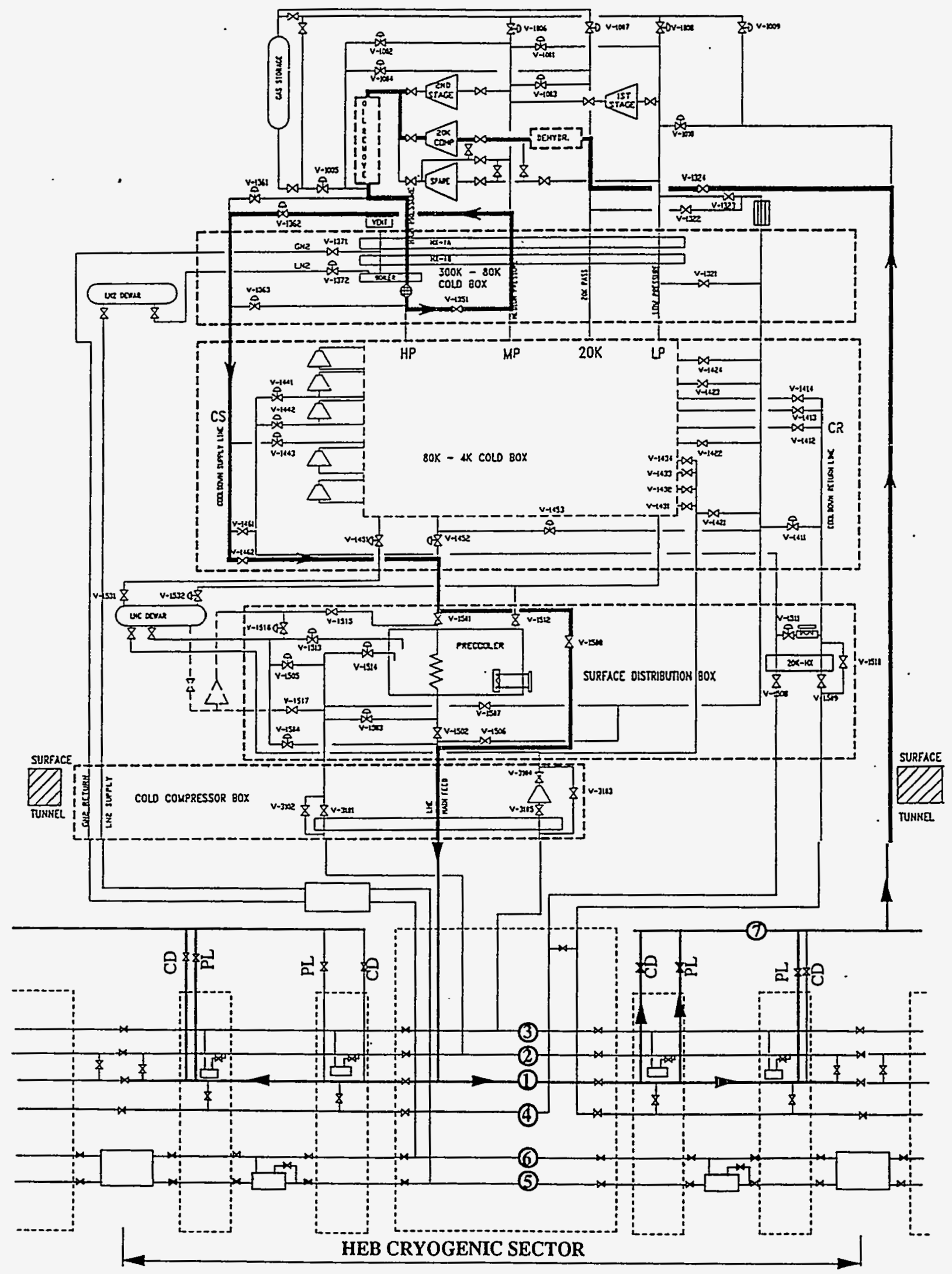

Figure 57. Sector Cleanup-Warm Gas Clrculation in Line 1, Current Leads, and Warm Return Header. 
The following process may be applied for sector cooldown when both strings of a sector are cooled down simultaneously. The sector cooldown process may be started after the insulating vacuum has been successfully pumped down and leak-checked. A software interlock inhibits the cooldown start-up if vacuum conditions are inadequate.

The cooldown of a sector is performed in three major steps, as dictated by the refrigerator design:

- Step 1: Sector cooldown from $300 \mathrm{~K}$ to $80 \mathrm{~K}$

- Step 2: Sector cooldown from $80 \mathrm{~K}$ to $20 \mathrm{~K}$

- Step 3: Sector cooldown from $20 \mathrm{~K}$ to $4-5 \mathrm{~K}$ and fill.

For the first step of cooldown only the warm coldbox is operated to prevent damage to the expanders due to possible release of contamination during an upset condition. During the steps the flows of the cryogens at different temperatures are routed in different ways. Software interlocks prevent disorder in the cooldown process.

A helium flow rate of $200 \mathrm{~g} / \mathrm{s}$ at $80 \mathrm{~K}$ is supplied to the magnet strings, $100 \mathrm{~g} / \mathrm{s}$ per string, and $332 \mathrm{~g} / \mathrm{s}$ of liquid nitrogen is expended for the $80-\mathrm{K}$ shield refrigeration, $166 \mathrm{~g} / \mathrm{s}$ per string. The required capacity for cooling the $200-\mathrm{g} / \mathrm{s}$ warm helium to $80 \mathrm{~K}$ is achieved by boiling $570 \mathrm{~g} / \mathrm{s}$ of liquid nitrogen. The refrigeration plant requires a continuous supply of the $570 \mathrm{~g} / \mathrm{s}$ of liquid nitrogen for the helium system and the $332 \mathrm{~g} / \mathrm{s}$ for the $80-\mathrm{K}$ shield. (Total $3240 \mathrm{~kg} / \mathrm{h}$ or 78 tons/day $\cong 4$ trucks/day.) Sector cooldown to $80 \mathrm{~K}$ will take about $10-12$ days.

Only the warm coldbox system is operating during this process. Liquid nitrogen is vaporized and warmed up to $300 \mathrm{~K}$ by heat exchange with the helium stream coming from the compressor system. For cooldown the minimum supply pressure required for the $80-\mathrm{K}$ helium is $10 \mathrm{bar}$, using two compression stages. Under normal operation the warm return header is pressurized to 4 bar, and only the 20-K compressor is required to provide the $100 \mathrm{~g} / \mathrm{s}$ needed. The supply pressure required can go up to $16 \mathrm{bar}$ because the suction pressure is at 4 bar. If the return header cannot be pressurized to $4 \mathrm{bar}$, then the system has to be operated at lower flow rates to prevent damage to the dehydration bed. The flow exiting the 80-K adsorber beds is routed to the cooldown supply line through V-1363 and to the LHe main feed line via crossover valve V-1462. The flow bypasses the surface precooler by valve V-1508. If the precooler is still warm, it should be cooled to $80 \mathrm{~K}$ by opening valve V-1514, with the warm gas vented through V-1512.

\subsubsection{Sector 80.K Shield Cooldown from $300 \mathrm{~K}$ to $80 \mathrm{~K}$}

The 80-K lines and shield should be cooled down before initiating helium cooldown of the $20-\mathrm{K}$ shield and the coldmass. The $80-\mathrm{K}$ shield and lines include 46.6 tons of steel and 60.2 tons of aluminum per sector; a total of $1.38 \mathrm{E} 10 \mathrm{~J}$ has to be removed from the shield by $\mathrm{LN}_{2}$ flow through line 5 (see Table 17 and Figure 48). $\mathrm{LN}_{2}$ is supplied to the magnet strings at the feed spool; the warm gas is removed from the magnet string at the end spool and vented to the atmosphere through the nitrogen dump tanks. Vapor generated in the $\mathrm{N}_{2}$ recoolers during cooldown is returned to the refrigerator through line 6 for helium precooling. Figure 58 shows the nitrogen circulation process for the 80-K shield cooldown.

Initially, the $\mathrm{LN}_{2}$ flow rate per string must be low $(20 \mathrm{~g} / \mathrm{s}$ maximum) to prevent thermal shocks and excessive thermal stresses. The expected cooldown time is 7 days (at an average flow of $60 \mathrm{~g} / \mathrm{s}$ ). This will consume 37 tons of $\mathrm{LN}_{2}$ per sector. Inventory of $\mathrm{LN}_{2}$ in the lines increases from $66 \mathrm{~kg}$ in both $\mathrm{N}_{2}$ lines ( $33 \mathrm{~kg}$ each) to $10816 \mathrm{~kg}$ in line 5 and $76 \mathrm{~kg}$ in line 6 at the end of cooldown. 


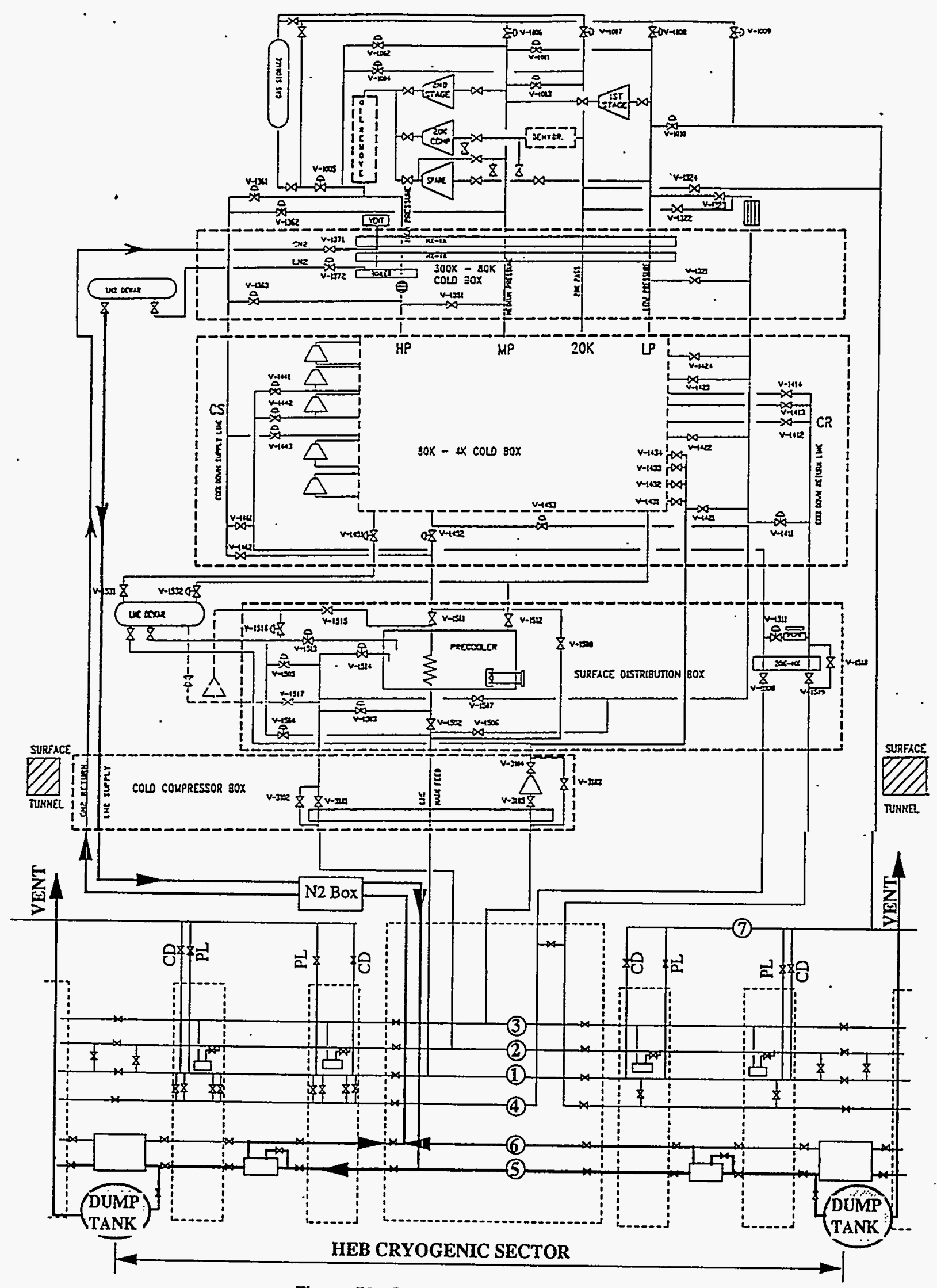

Figure 58. Sector 80-K Shield Cooldown. 


\subsubsection{Sector 20-K Shield Cooldown from $300 \mathrm{~K}$ to $80 \mathrm{~K}$}

The next step following the $80-\mathrm{K}$ shield cooldown is to cool down the $20-\mathrm{K}$ shield independently to $80 \mathrm{~K}$. This process is performed by using the $300-80 \mathrm{~K}$ coldbox, in which the helium flow is cooled using a counterflow of $80-\mathrm{K}$ nitrogen. The $80-\mathrm{K}$ helium is routed through crossover valves $\mathrm{V}-1461$ and $\mathrm{V}-1508$ and may be introduced to both strings of a sector at the feed spool. The warm gas is removed from the strings through the $20-\mathrm{K}$ cooldown valves at the isolation and end spools, and is returned to the refrigerator through the warm return header. An alternative is to carry out the $20-K$ shield cooldown together with the coldmass cooldown, as described in the next section.

The shield cooldown should be carried out at a controlled rate to prevent excessive thermal stresses. The flow rate is controlled in the tunnel distribution box and is limited to $20 \mathrm{~g} / \mathrm{s}$ per string initially. Once the $20-\mathrm{K}$ shield is cold, the flow rate to the string is increased to $100 \mathrm{~g} / \mathrm{s}$, and the normal $20-\mathrm{K}$ loop circulation is established (Figure 51).

The 20-K shield is composed of 33.6 tons of steel and 55.6 tons of aluminum per sector. A total of $1.25 \mathrm{E} 10 \mathrm{~J}$ is to be removed from the shield. Expected time for $20-\mathrm{K}$ shield cooldown is 2 days (at an average flow of $60 \mathrm{~g} / \mathrm{s}$ ), with a helium consumption of 35 tons ( $80-\mathrm{K}$ helium warmed up to $300 \mathrm{~K}$ ). The amount of nitrogen required for this process, assuming a $90 \%$ efficiency, is 34 tons.

\subsubsection{Sector Coldmass Cooldown from $300 \mathrm{~K}$ to $80 \mathrm{~K}$}

There are two possible ways to cool the magnet string. The first method (Figure 59) is to the supply the 80-K helium at one end of the string to both the single-phase feed and single-phase return. The warm flow is returned through the cooldown valves and the warm return header to the refrigerator. The recoolers valves are kept open, and the cooldown valves are open. A cooldown wave develops and travels along the string. Cooldown valves are successively closed as the cooldown wave progresses. A small part of the flow may be diverted through the current leads and bypass leads directly to the warm header. The quench valves may be opened to cool the $20-\mathrm{K}$ shield at the same time. To prevent excess thermal stresses in the system, the maximum temperature gradient in the cooldown wave should not exceed $30 \mathrm{~K} / \mathrm{m}$.

The second method (Figure 60 ) is to cool the magnets in parallel by supplying $80-\mathrm{K}$ helium through the $20-\mathrm{K}$ lines. There are one cooldown valve and two quench valves per cell. During this process, all the cooldown valves and every other quench valve are kept open. The $80-K$ helium supplied to the $20-K$ shield lines flows through the quench valves to the magnet half-cell and then through the cooldown valves into the $300-\mathrm{K}$ warm return header.

The cooldown supply temperature can be controlled by mixing warm gas through V-1361 and V-1362 with cold gas supplied from V-1363.

Total energy to be removed from a sector ( 2700 tons of coldmass) is $1.9 \mathrm{E} 11 \mathrm{~J}$. At an average flow rate of $100 \mathrm{~g} / \mathrm{s}$ per string, cooldown is expected to take about 10 days for a $2700-\mathrm{m}$-long string. The helium consumption for cooldown ( $80-\mathrm{K}$ helium to be warmed up to $300 \mathrm{~K}$ ) is 166 tons. Nitrogen consumption in the refrigerator for the coldmass cooldown to $80 \mathrm{~K}$ is 475 tons. If cooldown is done in.parallel, $80-\mathrm{K}$ helium can be supplied to the coldmass through the quench valves at a rate of $200 \mathrm{~g} / \mathrm{s}$ per string. Assuming the flow is distributed uniformly to each cell, the cooldown time can be reduced to approximately 5 days.

The status of the system after cooldown to $80 \mathrm{~K}$ is "COLDMASS AT $80 \mathrm{~K}$." The $80-\mathrm{K}$ shield is refrigerated by nitrogen at a nominal flow rate. Cooldown valves, quench valves, and recooler valves are closed. All parts of the string are at $80 \mathrm{~K}$, at a pressure of $0.3 \mathrm{MPa}$, and the $20-\mathrm{K}$ shield is at $80 \mathrm{~K}$. No flow is required in the coldmass. The helium inventory in a sector is about $247 \mathrm{~kg}$. 


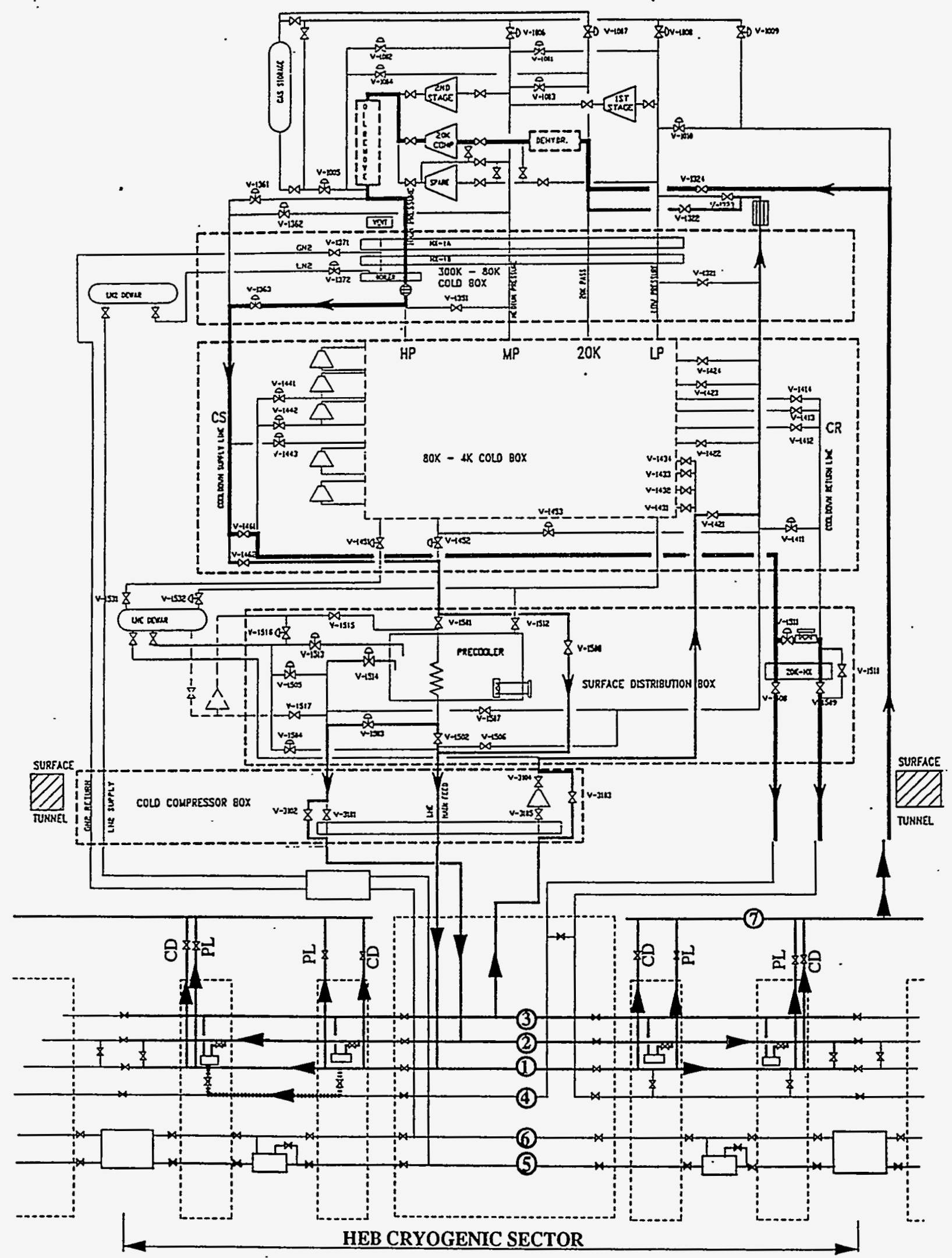

Figure 59. Sector Coldmass Cooldown from $300 \mathrm{~K}$ to $80 \mathrm{~K}$-Serial Cooldown. 


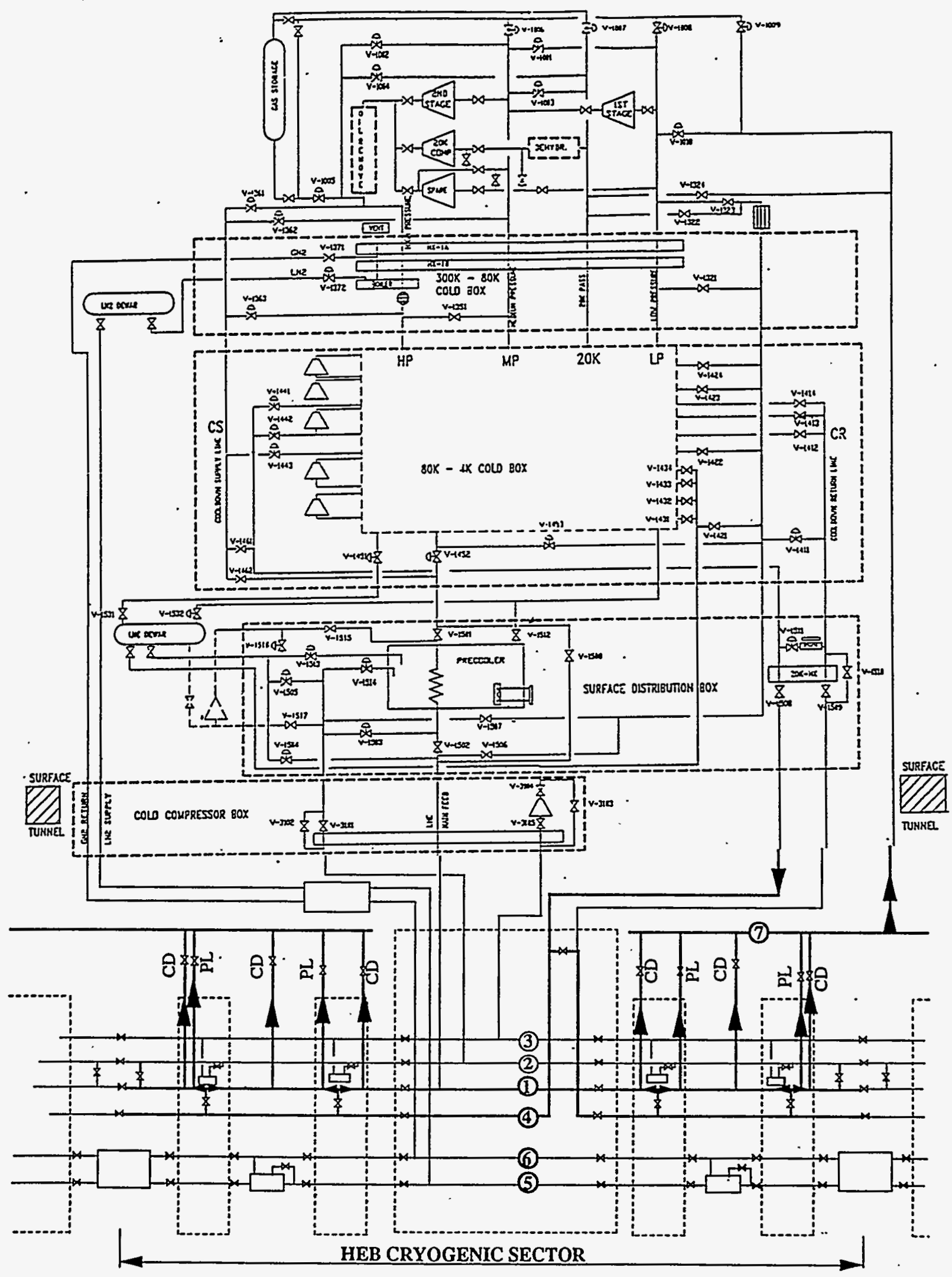

Figure 60. Sector Coldmass Cooldown from $300 \mathrm{~K}$ to $80 \mathrm{~K}$-Parallel Cooldown. 


\subsubsection{Sector Cooldown to $20 \mathrm{~K}$}

The cooldown process from $80 \mathrm{~K}$ to $20 \mathrm{~K}$ is designed to be performed in one step. However, if necessary, there is the capability to perform this cooldown in multiple steps by mixing $20-\mathrm{K}$ helium with warmer gas. High-pressure, 15-20-K gas from V-1443, through the cooldown supply line, is fed to the main single-phase feed line. The magnet string, the $20-\mathrm{K}$ shield, the $4-\mathrm{K}$ return line, and the GHe return line are cooled down from $80 \mathrm{~K}$ to $20 \mathrm{~K}$ during this process.

For $80-\mathrm{K}$ to $20-\mathrm{K}$ cooldown the available cooling capacity is about $50 \mathrm{~kW}$, defined by the expander capacity. Súpply of $140 \mathrm{~g} / \mathrm{s}$ of helium (70 g/s per string) at approximately $15 \mathrm{~K}$ and at high pressure is available from the high-pressure tap through valve $\mathrm{V}-1443$, located below the third expander. The cold flow is supplied to the single-phase feed line through valves V-1462 and V-1508, and also to the singlephase return line through V-1502, V-1503, and V-3102 (Figure 61).

The return flow to the plant is a combination of the flows through the quench valves, through the $20-\mathrm{K}$ lines to valves $\mathrm{V}-1508, \mathrm{~V}-1510, \mathrm{~V}-1411$, and through the recoolers and the vapor return line, through $\mathrm{V}-1421$. The combined flows are returned through valve $\mathrm{V}-1321$ to the first stage compressor(s).

Expected cooldown time is $60 \mathrm{~h}$. The status of the system after cooldown to $20 \mathrm{~K}$ is "SYSTEM AT $20 \mathrm{~K}$." The $80-\mathrm{K}$ and $20-\mathrm{K}$ thermal shields are kept at their nominal temperature range by nitrogen and helium flows. All helium valves in the string, i.e., cooldown, quench, recooler level, and lead cooling valves, are closed. No flow is necessary in the coldmass. The helium inventory in the sector is approximately $865 \mathrm{~kg}$ at a pressure of $0.3 \mathrm{MPa}$.

\subsubsection{Sector Cooldown to 4-5 $\mathrm{K}$ and Fill-up}

This is the final stage of cooldown, during which the magnet string is cooled to $4-5 \mathrm{~K}$ and filled. Before starting this process the helium dewar is filled with liquid delivered from external sources. The refrigerator supplies 4.5-K, 4-bar flow through V-1502 and through the single-phase feed lines. The flow can be supplied directly from the dewar via valve V-1504 (Figure 62), or if a pump is available, through valve V-1515 (Figure 63). As the cooldown wave travels through the string, inventory accumulates behind the wave. As a result, the returning flow rate is much lower than the supply flowrate (4-7\% of feed flow). The refrigerator will experience an imbalance in flows and will operate mainly in liquefaction mode. The mass to/from the coldbox is balanced by additional flow from the dewar, which is evaporated in the precooler. The $20-\mathrm{K}$ vapor returning from the tunnel bypasses the heat exchanger $(\mathrm{V}-3102)$ and is diverted through V-1507 and returned to the heat exchanger stack via V-1422. If the final cooldown and fill are directly from the dewar, without the plant operating, the flow to the strings is two-phase, which is undesirable. To prevent this situation a pump may be operated.

The flow rates in the $80-\mathrm{K}$ and $20-\mathrm{K}$ shields are kept at their nominal rates. About $200 \mathrm{~g} / \mathrm{s}$ of $4.5-\mathrm{K}$, 4-bar helium from the precooler (valve V-1502) is supplied to the single-phase main feed supply line. At $100 \mathrm{~g} / \mathrm{s}$ per string, the cooldown process takes approximately $12 \mathrm{~h}$.

System status after cooldown to liquid temperatures is "COLDMASS AT $4 \mathrm{~K}$," and the system . pressure is $3-4$ bar. After cooldown to $4-5 \mathrm{~K}$ the recoolers are filled, and their level control loops may be activated. At this point the cold compressor is started, and the pressure in the vapor return lines is lowered to their nominal values. After all the operating parameters have settled to their nominal values, the status of the ring is changed to "STANDBY COLD." About $9700 \mathrm{~kg}$ of helium inventory is present in the magnet strings when the cooldown and fill-up processes are completed. 


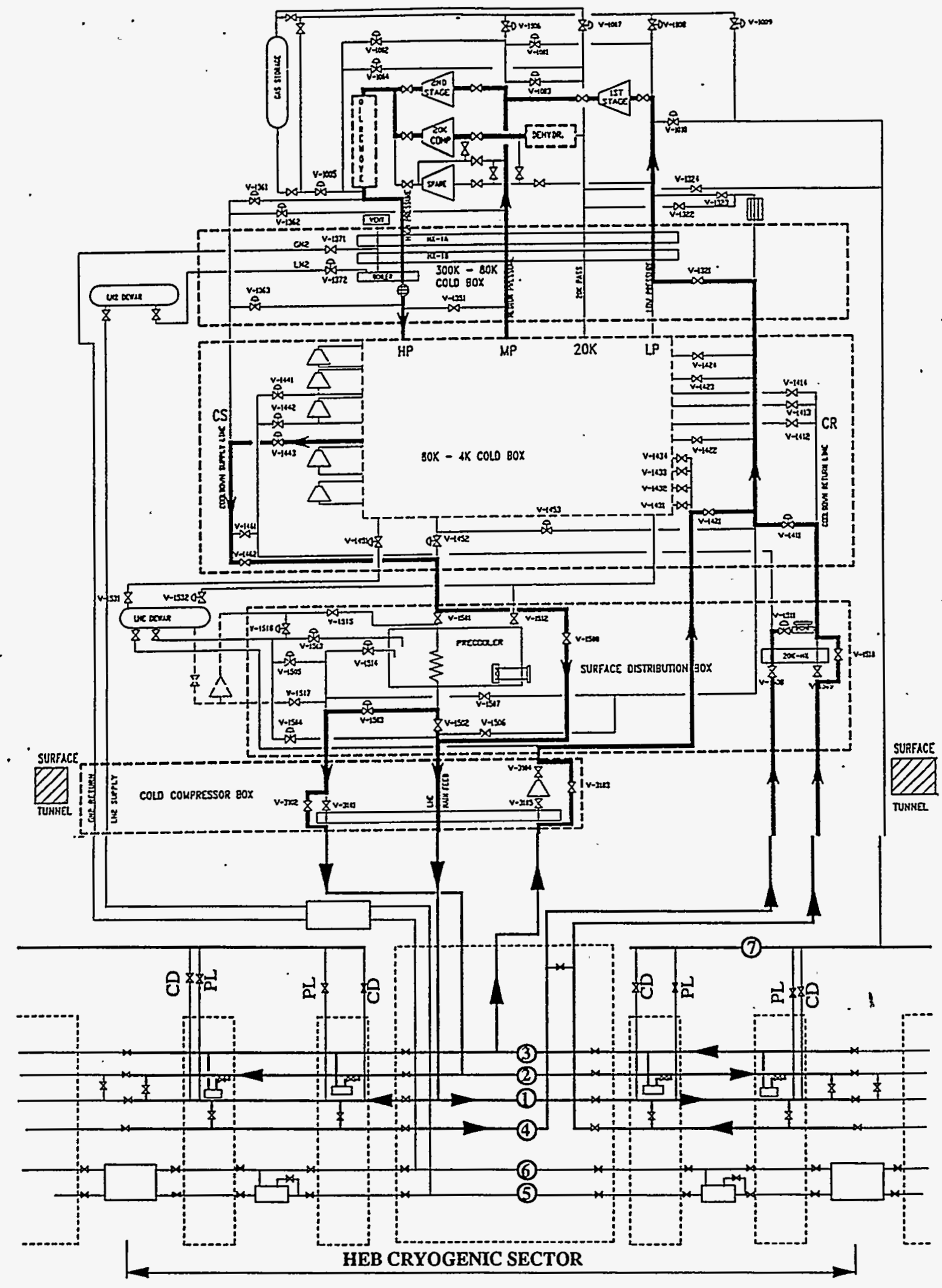

Figure 61. Sector Coldmass Cooldown, $80 \mathrm{~K}$ to $20 \mathrm{~K}$. 


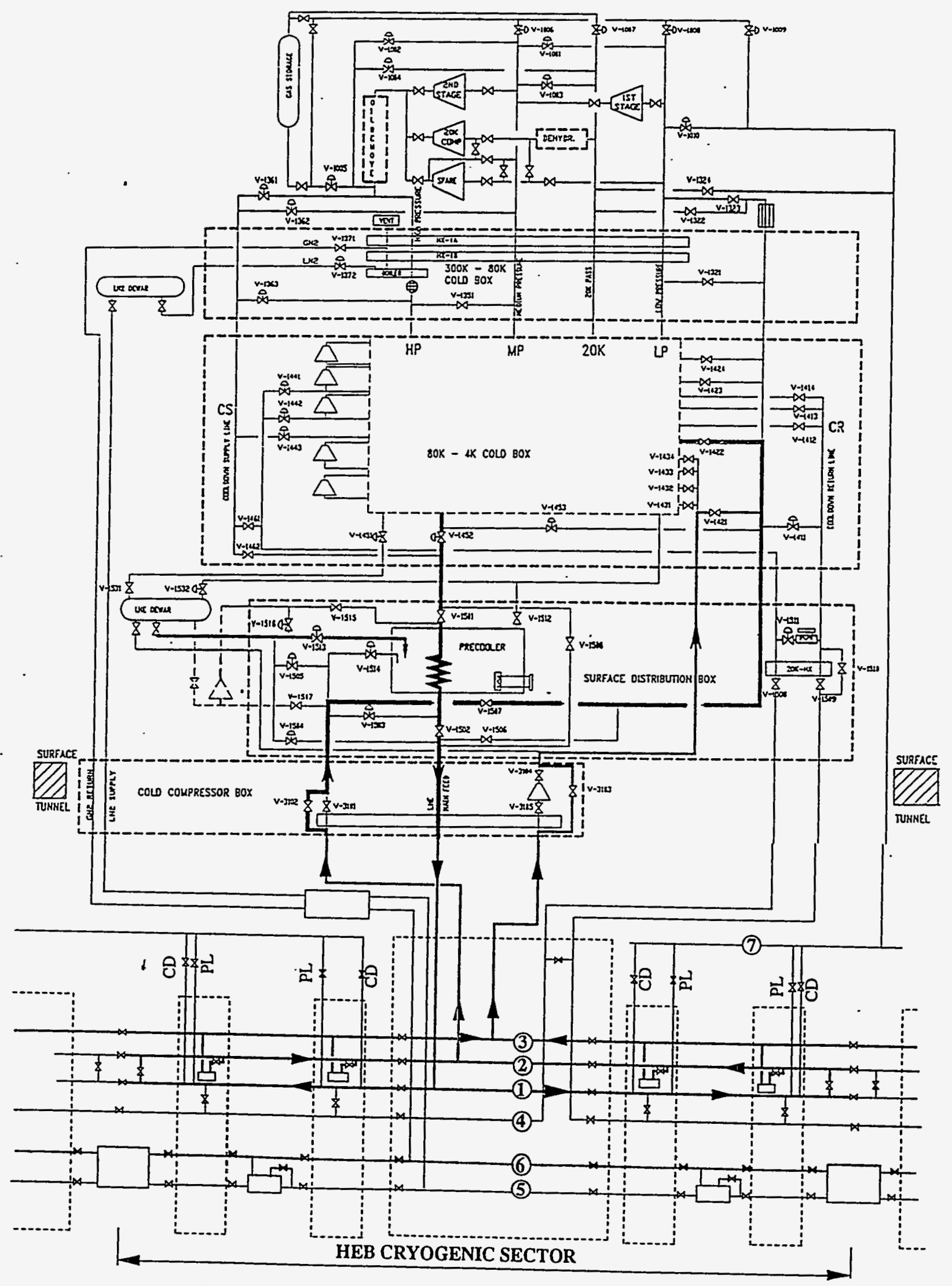

Figure 62. Sector Coldmass Cooldown from $20 \mathrm{~K}$ to $5 \mathrm{~K}$ and Fill-up. 


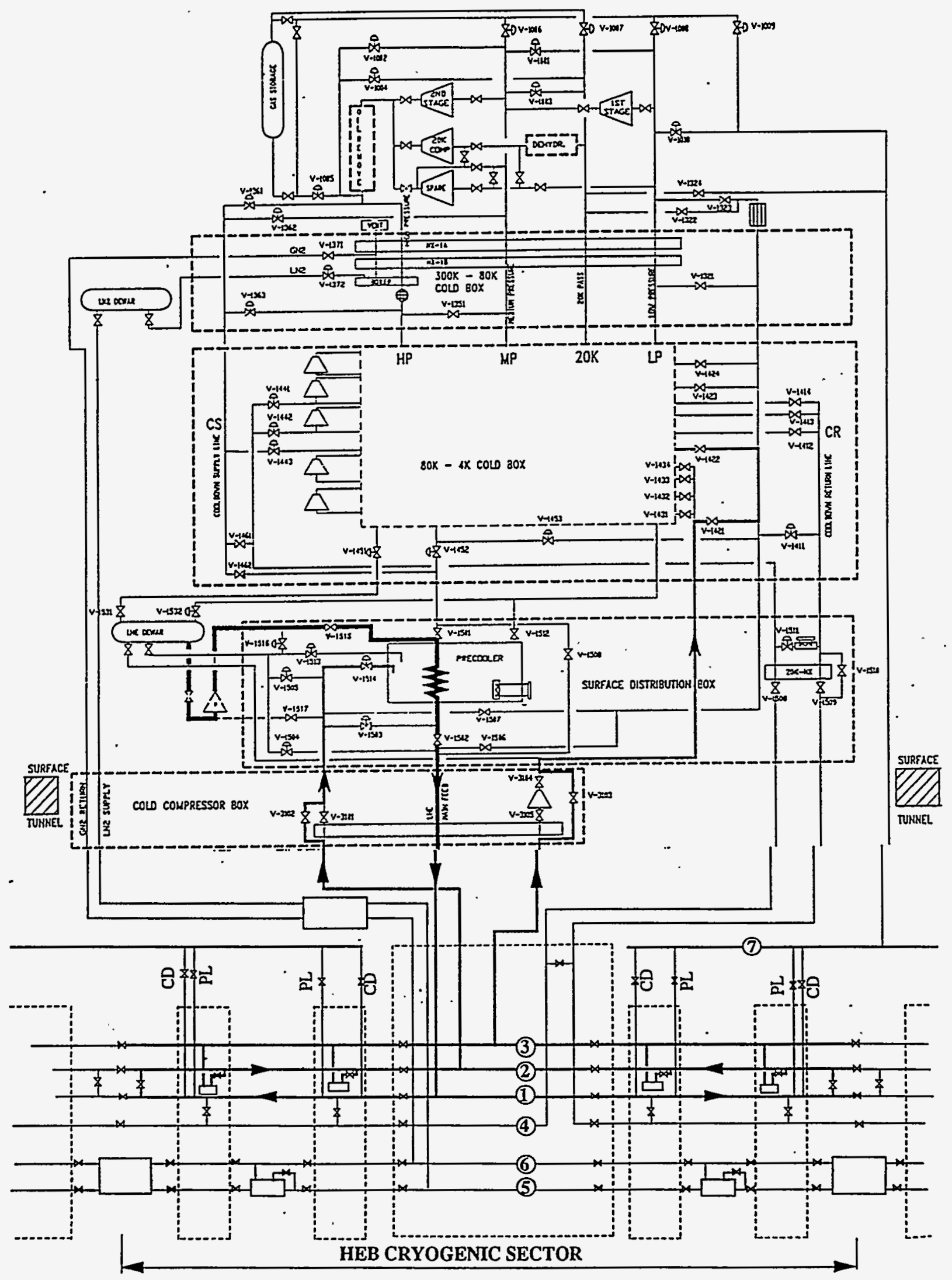

Figure 63. Sector Fill-up from Dewar Using Pump. 


\subsubsection{System Warm-up}

Warm-up of the system serves three major purposes:

1. Warm-up cycle for the desorption of gas from the beam tube. This process is designed to be performed for the whole sector at a time and not for particular sections. The final temperature may be in the range of $20-50 \mathrm{~K}$.

2. Long-term system storage. There are three different temperatures at which the system can be stored:

- Coldmass at $20 \mathrm{~K}$. The $20-\mathrm{K}$ and $80-\mathrm{K}$ shield systems are active.

- Coldmass at $80 \mathrm{~K}$. Only the $80-\mathrm{K}$ nitrogen shield system is active.

- Coldmass at $300 \mathrm{~K}$. System is empty and clean.

3. Warm-up for maintenance. System is warmed up to $300 \mathrm{~K}$ for maintenance or changes.

\subsubsection{System Emptying and Warm-up to $20 \mathrm{~K}$}

Prior to warm-up, the liquid inventory of the magnets has to be transferred to the storage dewars on the surface. System initial status before emptying is "STANDBY COLD." The strings are cold at $4 \mathrm{~K}$, and there is no flow in the coldmass. The 20-K shield and 80-K shield loops are running.

By opening a quench valve in the magnet string and lowering the pressure in the 4- $\mathrm{K}$ lines, highpressure ( $5-6$ bar) $20-\mathrm{K}$ helium is allowed into the magnet coldmass cooling channels. The flow rate is controlled to maintain the pressure supercritical during this procedure. The supercritical 4-K helium is pushed out of the magnet strings, displaced by the 20 -K helium gas in both directions: (1) toward the feed spool; and (2) toward the end spool and then back to the feed spool through the 4-K liquid return line (Figure 64). In order to empty the coldmass and the 4-K liquid return lines simultaneously, the 20-K helium is introduced into the coldmass through a quench valve, at approximately two-thirds of the length of the string from the feed spool.

The lower temperature loops in the refrigerator, including the expanders, are activated to process the 4-K gas from the dewar displaced by the 4-K liquid transferred to the dewar. Part of the 4-K gas is used to make up for the 20-K supply; the rest is liquefied and retumed to the dewar. For this process, the energy and mass balances in the refrigerator may require additional helium to be drawn from the warm-gas storage tanks. After emptying, this helium is returned to the tanks.

The inventory from the string is transferred to the dewars as long as the enthalpy of helium exiting the strings is below $30 \mathrm{~J} / \mathrm{g}$ (corresponding to the saturated vapor enthalpy in the dewar). At a flow rate of $100 \mathrm{~g} / \mathrm{s}$ of $20-\mathrm{K}$ helium for each string, this will take approximately $2-3 \mathrm{~h}$. After this time, the retum flow from the string is routed to the coldbox, and the process is continued until the string is warmed up to $-20 \mathrm{~K}$ in $4-5 \mathrm{~h}$. About $8000 \mathrm{~kg}$ of helium is removed from a sector to the surface dewars during this emptying and warm-up process.

\subsubsection{System Warm-up to $80 \mathrm{~K}$ and to $300 \mathrm{~K}$}

For warm-up to $300 \mathrm{~K}$, warm, clean, high-pressure gas from the refrigerator is supplied to the 4-K supply line through the cooldown supply line. Similar to the cooldown process to manage magnet stresses, the supply temperature of the warm-up gas is controlled by mixing warm and $80-\mathrm{K}$ gas.

System initial status is "SYSTEM AT $20 \mathrm{~K}$." Thermal shields operate at nominal temperatures and. nominal flow rates. The coldmass is at $20 \mathrm{~K}$ and at low pressure (1-2 bar).

Warm, pure, high-pressure gas is supplied through control valve V-1362 and via crossover valve V1462 into the single-phase main feed line (Figure 65). The surface precooler is bypassed by opening bypass valve V-1508 and closing V-1501 and V-1502. An alternative is to pressurize the warm return header to at least 2 bar in order to supply warm gas; in this case, the cold flow is returned through the $20-\mathrm{K}$ lines via the quench valves (also shown in Figure 65). This allows a parallel warm-up of the shorter lengths of the string, decreasing the warm-up time required. This also "softens" the warm-up rate, thereby reducing the stresses in the magnets during warm-up. 


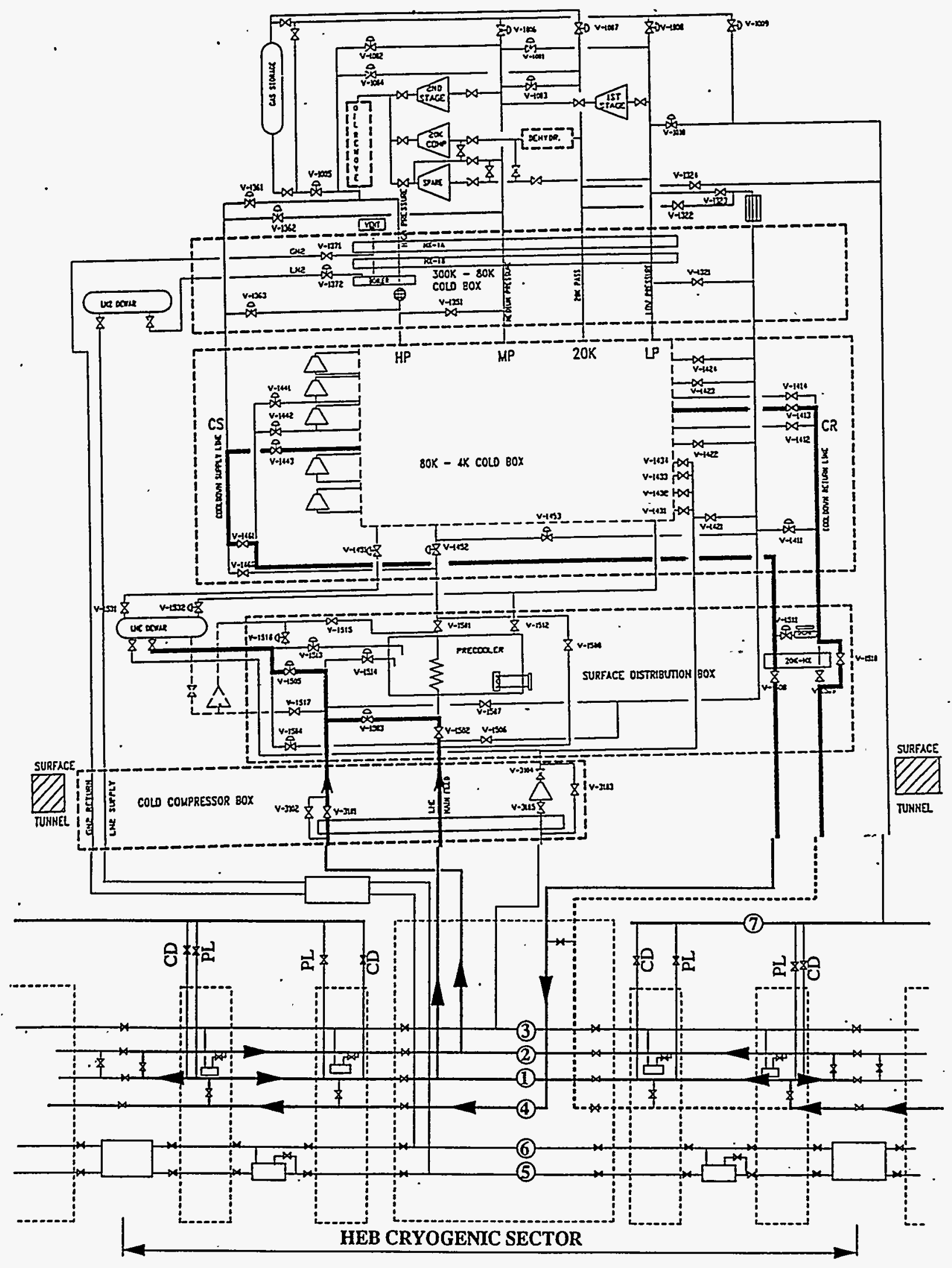

Figure 64. Sector Emptying. 


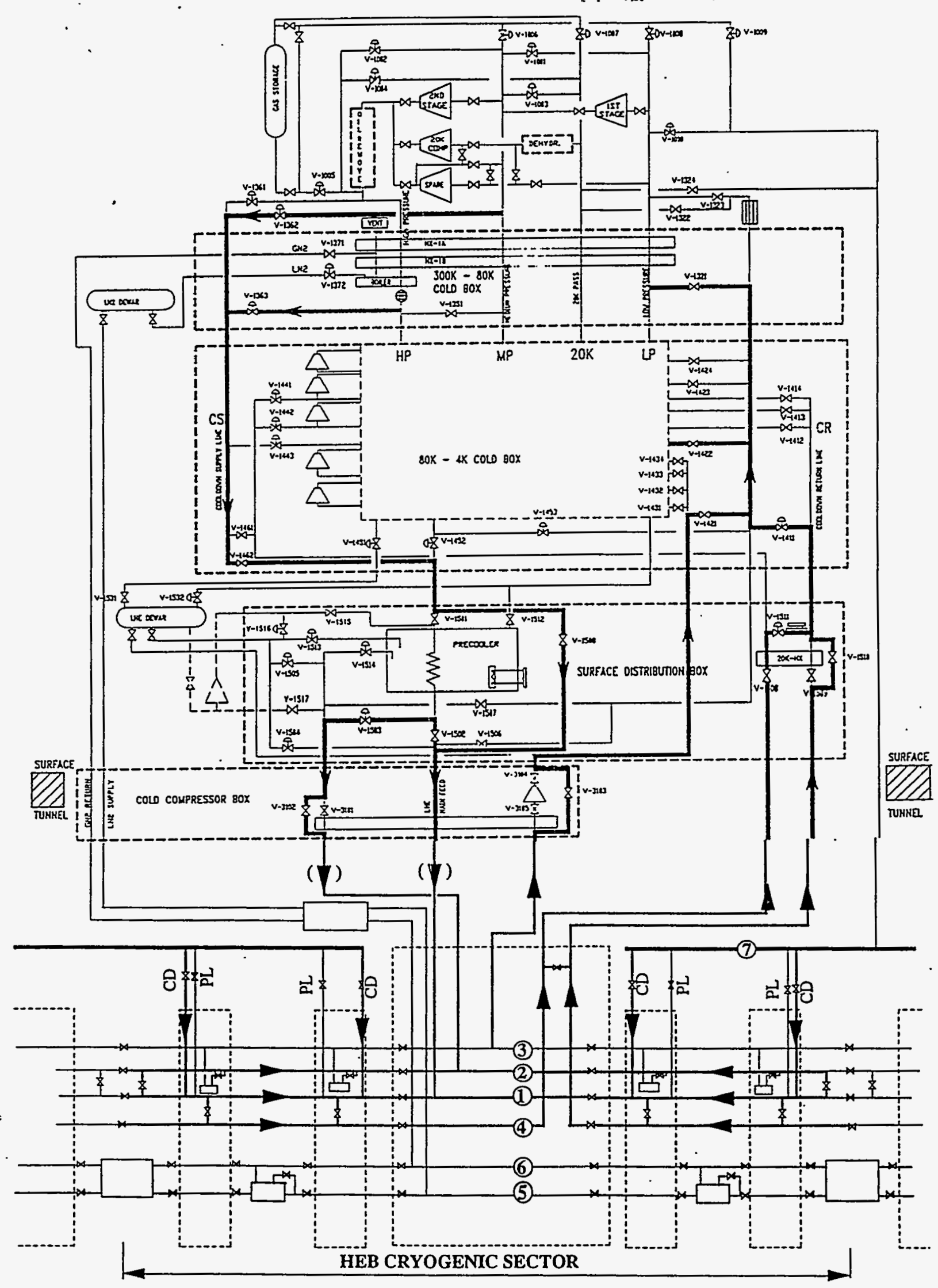

Figure 65. Sector Warm-up Using Helium from Pressurized Warm Return Header. 
The.warm-up process can be stopped at different temperature levels; the temperature level will define the status of the system. For long-time storage of the system at nitrogen temperatures, the $80-\mathrm{K}$ shields are operated at nominal conditions, and the $20-\mathrm{K}$ and $4-\mathrm{K}$ flows can be disconnected.

Excess inventory from the rings is stored on the surface in the gas tanks. The heater in the bypass between the 20-K feed and return lines is used to warm the cold gas from the strings.

Flow resistance limits the flow that can be circulated through the string. The warm-up rate will vary, depending on the routes used for the supply and return flows. The warm-up rate may be also be limited by the capacity of the 20-K bypass heater. At $100 \mathrm{~g} / \mathrm{s}$ per string and with adequate heater capacity, warm-up to $80 \mathrm{~K}$ will take approximately 3 days, and warm-up to $300 \mathrm{~K}$ about 10 days. Warm-up times can be reduced by using the parallel warm-up method and by using individual heaters for each cell.

\subsubsection{Section Repair}

The repair of a ring component such as a magnet or spool requires isolation of the section containing the faulty component from the rest of the ring. The flows to the rest of the ring must be rerouted to keep it cold. Removal or repair of a specific component also requires breaking of the vacuum in a half-cell, which is done at room temperature. A section is the smallest part of the ring that can be isolated and warmed up as a unit. HEB sections range from $1104 \mathrm{~m}$ to $1628 \mathrm{~m}$.

\subsubsection{String Emptying}

The entire string has to be emptied before maintenance personnel are allowed into the tunnel to perform isolation of the section for repair. This is done by a procedure similar to that described in Section 5.3.4.1.

\subsubsection{Section Isolation}

All the cryogenic lines are depressurized to 1 bar. The cryogenic flows in the neighboring sections are reconfigured to keep the rest of the system cold, and in particular, to keep the nitrogen in the 80-K lines running. Figure 66 shows configurations of the cryogen flows in the rest of the ring.

\subsubsection{Section Warmup}

The warm-up of a single section without warm-up of the remainder of the strings requires external warm helium circulation. There are three options for warm-up of a section:

1. Warm-up using helium from the warm-helium return header (Figure 67). This option requires a blower and heaters. The warm-up rate will be limited by the blower's head production, assuming the heaters have sufficient capacity. Warm gas in the warm return header is compressed by a blower and is supplied into the $20-\mathrm{K}$ line. The quench valves are opened to allow flow into the coldmass. The flow exits through the cooldown valves and is heated before it is returned to the warm return header.

2. Warm-up without a blower, using helium from the $20-\mathrm{K}$ line, requires a helium stream from the refrigeration loop (Figure 68). Some flow from the 20-K loop can be used for this warm-up process. The supply pressure is higher in this case, allowing a higher flow rate-and in turn, a higher warm-up rate-to be achieved. The $20-\mathrm{K}$ flow is heated and delivered through the quench valve into the coldmass. The flow exits through the cooldown valves and is heated before it is sent to the warm return header.

3. Warm-up without a blower can also be accomplished using helium from the pressurized warm return header (Figure 69). Warm gas from the return header is supplied into one end of the section via the cooldown valves. The cold gas exits at the other end of the section through a quench valve into the $20-\mathrm{K}$ line. The process is stopped when the exiting gas temperature is higher than $25-30 \mathrm{~K}$. 


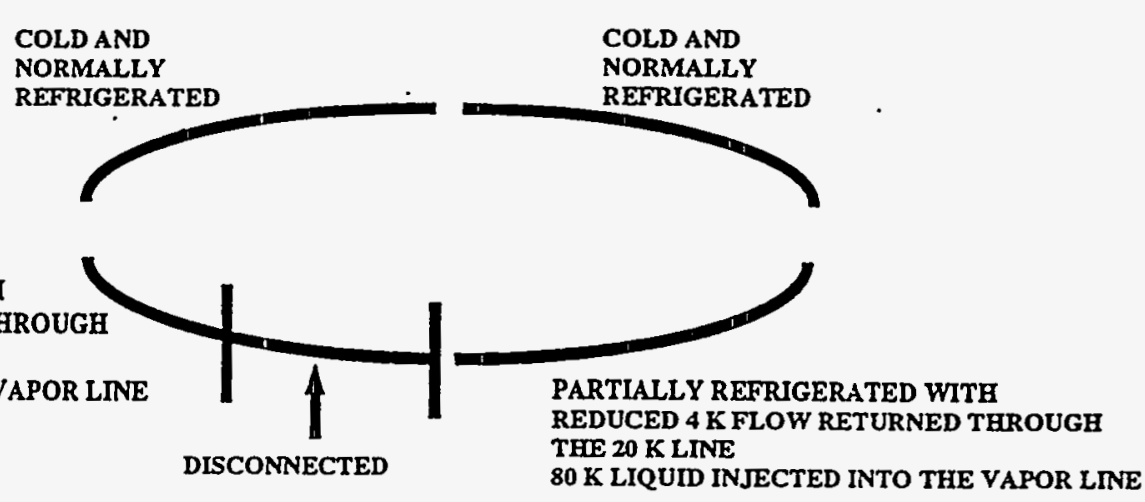

\section{HEB}

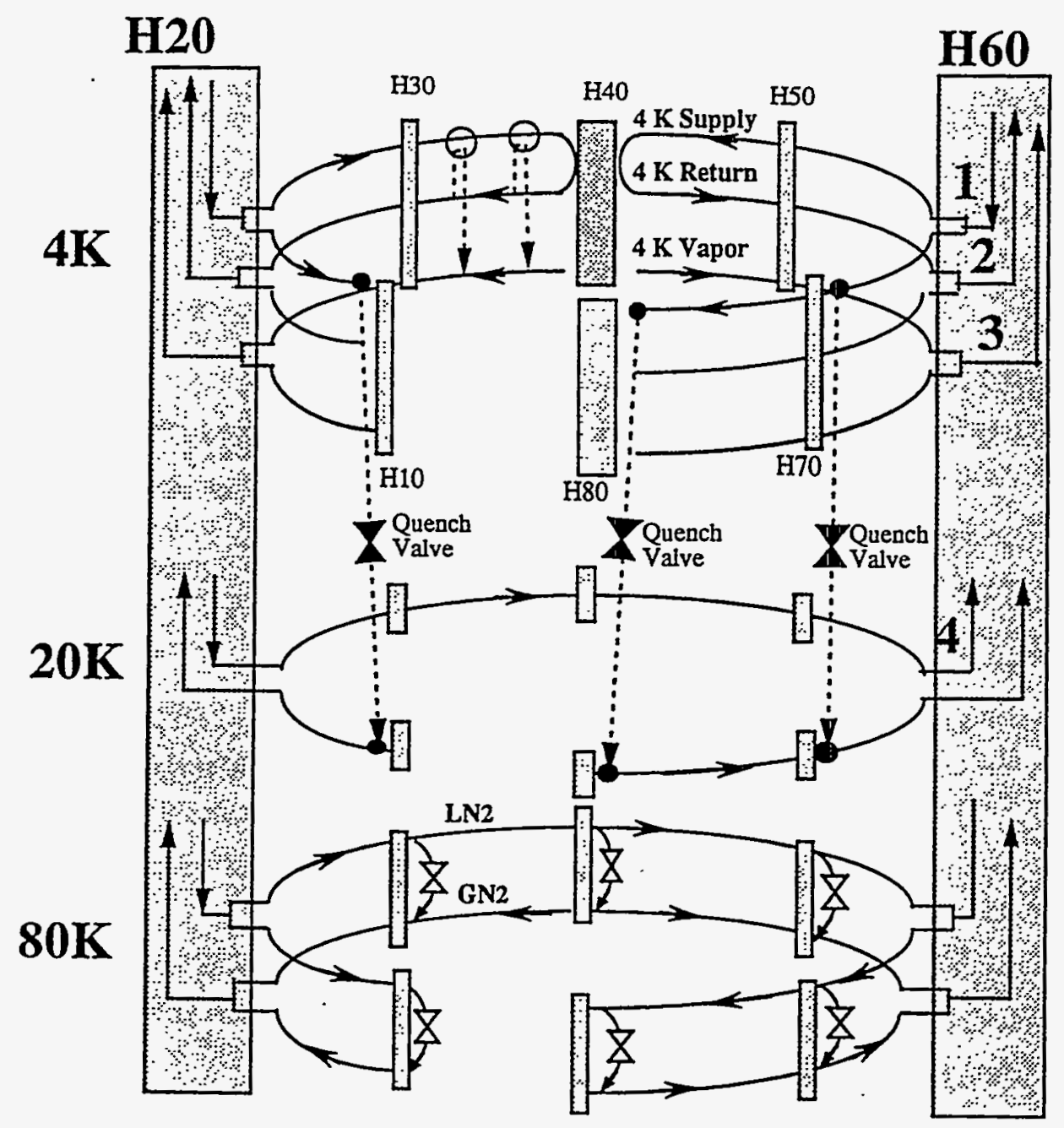

Figure 66. Flow Configuration for Section Repair. 


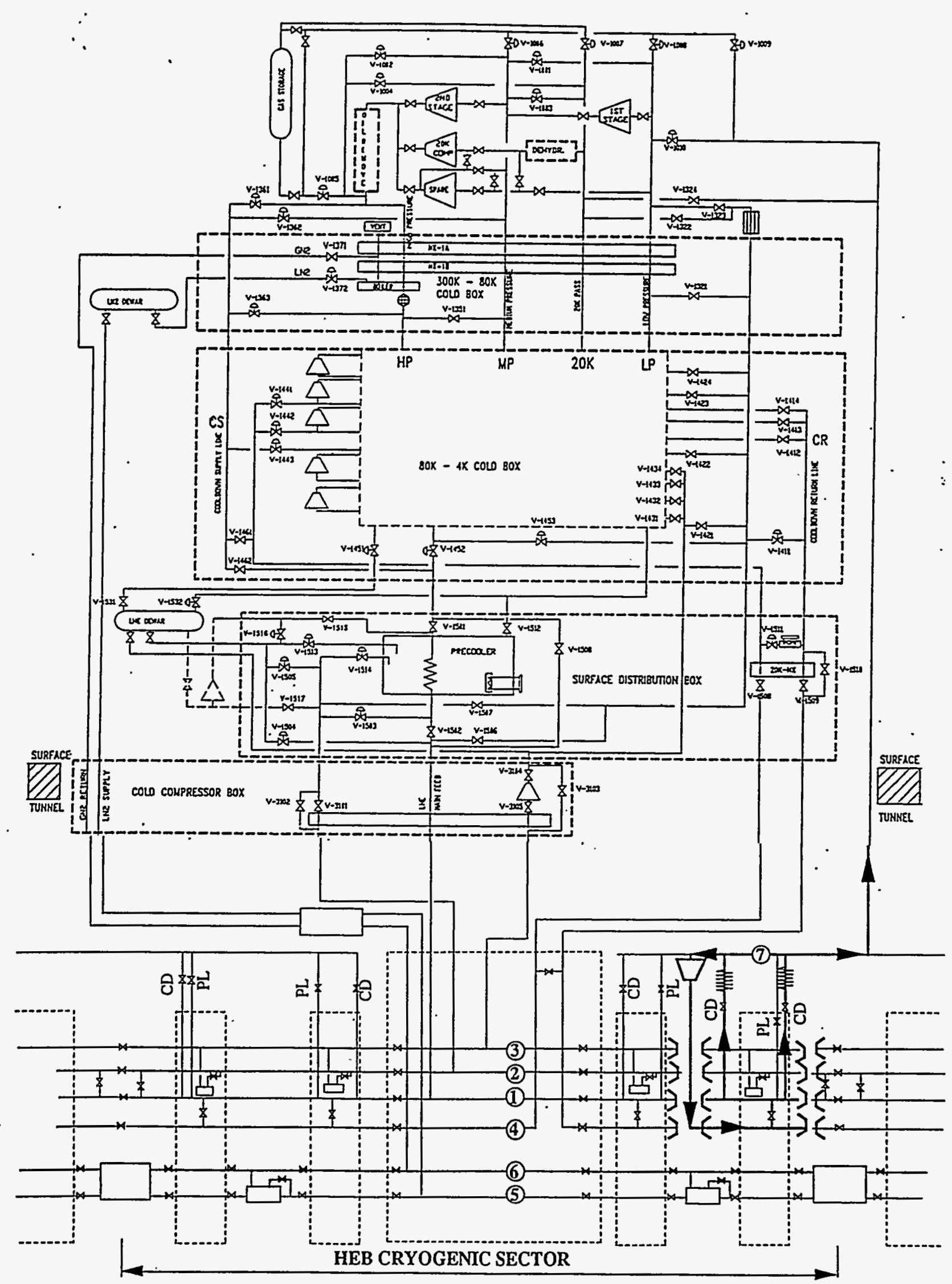

Figure 67. Section Warm-up Using Warm Return Header, Heaters, and Blower. 


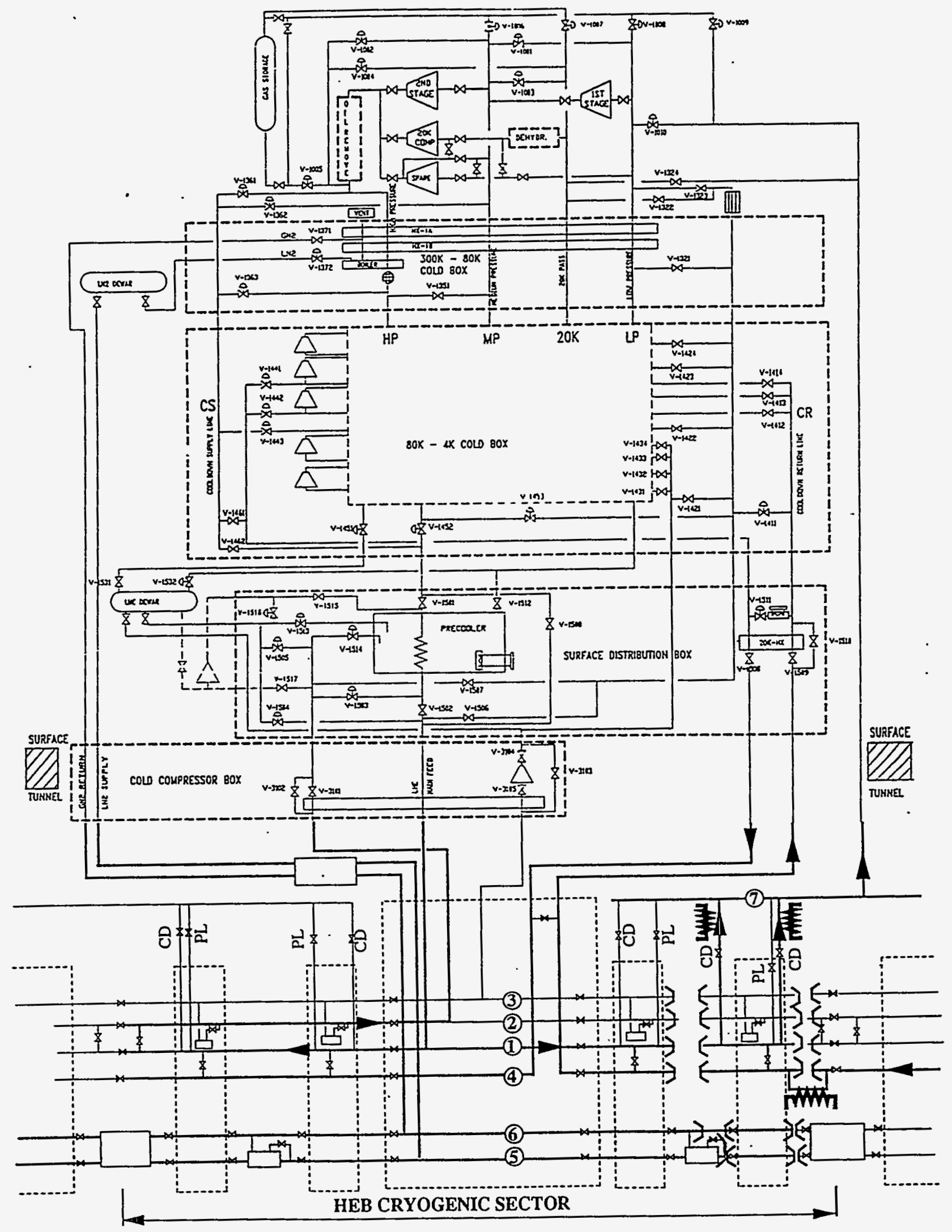

Figure 68. Section Warm-up Using 20-K Flow and Heaters. 


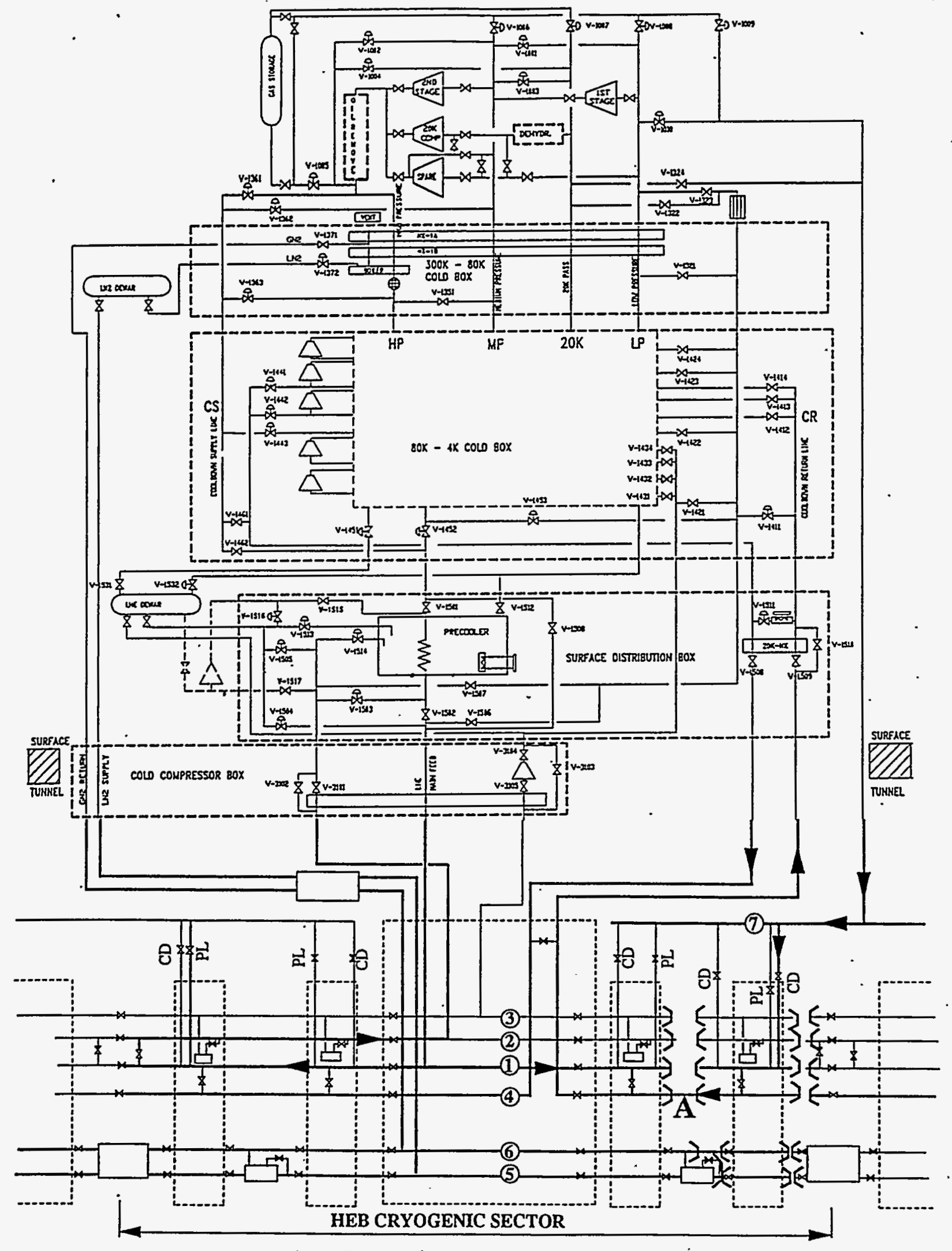

Flgure 69. Section Warm-up Using Hellum from Pressurized Warm Return Header. 


\subsubsection{Section Cleanup}

Part of the $20 \mathrm{~K}$ flow is used for cleanup, i.e., to remove contamination after repairs. The same arrangement used in option (2) for warm-up of the section can be used for cleanup. Another option is to supply high-purity helium from portable pressurized gas cylinders.

\subsubsection{Section Cooldown and Fill-up after Magnet Repair}

Cooldown of the section, with the other section already being cold, is accomplished by cooling of the $80-\mathrm{K}$ shield through release of nitrogen into the section. Next, the $20-\mathrm{K}$ shield is cooled by a controlled and moderate $20-\mathrm{K}$ flow. The coldmass is cooled by opening the quench valves and allowing the $20-\mathrm{K}$ into the coldmass, and the warm gas is vented through the cooldown valves to the warm return header (Figure 69). When the temperature of the warm gas drops below a setpoint value, the cooldown valves and the quench vaives are closed. A controlled flow rate of single-phase helium feed $(4 \mathrm{~K}, 4 \mathrm{bar})$ is allowed into the string for further cooldown and fill of the coldmass. For string cooldown to $5 \mathrm{~K}$ and fillup, the same process as defined in Section 5.3.3.5 is used.

\subsection{Emergency Operations - Line Failure or Vacuum Break}

In the case of a cryogen line failure or loss of insulating vacuum, the 4-K helium flow to the faulty string is stopped, and the string is emptied and depressurized as soon as possible. The section is then warmed up, repaired, and cooled down according to the procedure described in Section 5.3.5. References 7-9 and 19 present analyses of line rupture and cryogen spillage into the tunnel. 


\subsection{CRYOGENIC CONTROL INSTRUMENTATION}

The instrumentation for the HEB ring components is listed in Table 20. Schematics of cryogenic instrumentation for spools SPXA/SPRA, SPRF, SPRI, SPRE, SPRB, and SPRT are shown in Figures 28, $30,32,34,35$, and 36 , respectively. 
Table 20. Cryogenic Instrumentation for the Ring Components.

\begin{tabular}{|c|c|c|c|c|c|c|c|c|}
\hline Types of Spools & SPXA & SPRA & SPRF & SPRE & SPRI & SPRT & SPRB & \\
\hline Number of Spools & 139 & 139 & 2 & 2 & 4 & 17 & 12 & TOTAL \\
\hline Quench Valve Actuator & 139 & 139 & 2 & 2 & 4 & 17 & 12 & 315 \\
\hline Quench Valve Position & 278 & 278 & 4 & 4 & 8 & 34 & 24 & 630 \\
\hline Quench Valve Temperature & 139 & 139 & 2 & 2 & 4 & 17 & 12 & 315 \\
\hline Cooldown Valve Actuator & 139 & & 2 & 2 & 4 & & & 147 \\
\hline Cooldown Valve Position & 278 & & 4 & 4 & 8 & & & 294 \\
\hline Cooldown Valve Teonperature & 139 & & 2 & 2 & 4 & & & 147 \\
\hline Recooler Valve Actuator & & 139 & 2 & 2 & 4 & 17 & 12 & 176 \\
\hline Recooler Valve Position & & 278 & 4. & 4 & 8 & 34 & 24 & 352 \\
\hline Recooler Inlet Temperature & & 139 & 2 & 2 & 4 & 17 & 12 & $17 \overline{6}$ \\
\hline Recooler Outlet Temperature & & 139 & 2 & 2 & 4 & 17 & 12 & 176 \\
\hline Recooler Liquid Level & & 139 & 2 & 2 & 4 & 17 & 12 & 176 \\
\hline Line 1 Relief Valve Temperature & & & 4 & 4 & 8 & & & 16 \\
\hline Line 2 Relief Valve Iemperature & & & 4 & 4 & 8 & & & 16 \\
\hline Line 3 Relief Valve Temperature & & & 4 & 4 & 8 & & & 16 \\
\hline Line 4 Relief Valve Temperature & & & 4 & 4 & 8 & & & 16 \\
\hline Line 5 Relief Valve Temperature & & & 4 & 4 & 8 & & & 16 \\
\hline Line 6 Relief Valve Temperature & & & 4 & 4 & 8 & & & 16 \\
\hline Line 2 Temperature & & & 4 & 4 & 8 & & & 16 \\
\hline Line 3 Temperature & & & 4 & 4 & 8 & & & 16 \\
\hline Line 4 Temperature & & & 4 & 4 & 8 & & & î6 \\
\hline Line 5 Temperature & & & 4 & 4 & 8 & & & 16 \\
\hline Line 6 Temperature & & & 4 & 4 & 8 & & & 16 \\
\hline Linel Pressure & & & 4 & 4 & $\overline{8}$ & & & 16 \\
\hline Line 2 Pressure & & & 4 & 4 & 8 & & & 16 \\
\hline Line 3 Pressure & & & 4 & 4 & 8 & & & 16 \\
\hline Line 4 Pressure & & & 4 & 4 & 8 & & & 16 \\
\hline Line 5 Pressure & & & 4 & 4 & 8 & & & 16 \\
\hline Line 6 Pressure & & & 4 & 4 & 8 & & & 16 \\
\hline Power Leads Control Valve Actuator & & & 8 & 8 & 16 & & & 32 \\
\hline Power Leads Control Valve Position & & & 16 & 16 & 32 & & & 64 \\
\hline Power Leads Temperature & & & 8 & 8 & 16 & & & 32 \\
\hline CEPL Valve Actuator & & 278 & & & & & & 278 \\
\hline CEPL Valve Position & & 556 & & & & & & 556 \\
\hline CEPL Texperatuse & & 278 & & & & & & 278 \\
\hline Cooldown Valve Actuator, Lines 2,3,4,5,6 & & & 20 & 20 & 40 & & & 80 \\
\hline Cooldown Valve Position, Lines 2,3,4,5,6 & & & 40 & 40 & 80 & & & 160 \\
\hline Cooldown Valve Temperature, Lines $2,3,4,5,6$ & & & 20 & 20 & 40 & & & 80 \\
\hline LN Isolation Valves Actuation & & & & & 8 & & & 8 \\
\hline GN Isolation Valves Actuation & & & & & 8 & & & 8 \\
\hline LN Isolation Valves Position & & & & & 16 & & & 16 \\
\hline GN Isolation Valves Position & & & & & 16 & & & 16 \\
\hline N2 Recooler Control Valve Actuator & & & & & 4 & & & 4 \\
\hline N2 Rocooler Control Valve Position & & & & & 8 & & & 8 \\
\hline N2 Recooler Liquid Level & & & & & 4 & & & 4 \\
\hline N2 Recooler Outlet Temperature & & & & & 4 & & & 4 \\
\hline N2 Continuous Recooling Control Valve (Optional) & & & V & V & V & & & \\
\hline $4 \mathrm{~K}$ Injection Control Valve into $20 \mathrm{~K}$ & & & 7 & & & & & \\
\hline (Quench Valve may be used instead) & & & 2 & 2 & 4 & & & 8 \\
\hline & & & & & & & & \\
\hline SUMMARY & SPXA & SPRA & SPRF & SPRE & SPRI & SPRT & SPRB & TOTAL \\
\hline Total number of analog acturators & & $41 \overline{7}$ & 10 & 10 & 24 & 17 & 12 & 490 \\
\hline Total number of ON-OFF actuators & 278 & 139 & 24 & 24 & 64 & 17 & 12 & 558 \\
\hline Total number of position switches & 556 & 1112 & 68 & 68 & 176 & 68 & 48 & 2096 \\
\hline Total number of temperature sensors & 278 & 695 & 80 & 80 & 164 & 51 & 36 & 1384 \\
\hline Total number of Pressure sensors & & & 24 & 34 & 48 & & & $\overline{0}$ \\
\hline & & & 24 & 24 & 48 & & & 96 \\
\hline Total number of level sensors & & 139 & 2 & 2 & 8 & 17 & 12 & 180 \\
\hline & & & & & & & & \\
\hline Total 1/O Points $f$ & the & Ring & yoger & ystem & & & & 4804 \\
\hline
\end{tabular}




\subsection{VALUE ENGINEERING TRADE-OFFS}

The primary topics discussed in the "Value Engineering" working groups during August and September 1993 were the following:

- Is it possible to reduce the number of MLI layers on the 80-K shield?

The design of the 80-K shield MLI (multi-layer insulation) in the cryostats is based on 64 layers. The cost of the shield and the MLI may be reduced if the insulation is eliminated or the number of layers reduced. However, the resulting increase in the heat leak renders the $\mathrm{LN}_{2}$ demand too high for the designed distribution system. To handle this demand, an increase in the $\mathrm{LN}_{2}$ pipe diameter of the cryostats will probably be required. This may in turn require an increase in the external diameter of the cryostats to accommodate the larger pipes. In addition, the $20-\mathrm{K}$ refrigeration load will increase. This load is already large, so that the SRS has to be operated in a special way to support the additional load.

Based on the given data and calculations made by the Magnet Division, it is conceivable to reduce the number of layers to 48. However, the margins for the SRS operation and the limits on the temperature variations in the coldmass make this savings very dangerous.

- Is it possible to reduce the number of vacuum barriers in the spool pieces?

The vacuum barrier was removed from the SPXA spools in the HEB. The question was whether it is possible to go a step further and remove vacuum barriers from the SPRA.

The optimization of the distance between the vacuum barriers was done in the Central Design Group (CDG). The work was based on system reliability, maintainability, time to pump-down, and time to detect vacuum problems. Based on the CDG reasoning, the answer to the question was that it is not possible to remove the vacuum barriers from the SPRA in the HEB.

- Is it possible to replace the SPRI in H3O and H7O by a regular SPRA?

The design of the SPRI in $\mathrm{H} 30$ and $\mathrm{H} 70$ is very complicated and costly, requiring a wider tunnel and special transportation and installation procedures. The question was whether it is possible to replace it by a regular SPRA, thereby removing the "isolation" features.

It was suggested that an SPRA could be used with a special arrangement to connect to the nitrogen recooler. Canceling the isolation features will increase the time for pumpdown and leak-check of the beam tube, and the time for the desorption process. During maintenance or magnet replacement, the whole string will have to be warmed up.

- Is it possible to replace the collider-to-HEB Cryogenic Transfer Line by a direct local supply of nitrogen to the HEB (three trucks a day)?

Without the helium lines, there is no way through which one refrigeration system (HEB) can assist the other system (the cluster region of the collider).

- Is it possible to reduce the number of quench valves, from one quench valve per spool to one quench valve every other spool?

The high dynamic heat load of the HEB will probably require crossflow cooling in the magnets. Helium venting during a quench through magnets with crossflow cooling passages is not well understood and needs further study and experimental verification. The number, size, and frequency of quench valves can be revised, depending on experimental results with half-cell and full-cell string tests.

- Are bypass lead cooling valves required in every spool?

The HEB heat budget allocates liquefaction and refrigeration loads for bypass lead cooling in all the SPXA- and SPRA-type spools. Figure 3.2.1.1-2 in the HEB Level 3B Specification ${ }^{1}$ shows one bypass lead per cell (either at every SPXA or at every SPRA). Therefore, bypass cooling valves are not required at every spool; as a result, the total liquefaction and refrigeration budget loads can be reduced slightly. 


\section{REFERENCES}

\section{SSCL System Specifications}

1. "Element Specification (Level 3B) for the HEB Accelerator of the Superconducting Super Collider Laboratory," No. E10-000054, Superconducting Super Collider Laboratory, Dallas, Texas, Aug. 27, 1992.

2. "SSC HEB Conventional Construction Design Requirement Document (CCDRD)," SSC Laboratory, Dallas, Texas, 1993.

3. "Conceptual Design of the Superconducting Super Collider," SSC-SR-2020, SSC Central Design Group, Berkeley, California, March 1986.

4. "Site-Specific Conceptual Design," SSC-SR-1056, SSC Laboratory, Dallas, Texas, July 1990.

5. "HEB Preliminary Design Requirements Review," E13-000191, ASD/PMO, SSC Laboratory, Dallas, Texas,

6. "HEB Magnet Interface Control Document," M80-000075, SSC Laboratory, Dallas, Texas.

\section{Safety and Quench}

7. S. Abramovich and D. Clark, "Relief Valve Design Resulting from Cryogenic Line Rupture," SSCL-N-711, AS-CY-001, SSC Laboratory, Dallas, Texas, May 1990.

8. "Spilling of Helium Gas from the $20 \mathrm{~K}$ Shield into the Tunnel," Cryogenics Consultants, Inc., Allentown, PA, under Contract 4547110, University of California, SSC-N-441, 1987.

9. "Spillage of $80 \mathrm{~K}$ Shield Line Contents into the Tunnel of the SSC" Cryogenics Consultants, Inc., Allentown, PA, under Contract 4547110, University of California, SSC-N-442, 1987.

10. R. H. Carcagno and W. E. Schiesser, "Helium Venting Computer Simulation During an SSC Dipole Quench," Advances in Cryogenic Engineering, Vol. 37A, 1991.

11. R. H. Carcagno, "SSC Full Quench Simulation Results - First Attempt," SSC Laboratory, Dallas, Texas, Sept. 16, 1988.

12. R. H. Carcagno, M. S. McAshan and W. E. Schiesser, "Helium Venting Model for a SSC HalfCell," Supercollider 3, J. Nonte, ed., Plenum Press, NY, p. 847, 1991.

13. R. Carcagno, J. Demko, A. Yücel and X. Xu, "Catastrophic Loss of Insulating Vacuum to Air Analysis," Cryogenics Dept. Memorandum, SSC Laboratory, Dallas, Texas, Nov. 22, 1991.

14. R. H. Carcagno, W. E. Schiesser, H.-J. Shih, X. Xu and A. Yücel, "A Dynamic Model for Beam Tube-Vacuum Effects on the SSC Cryogenic System," Supercollider 4, J. Nonte, ed., Plenum Press, NY, pp. 897-904, 1992.

15. S. Augustynowicz, "ODH, Oxygen Deficiency Hazard, Cryogenic Analysis," Proceedings of Cryogenic Engineering Conference, Albuquerque, NM, 1993.

16. S. Augustynowicz and J. Maddocks, "ODH, Oxygen Deficiency Hazard, Magnet Test Laboratory Analysis," SSC Laboratory, Dallas, Texas, June 1993.

17. S. Augustynowicz, J. Maddocks, and G. Mulholland, "ODH - Oxygen Deficiency Hazard, N15 Site Analysis," AHA-8200001, SSC Laboratory, Dallas, Texas, September 1992.

18. J. Maddocks, S. Augustynowicz, and G. Mulholland, "Oxygen Deficiency Hazard Analysis for the ASST Building at the N15 Site,” AHA-9010001, SSC Laboratory, Dallas, Texas, April 1992. 
19. K. E. Stifle, "A Program to Analyze Rupture of Single Phase Helium Line in the SSC Magnet Cryostat," SSC Cryo Note 94-27, SSC Laboratory, Dallas, Texas, Jan. 1994.

20. R. H. Carcagno; W. E. Schiesser, and A. Yücel, "Prototype Helium Flow and Heat Transfer Model and Code," SSCL-N-850, SSC Laboratory, Dallas, Texas, Aug. 1993.

\section{Refrigerator System}

21. M. McAshan, "Refrigeration Plants for the SSC," SSC-129, Berkeley, California, SSC Central Design Group, May 1987.

22. R. Powell and H. Quack, "A Refrigeration Plant Concept for the SSC," Supercollider 2, M. McAshan, ed., pp. 199-208, Plenum Press, New York, 1990.

23. U. Wagner and W. Keyer, "Process Design Features of the SSC MTL Cryogenic System," Supercollider 3, J. Nonte, ed., pp. 873-883, Plenum Press, New York, 1991.

24. "Sector Refrigerator Surface System for the Collider Main Ring and High Energy Booster, Superconducting Supercollider Laboratory (SSCL)," Solicitation No. RFP SSC 93A-09339, SSC Laboratory, Dallas, Texas, 1992.

25. M. McAshan, V. Ganni, R. Than, and T. Niehaus, "Refrigeration Plants for the SSC," Supercollider 3, J. Nonte, ed., Plenum Press, New York, 1991.

26. R. Than, S. Abramovich and V. Ganni, "The SSC Cryogenic System Design and Operating Modes," SSC Cryo Note 92-12, SSC Laboratory, Dallas, Texas, October 1992.

27. W. Fietz, V. Ganni, S. Abramovich, and T. Niehaus, "Cryogenic Systems for the SSC and their Status," Cryogenic Engineering Conference, Albuquerque, New Mexico, 1993.

28. J. Demko and V. Ganni, "Procedure for Sector Refrigerator System Performance Calculations," SSC Cryo Note 93-17, SSC Laboratory, Dallas, Texas, 1993.

29. J. Weisend, A. McInturff, S. Augustynowicz, W. Burgett, R. Coombes, C. Dickey, T. Dombeck, W. Fietz, R. Flora, P. Kraushaar, M. McAshan, G. Mulholland, W. Robinson, F. Spinos, G. Tool, D. Wallis, and J. Zbasnik, "SSCL Half Cell Operational Test," Applied Superconductivity Conference, Chicago, Illinois, 1992.

30. A. McInturff, R. Flora, B. Norris, J. Theilacker, D. Wolff, S. Augustynowicz, C. Dickey, G. Tool, D. Wallis, and J. Weisend, "Half Cell SSC $40 \mathrm{~mm}$ Aperture Magnet String," XII International Conference on Magnet Technology, Leningrad, Russia, IEEE Transactions on Magnetics, Vol. 28, 1, pp. 5-12, 1992.

31. J. Weisend, S. Augustynowicz, C. Dickey, R. Flora, A. McInturff, B. Norris, J. Theilacker, D. Wallis, and D. Wolff, "SSC Magnet String Test at Fermilab: Capabilities and Goals," XVIII International Congress of Refrigeration, Montreal, Proceedings of IIR (Commission A1/2), 1992.

32. S. Augustynowicz, C. Dickey, A. McInturff, D. Wallis, and J. Weisend, "Cryogenic Installation for Superconducting Magnets: String.Test," XVIII International Congress of Refrigeration, Montreal, Proceedings of IIR (Commission A1/2), 1992.

33. "Sector Station Refrigeration System Preliminary Design Review" Cryogenics Department, SSC Laboratory, Dallas, Texas, September 1-2, 1992.

34. "Technical Specification, Sector Refrigerator Surface System (SRS) For The Collider Main Ring And High Energy Booster, Superconducting Supercollider Laboratory (SSCL)," AHA-6110002, SSC Laboratory, Dallas, Texas, October 1992.

35. "Statement of Work (SOW), Sector Refrigerator Surface System (SRS) for the Collider Main Ring and High Energy Booster Superconducting Supercollider Laboratory (SSCL)," RFP SSC-93-A09339, AHA-6110003 (with Appendices A-E), SSC Laboratory, Dallas, Texas, December 1992. 
36. "Cost Breakdown, Sector Refrigerator Surface System (SRS) For The Collider Main Ring And High Energy Booster, Superconducting Supercollider Laboratory (SSCL)," W.B.S. 311.1110, W.B.S. 322.1110, SSC Laboratory, Dallas, Texas, October 1992.

37. R. Carcagno, V. Ganni, D. Rivenbark, and B. Shuster, "Process Control Description, Example for a Compressor Skid," SSC Cryo Note 92-13, SSC Laboratory, Dallas, Texas, October 1992.

38. B. Zhang, V. Ganni, and J. Lobb, "Functionalities of the Cryogenic Facilities and Sector Underground Enclosure," Cryogenics Department, SSC Laboratory, Dallas, Texas, 1992.

39. D. Hartzog, V. Fox, P. Mathias, D. Nahmias, M. McAshan and R. Carcagno, "Dynamic Modeling and Simulation of the Superconducting Super Collider Cryogenic Helium System," Supercollider 1, M. McAshan, ed., Plenum Press, New York, pp. 301-320, 1989.

40. V. Ganni, R. Than and M. Thirumaleshwar, "Operational Modes and Control Philosophy of the SSCL Magnet Test Lab. (MTL) Cryogenic System," Supercollider 4, J. Nonte, ed., Plenum Press, NY,1992.

41. R. Than and V. Ganni, "Operational Modes and Control Philosophy of the Accelerator System String Test Cryogenic System,” SSC Cryo Note 94-42, SSC Laboratory, Dallas, Texas, December 1993.

42. V. Ganni, S. Abramovich, and T. Apparao, "Operating Modes and Design Features of the SSC Sector Station Cryogenic System," Supercollider 5, J. Nonte, ed., Plenum Press, New York, 1994 (Also SSCL Preprint 297).

43. V. Ganni and T. Apparao, "Design Verification of the ASST-A Helium Refrigeration System," Cryogenic Engineering Conference, Albuquerque, New Mexico, July 1993.

44. S. Abramovich and A. Scheidemantle, "84 K Nitrogen System for the SSC," (Two-phase flow in the liquid line), SSCL-N-712, AS-CY-002, SSC Laboratory, Dallas, Texas.

\section{Nitrogen System}

45. M. McAshan, M. Thirumaleshwar, S. Abramovich, V. Ganni, and A Scheidemantle, "84 K Nitrogen System for the SSC," Supercollider 4, J. Nonte, ed., Plenum Press, NY, pp. 207-217, 1992.

46. M McAshan, S. Abramovich, M.Thirumaleshwar, and V. Ganni, "84 K Nitrogen System for the SSC" (Continuous recooling system), SSCL-592, SSC Laboratory, Dallas, Texas, October 1992.

47. S. Abramovich, A. Yücel, J. Demko, and M Thirumaleshwar, "Thermal and Flow Considerations for the $80 \mathrm{~K}$ Shield of the SSC Magnet Cryostats," SSCL Preprint 212, Supercollider 5, J. Nonte, ed., Plenum Press, NY, 1994

48. S Abramovich, "Why $80 \mathrm{~K}$ MLI ?," Note for the Value Engineering Committee at the SSC showing the data on the $80 \mathrm{~K}$ shield heat load and the reduction due to multi-layer insulation on the thermal shield, SSC Laboratory, Dallas, Texas, October 1993.

49. K. Stifle and V. Ganni, "Two-Phase Pressure Drop for SSC Nitrogen System," SSC Cryo Note 9321, SSC Laboratory, Dallas, Texas, 1993.

50. S. Abramovich, J. Demko and M. Thirumaleshwàr, "Nitrogen System for the SSC: Continuous Recooling by Injection Liquid Into the Vapor Line" SSCL Cryo Note 94-30, SSC Laboratory, Dallas, Texas, January 1994.

51. A. Yücel and S. Abramovich, "Study of $80 \mathrm{~K}$ Shield Temperature Distributions," SSC Cryo Note 92-9, SSC Laboratory, Dallas, Texas. 


\section{Heat Load Budgets}

52. S. Abramovich and A. Yücel, "Cryogenics and Heat Load Budget for Collider Sector N1," SSC Cryo Note 92-3, SSC Laboratory, Dallas, Texas.

53. S. Abramovich and A. Yücel, "Cryogenics and Heat Load Budget for the HEB," SSC Cryo Note 9210, SSC Laboratory, Dallas, Texas.

54. A. Yücel and S. Abramovich, "Cryogenic System Layout and Heat Load Budget for Collider Sector N5," SSC Cryo Note 92-11, SSC Laboratory, Dallas, Texas.

\section{Design (Mechanical/Thermal/Flow)}

55. B. Zhang and K. Stifle, "Preliminary Design of Sector Cryogenic Shaft Transfer Line System," Supercollider 5, J. Nonte, ed., Plenum Press, New York, 1994.

56. K. Stifle and B. Zhang, "Experimental Strength Verification of SSC Cryogenic Transfer Line Internal Suspension System," Supercollider 5, J. Nonte, ed., Plenum Press, New York, 1994.

57. "Empty Cryostats Conceptual Design Review" SSCL, Magnet Division, SSC Laboratory, Dallas, Texas, September 1993.

58. K. Stifle, J. Demko, "Evaluation of The Accelerator System String Test (ASST) Heat Leak Measurements and Their Uncertainties," SSC Cryo Note 93-24, SSC Laboratory, Dallas, Texas, 1993.

59. K. Stifle and B. Zhang, "Development and Testing of a Prototype Internal Suspension System using Composite Materials for Cryogenic Transfer Lines," SSC Cryo Note 92-16, SSC Laboratory, Dallas, Texas, 1993.

60. K. Stifle, "Comparison of ASST Bellows vs. Externally Pressurized Expansion Joints for Use in the Transfer Line Prototype Development Program," SSC Technical Note 59, SSC Laboratory, Dallas, Texas, 1992.

61. A. Yücel and J. Maddocks, "Thermal Conductivity of Commercially Available 21-6-9 Stainless Steel," Advances in Cryogenic Engineering-Materials, Vol. 40, 1993.

62. J. Maddocks, J. Zbasnik, A. Yücel and R. Spidle, "Heat Leak Measurements and Thermal Modeling of a Mechanical Support for a SSC Beam Tube Liner," Supercollider 5, J. Nonte, ed., Plenum Press, NY, 1994.

63. Q. S. Shu et al., "Design Report on the SSCL Prototype $80 \mathrm{~K}$ Synchrotron Liner System," SSCLSR-1224, SSC Laboratory, Dallas, Texas, September 1993.

64. Q.S. Shu et al., "Second Workshop on the Testing of SSC Magnet Cryogenic Performance," SSCLN-798, SSC Laboratory, Dallas, Texas, August 1992.

65. A. Yücel and S. Abramovich, "Space for the Spool Pieces, Bypasses and Connection Boxes in the Clusters - Addendum: Collider Cryogenic Bypasses," SSC Cryo Note 93-18, SSC Laboratory, Dallas, Texas.

66. S. Abramovich and A. Yücel, "Increased Pressure Drop Allocations for HEB Magnets," SSC Cryo Note 92-8, SSC Laboratory, Dallas, Texas.

67. A. Yücel, "Analysis of Crossflow Cooling in 50mm-CDM with Orificed Channels," SSCL-N-852 SSC Laboratory, Dallas, Texas, April 1994, also SSC Cryo Note 92-5.

68. S. Abramovich and A. Yücel, "Space for the Spool Pieces, Bypasses and Connection Boxes in the Clusters," SSC Cryo Note 92-2, SSC Laboratory, Dallas, Texas.

69. S. Augustynowicz, J. Demko and V. Datskov, "Analysis of Multilayer Insulation Between $80 \mathrm{~K}$ and $300 \mathrm{~K}$," Proceedings of Cryogenic Engineering Conference, Albuquerque, NM, 1993. 
70. V Datskov, J. Bemko, S. Augustynowicz, and R. Hutton, "An Experimental Evolution of Joint Electrical Resistance on Power Lead Thermal Performance," Supercollider 5, J. Nonte, ed., Plenum Press, New York, 1994.

71. W. Boroski, S. Augustynowicz, J. Demko, "A MLI Comparison Performance: Laboratory Test and SSC Magnet String Test," Proceedings of The Ninth Intersociety Cryogenic Symposium, ASME, Houston, TX, 1993

72. S. D. Augistynowicz, J. A. Demko, and V. I. Datskov, "Analysis of Multi-layer Insulation between $80 \mathrm{~K}$ and $300 \mathrm{~K}$," Cryogenic Engineering Conference, Albuquerque, New Mexico, July 1993.

73. V. I. Datskov, J. A. Demko, S. D. Augustynowicz, and R. D. Hutton, "An Experimental Evaluation of Joint Electrical Resistance on Power Lead Thermal Performance," Supercollider 5, J. Nonte, ed., Plenum Press, New York, 1994.

74. A. Yücel, "Transient Response of the $20 \mathrm{~K}$ Shield of the Collider Dipole Magnets," SSCL-N-862, SSC Laboratory, Dallas, Texas, April 1994.

75. Q. S. Shu, J. Demko, R. Domam, D. Finan, T. Peterson, I. Syromyatnikov, and A. Zolotov, "The Thermal Optimum Analyses and Mechanical Design of 10kA Vapor Cooled Power Leads for the SSC Sunerconducting Magnet Tests at MTL", Paper LKB-8, Applied Superconductivity Conference, Chicago, Illinois, August 23-28, 1992.

76. J. A. Demko, W. E. Schiesser, R. Carcagno, and M. McAshan, "A Method of Lines Solution of the Transient Behavior of the Helium Cooled Power Leads for the SSC," Advances in Computer Methods for Partial Differential Equations - VII, Proceedings of the Seventh IMACS International Conference on Computer Methods for Partial Differential Equations, New Brunswick, New Jersey, June 22-24, 1992.

77. J. A. Demko, W. E. Schiesser, R. Carcagno, M. McAshan, and R. McConeghy, "Thermal Optimization of the Helium-Cooled Power Leads for the SSC," Supercollider 4, J. Nonte, ed., Plenum Press, NY, 1992 (Also as SSCL Preprint 24).

78. J. A. Demko and V. I. Datskov, "Operation and Control of the Helium Cooled Power Leads for the Superconducting Super Collider," Superconducting Super Collider Laboratory, SSC Cryo Note 93-23.

79. V. I. Datskov, J. A. Demko, and R. McConeghy, "Measurements of a 100 Ampere High Temperature Superconductor Lead," SSC Cryo Note 94-26, SSC Laboratory, Dallas, Texas.

80. N. Saho, V. Ganni, S. Abramovich, and T. Apparao, "Preliminary Design of Cold Compressor for Large Scale Accelerator With Superconducting Magnets," SSC Cryo Note 94-41, SSC Laboratory, Dallas, Texas, December 1993.

81. N. Saho and T. Apparao, "Modeling and Simulation of the Cold Compressor," SSC Cryo Note 9443, SSC Laboratory, Dallas, Texas, December 1993.

Maintenance and Availability

82. R. H. Carcagno, "A Cooldown/Warmup Computer Model for the SSC," SSC-N-38, SSC Laboratory, Dallas, Texas, September 1987.

83. M. McAshan, "Ring Component Replacement," Project Leaders Meeting, SSC Laboratory, Dallas, Texas, May 14, 1991.

84. K. T. Dixon and B. L. Blackford, "Design Reference Mission and Operational Timelines for the Reliability/Maintainability/Availability Allocations for the Collider Subsystems," AQA-10110055, SSC Laboratory, Dallas, Texas, 27 March 1992 (Released May 1993). 
85. K. Dixon and J. Franciscovich, "SSC Accelerator Availability Allocation," Supercollider 3, J. Nonte, ed., Plenum Press, NY, 1991.

86. R. Carcagno, W. E. Schiesser and A. Yücel, "Cooldown and Warmup Simulations of the SSC Ring," Advances in Cryogenic Engineering, Vol. 37A, pp. 699-788, 1991. 
APPENDIX

DETAILED HEAT LOAD BUDGETS FOR THE HEB 


\section{Appendix \\ Detailed Heat Load Budgets for the HEB}

May 1993: A. Yucel and S. Abramovich

1) HQM3's replaced by HQM's in the lattice

2) Updated numbers for $\mathrm{N} 2$ distribution loads

Mar 1994: A. Yucel and S. Abramovich

1) Updated support and radiant heat loads for connection boxes

2) Added valve heat leaks for connection boxes

3) Deleted nominal vs design heat loads - have design only $(1 \mathrm{~W} / \mathrm{m})$

4) Updated bypass elements in short and long straight segments

5) Updated sector distribution loads

A. MODEL INPUTS

1a) Component Arrangement

Number of Dipoles per Cell

1b) Component Lengths

Length of Cell

Length of Short Straight Section

Length of Long Straight Section

2a) Dipole Parameters

Length of Dipole

Number of Posts in Dipole

Number of Splices in Dipole

2b) Empty Cryostat

Length of Cryostat EC 6.5

Number of Posts in Cryostat

Number of Splices in Cryostat

Length of Cryostat EC 2.8
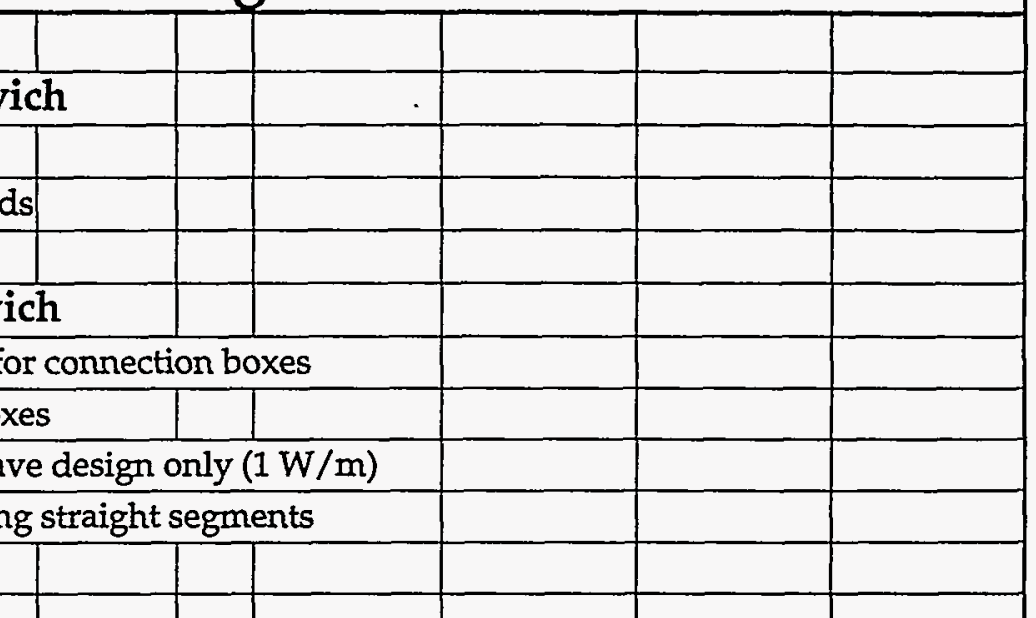


\begin{tabular}{|c|c|c|c|c|c|}
\hline & & Liquif. & $4 \mathrm{~K}$ & $20 \mathrm{~K}$ & $80 \mathrm{~K}$ \\
\hline & & $\mathrm{g} / \mathrm{s}$ & Watts & Watts & \\
\hline \multicolumn{6}{|l|}{ 3) Quadrupole Parameters } \\
\hline Length of Quadrupole & $1.6 \mid \mathrm{m}$ & & & & \\
\hline Number of Posts in Quadrupole & 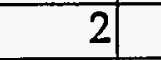 & & & & \\
\hline Number of Splices in Quadrupole & 11 & & & & \\
\hline Length of Quadrupole HQM1 & $0.902 \mathrm{~m}$ & & & & \\
\hline Length of Quadrupole HQM2 & $1.173 \mathrm{~m}$ & & & & \\
\hline Length of Quadrupole HQM3 & $2.258 / \mathrm{m}$ & & & & \\
\hline Length of Quadrupole HQM4 & $3.347 \mathrm{~m}$ & & & & \\
\hline \multicolumn{6}{|l|}{ 4) Spool Parameters } \\
\hline Length of Spool & $3.675 \mathrm{~m}$ & & & & \\
\hline Number of Posts in Spool & 2 & & & & \\
\hline Number of Splices in Spool & 4 & & & & \\
\hline MLI Factor & & & 2 & 2 & 2 \\
\hline \multicolumn{6}{|c|}{ 4) Bypass Feed/End//solation Spool Parameters } \\
\hline Length of Feed/End/Iso. Spool & $7.35 \mathrm{~m}$ & & & & \\
\hline Number of Posts in Spool & 4 & & & & \\
\hline Number of Splices in Spool & 8 & & & & \\
\hline MLI Factor & & & 2 & 2 & 2 \\
\hline & & & & & \\
\hline \multicolumn{6}{|l|}{ 5a) Special Spool Parameters } \\
\hline \multirow{2}{*}{\multicolumn{6}{|c|}{$\begin{array}{l}\text { Length of Spool-1m } \\
\text { Length of Spool-2m }\end{array}$}} \\
\hline & & & & & \\
\hline \multicolumn{6}{|l|}{ Number of Posts in Spool } \\
\hline \multicolumn{6}{|l|}{ Number of Splices in Spool } \\
\hline \multicolumn{6}{|l|}{ MLIFactor } \\
\hline \multirow{2}{*}{\multicolumn{6}{|c|}{ 5b) Bypass Parameters }} \\
\hline Length of Bypass Cryostat & $13.171 \mid \mathrm{m}$ & & & & \\
\hline Number of Supports & 3 & & & & \\
\hline Number of Splices & 4 & & & & \\
\hline \multicolumn{6}{|l|}{ Number of lines in bypass } \\
\hline & & & & & \\
\hline \multicolumn{6}{|l|}{ 6) Interconnect Parameters } \\
\hline Interconnect Length & $0.883 \mid \mathrm{m}$ & & & & \\
\hline \multicolumn{2}{|c|}{\begin{tabular}{l|l|} 
Interconnect Heat Leak Allowances & \\
\end{tabular}} & & 0.21 & 0.44 & 3.5 \\
\hline
\end{tabular}




\begin{tabular}{|c|c|c|c|c|c|}
\hline & & Liquif. & $4 \mathrm{~K}$ & $20 \mathrm{~K}$ & $80 \mathrm{~K}$ \\
\hline & & $\mathrm{g} / \mathrm{s}$ & Watts & Watts & Watts \\
\hline \multicolumn{6}{|l|}{ 7) Beam-Dependent Heat Loads } \\
\hline \multicolumn{2}{|c|}{ Ramping Heat Load per Meter (Nominal) } & & 0.5 & & \\
\hline \multicolumn{2}{|c|}{ Ramping Heat Load per Meter (Design) } & & 1 & & \\
\hline Splice Heat Load per Splice & & & 0.02 & & \\
\hline \multicolumn{2}{|c|}{ Beam Microwave Heat Load per Meter } & & 0.0023 & & \\
\hline \multicolumn{2}{|c|}{ Beam Microwave Heat Load per Connection } & & 0.16 & & \\
\hline \multirow[t]{2}{*}{ Beam - Gas Heat Load per Meter } & & & 0.0086 & & \\
\hline \multirow{2}{*}{\multicolumn{6}{|c|}{ 8) Component Parameters, General }} \\
\hline & & & & & \\
\hline Infrared Heat Load per Meter & & & 0.0044 & 0.185 & 1.52 \\
\hline Conduction Heat Leak per Post & & & 0.04 & 0.58 & 3.8 \\
\hline \multirow[t]{2}{*}{ Beam Position Monitor Heat Load } & & & 0.2 & 0.6 & \\
\hline \multirow{2}{*}{\multicolumn{6}{|c|}{ 9) Component Parameters, Spool }} \\
\hline & & & & & \\
\hline \multicolumn{2}{|l|}{ Number of Support Posts } & & & & \\
\hline \multicolumn{2}{|l|}{ Vacuum Barrier Heat Load } & & 0.5 & 4 & 15 \\
\hline \multicolumn{2}{|l|}{ Quench Vent Valve } & & 0.033 & 5 & \\
\hline \multicolumn{2}{|l|}{ Recooler Feed Valve } & & 0.033 & 0.288 & 1.4 \\
\hline \multicolumn{2}{|l|}{ Recooler Level Gauge } & & 0.033 & 0.288 & 1.4 \\
\hline \multirow[t]{2}{*}{ Beam Tube Sniffer Line } & & & 0.033 & 0.288 & 1.4 \\
\hline & & & & & \\
\hline \multicolumn{6}{|l|}{ 10) Relief Line Heat Loads } \\
\hline \multicolumn{2}{|l|}{ Single Phase Relief Line } & & 0.033 & 0.288 & 1.4 \\
\hline Helium Return Relief Line & & & 0.033 & 0.288 & 1.4 \\
\hline Gas Return Relief Line & & & 0.033 & 0.288 & 1.4 \\
\hline 20 K Shield Relief Line & & & & 0.3 & 1.5 \\
\hline 80 K Shield Relief Line & & & & & 2 \\
\hline
\end{tabular}




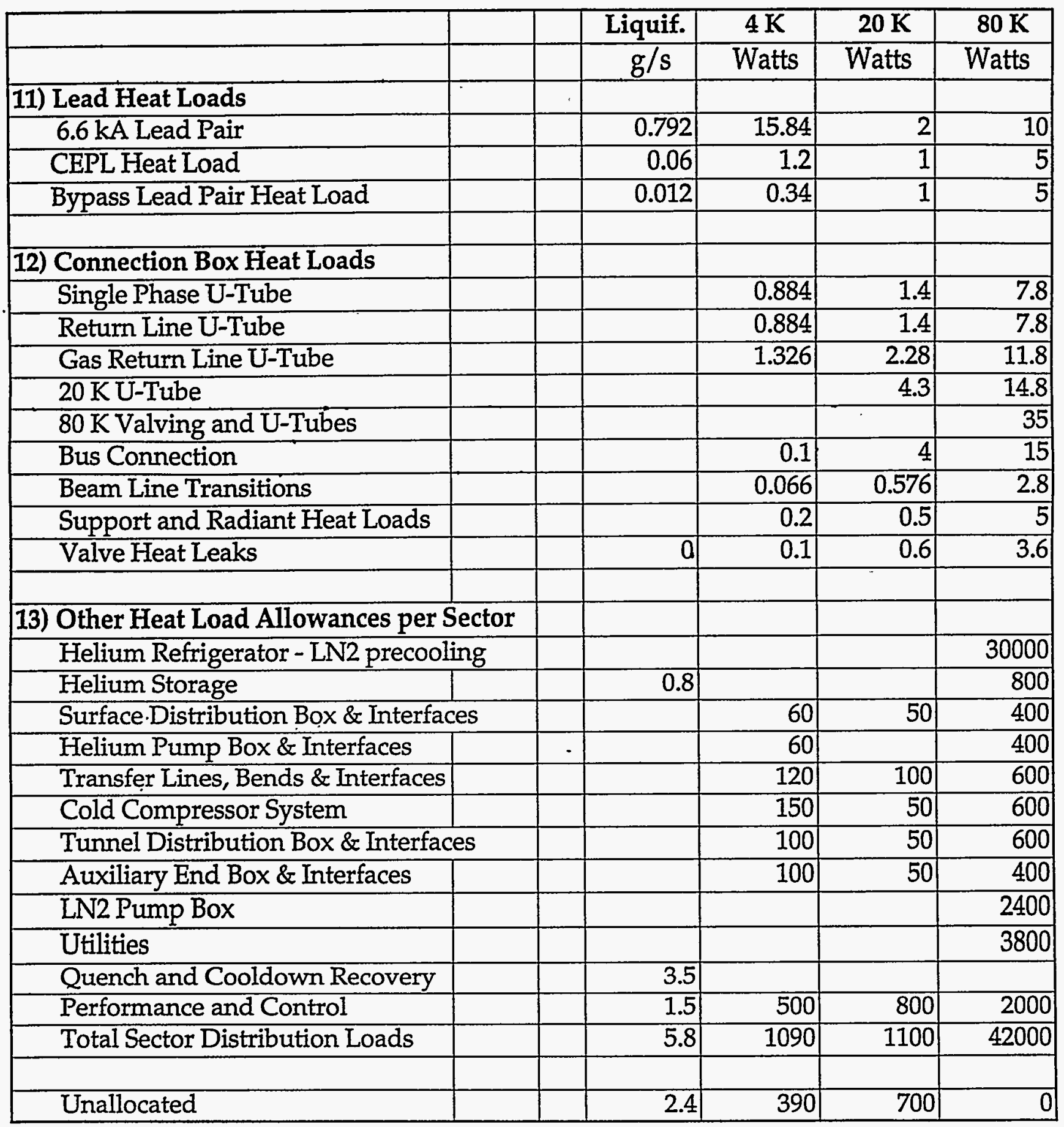




\begin{tabular}{|l|r|r|r|r|r|r|}
\hline & & & Liquif. & \multicolumn{1}{|c|}{$4 \mathrm{~K}$} & $20 \mathrm{~K}$ & $80 \mathrm{~K}$ \\
\hline & & & $\mathrm{g} / \mathrm{s}$ & Watts & Watts & Watts \\
\hline \multicolumn{2}{|l|}{ B1. DIPOLE HEAT BUDGET (Including Interconnect) } & & & \\
\hline & & & & & & \\
\hline 1) Static Heat Loads & & & & & & \\
\hline Infra-red & & & & 0.0541 & 2.2733 & 18.6778 \\
\hline Suppórt & & & & 0.2000 & 2.9000 & 19.0000 \\
\hline Interconnect & & & & 0.2100 & 0.4400 & 3.5000 \\
\hline Total Static & & & & 0.4641 & 5.6133 & 41.1778 \\
\hline 2) Dynamic Heat Loads & & & & & & \\
\hline Ramping & & & & & & \\
\hline Splices & & & & 12.2880 & & \\
\hline Beam Microwave Heat Load & & & & 0.1883 & & \\
\hline Beam - Gas Heat Load & & & & 0.1133 & & \\
\hline Total Dynamic & & & & 12.7295 & & \\
\hline Total Dipole & & & & & & \\
\hline
\end{tabular}




\begin{tabular}{|c|c|c|c|c|c|}
\hline & & Liquif. & $4 \mathrm{~K}$ & $20 \mathrm{~K}$ & $80 \mathrm{~K}$ \\
\hline & & $\mathrm{g} / \mathrm{s}$ & Watts & Watts & Watts \\
\hline \multicolumn{6}{|c|}{ B2. EMPTY CRYOOSTAT HEÄT BUDGET (Including Interconnect) } \\
\hline \multirow{2}{*}{\multicolumn{6}{|c|}{ 1) Static Heat Loads }} \\
\hline & & & & & \\
\hline Infra-red EC 6.5 & & & 0.0286 & 1.2025 & 9.8800 \\
\hline Infra-red EC 2.8 & & & 0.0123 & 0.5180 & 4.2560 \\
\hline Support & & & 0.0800 & 1.1600 & 7.6000 \\
\hline Interconnect : & & & 0.2100 & 0.4400 & 3.5000 \\
\hline Total Static EC 6.5 & & & 0.3186 & 2.8025 & 20.9800 \\
\hline Total Static EC 2.8 & & & 0.3023 & 2.1180 & 15.3560 \\
\hline \multirow{2}{*}{\multicolumn{6}{|c|}{ 2) Dynamic Heat Loads }} \\
\hline & & & & & \\
\hline Splices & & & 0.0800 & & \\
\hline Beam Microwave Heat Load EC 6.5 & & & 0.1750 & & \\
\hline Beam - Gas Heat Load EC 6.5 & & & 0.0635 & & \\
\hline Beam Microwave Heat Load EC 2.8 & & & 0.1664 & & \\
\hline Beam - Gas Heat Load EC 2.8 & & & 0.0317 & & \\
\hline Total Dynamic EC 6.5 & & & 0.3184 & & \\
\hline Total Dynamic EC 2.8 & & & 0.2781 & & \\
\hline & & & & & \\
\hline Total Empty Cryostat EC 6.5 & & & 0.6370 & 2.8025 & 20.9800 \\
\hline Total Empty Cryostat EC 2.8 & & & 0.5804 & 2.1180 & 15.3560 \\
\hline \multirow{2}{*}{\multicolumn{6}{|c|}{ B3. BYPASS CRYOSTAT HEAT BUDGET (Including Interconnect) }} \\
\hline & & & & & \\
\hline \multicolumn{6}{|l|}{ 1) Static Heat Loads } \\
\hline Infra-red & & & 0.0580 & 2.4366 & 20.0199 \\
\hline Support & 0.6000 & & 0.0720 & 1.0440 & 6.8400 \\
\hline Total Static & & & 0.1300 & 3.4806 & 26.8599 \\
\hline & & & & & \\
\hline \multicolumn{6}{|l|}{ 2) Dynamic Heat Loads } \\
\hline Splices & & & 0.0800 & & \\
\hline Total Bypass Cryostat & & & 0.2100 & 3.4806 & 26.8599 \\
\hline
\end{tabular}




\begin{tabular}{|c|c|c|c|c|}
\hline & Liquif. & $4 \mathrm{~K}$ & $20 \mathrm{~K}$ & $80 \mathrm{~K}$ \\
\hline & $\mathrm{g} / \mathrm{s}$ & Watts & Watts & Watts \\
\hline \multicolumn{5}{|c|}{ C. QUADRUPOLE HEAT BUDGET (Including Interconnect) } \\
\hline & & & & \\
\hline \multicolumn{5}{|l|}{ 1) Static Heat Loads } \\
\hline Infra-red & & 0.0070 & 0.2960 & 2.4320 \\
\hline Support & & 0.0800 & 1.1600 & 7.6000 \\
\hline Interconnect & & 0.2100 & 0.4400 & 3.5000 \\
\hline Total Static & 0 & 0.2970 & 1.8960 & 13.5320 \\
\hline \multirow{2}{*}{\multicolumn{5}{|c|}{ 2) Dynamic Heat Loads }} \\
\hline & & & & \\
\hline Ramping & & 1.6000 & & \\
\hline Splices & & 0.2200 & & \\
\hline Beam Microwave Heat Load & & 0.1637 & & \\
\hline Beam - Gas Heat Load & & 0.0214 & & \\
\hline Total Dynamic & & 2.0050 & & \\
\hline Total Quadrupole & & 2.3021 & 1.8960 & 13.5320 \\
\hline & & & & \\
\hline
\end{tabular}




\begin{tabular}{|c|c|c|c|c|}
\hline & Liquif. & $4 \mathrm{~K}$ & $20 \mathrm{~K}$ & $80 \mathrm{~K}$ \\
\hline & $\mathrm{g} / \mathrm{s}$ & Watts & Watts & Watts \\
\hline \multicolumn{5}{|c|}{ C1. HQM1 HEAT BUDGET (Including Interconnect) } \\
\hline Total Static & & 0.2940 & 1.7669 & 12.4710 \\
\hline Total Dynamic & & 1.2994 & & \\
\hline & & & & \\
\hline Total HQM1 & & 1.5934 & 1.7669 & 12.4710 \\
\hline \multicolumn{5}{|c|}{ C2. HQM2 HEAT BUDGET (Including Interconnect) } \\
\hline Total Static & & 0.2952 & 1.8170 & 12.8830 \\
\hline Total Dynamic & & 1.5734 & & \\
\hline & & & & \\
\hline Total HQM2 & & 1.8685 & 1.8170 & 12.8830 \\
\hline & & & & \\
\hline \multicolumn{5}{|c|}{ C3. HQM3 HEAT BUDGET (Including Interconnect) } \\
\hline Total Static & & 0.2999 & 2.0177 & 14.5322 \\
\hline Total Dynamic & & 2.6702 & & \\
\hline & & & & \\
\hline Total HQM3 & & 2.9701 & 2.0177 & 14.5322 \\
\hline & & & & \\
\hline \multicolumn{5}{|c|}{ C4. HQM4 HEAT BUDGET (Including Interconnect) } \\
\hline \begin{tabular}{|l} 
Total Static \\
\end{tabular} & & 0.3047 & 2.2192 & 16.1874 \\
\hline Total Dynamic & & 3.7711 & & \\
\hline & & & & \\
\hline Total HQM4 & & 4.0758 & 2.2192 & 16.1874 \\
\hline & & & & \\
\hline
\end{tabular}




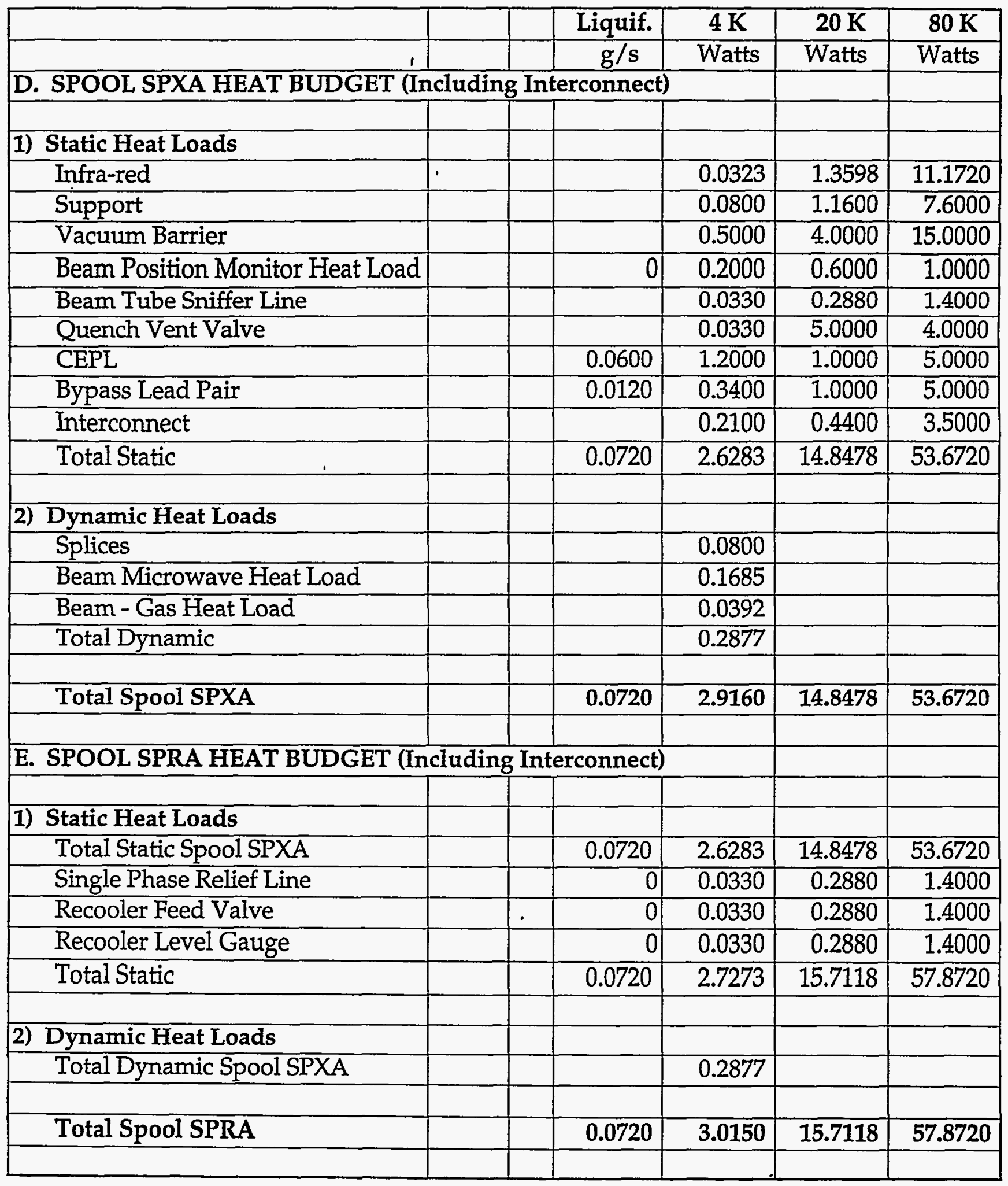




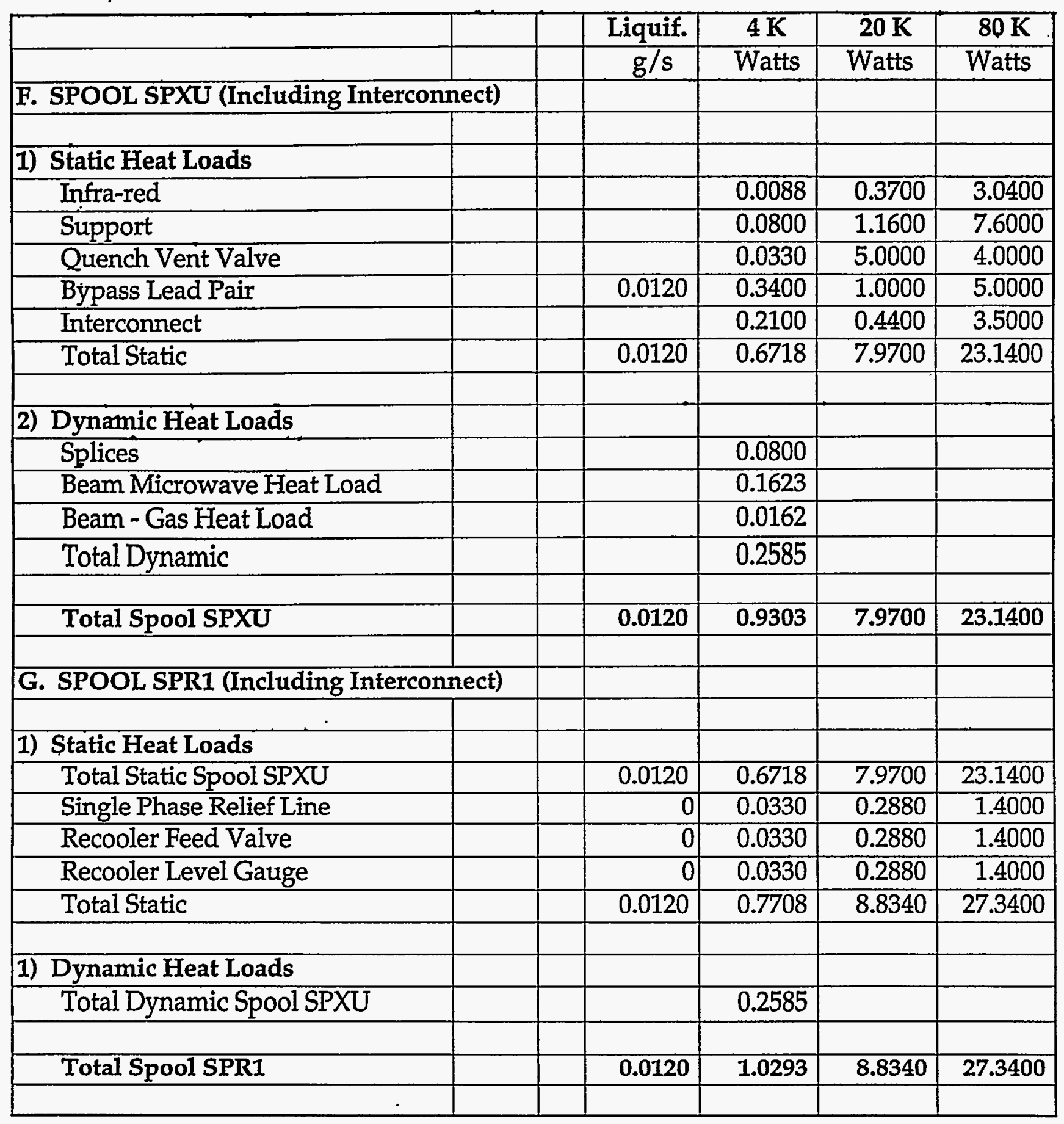




\begin{tabular}{|c|c|c|c|c|c|}
\hline 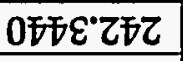 & SLE9.6E & $0 Z 8 Z^{\circ} 07$ & $08 Z \angle L^{\circ} I$ & & [oods giddS/TddS [ejoL \\
\hline \multirow[t]{2}{*}{0} & 0 & $\operatorname{csg} 9^{\circ} 0$ & 0 & & 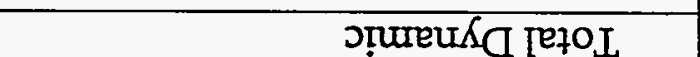 \\
\hline & & $0080^{\circ} 0$ & & & SoगtTdS -7 \\
\hline \multirow[t]{2}{*}{$\underline{0}$} & 0 & ESLG०0 & 0 & & 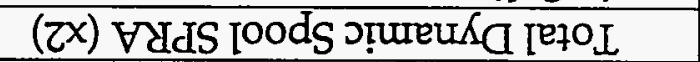 \\
\hline & & & & & 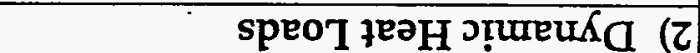 \\
\hline & & & & & \\
\hline Оニモどでて & SLE9.6E & $\angle 9 Z 9^{\circ} 6 \varepsilon$ & $082 \angle I$ & & ग!ฺETS IETOL \\
\hline $0000^{\circ} 02$ & $0000^{\circ} \mp$ & $0089^{\circ} \tau \varepsilon$ & $0 \mp 8 G^{\circ} I$ & & 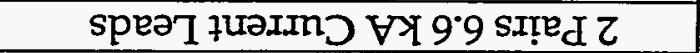 \\
\hline $0000^{\circ} \subseteq$ & $0009^{\circ} 0$ & $000 z^{\circ} 0$ & 0 & & speo 7 feəH furetpey pue floddns \\
\hline $0008^{\circ} \tau$ & $09 \angle 9^{\circ} 0$ & $0990^{\circ} 0$ & 0 & & suot!̣!surex I əu!̣ $\mathrm{I}$ ureəg \\
\hline $0000^{\circ} 04$ & 0 & 0 & 0 & & 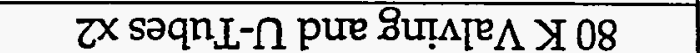 \\
\hline $0008^{\prime} \pm I$ & $\left.000 \varepsilon^{\circ}\right\rceil$ & 0 & 0 & & aqnI- $\Omega \times 0 Z$ \\
\hline $0008^{\circ} \mathrm{LI}$ & $008 Z^{\circ} Z$ & $09 Z E^{\circ} L$ & 0 & & 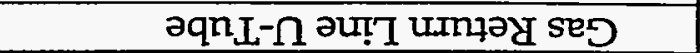 \\
\hline $0008 \%$ & $000 \bar{D}^{\circ} \mathrm{I}$ & $0788^{\circ} 0$ & 0 & & 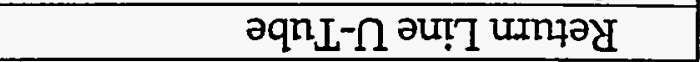 \\
\hline $0008^{\circ} \mathrm{L}$ & $000 F^{\circ} \mathrm{I}$ & $0788^{\circ} 0$ & 0 & & 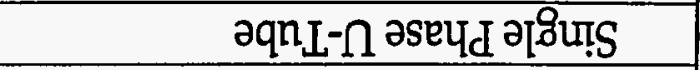 \\
\hline $0000^{\circ} 8$ & 0 & 0 & 0 & & 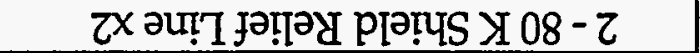 \\
\hline $0000^{\circ} \varepsilon$ & $0009^{\circ} 0$ & 0 & 0 & & 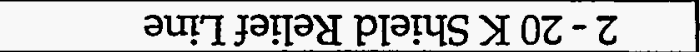 \\
\hline $0008^{\circ} \mathrm{Z}$ & $09 \angle 9^{\circ} 0$ & $0990^{\circ} 0$ & $\underline{0}$ & & 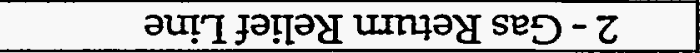 \\
\hline $0008 \mathrm{Z}$ & $09 \angle 90$ & $0990^{\circ} 0$ & 0 & & 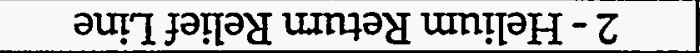 \\
\hline $0000^{\circ} 0 \varepsilon$ & $0000^{\circ} 8$ & $0000^{\circ} \tau$ & 0 & & 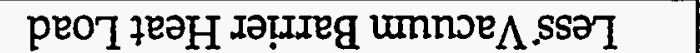 \\
\hline \multirow[t]{4}{*}{ ODTLGIL } & SEZ๐ $โ \varepsilon$ & $\angle \mathcal{E} \mathbb{T}^{\circ} \mathrm{G}$ & 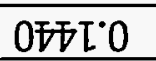 & & 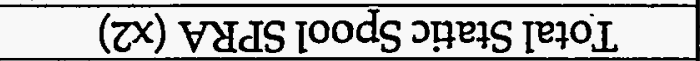 \\
\hline & & & & & 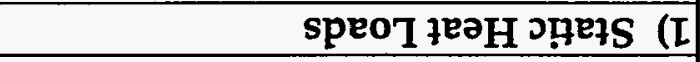 \\
\hline & & & & & \\
\hline & & & & \multicolumn{2}{|c|}{ IgOCNG LVBH AUdS/IYdS/AYdS TOOdS 'H } \\
\hline SHeM & $\operatorname{SHE}^{\prime}$ & $\mathrm{St7P}_{M}$ & $\mathrm{~s} / 8$ & & \\
\hline Y 08 & YYOZ & Ẍ & 于!nb!T & & \\
\hline
\end{tabular}




\begin{tabular}{|c|c|c|c|c|c|c|}
\hline & & & Liquif. & $4 \mathrm{~K}$ & $20 \mathrm{~K}$ & $80 \mathrm{~K}$ \\
\hline & & & $\mathrm{g} / \mathrm{s}$ & Watts & Watts & Watts \\
\hline \multicolumn{7}{|l|}{ J1. END BOX Heat Budget } \\
\hline \multicolumn{7}{|l|}{ (END BOX $=$ BPEB + CBEB + Tube Set) } \\
\hline \multicolumn{7}{|l|}{ 1) Static Heat Loads } \\
\hline Valve Heat Leaks & & 2 & & 0.6000 & 4.8000 & 43.2000 \\
\hline Single Phase U-Tube & & & & 0.884 & 1.4 & 7.8 \\
\hline Return Line U-Tube & & & & 0.884 & 1.4 & 7.8 \\
\hline Gas Return Line U-Tube & & & & 1.326 & 2.28 & 11.8 \\
\hline $20 \mathrm{~K} \mathrm{U}-\mathrm{Tube}$ & & & & & 4.3 & 14.8 \\
\hline $80 \mathrm{~K}$ Valving and U-Tubes $\times 2$ & & & & & & 70 \\
\hline Beam Line Transition & & & & 0.033 & 0.288 & 1.4 \\
\hline Support and Radiant Heat Loads & & 2 & & 0.4 & 1 & 10 \\
\hline Total Static & & & & 4.1270 & 15.4680 & 166.8000 \\
\hline \multicolumn{7}{|l|}{ 1) Dynamic Heat Loads } \\
\hline Splices & 4 & & & 0.0800 & & \\
\hline Total Bypass End Box & & & & 4.2070 & 15.4680 & 166.8000 \\
\hline \multicolumn{7}{|l|}{ J2. T-BOX Heat Budget } \\
\hline \multirow{2}{*}{\multicolumn{7}{|c|}{$(\mathrm{T}-\mathrm{BOX}=\mathrm{BPTB}+\mathrm{CBTB}+\mathrm{Tube}$ Set) }} \\
\hline \multicolumn{5}{|l|}{ 1) Static Heat Loads. } & & \\
\hline Valve Heat Leaks & & & & 0.3000 & 2.4000 & 21.6000 \\
\hline Single Phase U-Tube & & & & 0.884 & 1.4 & 7.8 \\
\hline Return Line U-Tube & & & & 0.884 & 1.4 & 7.8 \\
\hline Gas Return Line U-Tube & & & & 1.326 & 2.28 & 11.8 \\
\hline $20 \mathrm{~K} \mathrm{U}$-Tube & & & & & 4.3 & 14.8 \\
\hline $80 \mathrm{~K}$ Valving and U-Tubes $\times 2$ & & & & & & 70 \\
\hline Support and Radiant Heat Loads & & 2 & & 0.4 & 1 & 10 \\
\hline Total Static & & & & 3.7940 & 12.7800 & 143.8000 \\
\hline \multicolumn{7}{|l|}{ 1) Dynamic Heat Loads } \\
\hline Splices & 4 & & & 0.0800 & & \\
\hline & & & & & & \\
\hline Total T-Box & & & & 3.8740 & 12.7800 & 143.8000 \\
\hline
\end{tabular}




\begin{tabular}{|l|r|r|r|r|r|r|}
\hline & & & Liquif. & \multicolumn{1}{|c|}{$4 \mathrm{~K}$} & $20 \mathrm{~K}$ & $80 \mathrm{~K}$ \\
\hline & & & $\mathrm{g} / \mathrm{s}$ & Watts & Watts & Watts \\
\hline K1. CELL HEAT LOAD & & & & & & \\
\hline & & & & & & \\
\hline 1) Static Heat Loads & & & & & & \\
\hline Dipoles & & & 0 & 1.856 & 22.453 & 164.711 \\
\hline Quadrupole & & & 0 & 0.594 & 3.792 & 27.064 \\
\hline SP-Type Spool & & & 0.072 & 2.628 & 14.848 & 53.672 \\
\hline SPR Type Spool & & & 0.072 & 2.727 & 15.712 & 57.872 \\
\hline Total Static & & & 0.144 & 7.806 & 56.805 & 303.319 \\
\hline & & & & & & \\
\hline 2) Dynamic Heat Loads & & & & & & \\
\hline Dipoles & & & 0 & 50.918 & & 0 \\
\hline Quadrupole & & & 0 & 4.010 & & 0 \\
\hline SP-Type Spool & & & 0 & 0.288 & & 0 \\
\hline SPR Type Spool & & & 0 & 0.288 & & 0 \\
\hline Total Dynamic & & & 0 & 55.504 & & 0 \\
\hline & & & & & & 0 \\
\hline Total Cell Heat Load & & & $\mathbf{0 . 1 4 4}$ & 63.310 & $\mathbf{5 6 . 8 0 5}$ & $\mathbf{3 0 3 . 3 1 9}$ \\
\hline
\end{tabular}




\begin{tabular}{|c|c|c|c|c|c|}
\hline & & Liquif. & $4 \mathrm{~K}$ & $20 \mathrm{~K}$ & $80 \mathrm{~K}$ \\
\hline & & $\mathrm{g} / \mathrm{s}$ & Watts & Watts & Watts \\
\hline \multicolumn{6}{|c|}{ K2. DISPERSION SUPPRESSOR CELL HEAT LOAD } \\
\hline \multicolumn{6}{|c|}{ (A DS cell has 2 dipoles,"3.5/2" quads+4 EC 6.5s(drift space)) } \\
\hline \multicolumn{6}{|c|}{\begin{tabular}{|l|l|l|l} 
1) Static Heat Loads & & & \\
\end{tabular}} \\
\hline Dipoles & & 0 & 0.928 & 11.227 & 82.356 \\
\hline Empty Cryostats (for drift spaces) & & 0 & 1.274 & 11.210 & 83.920 \\
\hline Quadrupole & & 0 & 0.520 & 3.318 & 23.681 \\
\hline SPXA Spool & & 0.072 & 2.628 & 14.848 & 53.672 \\
\hline SPRA Spool & & 0.072 & 2.727 & 15.712 & 57.872 \\
\hline Total Static . & & 0.144 & 8.078 & 56.314 & 301.501 \\
\hline & & & & & \\
\hline \multicolumn{6}{|l|}{ 2) Dynamic Heat Loads } \\
\hline Dipoles & & 0 & 25.459 & 0 & 0 \\
\hline Empty Cryostats (for drift spaces) & & 0 & 1.274 & 0 & 0. \\
\hline Quadrupole & & 0 & 3.509 & 0 & 의 \\
\hline SPXA Spool & & 0 & 0.288 & 0 & 0 \\
\hline SPRA Spool & & 0 & 0.288 & 0 & 0 \\
\hline Total Dynamic & & 0 & 30.817 & 0 & 0 \\
\hline Total Dispersion Suppressor Heat & Load & 0.144 & 38.895 & 56.314 & 301.501 \\
\hline
\end{tabular}




\section{H20 CCW-String HEAT LOAD}

(CCW-String has 28 arc cells $+2 * 1 / 2 \mathrm{SS}+\mathrm{LS}$ )

\section{1) Static Heat Loads}

Arc.Cells

Short Straight Sections

6D, 6Q

2 SPXA, 3 SPRA

$11 \mathrm{EC} 6.5$

SPRF

Total-Short Straight Sections

West Long Straight Section

$8 \mathrm{D}, 7 \mathrm{Q}, 8 \mathrm{HQM} 1,2 \mathrm{HQM} 2$

1 SPXA, 17 SPRA, 9 SPXU

6 EC6.5, 7 EC2.8

1 SPRI

44 Bypass Cryostats

2 End Boxes

9 T-Boxes

Total- Long Straight Section

Total Static

\section{2) Dynamic Heat Loads}

Arc Cells

Short Straight Sections

$6 \mathrm{D}, 6 \mathrm{Q}$

2 SPXA, 3 SPRA

$11 \mathrm{EC} 6.5$

SPRF

Total- Short Straight Sections

West Long Straight Section

8D, $7 \mathrm{Q}, 8 \mathrm{HQM1}, 2 \mathrm{HQM} 2$

1 SPXA, 17 SPRA, 9 SPXU

$6 \mathrm{EC} 6.5,7 \mathrm{EC} 2.8$

1 SPRI

44 Bypass Cryostats

2 End Boxes

9 T-Boxes

Total- Long Straight Section

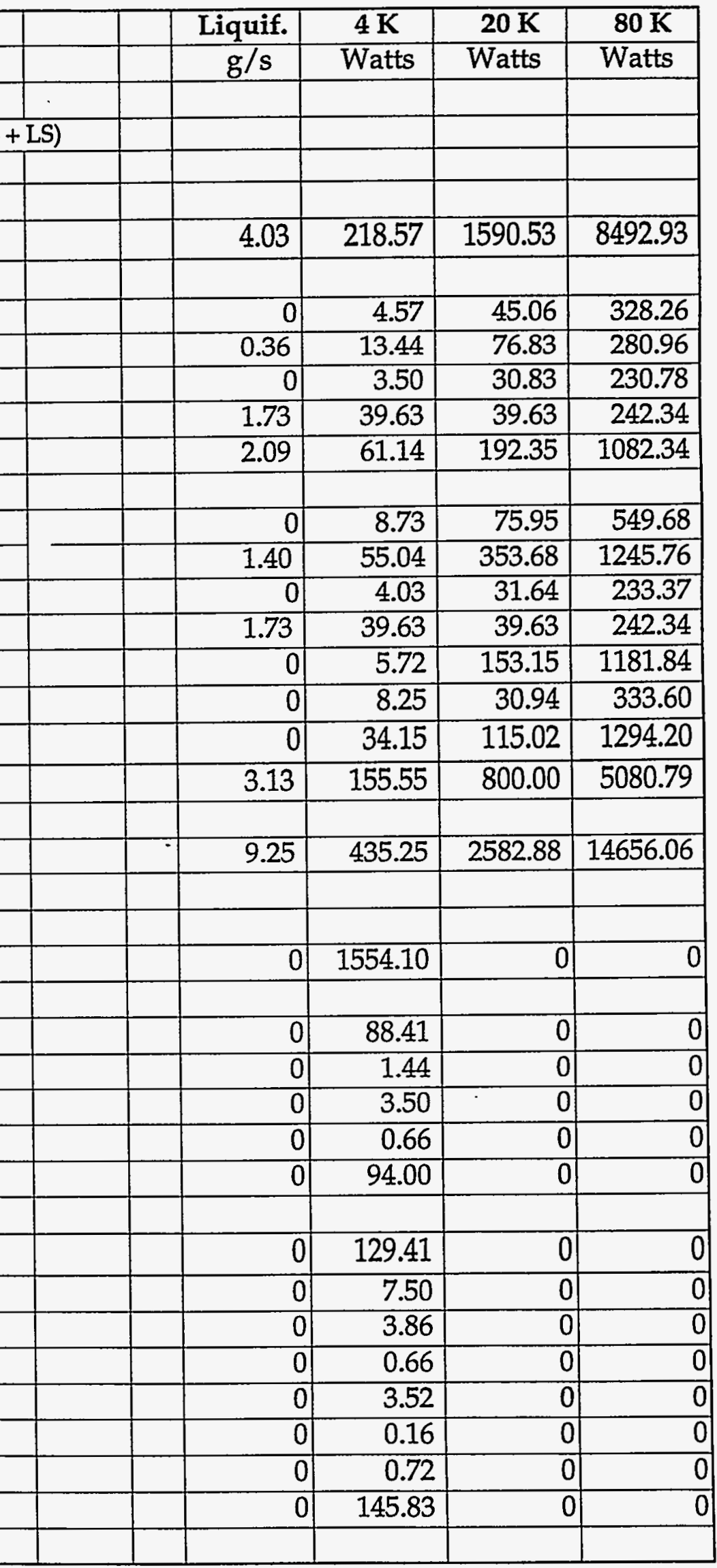




\begin{tabular}{|c|c|c|c|c|}
\hline Total Dynamic & 0 & 1793.93 & 0 & 0 \\
\hline & & & & \\
\hline Total H20 CCW-String Load & 9.25 & 2229.18 & 2582.88 & 14656.06 \\
\hline & & & & \\
\hline & & & & \\
\hline \multirow{2}{*}{\multicolumn{5}{|c|}{$\begin{array}{l}\text { M. H20 CW-String HEAT LOAD } \\
\left.\text { (CW-String has } 30 \text { cells }+2^{*} 1 / 2 \mathrm{SS}\right)\end{array}$}} \\
\hline & & & & \\
\hline \multicolumn{5}{|l|}{ 1) Static Heat Loads } \\
\hline Arc Cells & 5.98 & 271.08 & 1728.06 & 9284.04 \\
\hline \multicolumn{5}{|l|}{ Short Straight Sections } \\
\hline $10 \mathrm{D}, 8 \mathrm{Q}, 4 \mathrm{HQM} 3,8 \mathrm{HQM} 4$ & 0 & 10.65 & 97.13 & 707.66 \\
\hline 5 SPXA, 11 SPRA, 4 SPXU & 1.20 & 45.83 & 278.95 & 997.51 \\
\hline $19 \mathrm{EC} 6.5,2 \mathrm{EC} 2.8$ & 0 & 6.66 & 57.48 & 429.33 \\
\hline 1 SPRF & 1.73 & 39.63 & 39.63 & 242.34 \\
\hline 36 Bypass Cryostats & 0 & 4.68 & 125.30 & 966.96 \\
\hline 4 End Boxes & 0 & 16.51 & 61.87 & 667.20 \\
\hline 4T-Boxes & 0 & 15.18 & 51.12 & 575.20 \\
\hline Total-Short Straight Sections & 2.93 & 139.13 & 711.48 & 4586.21 \\
\hline Total Static & 8.90 & 410.21 & 2439.54 & 13870.25 \\
\hline \multirow{2}{*}{\multicolumn{5}{|c|}{ 2) Dynamic Heat Loads }} \\
\hline & & & & \\
\hline Cells & 0 & 1665.47 & 0 & 0 \\
\hline \multicolumn{5}{|l|}{ Short Straight Sections } \\
\hline $10 \mathrm{D}, 8 \mathrm{Q}, 4 \mathrm{HQM} 3,8 \mathrm{HQM} 4$ & 0 & 184.19 & $\overline{0}$ & 0 \\
\hline 5 SPXA, 11 SPRA, 4 SPXU & 0 & 5.64 & 0 & 0 \\
\hline $19 \mathrm{EC} 6.5,2 \mathrm{EC} 2.8$ & 0 & 6.61 & 0 & 0 \\
\hline 1 SPRF & 0 & 0.66 & 0 & 0 \\
\hline 36 Bypass Cryostats & 0 & 2.88 & 0 & 0 \\
\hline 4 End Boxes & $\underline{0}$ & 0.32 & 0 & 0 \\
\hline 4 T-Boxes & 0 & 0.32 & 0 & 0 \\
\hline Total-Short Straight Sections & 0 & 200.60 & 0 & 0 \\
\hline Total Dynamic & 0 & 1866.08 & 0 & 0 \\
\hline Total H20 CW-String Load & 8.90 & 2276.29 & 2439.54 & 13870.25 \\
\hline & & & & \\
\hline
\end{tabular}




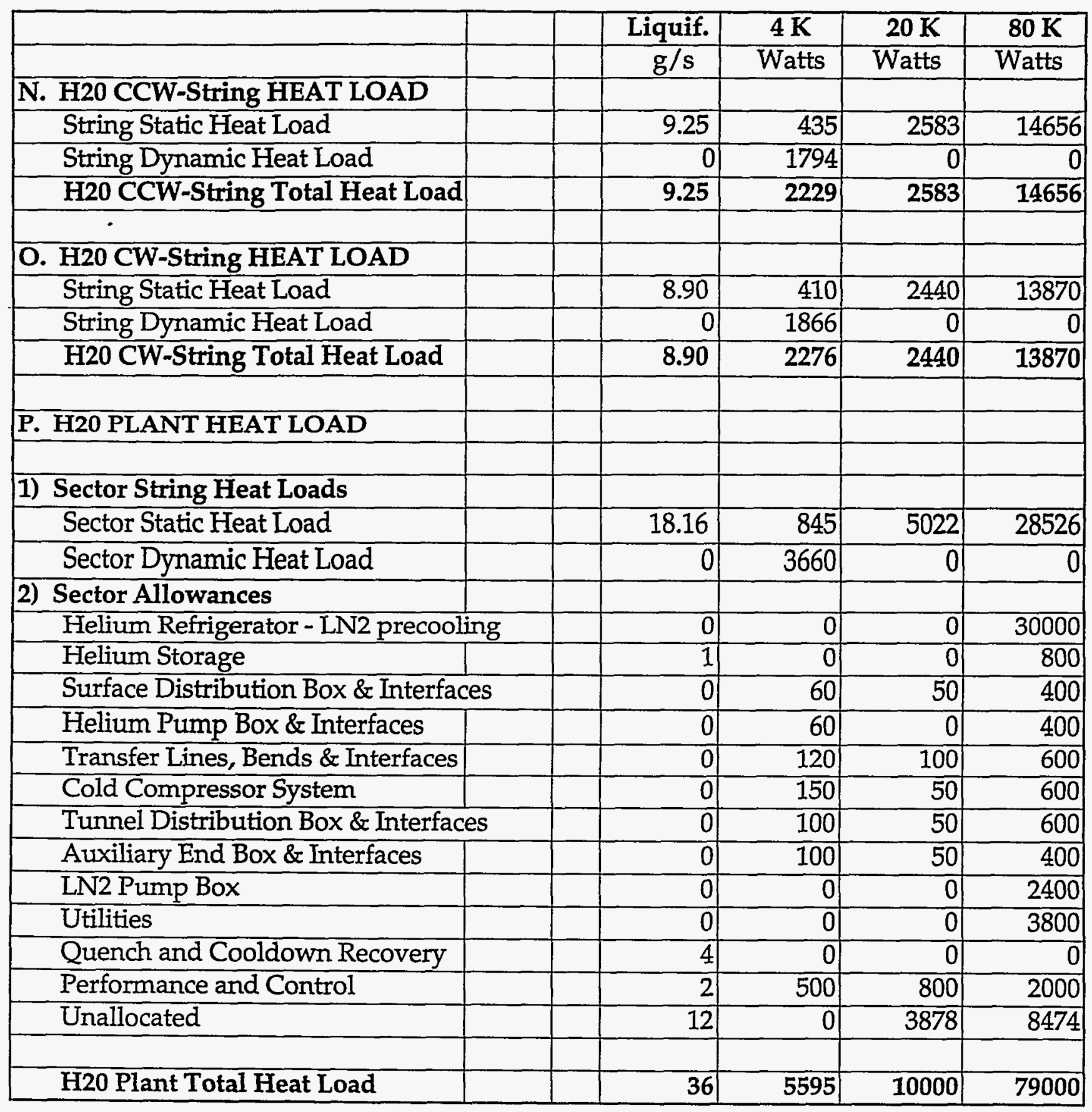




\begin{tabular}{|c|c|c|c|c|c|}
\hline & & Liquif. & $4 \mathrm{~K}$ & $20 \mathrm{~K}$ & $80 \mathrm{~K}$ \\
\hline & & $\mathrm{g} / \mathrm{s}$ & Watts & Watts & Watts \\
\hline \multicolumn{6}{|l|}{ Q. H20 CCW-String HEAT LOAD } \\
\hline \multicolumn{6}{|l|}{ 1) String Static Heat Load } \\
\hline Dipoles (126) & & 0 & 58.47 & 707.27 & 5188.40 \\
\hline Quadrupoles (69) & & 0 & 20.50 & 130.82 & 933.71 \\
\hline HQM1 (8) & & 0 & 2.35 & 14.13 & 99.77 \\
\hline HQM2 (2) & & 0 & 0.59 & 3.63 & 25.77 \\
\hline SPXA Spools (31) & & 2.23 & 81.48 & 460.28 & 1663.83 \\
\hline SPRA Spools (48) & & 3.46 & 130.91 & 754.16 & 2777.86 \\
\hline SPXU Spools $(9)$ & & 0.11 & 6.05 & 71.73 & 208.26 \\
\hline Empty Cryostats $6.5 \mathrm{mt}(17)$ & & 0 & 5.42 & 47.64 & 356.66 \\
\hline Empty Cryostats $2.8 \mathrm{~m}(7)$ & & 0 & 2.12 & 14.83 & $107: 49$ \\
\hline SPRI/SPRF/SPRE Spools & & 3.46 & 79.25 & 79.26 & 484.69 \\
\hline Bypass Cryostats (44) & & 0 & 5.72 & 153.15 & 1181.84 \\
\hline End Boxes (2) & & 0 & 8.25 & 30.94 & 333.60 \\
\hline T-Boxes (9) & & 0 & 34.15 & 115.02 & 1294.20 \\
\hline Total Static & & 9.25 & 435 & 2583 & 14656 \\
\hline \multicolumn{6}{|l|}{ 2) String Dynamic Heat Load } \\
\hline Dipoles (126) & & 0 & 1603.92 & 0 & \\
\hline Quadrupoles (69) & & 0 & 138.35 & 0 & 0 \\
\hline HQM1 (8) & & 0 & 10.40 & 0 & 0 \\
\hline HQM2 (2) & & 0 & 3.15 & 0 & 0 \\
\hline SPXA Spools (31) & & 0 & 8.92 & 0 & $\underline{0}$ \\
\hline SPRA Spools (48) & & 0 & 13.81 & 0 & \\
\hline SPXU Spools (9) & & 0 & 2.33 & 0 & 0 \\
\hline Empty Cryostats $6.5 \mathrm{~m}(17)$ & & 0 & 5.41 & 0 & 0 \\
\hline Empty Cryostats $2.8 \mathrm{~m} \mathrm{(7)}$ & & 0 & 1.95 & 0 & 0 \\
\hline SPRI/SPRF/SPRE Spools & & 0 & 1.31 & 0 & 0 \\
\hline Bypass Cryostats (44) & & 0 & 3.52 & 0 & 0 \\
\hline End Boxes (2) & & 0 & 0.16 & 0 & 0 \\
\hline T-Boxes (9) & & 0 & 0.72 & 0 & 0 \\
\hline Total Dynamic & & 0 & 1793.93 & 0 & 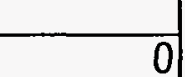 \\
\hline & & & & & \\
\hline Total H20 CCW-String Heat Load & & 9.25 & 2229 & 2583 & 14656 \\
\hline
\end{tabular}




\begin{tabular}{|c|c|c|c|c|c|}
\hline & & Liquif. & $4 \mathrm{~K}$ & $20 \mathrm{~K}$ & $80 \mathrm{~K}$ \\
\hline & & $\mathrm{g} / \mathrm{s}$ & Watts & Watts & Watts \\
\hline \multicolumn{6}{|l|}{ R. H20 CW-String HEAT LOAD } \\
\hline \multirow{2}{*}{\multicolumn{6}{|c|}{ 1) String Static Heat Load }} \\
\hline & & & & & \\
\hline Dipoles (130) & & 0 & 60.33 & 729.73 & 5353.11 \\
\hline Quadrupoles (68) & & 0 & 20.20 & 128.93 & 920.18 \\
\hline HQM3 (4) & & 0 & 1.20 & 8.07 & 58.13 \\
\hline HQM4 (8) & & 0 & 2.44 & 17.75 & 129.50 \\
\hline SPXA Spools (35) & & 2.52 & 91.99 & 519.67 & 1878.52 \\
\hline SPRA Spools (40) & & 2.88 & 109.09 & 628.47 & 2314.88 \\
\hline SPRI/SPRF/SPRE Spools (2) & & 3.46 & 79.25 & 79.26 & 484.69 \\
\hline SPXU Spools (4) & & 0.05 & 2.69 & 31.88 & 92.56 \\
\hline Empty Cryostats 6.5 m (19) & & 0 & 6.05 & 53.25 & 398.62 \\
\hline Empty Cryostats $2.8 \mathrm{~m} \mathrm{(2)}$ & & 0 & 0.60 & 4.24 & 30.71 \\
\hline Bypass Cryostats (36) & & 0 & 4.68 & 125.30 & 966.96 \\
\hline End Boxes (4) & & 0 & 16.51 & 61.87 & 667.20 \\
\hline T-Boxes (4) & & 0 & 15.18 & 51.12 & 575.20 \\
\hline Total Static & & 8.90 & $\mid 410$ & 2440 & 13870 \\
\hline & & & & & \\
\hline \multicolumn{6}{|l|}{ 2) String Dynamic Heat Load } \\
\hline Dipoles (130) & & 0 & 1654.84 & 0 & 0 \\
\hline Quadrupoles (68) & & 0 & 136.34 & 0 & 0 \\
\hline HQM3 (4) & & $\underline{0}$ & 10.68 & 0 & 0 \\
\hline HQM4 (8) & & 0 & 30.17 & 0 & 0 \\
\hline SPXA Spools (35) & & 0 & 10.07 & 0 & 0 \\
\hline SPRA Spools (40) & & 0 & 11.51 & 0 & 0 \\
\hline SPRI/SPRF/SPRE Spools (2) & & 0 & 1.31 & 0 & $\underline{0}$ \\
\hline SPXU Spools (4) & & 0 & 1.03 & 0 & 0 \\
\hline Empty Cryostats $6.5 \mathrm{~m} \mathrm{(19)}$ & & 0 & 6.05 & 0 & 0 \\
\hline Empty Cryostats $2.8 \mathrm{~m}(2)$ & & 0 & 0.56 & 0 & 0 \\
\hline Bypass Cryostats (36) & & 0 & 2.88 & 0 & 0 \\
\hline End Boxes (4) & & 0 & 0.32 & 0 & 0 \\
\hline T-Boxes (4) & & 0 & 0.32 & 0 & 0 \\
\hline Total Dynamic & & 0 & 1866.08 & 0 & $\overline{0}$ \\
\hline & & & & & \\
\hline Total H20 CW-String Heat Load & & 8.90 & $\therefore \quad 2276$ & 2440 & 13870 \\
\hline
\end{tabular}




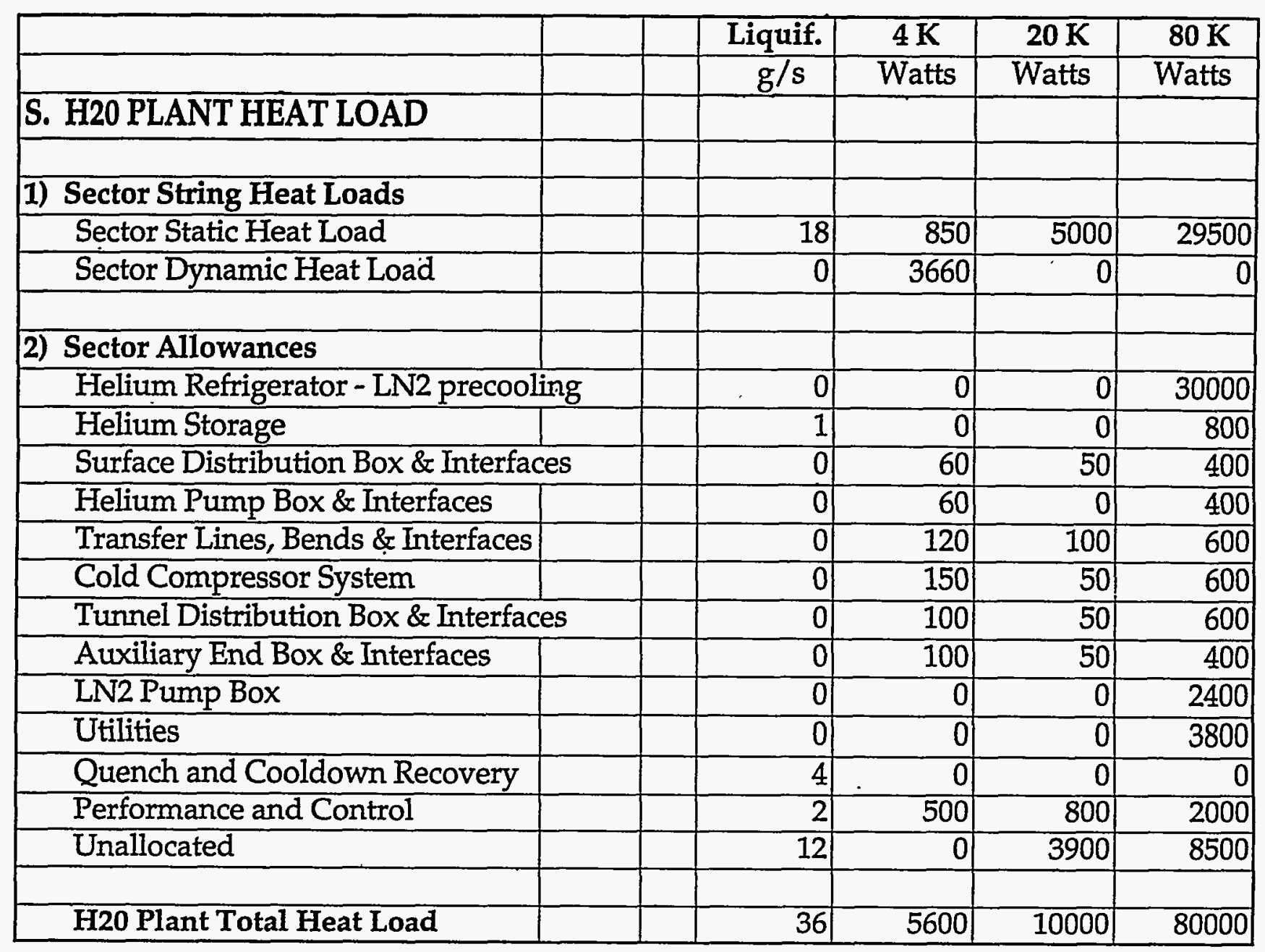

